\title{
Niobia-Supported Metal Catalysts for Synthesis Gas Conversion
}

Carlos Hernández Mejía 
ISBN: 978-94-6416-084-0

Cover design: Thomas Hartman | www.thisillustrations.com

Print: Ridderprint | www.ridderprint.nl 


\section{Niobia-Supported Metal Catalysts for Synthesis Gas Conversion}

Niobia-gedragen metaalkatalysatoren voor synthesegasconversie (met een samenvatting in het Nederlands)

\section{Proefschrift}

ter verkrijging van de graad van doctor aan de Universiteit Utrecht op gezag van de rector magnificus, prof. dr. H.R.B.M. Kummeling, ingevolge het besluit van het college voor promoties in het openbaar te verdedigen op

maandag 7 september 2020 des middags te 4.15 uur

door

Carlos Hernández Mejía

geboren op 4 juli 1989

te Tijuana, Mexico 
Promotor: Prof. dr. ir. K.P. de Jong

The research in this thesis was financially supported by Companhia Brasileira de Metalurgia e Mineração - CBMM 
Para Rosy 



\section{Contents}

$\begin{array}{lll}\text { Chapter } 1 \quad \text { General Introduction } & 9\end{array}$

Chapter 2 Control of Metal-Support Interactions in Heterogeneous 17

Catalysts to Enhance Activity and Selectivity

Chapter 3 Crystalline Niobia with Tailored Porosity as Support for 49

Cobalt Catalysts for the Fischer-Tropsch Synthesis

Chapter 4 Activity Enhancement of Cobalt Catalysts by Tuning MetalSupport Interactions

Chapter 5 Cobalt-Nickel Nanoparticles Supported on Reducible Oxides 77 as Fischer-Tropsch Catalysts

Chapter 6 Stable Niobia-Supported Nickel Catalysts for the Hydrogenation of Carbon Monoxide to Hydrocarbons

Chapter 7 Niobium-based Solid Acids in Combination with a Methanol Synthesis Catalyst for the Direct Production of Dimethyl Ether from Synthesis Gas

Chapter 8 Summary, Conclusions and Outlook

Nederlandse samenvatting $\quad 143$

Appendices A-F 147

List of publications and presentations 191

Aknowledgments 194

$\begin{array}{ll}\text { Curriculum vitae } & 197\end{array}$ 



\section{General Introduction}


Human development is strongly intertwined with access to energy. In order to fulfil the enhancement in technology and life quality standards of a growing population, the global energy demand has been increasing ${ }^{1-3}$. Particularly during the last decades, the rapid development has resulted in an unprecedented rise in energy consumption, tripling from 200 to $600 \mathrm{EJ} /$ year in the last 50 years and projected to steadily increase ${ }^{3,4}$ (figure $1 \mathrm{~A}$ ). Consequently, to meet the current and future energy demand, affordable, accessible and sustainable sources of energy are fundamental ${ }^{5,6}$.

Despite the significant growth of alternative energy sources, oil and gas are foreseen to remain crucial energy providers ${ }^{7-10}$ (figure 1A). Liquid fuels in particular prevail as source of energy due to their high energy density, easiness in handling and a well-established production and delivery infrastructure ${ }^{11}$. These qualities are critical for various applications, but notoriously important for the transportation sector and the main consumer of liquid fuels (figure 1B). In fact, liquid fuels constitute $94 \%$ of the energy source for the transport industry and although it is projected to decrease, around $85 \%$ is predicted by $2040^{3}$. This high demand for transportation fuels has stimulated research towards efficient fuel production and a diversification of their sources, preferably towards renewable ones ${ }^{7,12,13}$.

a

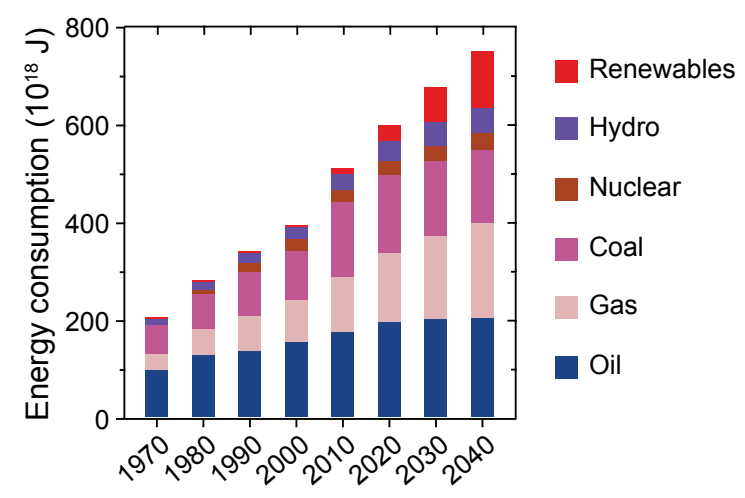

b

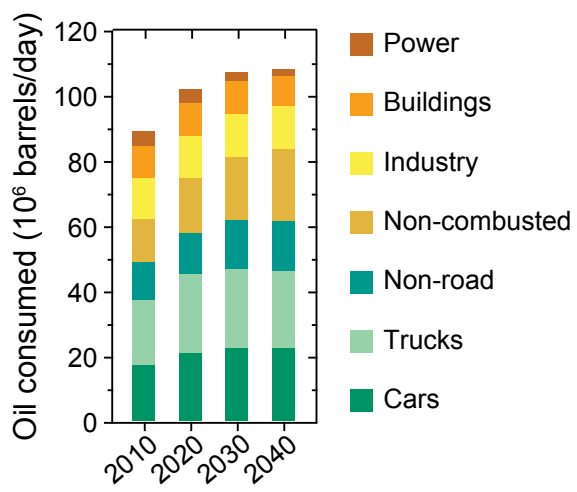

Figure 1.1 a, Global energy consumption and its main sources during the last five decades and a projection for the upcoming ones. $\mathbf{b}$. Oil consumed in barrels per day $\left(1\right.$ oil barrel $\left.\approx 159 \mathrm{~m}^{3}\right)$ by different sectors in recent years and an estimation for the following years, in green the sectors related to the tranpostation industry. Reproduced from reference 3 .

Production of liquid fuels and chemicals from synthesis gas, a mixture of carbon monoxide and hydrogen to which carbon dioxide might be added, has gained ample interest due to the versatility of the process and the feasibility to generate ultra-clean fuels. On the one hand, synthesis gas can be obtained via gasification of numerous carbon-based feedstocks such as biomass, methane-rich gases, coal and even waste materials ${ }^{13-15}$. This enables the decentralization of fuel production and a shift towards renewable resources. In fact, recent implementation of processes for the production of liquid fuels such as gas-to- 
liquids (GTL) and coal-to-liquids (CTL), which rely on the conversion of synthesis gas, have materialized as a result of the shale gas revolution in the USA and the demand for alternative use of coal in China ${ }^{16-18}$. On the other hand, the variety of possible products that can be selectively obtained from synthesis gas makes it an attractive resource for the chemical and energy industries. Synthesis gas can be directly or indirectly (e.g. via methanol) transformed to alcohols, long-chain hydrocarbons, olefins and aromatics, which constitute a large portion of industrial bulk chemicals and precursors for synthetic fuels ${ }^{19-21}$. This successful transformation to desired products relies largely on solid catalysts ${ }^{19,22}$.

Nowadays, due to their good performance and accessibility the main catalysts used are based on late transition metals $(\mathrm{Fe}, \mathrm{Co}, \mathrm{Ni}$ and $\mathrm{Cu}$ ), either in bulk or supported. Iron in carbidic form is employed in the production of hydrocarbons with a high olefin content, it also shows high water-gas-shift activity which can be exploited to balance the $\mathrm{H}_{2}$ to $\mathrm{CO}$ ratio in CO-rich synthesis gas from coal or biomass ${ }^{23,24}$. Cobalt-based catalysts are used in the production of long-chain hydrocarbons $\left(\mathrm{C}_{5+}\right)$, and contrary to iron, it shows low watergas-shift activity so $\mathrm{H}_{2}$-rich synthesis gas is preferred ${ }^{22}$. Cobalt-based catalysts therefore find application in the GTL process, in which the $\mathrm{C}_{5^{+}}$products are subsequently upgraded to liquid fuels. Conversion of synthesis gas based on Fe or Co catalysts is commonly known as Fischer-Tropsch (FT) synthesis reaction. Nickel has a high hydrogenation activity, and together with the reaction conditions needed to avoid the formation of volatile nickel carbonyls, it shows high selectivity towards methane, which can be used in the purification of $\mathrm{H}_{2}$ from $\mathrm{CO}^{25-27}$. Finally, copper-based catalysts typically in combination with zinc oxide are highly selective for the synthesis of methanol and therefore widely used in industry ${ }^{28}$. Moreover, the product spectrum derived from synthesis gas can be expanded besides these products, for instance by combining these primary hydrogenation functions with a second catalyst (e.g. a solid acid) and produce alcohols, ethers, branched hydrocarbons and aromatics ${ }^{29-33}$.

Besides the nature of the metal, the size of the metal particles matters. Metals in the nanoscale size offer a larger number of surfaces sites per unit mass. Simultaneously however, the reactivity of the surface sites is also modified which can affect their catalytic performance. In synthesis gas conversion, the nanoparticle size of late transition metals can have a significant influence on their overall performance ${ }^{34-40}$. Therefore, a strategy to control the nanoparticles size is to immobilize them on a support to enhance their stability and control their spatial distribution ${ }^{41}$. For this, porous materials with mechanical stability are typically employed as support matrix for metal nanoparticles. Moreover, supports in catalysis have to withstand harsh environments commonly comprising high temperatures, pressures and reactive media. A large family of materials that can fulfil these characteristics are refractory oxides (e.g. $\mathrm{SiO}_{2}, \mathrm{TiO}_{2}, \mathrm{Al}_{2} \mathrm{O}_{3}, \mathrm{CeO}_{2}$, etc.) and have therefore been extensively employed as support $^{42}$.

Niobia $\left(\mathrm{Nb}_{2} \mathrm{O}_{5}\right)$ is a transition metal oxide with various polymorphs, rich redox chemistry and acidic properties. It has attracted interest in catalysis as support material or as a promotor for various reactions ${ }^{43,44}$. For FT synthesis, niobia-supported cobalt catalysts have proven particularly interesting due to their notably high selectivity towards long-chain hydrocarbons and great activity per unit weight of cobalt ${ }^{45,46}$. Niobia being a reducible sup- 
port, the origin of the enhanced FT performance has partially to do with the Lewis acidity of the material and the strong metal-support interaction (SMSI) effect ${ }^{47,48}$. SMSI occurs for nanoparticles of late transition metals supported on reducible oxides ${ }^{49,50}$. During reductive conditions, the support at the periphery of the nanoparticles can be partially reduced and forms suboxides (e.g. $\mathrm{NbO}_{\mathrm{x}}$ ). This suboxides can migrate onto the surface of the metal particles. With a partial surface coverage, the mild Lewis acidic character of the suboxides can promote the intrinsic FT catalytic activity and $\mathrm{C}_{5+}$ selectivity.

Niobium-based materials can present both Lewis and Brønsted acid sites. For example, $\mathrm{Nb}_{2} \mathrm{O}_{5} \cdot n \mathrm{H}_{2} \mathrm{O}$ and $\mathrm{NbOPO}_{4}$ have shown exceptional performance for various acid-catalysed reactions ${ }^{44}$. Contrary to many solid acids, these materials are capable of maintaining high catalytic activity and stability when water is involved ${ }^{51,52}$. Therefore, niobium-based solid acids are promising components as stable catalysts for hydration and dehydration reactions. In synthesis gas conversion, solid acids can serve as dimethyl ether (DME) synthesis catalyst by combining a methanol synthesis functionality. Overall, niobium-based materials have shown great potential in the conversion of synthesis gas to hydrocarbons, either as support material or promoter in FT and DME synthesis catalysts. Further research into these materials might increase our tools for the effective conversion of synthesis gas and allow us to find new applications.

The aim of this thesis is to explore and understand different strategies to enhance the catalytic performance, either in terms of activity, selectivity and/or stability, of niobium-based catalyst employed in the conversion of synthesis gas. Previous research carried out in the group on cobalt catalysts supported on niobia ${ }^{53}$ set a strong base for the work presented here. Based on those insights, we focus on $\mathrm{Co} / \mathrm{Nb}_{2} \mathrm{O}_{5}, \mathrm{Ni} / \mathrm{Nb}_{2} \mathrm{O}_{5}$ and $\mathrm{CoNi} / \mathrm{Nb}_{2} \mathrm{O}_{5}$ systems for $\mathrm{FT}$ and $\mathrm{Nb}_{2} \mathrm{O}_{5} \cdot n \mathrm{H}_{2} \mathrm{O}$ and $\mathrm{NbOPO}_{4}$ as solid acids in combination with a methanol synthesis catalyst for the direct synthesis of DME. Starting in chapter 2 we review recent literature on metal-support interactions and tuning strategies which serves as an introduction to the field of supported metal nanoparticles and the tools to modify their catalytic performance. In addition to creating a critical overview of the field, the effect of modifying metal-support interactions on catalysis is quantified by systematically reporting the productivity enhancements obtained in C1-chemistry.

Thereafter, chapters 3 to 5 focus on niobia used as support for cobalt and bimetallic cobalt-nickel catalysts for the Fischer-Tropsch (FT) reaction. In chapter 3 the importance of crystal phase, porosity and cobalt loading in $\mathrm{Co} / \mathrm{Nb}_{2} \mathrm{O}_{5}$ is highlighted. Additionally, a carbon-templated crystallization method was carried out to overcome the limited porosity of crystalline niobia and allow higher Co loadings. The resulting crystalline niobia partially preserved the porosity of the precursor niobium oxide hydrate. With a higher Co loading, the catalyst-weight normalized FT activity increased without sacrificing $\mathrm{C}_{5+}$ selectivity. Chapter 4 describes a method and a related mechanism to tune the coverage of metal nanoparticles by SMSI-species and the resulting catalytic activity. This was achieved by reduction-oxidation-reduction pre-treatments of cobalt catalysts supported on reducible metal oxides, i.e. $\mathrm{Nb}_{2} \mathrm{O}_{5}$ and $\mathrm{TiO}_{2}$. The positive effects of this treatment resulted in enhanced accessible cobalt surface area and proportional increase in FT activity. In chapter $\mathbf{5}$, we gradually 
changed the composition of the metal nanoparticles from Co to Ni. We observed that when supported on reducible metal oxides, i.e. $\mathrm{Nb}_{2} \mathrm{O}_{5}, \mathrm{TiO}_{2}$, bimetallic Co-Ni nanoparticles displayed enhanced FT activities and high $\mathrm{C}_{5+}$ selectivities, phenomenon not observed when supported on $\alpha-\mathrm{Al}_{2} \mathrm{O}_{3}$, a non-reducible metal oxide. Characterization pointed to a cobalt enrichment of the nanoparticles surfaces and a weaker adsorption of $\mathrm{CO}$ on $\mathrm{Co}-\mathrm{Ni}$ supported on reducible oxides, modifying the FT mechanism.

Chapters 6 and 7 explore alternative catalytic applications of niobium-based materials for the conversion of synthesis gas. Chapter $\mathbf{6}$ presents the change in reactivity of nickel nanoparticles when supported on niobia and the effect of different reduction temperatures to obtain stable $\mathrm{Ni} / \mathrm{Nb}_{2} \mathrm{O}_{5}$ for the hydrogenation of carbon monoxide. Here, the formation of niobium suboxides and their partial coverage of the nickel particles after high temperature reduction limited the formation of nickel carbonyl and slow down particle growth. Although this also led to a decrease in nickel-normalized catalytic activity, stable catalytic performance was gained in return. For Chapter 7 we exploited the acidic character of hydrated niobium pentoxide and niobium phosphate as dehydration materials in the direct synthesis of DME from synthesis gas. In combination with a copper-based methanol synthesis catalyst, the niobium-based solid acids proved active and selective in the production of DME. Particularly the high volume-based activity of these materials and their water-tolerant acid sites makes them promising components for DME production.

Finally, conclusions of the work presented in this thesis and an outlook for future research are given in chapter $\mathbf{8}$. 


\section{References}

1. Martínez, D. M. \& Ebenhack, B. W. Understanding the role of energy consumption in human development through the use of saturation phenomena. Energy Policy 36, 1430-1435 (2008).

2. Arto, I., Capellán-Pérez, I., Lago, R., Bueno, G. \& Bermejo, R. The energy requirements of a developed world. Energy Sustain. Dev. 33, 1-13 (2016).

3. BP. BP Energy Outlook, 2019 edition. London, United Kingdom (2019).

4. U.S. Energy Information Administration. Global Transportation Energy Consumption: Examination of Scenarios to 2040 using ITEDD. 44 (2017).

5. IEA. World Energy Outlook 2019 edition. Paris, France (2019).

6. Keijer, T., Bakker, V. \& Slootweg, J. C. Circular chemistry to enable a circular economy. Nat. Chem. 11, 190-195 (2019).

7. Chu, S. \& Majumdar, A. Opportunities and challenges for a sustainable energy future. Nature 488, 294-303 (2012).

8. IEA. World Energy Balances 2019 edition. Paris, France (2019).

9. Cano, Z. P. et al. Batteries and fuel cells for emerging electric vehicle markets. Nat. Energy 3, 279-289 (2018).

10. Kwade, A. et al. Current status and challenges for automotive battery production technologies. Nat. Energy 3, 290-300 (2018).

11. Armstrong, R. C. et al. The frontiers of energy. Nat. Energy 1, 15020 (2016).

12. Staples, M. D., Malina, R. \& Barrett, S. R. H. The limits of bioenergy for mitigating global life-cycle greenhouse gas emissions from fossil fuels. Nat. Energy 2, 1-8 (2017).

13. Hildebrandt, D., Glasser, D., Hausberger, B., Patel, B. \& Glasser, B. J. Producing transportation fuels with less work. Science 323, 1680 LP - 1681 (2009).

14. Noureldin, M. M. B., Elbashir, N. O. \& El-Halwagi, M. M. Optimization and selection of reforming approaches for syngas generation from natural/shale gas. Ind. Eng. Chem. Res. 53, 1841-1855 (2014).

15. Iaquaniello, G., Centi, G., Salladini, A., Palo, E. \& Perathoner, S. Waste to chemicals for a circular economy. Chem. - A Eur. J. 24, 11831-11839 (2018).

16. Wood, D. A., Nwaoha, C. \& Towler, B. F. Gas-to-liquids (GTL): A review of an industry offering several routes for monetizing natural gas. J. Nat. Gas Sci. Eng. 9, 196-208 (2012).

17. Kong, Z., Dong, X. \& Jiang, Q. Forecasting the development of China's coal-to-liquid industry under security, economic and environmental constraints. Energy Econ. 80, 253-266 (2019).

18. Kong, Z., Dong, X. \& Jiang, Q. The net energy impact of substituting imported oil with coal-to-liquid in China. J. Clean. Prod. 198, 80-90 (2018).

19. Cheng, K. et al. Advances in catalysis for syngas conversion to hydrocarbons. Adv. Catal. 60, 125-208 (2017).

20. Sun, J.et al. Beyond Cars: Fischer-Tropsch synthesis for non-automotive applications. ChemCatChem 11, 14121424 (2019).

21. Bao, J., Yang, G., Yoneyama, Y. \& Tsubaki, N. Significant advances in C1 catalysis: highly efficient catalysts and catalytic reactions. ACS Catal. 9, 3026-3053 (2019).

22. Khodakov, A. Y., Chu, W. \& Fongarland, P. Advances in the development of novel cobalt Fischer-Tropsch catalysts for synthesis of long-chain hydrocarbons and clean fuels. Chem. Rev. 107, 1692-1744 (2007).

23. Torres Galvis, H. M. et al. Iron particle size effects for direct production of lower olefins from synthesis gas. $J$. Am. Chem. Soc. 134, 16207-16215 (2012).

24. Torres Galvis, H. M. \& De Jong, K. P. Catalysts for production of lower olefins from synthesis gas: A review. ACS Catal. 3, 2130-2149 (2013).

25. Enger, B. C. \& Holmen, A. Nickel and Fischer-Tropsch synthesis. Catal. Rev. 54, 437-488 (2012).

26. Agnelli, M., Swaan, H. M., Marquez-Alvarez, C., Martin, G. A. \& Mirodatos, C. CO hydrogenation on a nickel catalyst. J. Catal. 175, 117-128 (1998).

27. Shen, W. M., Dumesic, J. A. \& Hill, C. G. Criteria for stable Ni particle size under methanation reaction conditions: Nickel transport and particle size growth via nickel carbonyl. J. Catal. 68, 152-165 (1981).

28. Sehested, J. Industrial and scientific directions of methanol catalyst development. J. Catal. 371, 368-375 
(2019).

29. Weber, J. L., Dugulan, I., de Jongh, P. E. \& de Jong, K. P. Bifunctional catalysis for the conversion of synthesis gas to olefins and aromatics. ChemCatChem 10,1107-1112 (2018).

30. Prieto, G. et al. Design and synthesis of copper-cobalt catalysts for the selective conversion of synthesis gas to ethanol and higher alcohols. Angew. Chemie - Int.Ed. 53, 6397-6401 (2014).

31. Azizi, Z., Rezaeimanesh, M., Tohidian, T. \& Rahimpour, M. R. Dimethyl ether: A review of technologies and production challenges. Chem. Eng. Process. Process Intensif. 82, 150-172 (2014).

32. Udaya, V., Rao, S. \& Gormley, R. J. Bifunctional catalysis in syngas conversions. Catal. Today 6, 207-234 (1990).

33. Sartipi, S., Makkee, M., Kapteijn, F. \& Gascon, J. Catalysis engineering of bifunctional solids for the one-step synthesis of liquid fuels from syngas: a review. Catal. Sci. Technol. 4, 893-907 (2014).

34. Torres Galvis, H. M. et al. Iron particle size effects for direct production of lower olefins from synthesis gas. J. Am. Chem. Soc. 134, 16207-16215 (2012).

35. Xie, J. et al. Size and promoter effects on stability of carbon-nanofiber-supported iron-based Fischer-Tropsch catalysts. ACS Catal. 6, 4017-4024 (2016).

36. Xie, J. et al. Size and promoter effects in supported iron Fischer-Tropsch catalysts: Insights from experiment and theory. ACS Catal. 6, 3147-3157 (2016).

37. Van Den Berg, R. et al. Structure sensitivity of $\mathrm{Cu}$ and CuZn catalysts relevant to industrial methanol synthesis. Nat. Commun. 7, 13057 (2016).

38. Bezemer, G. L. et al. Cobalt particle size effects in the Fischer-Tropsch reaction studied with carbon nanofiber supported catalysts. J. Am. Chem. Soc. 128, 3956-3964 (2006).

39. Den Breejen, J. P. et al. On the origin of the cobalt particle size effects in Fischer-Tropsch catalysis. J.Am. Chem. Soc. 131, 7197-7203 (2009).

40. Munnik, P., Velthoen, M. E. Z., De Jongh, P. E., De Jong, K. P. \& Gommes, C. J. Nanoparticle growth in supported nickel catalysts during methanation reaction - Larger is better. Angew. Chemie - Int. Ed. 53, 9493-9497 (2014).

41. Prieto, G., Zecevic, J., Friedrich, H., De Jong, K. P. \& De Jongh, P. E. Towards stable catalysts by controlling collective properties of supported metal nanoparticles. Nat. Mater. 12,34-39 (2013).

42. Munnik, P., De Jongh, P. E. \& De Jong, K. P. Recent developments in the synthesis of supported catalysts. Chem. Rev. 115, 6687-6718 (2015).

43. Nowak, I. \& Ziolek, M. Niobium compounds: Preparation, characterization, and application in heterogeneous catalysis. Chem. Rev. 99, 3603-3624 (1999).

44. Tanabe, K. Catalytic application of niobium compounds. Catal. Today 78, 65-77 (2003).

45. Silva, R. R. C. M., Schmal, M., Frety, R. \& Dalmon, J. A. Effect of the support on the fischer-tropsch synthesis with $\mathrm{Co} / \mathrm{Nb}_{2} \mathrm{O}_{5}$ catalysts. J. Chem. Soc. Faraday Trans. 89, 3975-3980 (1993).

46. Den Otter, J.H. \& De Jong, K.P. Highly selective and active niobia-supported cobalt catalysts for fischer-tropsch synthesis. Top. Catal. 57, 445-450 (2014).

47. Johnson, G. R. \& Bell, A. T. Effects of Lewis acidity of metal oxide promoters on the activity and selectivity of Co-based Fischer-Tropsch synthesis catalysts. J. Catal. 338, 250-264 (2016).

48. Prieto, G. et al. Cobalt-catalyzed Fischer-Tropsch synthesis: Chemical nature of the oxide support as a performance descriptor. ACS Catal. 5, 3323-3335 (2015).

49. Tauster, S. J., Fung, S. C. \& Garten, R. L. Strong metal-support interactions. Group 8 noble metals supported on titanium dioxide. J.Am. Chem. Soc. 100, 170-175 (1978).

50. Tauster, S. J. Strong metal-support interactions. Acc. Chem. Res. 20,389-394 (1987).

51. Hayashi, S. et al. $\mathrm{Nb}_{2} \mathrm{O}_{5} \cdot n \mathrm{H}_{2} \mathrm{O}$ as a heterogeneous catalyst with water-tolerant Lewis acid sites. J.Am. Chem. Soc. 133, 4224-4227 (2011).

52. Carniti, P., Gervasini, A., Bossola, F. \& Dal Santo, V. Cooperative action of Brønsted and Lewis acid sites of niobium phosphate catalysts for cellobiose conversion in water. Appl. Catal. B Environ. 193, 93-102 (2016).

53. Den Otter, J. H. Niobia-supported Cobalt Catalysts for Fischer-Tropsch Synthesis. (Utrecht University, 2016). 



\section{Control of Metal-Support Interactions in Heterogeneous Catalysts to Enhance Activity and Selectivity}

Metal nanoparticles stabilised on a support material catalyse many major industrial reactions. Metal-support interaction (MSI) in these nanomaterials can have a substantial influence on the catalysis, making MSI modulation one of the few tools to enhance catalytic performance. This topic has received much attention in recent years, however, a systematic rationalisation of the field is lacking due to the great diversity in catalysts, reactions and MSI modification strategies. In this review, we cover and categorise the recent progress in MSI tuning strategies to enhance catalytic performance for various reactions. Furthermore, we quantify the productivity enhancements resulting from MSI control that have been achieved in $\mathrm{C} 1$ chemistry in recent years. Our analysis shows that up to 15 -fold productivity enhancement has been achieved and that MSI is most impactful for metal nanoparticles smaller than $4 \mathrm{~nm}$. These findings demonstrate the importance of MSI to improve performance in catalysis.

van Deelen, T. W.\#, Hernández Mejía, C.\# \& de Jong, K. P. Control of metal-support interactions in heterogeneous catalysts to enhance activity and selectivity. Nat. Catal. 2, 955-970 (2019).

\# Both authors contributed equally to this manuscript. 
a

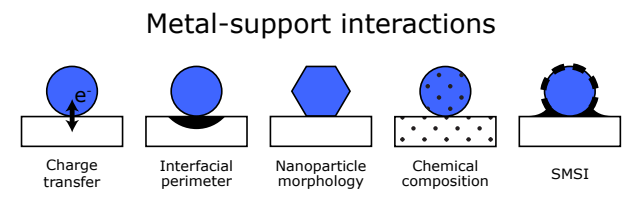

b

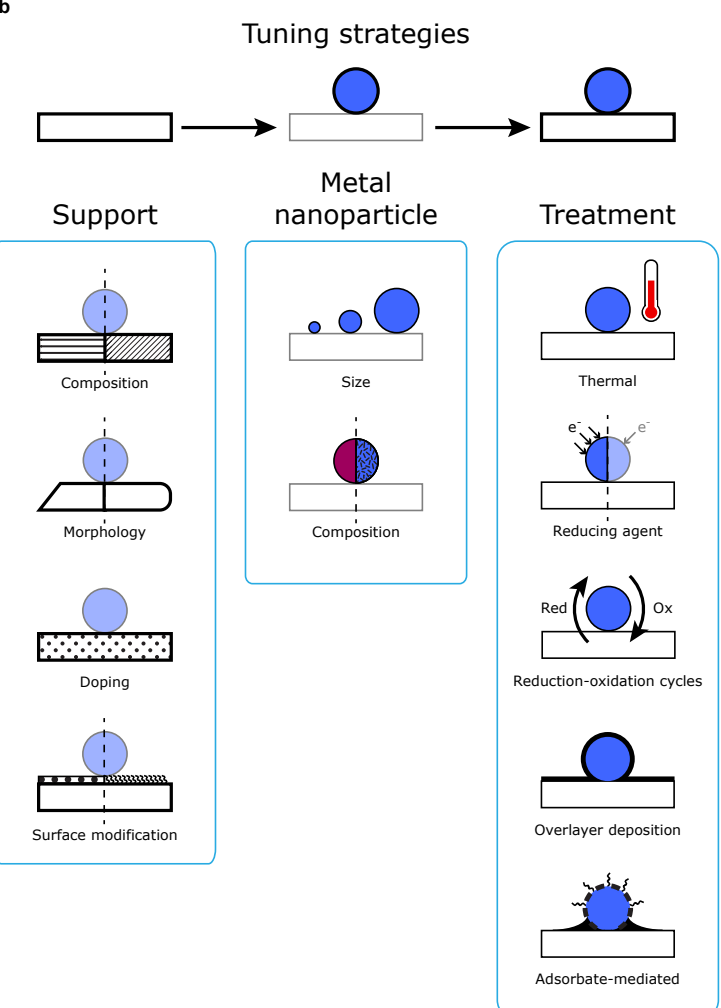

Figure 2.1 Schematic representation of main metal-support interactions and their tuning strategies. The five main phenomena of metal-support interactions are depicted in $\mathbf{a}$. The approaches for tuning such interactions are illustrated in $\mathbf{b}$ and divided after the different stages of catalyst modification, i.e., via solely the support or the nanoparticle or via treatments on the metal-support composite material.

\subsection{Introduction}

Metal nanoparticles are the key functional component in various nanotechnological applications, owing to the unique properties that arise from their size, shape and composition $^{1,2}$. Consequently, several strategies have been developed to design and control these properties. A key strategy is to immobilise nanoparticles on a support to enhance their stability and control their spatial distribution ${ }^{3,4}$. However, supports are typically not inert and the interaction with nanoparticles gives rise to new interface phenomena. Such metal-support interaction (MSI) may have a profound impact on the resulting performance of the metal nanoparticles ${ }^{5,6}$. Hence, strategies for controlling these interactions to optimise performance are highly desirable. 
In heterogeneous catalysis, MSI affects the catalytic performance and its regulation thus provides options for catalyst design. Recently, the topic has gained much attention as judged by the increasing number of reports on the subject and substantial progress has been made in methodology to tune metal-support interactions with the aim to improve the performance of supported metal catalysts. Because of the great diversity in MSI tuning approaches, catalytic systems and reactions, a systematic and critical overview would be helpful to determine the most effective tuning strategies for real working catalysts.

This review starts with a brief introduction covering the relevant concepts of MSI phenomena and the following sections discuss the latest reports on MSI tuning strategies for catalysis, systematically arranged after the different stages of catalyst modification. Several interesting reviews have already been published in the field of $\mathrm{MSI}^{7-10}$. In comparison, we have reviewed the literature published since 2015 on tuning interactions between metals and supports to improve catalytic performance, covering mainly $3 \mathrm{D}$ catalysts containing metal nanoparticles or clusters under industrially relevant conditions. For a general discussion, we provide a quantitative analysis of the scale of performance enhancement that has been reported in the past years. To quantify the effects of MSI modulation on catalytic performance, we focus on intrinsic activity and selectivity as performance descriptors and less on stability. Although highly relevant from an application point of view, activity enhancement due to changes in metal dispersion (increased metal specific surface area) are not covered here. Relative scaling factors are obtained by comparing the productivities of tuned and reference catalysts in C1 chemistry, which allow us to point out the most successful tuning strategies and opportunities in this field.

\subsection{Metal-support interactions}

Impact on catalysis originates from interactions between metal nanoparticles and their supporting matrix (Figure 2.1a). Typical metal-support phenomena relate to charge transfer, the interfacial perimeter, nanoparticle morphology, chemical composition and strong metal-support interaction (SMSI). These phenomena are often entangled and some will have a stronger influence than others, depending on the catalyst and the reaction.

Charge transfer. The interface between a metal NP and the support can give rise to a rearrangement of electrons within both materials ${ }^{5}$. Redistribution of electrons with noticeable effects is limited to a couple of atomic layers at the interface and might be accompanied in some cases by a change in oxidation state of the metal atoms from the NP or of the support's metal ions ${ }^{11,12}$. The magnitude and direction of the charge transfer is driven by differences in the Fermi level of the metal NP and the support, ultimately seeking equilibration of the electron chemical potentials. The metallic character of the NPs enables electron mobility, however their size is relevant in the nanometer regime, since the smaller the NP the more localised are its electronic states. Several characteristics of the support are important for charge transfer, such as its conductivity, reducibility, exposed crystal planes, morphology and occurrence of defects ${ }^{13,14}$. 
Interfacial perimeter. Interface sites at the perimeter of the NP are a unique environment given that they are in direct contact with the NP, the support and the reactants, facilitating synchronised reactions ${ }^{15,16}$. Furthermore, it has been shown that upon charge transfer, atoms at the perimeter favour the accumulation of excess charges ${ }^{17}$. All this can significantly enhance adsorption and reactions of molecules at the perimeter ${ }^{18,19}$. Additionally, close proximity of the nanoparticle to different functionalities or defects at the surface of the support (e.g., oxygen vacancies, hydroxyl groups, Lewis acids or bases) might also aid local sequential reactions or stabilise transition states of reactants or products ${ }^{20,21}$.

Spillover via the interfacial perimeter can occur as well. This initiates with the activation of a reactant on one surface, typically on the metal NP, which is then transferred to the other surface, e.g., the support. Note that this second surface does not activate the reactants itself under the same conditions. The most studied spillover is for $\mathrm{H}$ and to a lesser extent $\mathrm{O}$ or other molecules (e.g., $\mathrm{CO},-\mathrm{OCH}_{3}$, etc.). Spillover from the support to the metal nanoparticle can also occur, referred sometimes as reverse spillover ${ }^{22-24}$. The nature of the support is crucial for spillover; whereas hydrogen spillover on reducible supports occurs fast and at relative large distances, it has been shown to proceed ten orders of magnitude slower on non-reducible supports and is restricted to short distances ${ }^{25}$.

NP morphology. The shape and crystal structure of nanoparticles have a strong influence on their catalytic performance, considering that different shapes expose certain facets and these facets can have favourable or unfavourable configurations of atoms ${ }^{26,27}$. The adhesion energy at the metal-support interface affects the shape of the nanoparticles ${ }^{26,28}$. In general, supports with stronger adhesion result in particles with more faceted and sometimes raftlike shapes ${ }^{29}$. A trend observed for metal oxide supports suggests that adhesion energies increase with increasing heat of formation of the most stable oxide of the metal ${ }^{30}$ and by decreasing the metal NP's size ${ }^{31}$. Besides NP shape, high adhesion energy will also reduce the mobility of the NPs and hence their tendency to grow ${ }^{6,32}$.

The equilibrium shape of a metal NP is often determined by minimisation of its total surface free energy. Contact with the support can lower the surface energy of certain NP's planes, favouring some shapes over others. The surface energy of a metal can also change under reaction conditions upon adsorption of a gas, where the change in its surface energy tends to affect the contact surface area with the NP and hence modifies the NP's shape ${ }^{33,34}$. Moreover, a misfit between the lattices of the support and the nanoparticle can generate strain and defects, modifying the morphology of the NP ${ }^{35}$. Additionally, the effect of lattice mismatching is more pronounced for smaller metal nanoparticles, as observed for gold nanoparticles smaller than $3 \mathrm{~nm}$ supported on titania ${ }^{36}$.

Chemical composition. A solid state reaction can take place between metal NPs and the support resulting in the formation of new phases. Exchange of species is possible in both directions, usually coupled with a redox process, with oxidation of the metal atoms from the nanoparticle or reduction of metal ions from the support. This phenomenon has ambivalent consequences, since the resulting species can both lower or enhance catalytic per- 
formance. On the one hand, formation of inactive phases such as mixed metal oxides (e.g., metal aluminates) at the expense of active metal sites has been recognised for long time as a prominent deactivation process ${ }^{37,38}$. On the other hand, formation of highly active intermetallic nanoparticles is also possible by reduction of metal or metalloid ions from the support to incorporate into the metal NP. This phenomenon has recently attracted significant attention and is sometimes referred as reactive metal-support interaction (RMSI) ${ }^{39}$. The pre-deposited metal nanoparticles aid in the activation of the support. Upon high temperatures and reductive conditions, the former cations from the support can migrate to the nanoparticle. This can be facilitated by doping the support or employing $2 \mathrm{D}$ supports. The strategy has been effectively applied to incorporate difficult-to-reduce metals or metalloids (e.g., Si, Al, V, Ti, Nb, etc.) into late transition metal NPs, resulting in novel catalytic systems ${ }^{40}$.

The local composition of alloyed metal nanoparticles can be affected by interacting with the support, where re-arrangement of the components in an alloyed nanoparticle is driven by preferential interaction of one of its elements with the support at the interface ${ }^{41}$. This can lead to compositional rearrangements different from the initially uniform composition, such as core-shell or segregated sub-cluster structures, affecting the synergy of the metals and hence their catalytic performance ${ }^{42,43}$.

Strong metal-support interaction. The term strong metal-support interaction (SMSI) refers to metal NP coverage by suboxides, which are generated from the support under reducing conditions ${ }^{44,45}$. The phenomenon is driven by minimisation of the high surface energy of the metal NP by mobile support suboxide species. High surface energy metals that are capable of activating hydrogen are prone to encapsulation and reducible supports are necessary to generate the suboxide species. The suboxides covering the nanoparticle consist of a few atomic layers with probably amorphous character and possess dynamic structures under different gas atmospheres as shown in the case of titanium and iron oxide ${ }^{46-48}$. Extensive coverage of the NP is detrimental for the catalytic performance due to blockage of active sites. However, these suboxides can change the (local) electronic structure of the metal surface and act as Lewis acids, thereby promoting the activation of reactants and improve the catalytic performance ${ }^{49}$.

\subsubsection{Modification of metal-support interactions}

The aforementioned MSI phenomena can have a major impact on the catalytic performance. Therefore, modification of MSI can be employed as a tool for the design of catalytic systems with enhanced performance. Several synthetic strategies for the control of the MSI have been reported, which can be classified according to changes to the catalyst's components before and after assembly of the composite material (Figure 2.1b). Through this distinction, we aim to emphasise the similarities within one strategy, when applied to different families of catalysts, supports and reactions. In the coming section we start by discussing reports targeting modification mainly of the support, divided into strategies involving support composition, morphology, doping and surface modifications. Thereafter, 
strategies that focus on nanoparticle modifications are discussed, particularly changes in NP's size and composition. Lastly, we cover the approaches to tune MSI on the as-prepared catalyst by use of a treatment. The identified treatments include thermal, reducing agent, reduction-oxidation cycles, overlayer deposition and adsorbate-mediated treatments.

\subsection{Support}

The first approach to tune the metal-support interactions is through a judicious choice of support characteristics. The support provides numerous opportunities for changing its structure and surface composition, making it one of the most employed handles to tune MSI. In this section, we will discuss modifications of supports prior to deposition of NPs. Support tuning strategies after NP loading are classified as a post-synthesis treatment and will be discussed in the Treatment section.

Support composition. The first point of consideration is the chemical composition of the support, as that partially defines the starting point for MSI. The discussion of support composition involves comparisons between different types of supports as well as between different chemical compositions of related support compounds. Examples of support properties impacting MSI include the surface composition of the support (such as extent of hydroxylation), the electronic structure of the support (especially important for electro- or photocatalysis), ion mobility (e.g., formation of oxygen vacancies or cation diffusion), reactivity of the support, and the possibility to segregate cations to form intermetallic compounds.

Several recent publications investigated the role of the support in the catalytic oxidation of CO by Au NPs. Saavedra et al. ${ }^{50}$ studied in detail the origin of lower CO oxidation activity at room temperature of $\mathrm{Au} \mathrm{NP}$ supported on $\mathrm{Al}_{2} \mathrm{O}_{3}$ compared to $\mathrm{TiO}_{2}$. They concluded that activity was to a large extent determined by competitive adsorption of water (promoting) and carbonates (poisoning) on the support and active metal sites. The role of the support was mainly to supply adsorbed water to the Au NPs. This was more efficient on $\mathrm{TiO}_{2}$, given that carbonates bind stronger to $\mathrm{Al}_{2} \mathrm{O}_{3}$ than to $\mathrm{TiO}_{2}$ and they propose that oxygen vacancies do not participate significantly in the catalysis. Contrary, Wang et al. ${ }^{51,52}$ reported that oxygen vacancies are generated in $\mathrm{TiO}_{2}$ and that these vacancies are mainly responsible for the modified catalytic activity. The vacancies caused overall electron donation to the Au NPs, making these NP negatively charged. The charge donation resulted in strongly modified $\mathrm{CO}$ adsorption strength and lower intrinsic activity at $80^{\circ} \mathrm{C}$. Interestingly, the TOF could be enhanced by one order of magnitude by re-oxidation of the catalyst, which reduced the amount of oxygen vacancies. One possibility for these two different explanations of the same catalytic system could be the different pre-treatment or reaction conditions, such as reaction temperature (RT vs. $80{ }^{\circ} \mathrm{C}$ ), feed composition ( 1 vs $20 \% \mathrm{O}_{2}$ ), or dilution with inert $\mathrm{SiC}$. For example, it has been reported that the mechanism of CO oxidation changes with reaction temperature ${ }^{52}$.

The activity for benzyl alcohol oxidation followed the opposite trend as for CO oxidation with the intrinsic activity decreasing in the order $\mathrm{Au} / \mathrm{Al}_{2} \mathrm{O}_{3}>\mathrm{Au} / \mathrm{SiO} \mathrm{O}_{2}>\mathrm{Au} / \mathrm{TiO}{ }_{2}>\mathrm{Au} /$ 
$\mathrm{ZnO}^{53}$ (Figure 2.2a). Charge transfer occurred to a different extent from various supports to $\mathrm{Au}$ NPs of 2-4 nm size and correlated inversely with the electron donation capacity of the support. Hydride transfer from the alcohol to Au was argued to be the rate determining in this case and would account for lower activity of more negatively charged Au NP.

In photocatalysis, a semiconductor support's bandgap of appropriate size and position facilitates light absorption and transfer of the generated charge to or from metal NPs performing catalysis. The activity of $\mathrm{Rh} / \mathrm{TiO}_{2}$ in steam reforming of methane was already 13 times higher than that of $\mathrm{Rh} / \mathrm{SiO}_{2}$ and $\mathrm{Rh} / \mathrm{ZrO}_{2}$ in dark conditions and the activity of $\mathrm{Rh} / \mathrm{TiO}_{2}$ was enhanced further nearly 3 times when exposed to light (Figure 2.2b) ${ }^{54}$. However, the opposite has been observed as well; $\mathrm{Pt} / \mathrm{Ta}_{2} \mathrm{O}_{5}$ was more active than $\mathrm{Pt} / \mathrm{TiO}$ for 2-propanol oxidation to acetone, because hot electrons generated on the Pt NPs were not transferred to the support and hence drove the catalysis on the Pt NPs ${ }^{55}$. XPS analysis indicated that the Pt phase was more negatively charged on $\mathrm{Ta}_{2} \mathrm{O}_{5}$ than on other supports. Similar considerations also apply to electrocatalysis. The activity of Pt NPs for electrocatalytic reduction of oxygen was significantly enhanced when a mixture of boron carbide and graphite was used as support instead of pure graphite and it was argued that this was solely an electronic effect ${ }^{56}$.

Perovskites are a class of metal oxides with the general formula $\mathrm{ABO}_{3}$ in which a large variety of metal ions can be incorporated in the A- and B-sites of their crystal structures. Some of these ions can be extracted from the perovskite lattice upon reduction to form nanoparticles. This approach has received great attention for electrochemical systems ${ }^{57}$ mainly due to the beneficial conductive properties of perovskites for electrodes. However, this approach has been employed to a lesser extent for catalysis due to the resulting low metal loading and limitation to easy-to-reduce metal ions, such as noble metals. Recently, non-stoichiometric perovskites with A-site deficiency extended the range of metal ions capable of forming nanoparticles to more difficult to reduce metal ions (e.g., $\mathrm{Ti}^{4+}, \mathrm{Fe}^{2+/ 3+}, \mathrm{Mn}^{2+/ 3+}$, $\left.\mathrm{Ni}^{2+}\right)^{58,59}$. The resulting nanoparticles resisted the harsh conditions of methane reforming due to partial embedding in the support, avoiding the formation of carbon fibres at the periphery of the nanoparticles. Formation of alloyed nanoparticles is also possible by use of this strategy. Alloyed $\mathrm{Pt}_{3} \mathrm{Ni}$ nanoparticles obtained from $\mathrm{La}_{0.9} \mathrm{Mn}_{0.9} \mathrm{Pt}_{0.075} \mathrm{Ni}_{0.025} \mathrm{O}_{\mathrm{x}}$ perovskite have shown high activity for the electrocatalytic oxygen reduction reaction ${ }^{60}$. The strong connection with the conductive perovskite, uniform NP distribution and small NP size for the obtained particles were beneficial to the measured activity.

The disadvantage, however, of using perovskites to form nanoparticles in catalysis is the low specific surface area of these compounds, due to the high temperatures needed to synthesise the perovskites. Progress has been achieved in fabricating high surface area perovskites by templating methods, however the challenge remains with the high temperatures needed to form the metal nanoparticles, which usually leads to collapse of the pore structure of the perovskites ${ }^{61}$.

Support morphology. Various allotropes or morphologies can exist for one type of support. We will discuss these two properties together, because they are often interrelated and exert 


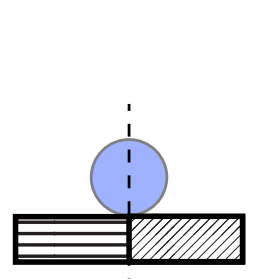

Composition

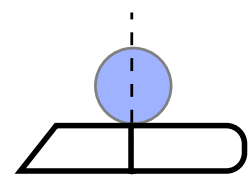

Morph'ology a

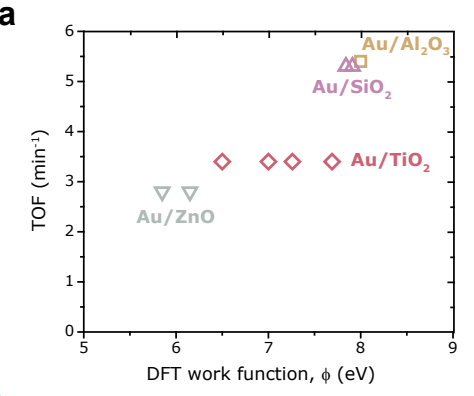

b
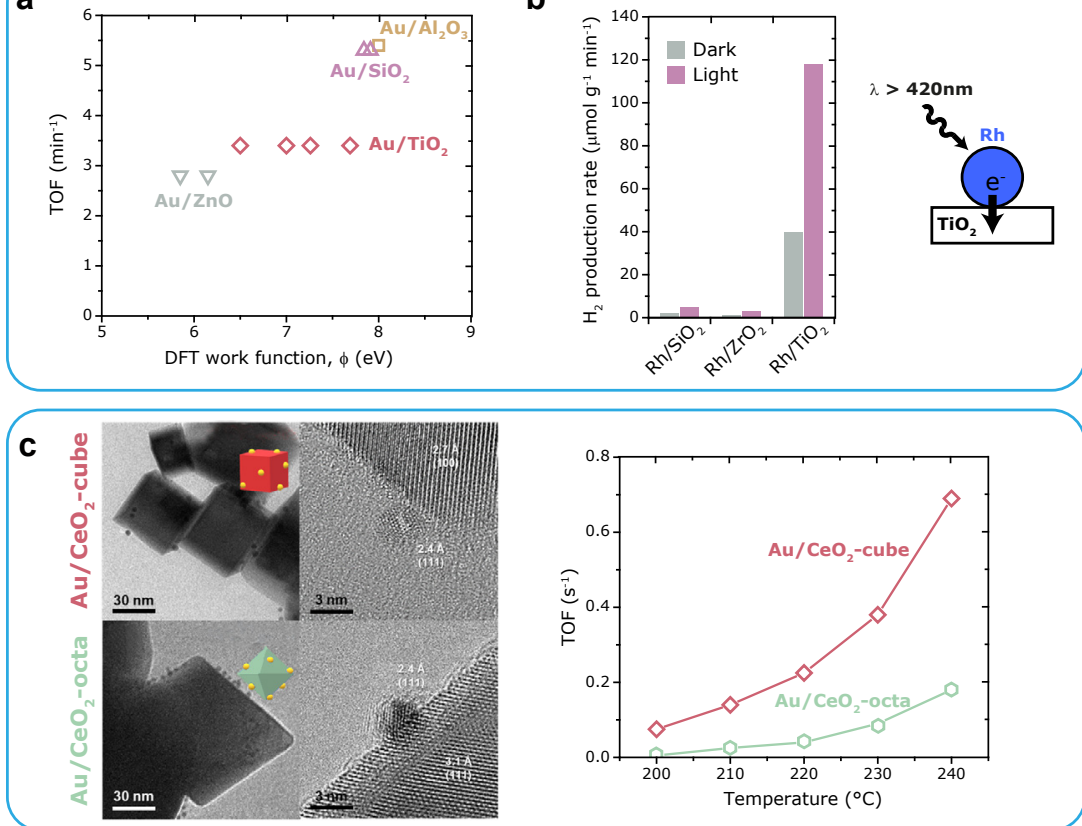

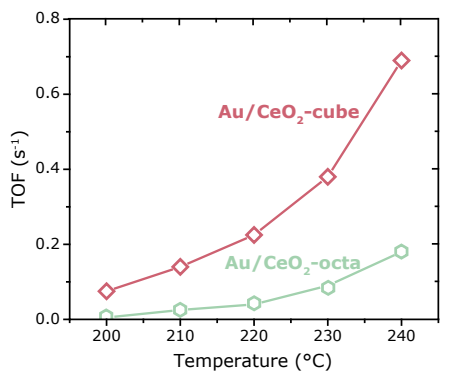

Figure 2.2 MSI tuning strategies involving modification of the support composition and morphology. a, TOF for benzyl alcohol selective oxidation plotted against the work function of the supports, which is the inverse of the support's electron-donating ability to gold NPs. Multiple work function values were obtained for some supports, because these values were calculated for individual support crystal facets (ref. 53). b, Methane steam reforming activity expressed as $\mathrm{H}_{2}$ production rate for $\mathrm{Rh} \mathrm{NPs}$ supported on $\mathrm{SiO}_{2}, \mathrm{ZrO}_{2}$ and $\mathrm{TiO}_{2}$ with and without exposure to visible light (ref. 54). c, Use of different ceria morphologies (cubes or octahedra) as support for gold NPs and their effect on CO oxidation (ref. 70).

a combined effect. For example, the crystal structure and morphology of the support jointly determine the facets that are exposed at the surface of the support and thereby regulate the local environment for the metal nanoparticles. In this section, we will highlight some recent examples of how the crystal structure of metal oxides can direct NP shape and SMSI, and how shaped support particles can expose special surface sites or confine NPs.

The crystal structure of metal oxides can affect the NPs deposited onto it by directing the shape of the metal NPs. For example, when $\mathrm{Pd} / \mathrm{Al}_{2} \mathrm{O}_{3}(\alpha, \gamma$, and $\theta)$ catalysts were investigated for methane oxidation, the crystal structure of the support affected the shape of Pd NPs, with more distorted NP on $\gamma-\mathrm{Al}_{2} \mathrm{O}_{3}$ and more regularly shaped and facetted NP on $\alpha$ - and $\theta-\mathrm{Al}_{2} \mathrm{O}_{3}{ }^{62}$. The shape of the NP together with NP size determined the number of step sites, which could be correlated with intrinsic activity. The presence of pentacoordinate $\mathrm{Al}^{3+}$-sites on the surface of $\gamma-\mathrm{Al}_{2} \mathrm{O}_{3}$, as observed by NMR, and their absence in $\alpha$ - and $\theta-\mathrm{Al}_{2} \mathrm{O}_{3}$ were proposed to distort the NP shape and increase the TOF of $7.5 \mathrm{~nm}$ NP from 0.1 to $0.6 \mathrm{~s}^{-1}$. A similar effect was observed for Pt NPs on $\gamma-\mathrm{Al}_{2} \mathrm{O}_{3}$ and $\mathrm{CeO}_{2}{ }^{35}$. Especially on $\mathrm{CeO}_{2}$, the authors were able to show that epitaxial NP growth, dictated by the support crystal structure, directed the shape of the NPs and caused strain. From theoretical investigations, 
the predicted intrinsic activity for CO oxidation varied between $2 \cdot 10^{-3}$ and $5 \cdot 10^{-3} \mathrm{~s}^{-1}$ with the occurrence of specific Pt surface sites, related to the shape and strain of these NPs.

In addition, one crystal structure can be more susceptible to partial reduction and SMSI. In the case of $\mathrm{TiO}_{2}$-supported Ru-promoted cobalt catalysts for the Fischer-Tropsch synthesis ${ }^{63}$ and rhodium catalysts for steam reforming of propane ${ }^{64}$, suboxide coverage was more extensive on $\mathrm{TiO}_{2}$ in the anatase phase than in the rutile phase. In both cases, the overall activity of the catalysts was higher on rutile, because of fewer blockages of active sites by the $\mathrm{TiO}_{x}$ species. Furthermore, the specific surface area of the $\mathrm{TiO}_{2}$-anatase support was shown to also influence the extent of SMSI and activity on $\mathrm{Ru}-\mathrm{Co} / \mathrm{TiO}_{2}$ catalysts for the Fischer-Tropsch synthesis ${ }^{65}$ and $\mathrm{Ru} / \mathrm{TiO}_{2}$ catalysts for $\mathrm{CO}$ methanation ${ }^{66}$. The cobalt-weightbased activity decreased for both catalysts with increasing specific surface area of the support, again because of a larger number of blocked sites. The TOF was, however, not affected by the support specific surface area. In this case, the anatase supports with higher surface area displayed a higher concentration of defects, as inferred from Raman spectroscopy, and this probably led to more facile formation of $\mathrm{TiO}_{x}$ species during reduction.

The shape of the support, i.e., the exposed crystal facets, also influence the catalytic performance through MSI. The activity of $\mathrm{Pt} / \mathrm{TiO}_{2}$ for methanol oxidation ${ }^{67}, \mathrm{Co} / \mathrm{CeO}_{2}$ and $\mathrm{Ru} / \mathrm{CeO}_{2}$ for ammonia synthesis ${ }^{68,69}$ and $\mathrm{Au} / \mathrm{CeO}_{2}$ (Figure 2.2c) and $\mathrm{Au} / \mathrm{ZnO}$ for $\mathrm{CO}$ oxidation $^{70,71}$ showed large differences depending on the facets on which the metal NPs were situated. The facets were controlled by synthesising nanostructured support particles of controlled shapes. The reason for the modified catalytic performance varied, however, from facilitated reactant/intermediate binding and charge transfer $\left(\mathrm{Pt} / \mathrm{TiO}_{2}\right)$, enhanced support reduction $\left(\mathrm{Co}\right.$ and $\mathrm{Ru}$ on $\mathrm{CeO}_{2}$ ) to the occurrence of more vacancies ( $\mathrm{Au}$ on $\mathrm{CeO}_{2}$ and $\mathrm{ZnO}$ ). For $\mathrm{Au} / \mathrm{ZnO}$, the vacancies allowed $\mathrm{Au}$ to replace $\mathrm{Zn}$ in the $\mathrm{ZnO}$ crystal lattice and promote a Mars-van Krevelen mechanism through the formation of Au-O-AuZn bonds, which are broken easier than Au-O-Zn bonds. This led to a remarkable 150 times increase in specific activity that was amplified using a very low activity reference catalyst (see Appendix A, entry 6).

One- and two-dimensional supports can give rise to confinement or exposure of special sites on the support surface. For example, Zhu et al. ${ }^{72}$ demonstrated enhanced CO oxidation activity for Pt NPs supported on boron nitride nanosheets. The NPs associated to $\mathrm{B}$-vacancies displayed lower electron density while $\mathrm{N}$-vacancies donated electron density to Pt-NPs. Since the N-vacancies were the main Pt-binding sites, the Pt NPs were electron rich compared to those supported on bulk boron nitride, which contained less vacancies. This enhanced $\mathrm{O}_{2}$ adsorption and increased $\mathrm{CO}$ oxidation activity from 30 to $70 \%$ conversion at $47{ }^{\circ} \mathrm{C}$. Similarly, the selectivity towards $\mathrm{CH}_{4}$ of Ni NPs on planar siloxenes in $\mathrm{CO}_{2}$ hydrogenation was $90 \%$ when the NPs were confined in the interior of the siloxenes structures and $53 \%$ when the Ni NPs were located on the exterior of the support ${ }^{73}$. In this case, confinement tuned the balance between the formate and the CO intermediate reaction pathway. Another example is confinement of Pt NPs in the interior of carbon nanotubes (CNT), which reduced NP size and prevented oxidation of $\mathrm{Pt}^{74}$. This kept the metal in the active state and increased toluene oxidation activity from 4 to $27 \mu \mathrm{mol} \cdot \mathrm{g}_{\mathrm{Pt}}{ }^{-1} \cdot \mathrm{s}^{-1}$ at $140{ }^{\circ} \mathrm{C}$ compared to NPs located on the exterior surface of the CNT. 
Two-dimensional early transition metal carbides present weaker metal-carbon bonds, due to their dimensionality, compared to bonds in traditional metal oxides or metal carbides. This results in increased chemical reactivity of the metal ions and facilitating RMSI. A two-dimensional niobium carbide $\mathrm{Nb}_{2} \mathrm{CT}_{\mathrm{x}}$ (where $\mathrm{T}$ accounts for various elements/groups) has been used as support for platinum nanoparticles and applied for the water-gas shift reaction $^{75}$. The two-dimensionality of this carbide material aided in the formation of a Pt- $\mathrm{Nb}$ surface alloy by $\mathrm{H}_{2}$ reduction at $350{ }^{\circ} \mathrm{C}$. Furthermore, the removal of functional groups (T) such as $-\mathrm{OH},-\mathrm{O}$ and $-\mathrm{F}$, exposed terminal niobium sites which were identified as interfaces for $\mathrm{H}_{2} \mathrm{O}$ activation. These exposed niobium atoms in contact with the Pt-Nb surface alloy showed strong affinities for $\mathrm{H}_{2} \mathrm{O}$ or $\mathrm{OH}$, as indicated by the WGS kinetics. However, this catalyst showed a similar reaction rate of $\sim 1.5 \cdot 10^{-2} \mathrm{~mol}_{\mathrm{H} 2} \cdot \mathrm{mol}_{\mathrm{Pt}}{ }^{-1} \cdot \mathrm{s}^{-1}$ as a $\mathrm{Pt} / \mathrm{Al}_{2} \mathrm{O}_{3}$ reference catalyst. The same research group has employed this material, platinum supported on niobium carbide $\left(\mathrm{Pt} / \mathrm{Nb}_{2} \mathrm{CT}\right.$ ), as well as platinum supported on titanium carbide $\left(\mathrm{Pt} / \mathrm{Ti}_{3} \mathrm{C}_{2} \mathrm{~T}_{\mathrm{x}}\right)$ as catalysts for dehydrogenation of light alkanes ${ }^{76}$. In this case, $\mathrm{Pt}-\mathrm{Ti}\left(\mathrm{Pt}_{3} \mathrm{Ti}\right)$ or $\mathrm{Pt}-\mathrm{Nb}\left(\mathrm{Pt}_{3} \mathrm{Nb}\right)$ alloy formation increased selectivity towards propene from 60 to $\sim 95 \%$ at $15 \%$ conversion through facilitating olefin desorption, which prevented secondary reactions.

The amount of literature on tuning MSI via support morphology for electro- or photo-catalysis is limited. This can be rationalised by considering that this strategy often concerns metal oxides with limited conductivity. One exception is the work by Shi et al. ${ }^{77}$ on $\mathrm{Au}$ NPs supported on disordered $\mathrm{TiO}_{2}$ rich in oxygen vacancies, i.e., black titania. They found that the presence of intermediate energy levels within the band gap enhanced trapping of hot plasmonic electrons from gold and increased the photocurrent densities from 126 to $280 \mu \mathrm{A} \cdot \mathrm{cm}^{-1}$ with respect to $\mathrm{Au}$ on regular white $\mathrm{TiO}_{2}$, making photocatalytic water splitting more efficient.

Doping. Doping of supports with elements of different valency mainly serves to regulate the electronic structure of the support (and metal NP) and typically results in enhanced or reduced electron donating properties.

Doping of carbons is an active field, especially for electrochemical applications such as batteries and supercapacitors and metal-free catalysis. When used as a support material for metallic nanoparticles, carbon can be doped with a variety of heteroatoms of which $\mathrm{N}$ has been most investigated. For a more comprehensive overview of how this strategy can be applied to obtain the desired reactivities, we refer to a recent review ${ }^{78}$. Here, we will cover the basics and highlight two studies which we believe illustrate the concept and possibilities.

$\mathrm{N}$-doping is often reported to increase the support-metal nanoparticle binding strength and therefore leads to smaller NPs and higher stabilities ${ }^{79}$. Incorporating $\mathrm{N}$ in a carbon matrix can have various effects on its electronic structure, depending on the position of incorporation (e.g., pyrrolic, pyridinic or graphitic). Ning et al. ${ }^{80}$ investigated the electronic effect of different $\mathrm{N}$ species interacting with Pt nanoparticles of 2-4 $\mathrm{nm}$ and found that pyridinic $\mathrm{N}$ acted as an electron acceptor and graphitic $\mathrm{N}$ functioned as an electron donor for the Pt nanoparticles. The electron-enriched Pt NPs (in contact with graphitic N) gave the highest activity in electro-oxidation reactions of glycerol and formic acid. The high 
activity was partially related to an increased rate of CO removal, which otherwise poisons the catalyst. On the other hand, the electron-deficient Pt NPs (in contact with pyridinic $\mathrm{N})$ showed the highest activity in ammonia borane hydrolysis. For both the electron-rich and -deficient NPs, the modified electronic structure was proposed to tune the Pt-reactant bonds, thereby optimising reactant activation.

The application of carbon nitride with a stoichiometry of $\mathrm{C}_{2} \mathrm{~N}$ can be considered one of the most extreme cases of $\mathrm{N}$-doping of a support ${ }^{81}$. These materials have a higher standard electrochemical potential than gold and are therefore termed noble carbons ${ }^{82}$. This means that even gold is electron deficient, when supported on $\mathrm{C}_{2} \mathrm{~N}$, resulting in active materials for ammonia synthesis via electrocatalytic reduction of nitrogen ${ }^{83}$. The positive effect of the $\mathrm{C}_{2} \mathrm{~N}$ support on catalysis was more pronounced when gold was dispersed as single atoms compared to nanoparticles, because of maximal MSI in the case of atomically dispersed metal.

Doping of a magnesium aluminate spinel support with Fe was investigated to improve the performance of a supported Ni catalyst for dry reforming of methane ${ }^{84}$. During the reduction process, Ni catalysed the reduction of Fe from the support most probably via $\mathrm{H}$-spillover and, as a result, up to $50 \%$ Fe was extracted from the support and an Ni-Fe alloy was formed at the NP surface. At an Fe/Ni ratio of $\sim 10$, carbon (coke) formation was inhibited. Interestingly, doping (Fe incorporated in the spinel) was more effective than surface modification (Fe on the surface of spinel), demonstrating the importance of the residual Fe ions left in the spinel structure of the $\mathrm{MgFe}_{\mathrm{x}} \mathrm{Al}_{2-\mathrm{x}} \mathrm{O}$ support.

Doping $\gamma-\mathrm{Al}_{2} \mathrm{O}_{3}$ with $\mathrm{Mg}^{2+}$ ions prior to introduction of $\mathrm{Ni}$ partially prevented undesired mixed metal oxide formation during dry reforming of methane ${ }^{85}$. This left more metallic Ni surface area available for catalysis and reduced deactivation. In addition, coke formation was suppressed, although that was mainly ascribed to the presence of small $(\sim 2$ $\mathrm{nm}$ ) Ni particles. Recently, a related study on Ni-based catalysts for dry methane reforming was conducted, focusing on doping the $\mathrm{Al}_{2} \mathrm{O}_{3}$ with $\mathrm{La}^{3+}$ ions ${ }^{86}$. The addition of $\mathrm{La}^{3+}$ had several effects on catalysis, such as increased activity at $\mathrm{La}^{3+}$ loadings between 2 and $10 \mathrm{wt} . \%$ and decreased selectivity towards coke formation, resulting in increasing stability with $\mathrm{La}^{3+}$ content. The positive influence of $\mathrm{La}^{3+}$ was ascribed to the introduction of basic sites and stronger MSI. It is quite possible that doping with $\mathrm{Mg}^{2+}$ and $\mathrm{La}^{3+}$ affects catalytic performance via the same mechanisms, as both form basic oxides, which may counteract the typically acidic nature of $\gamma-\mathrm{Al}_{2} \mathrm{O}_{3}$.

Adding cationic or anionic dopants to reducible supports such as $\mathrm{TiO}_{2}$ can increase their conductivity, making them more attractive supports for electrocatalysis. When both type of dopants were applied simultaneously, more charge transfer to $3 \mathrm{~nm}$ Pt NPs was observed $^{87}$. This resulted in 3 to 5 times higher Pt mass specific activity in electrocatalytic oxygen reduction than obtained with only one dopant (Figure 2.3a). Similarly, an increase in charge transfer from $\mathrm{Fe}^{3+}$-doped $\mathrm{ZnO}$ to Pt NPs reportedly led to a 5-fold increase in TOF in $\mathrm{CO}$ oxidation ${ }^{88}$. Other examples of dopants that affect oxygen vacancies or charge transfer in reducible supports examples are available as well ${ }^{89-91}$. Furthermore, Schumann et al. ${ }^{92}$ found that dopants can stabilise the metal oxide by changing their reducibility. Trivalent dopants 

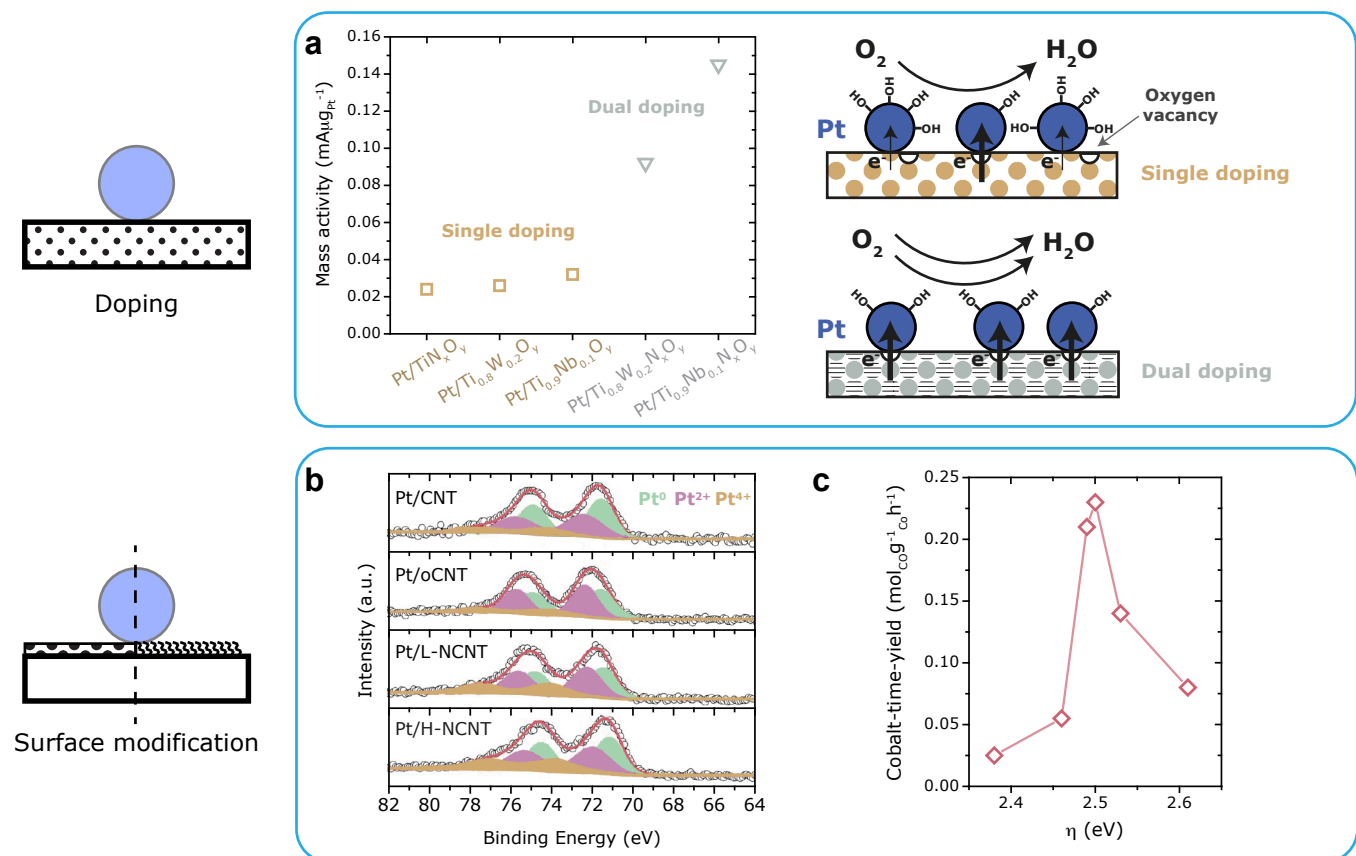

Figure 2.3 MSI tuning strategies based on doping and surface modification of the support. a, Chart comparing the electrochemical performance in the oxygen reduction reaction of Pt on various single- and dual-doped titania supports and schematic representation of the degree of charge transfer from the support to the Pt NPs depending on the kind of doping, as depicted by the thickness of the arrows (ref. 87). $\boldsymbol{b}$, XPS spectra of Pt $4 \mathrm{f}$ for Pt supported on carbon nanotubes (CNT) with various pre-treatments: pristine $(\mathrm{Pt} / \mathrm{CNT})$, oxidised $(\mathrm{Pt} / \mathrm{oCNT})$, ammonia treated $(\mathrm{Pt} / \mathrm{L}-\mathrm{NCNT})$ or high nitrogen content $(\mathrm{Pt} / \mathrm{H}-\mathrm{NCNT})$. The spectra show changes in the oxidation state of Pt depending on the CNT surface modification (ref. 98). c, Cobalt-normalised activities at pseudo-steady state for the Fischer-Tropsch synthesis reaction as a function of the acid-base character of the metal oxide surface layer inferred from the UV-vis band shift of a probe molecule ( $\eta$ ) due to charge transfer (ref. 104).

$\left(\mathrm{Al}^{3+}, \mathrm{Ga}^{3+}\right)$ increased the conductivity of the support and activity in reverse water-gas shift and methanol synthesis, whereas divalent $\mathrm{Mg}^{2+}$ lowered the activity.

Surface modification. We distinguish two types of surface modification: introduction of functional groups and (complete) coating of the surface with another phase up to the point that the surface properties are completely dictated by the coating material.

Oxygen- or nitrogen-containing functional groups are often introduced on carbon supports as a way to regulate MSI. The basic concept is that these functionalities act as anchoring sites for the metal NPs. That just anchoring NPs is not a complete picture was recognised for example by two groups working on surface functionalisation of CNT as support for Co catalysts for the Fischer-Tropsch synthesis ${ }^{93-95}$. Eschemann et al. ${ }^{95}$ reported substantially higher TOF for Co supported on pristine carbon nanotubes (CNT) compared to surface-oxidised CNT. The authors proposed an increased fraction of more active hcp Co on pristine CNT as the cause of these differences. This hypothesis can be strengthened by earlier literature, as Co was previously shown to form of an hcp phase on graphite $(0001)^{96}$. 
In addition, several other studies showed that the role of functional groups was not limited to anchoring of NPs in hydrogenation ${ }^{97,98}$ and oxidation ${ }^{99}$ of organic compounds. Charge transfer between the functionalised support and noble metal nanoparticles substantially altered catalytic performance (Figure 2.3b).

Metal oxides can also be functionalised to facilitate metal NP binding using, e.g., amine or thiol groups to anchor metal NPs to a support. These functional groups can affect the activity and selectivity of catalysts supported on irreducible oxides ${ }^{100,101}$, but this is not very common. Often the functional groups do not change the intrinsic activity of the catalysts and rather facilitate binding to the support and can impart greater stability to the catalysts $^{102}$.

Surface coating can be applied to the support via precursor decomposition (glucose, organometallic precursors, etc.) or atomic-layer deposition. For example, coating the surface of a nanostructured $\mathrm{In}_{2} \mathrm{O}_{3}$ with carbon made this support more suitable for photocatalytic $\mathrm{CO}_{2}$ reduction using $\mathrm{Pt}$ as the metal ${ }^{103}$. The Pt NPs were the catalytically active sites and the carbon increased absorption of visible light through lowering of the bandgap, lowered electron-hole recombination, suppressed $\mathrm{H}_{2}$ production from protons, and facilitated $\mathrm{CO}_{2}$ adsorption. Through all these support functions, the production rate of CO increased from 27 to $127 \mu \mathrm{mol}_{\mathrm{CO}} \cdot \mathrm{h}^{-1}$ and the production of methane increased from 4 to $28 \mu \mathrm{mol}_{\mathrm{CH} 4} \cdot \mathrm{h}^{-1}$. It should be noted that (electronic) interactions between $\operatorname{In}_{2} \mathrm{O}_{3}$ and $\mathrm{C}$ were present, so the composite material displayed the combined properties of both materials.

Prieto et al. utilised coatings to isolate the intrinsic properties of different metal oxide supports from other factors such as support morphology and verified the effect of these properties on the performance of Ru-promoted Co catalysts ${ }^{104}$. The authors found a correlation between the Lewis acidity of the metal oxide surface layer and the catalytic activity and selectivity in the Fischer-Tropsch synthesis (Figure 2.3c). These studies show that a surface layer can be applied to effectively replace the surface properties of the original support with that of the coating.

\subsection{Metal nanoparticles}

The second category of MSI tuning focusses mainly on the metal NPs. Of the three stages for MSI tuning (support, metal NP, treatment), this is least reported yet it does provide interesting opportunities. In this section, we will discuss recent examples of how modification of the size or composition of the nanoparticles affects MSI and hence catalytic performance.

Size. MSI can have a strong influence on the size of metal NPs, clusters and single atoms during catalysis and we refer to a recent review for a detailed discussion on this topic ${ }^{105}$. Focussing on metal NPs, the vast majority of literature on MSI tuning deals with NPs $<5 \mathrm{~nm}$. Most probably because the effect of the support on the metal NPs is attenuated for larger NPs because of reduced impact of charge transfer and relatively less metallic surface area in intimate contact with the support, i.e., less interface sites. NP size has the most pronounced 


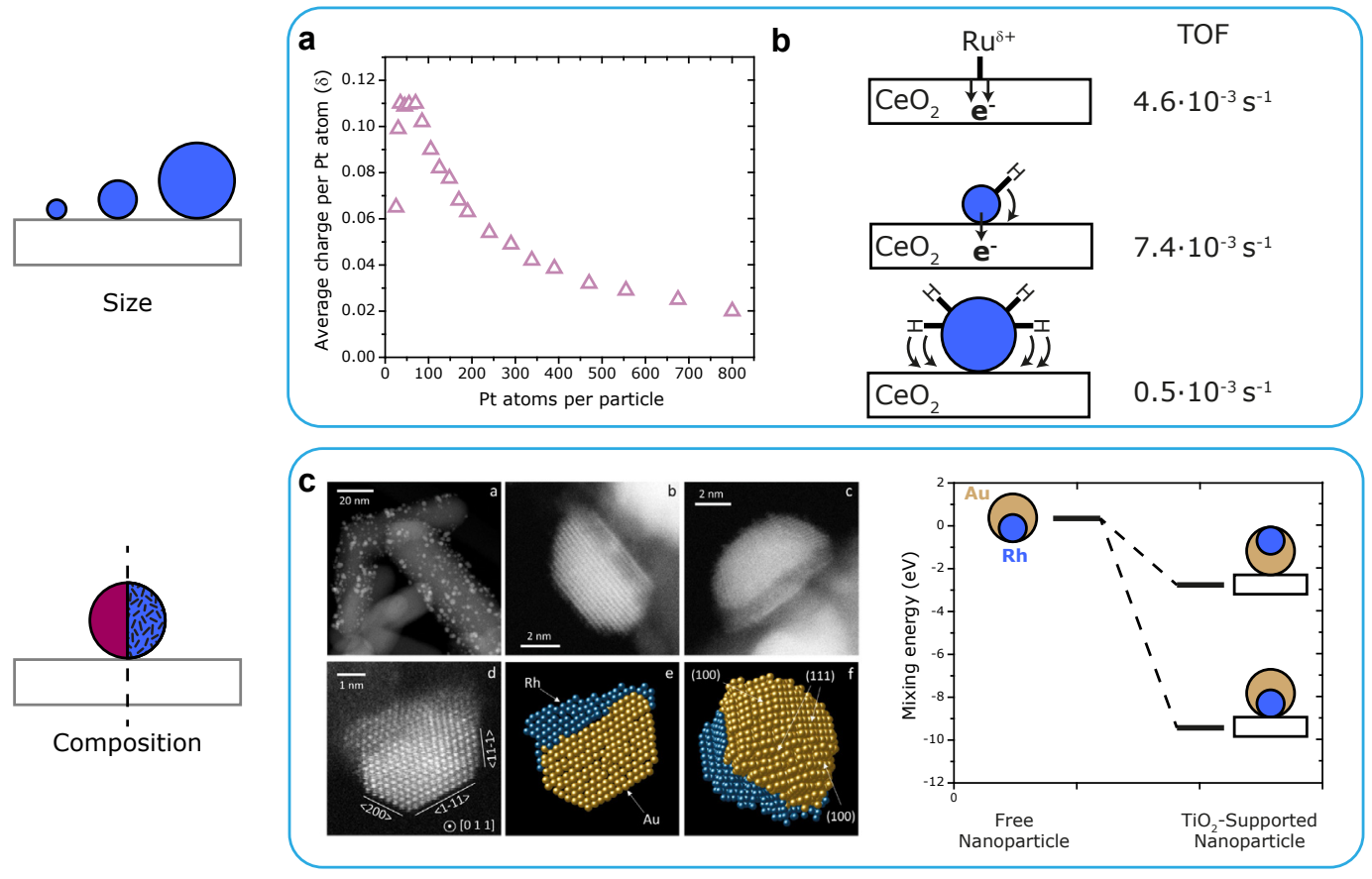

Figure 2.4 MSI tuning strategies involving alterations to the metal nanoparticle size or composition. a, Average charge per Pt atom to the ceria support as a function of the Pt particle size (ref. 106). b, Schematic representation of the balance between charge transfer and $\mathrm{H}$-spillover for Ru of different sizes (atoms, $1 \mathrm{~nm}$ nanoclusters and $4 \mathrm{~nm}$ nanoparticles) supported on ceria and its effect on the TOF in $\mathrm{CO}_{2}$ methanation (ref. 107). c, HAADF images and model reconstruction showing $\mathrm{Rh}$ segregation to the $\mathrm{TiO}_{2}$ support for a reduced $\mathrm{AuRh} / \mathrm{TiO}_{2}$ sample and the energy scheme for two binding configurations of AuRh clusters to $\mathrm{TiO}_{2}$ derived from DFT. Calculations point to Rh segregation to the support as the most favourable configuration (ref.110).

influence on purely electronic MSI effects, which are short range, as Lykhach et al. ${ }^{106}$ showed for 1.0-1.5 nm Pt NPs with a partial positive charge of 0.11 per Pt atom in $\mathrm{Pt} / \mathrm{CeO}_{2}$ catalyst (Figure 2.4a). They observed using resonant photoemission spectroscopy on 2D model systems that the partial positive charge per Pt atom decayed for larger particles. Furthermore, the overall charge transfer was limited by the support $\left(17 \%\right.$ surface $\mathrm{Ce}^{3+}$ seems the limit for $\mathrm{CeO}_{2}$ reduction). The need for small NPs to induce effective electronic MSI is also reflected in literature where most reports on catalytic performance relate to particles smaller than $5 \mathrm{~nm}$ (Figure 2.7b). Conversely, this also means that it is unlikely that electronic MSI plays a significant role in large $(>2 \mathrm{~nm}) \mathrm{NPs}$, unless the NPs are encapsulated by the support in which case charge transfer could still occur to all surface sites.

Guo et al. ${ }^{107}$ investigated the effect of Ru NP size on the performance of $\mathrm{Ru} / \mathrm{CeO}_{2}$ in $\mathrm{CO}_{2}$ hydrogenation varying between single atoms, $1 \mathrm{~nm}$ clusters and $4 \mathrm{~nm}$ NP. With increasing NP size, the electronic MSI interaction decreased which facilitated $\mathrm{CO}_{2}$ activation and increased reactivity (Figure 2.4b). At the same time, H-spillover increased with NP size, hindering $\mathrm{H}_{2} \mathrm{O}$ removal and decreasing activity. Competition between both effects makes the $1 \mathrm{~nm}$ clusters (intermediate size) the most active system with a TOF about $50 \%$ higher 
than single atoms and one order of magnitude higher than NPs. Interestingly, the selectivity to $\mathrm{CH}_{4}$ was $100 \%$ for all sizes. This is in contradiction to a recent report by Yan et al. ${ }^{108}$, who observed a $\mathrm{Ru} \mathrm{NP}$ size-dependent selectivity in $\mathrm{CO}_{2}$ hydrogenation on $\gamma-\mathrm{Al}_{2} \mathrm{O}_{3}$. $\mathrm{CO}$ formation via reverse WGS was favoured for Ru clusters while the selectivity shifted to $\mathrm{CH}_{4}$ for larger NPs. One possible explanation for the different observations could be the nature of the supports that were employed $\left(\mathrm{CeO}_{2}\right.$ and $\left.\gamma-\mathrm{Al}_{2} \mathrm{O}_{3}\right)$, because the support was involved in the reaction in both cases. Notably, in $\mathrm{Ru} / \gamma-\mathrm{Al}_{2} \mathrm{O}_{3}$, the interface oxygen (Ru-O-Al) was shown via isotope labelling to exchange oxygen atoms with $\mathrm{CO}_{2}$ during the reaction.

Composition. The metal distribution in an NP depends to a large extent on the strength of the bonds between the metal atoms and between metal atoms and support. Theoretical calculations ${ }^{109}$ on $\mathrm{Au}-\mathrm{Rh}$ and Pd-Ir nanoparticles supported on titania showed that the surface binding strength of $\mathrm{Rh}$ or Ir atoms to $\mathrm{TiO}_{2}(110)$ is greater than for $\mathrm{Pd}$ or Au to the support, due to stronger $\mathrm{Rh}-\mathrm{O}$ or Ir-O interactions than $\mathrm{Au}-\mathrm{O}$ or Pd-O. Therefore, $\mathrm{Rh}$ or Ir segregated towards $\mathrm{TiO}_{2}$. This has been experimentally observed for $\mathrm{Au}-\mathrm{Rh}$ nanoparticles supported on titania nanorods ${ }^{110}$ (Figure 2.4c) and employed for tetralin hydrogenation in the presence of $\mathrm{H}_{2} \mathrm{~S}^{111}$. The $\mathrm{Au} / \mathrm{Rh} / \mathrm{TiO}_{2}$ stacking configuration had a detrimental effect on the initial hydrogenation activity. Eventually, $\mathrm{Au} / \mathrm{Rh} / \mathrm{TiO}_{2}$ was more stable due to the stabilising effect of gold against $\mathrm{H}_{2} \mathrm{~S}$ poisoning of $\mathrm{Rh}$. Likewise, a segregation of iridium from Au-Ir nanoparticles towards $\mathrm{TiO}_{2}$ has been experimentally observed, resulting in higher resistance towards sintering than $\mathrm{Au} / \mathrm{TiO}_{2}$ during thermal treatments ${ }^{112}$.

For $\mathrm{Au}-\mathrm{Cu}$ on $\mathrm{Al}_{2} \mathrm{O}_{3}$ and $\mathrm{SiO}_{2}$ the NPs de-alloyed under oxidising conditions on both supports to form $\mathrm{Au}$ NPs and $\mathrm{CuO}_{\mathrm{x}}$ phase. However, on $\mathrm{Al}_{2} \mathrm{O}_{3}, \mathrm{CuO}_{\mathrm{x}}$ formed separate patches on the support, which prevented the creation of active $\mathrm{Au}-\mathrm{CuO}_{\mathrm{x}}$ interfacial sites present on $\mathrm{SiO}_{2}{ }^{113}$. Consequently, $\mathrm{Au}-\mathrm{CuO} / \mathrm{SiO}_{2}$ approached $100 \% \mathrm{CO}$ conversion while $\mathrm{Au}-$ $\mathrm{CuO} / \mathrm{Al}_{2} \mathrm{O}_{3}$ converted $11 \%$ of the $\mathrm{CO}$ at $150{ }^{\circ} \mathrm{C}$.

Seemala et al. ${ }^{114}$ studied $\mathrm{Cu}$-Ni nanoparticles supported on either $\theta$-alumina or titania and observed $\mathrm{TiO}_{2}$-induced metal segregation upon reduction using $\mathrm{H}_{2}$, during which $\mathrm{Cu}$ enriched the NP surface while Ni segregated to the NP-support interface. This arrangement was explained by a stronger interaction between nickel and titania than copper and titania. The $\mathrm{Cu}-\mathrm{Ni} / \mathrm{TiO}_{2}$ catalyst showed high activity in furfural hydrodeoxygenation, high selectivity to methyl furan and good recyclability, outperforming the $\mathrm{Cu}-\mathrm{Ni}$ supported on alumina and the titania-supported monometallic catalysts. A similar phenomenon was observed in the case of Ni-Pt supported on mesoporous silica (SBA-15) ${ }^{115}$. Here, a strong nickel-support interaction, most likely generated during metal precursor deposition on silica at basic conditions, led to the formation of a $\mathrm{Pt}$-rich $\left(\mathrm{Pt}_{3} \mathrm{Ni}\right)$ intermetallic compound thus favouring the formation of active $\mathrm{Pt}-\mathrm{Ni}$ bonds rather than $\mathrm{Ni}-\mathrm{Ni}$. This in turn increased the selectivity of $\mathrm{CO}_{2}$ reduction to $\mathrm{CO}$ instead of $\mathrm{CH}_{4}$, as the latter product is typical for Ni-based catalysts.

Divins et al. ${ }^{116}$ showed that ceria as support influenced the oxidation state and metal arrangement of Rh-Pd nanoparticles under different atmospheres using NAP-XPS at 0.05 mbar. Upon reduction at $573 \mathrm{~K}, \mathrm{Rh}-\mathrm{Pd} / \mathrm{CeO}_{2}$ and non-supported $\mathrm{Rh}-\mathrm{Pd}$ nanoparticles showed segregation of palladium to the surface. However, at conditions close to eth- 
anol steam reforming the metals in the non-supported nanoparticles re-arranged back to a uniform distribution, whereas the $\mathrm{CeO}_{2}$-supported ones maintained the Pd-rich surface. Because the Rh- $\mathrm{CeO}_{2}$ interaction was stronger, the core-shell structure was maintained. Furthermore, the $\mathrm{CeO}_{2}$-supported nanoparticles presented higher oxidation states, especially at the outermost layers due to $\mathrm{H}_{2} \mathrm{O}$ activation at the $\mathrm{CeO}_{2}$ surface. The high $\mathrm{H}_{2}$ selectivity of the supported catalyst, compared to the non-supported nanoparticles, was derived from promotion of WGS and methane steam reforming.

Gubó et al. ${ }^{117}$ showed that an increase of the relative Au concentration in Au-Pd nanoparticles supported on rutile $\mathrm{TiO}_{2}$ prevented the encapsulation of the nanoparticles by $\mathrm{TiO}_{\mathrm{x}}$. The nanoparticles formed a bimetallic core with an Au enriched shell and became less prone to SMSI due to the lower surface free energy of Au.

Organic ligands coordinated to the surface of metal NPs can affect MSI, e.g. by acting as a carbon-precursor. Zhan et al. ${ }^{118}$ placed pre-formed Au colloids, capped with oleylamine ligands, on $\mathrm{TiO}_{2}$. The ligands were decomposed using an $\mathrm{N}_{2}$ treatment to form a carbon shell, which protected Au NPs from sintering. The higher overall CO oxidation activity of the $\mathrm{N}_{2}$-treated sample was ascribed to smaller NP size. Gao et al. ${ }^{119}$ co-impregnated a nickel precursor and ligands on $\mathrm{SiO}_{2}$ and obtained different NP sizes and stability during dry reforming, depending on the ligands (oleic acid, oleylamine or a mixture of both). The smaller NP size led to doubling of the $\mathrm{CH}_{4}$ conversion, while the surface-specific activity remained unchanged $\left(\sim 2.5 \mathrm{~s}^{-1}\right)$.

\subsection{Treatments}

We define treatments as any action to modify MSI that is performed on the metal-support composite material prior to catalysis. This has mainly been investigated in the context of tuning MSI of metals with reducible supports, i.e., SMSI.

Thermal treatment. Tang et al. investigated MSI for various group 11 metals on $\mathrm{TiO}_{2}$ and for Au supported on various reducible oxidic supports ${ }^{120}$. They observed that metal NP overgrowth under reducing conditions started at $200{ }^{\circ} \mathrm{C}$ and was most pronounced at 400$500{ }^{\circ} \mathrm{C}$. The overgrowth blocked the accessible metallic surface area and thereby quenched the reactivity for $\mathrm{CO}$ oxidation, in line with earlier literature on group 8-10 metals on reducible oxides. Furthermore, a simultaneous charge transfer from the support to Au was observed by XPS, resulting in an electron rich Au phase. These effects could be reversed and the reactivity could be restored by an oxidative treatment at $400{ }^{\circ} \mathrm{C}$. Interestingly, the same authors also observed similar effects for Au NPs supported on a phosphate hydroxyapatite, yet with the reverse response to oxidising and reducing conditions ${ }^{121}$; now oxidation at $300{ }^{\circ} \mathrm{C}$ and higher resulted in the support encapsulating the Au NPs and lowering the CO oxidation activity, which could be reversed by a reductive treatment at $500{ }^{\circ} \mathrm{C}$. It was recently suggested that loss of $\mathrm{OH}$ groups at high temperature gave rise to this type of interaction and the phenomenon was also observed on group 10 metals supported on $\mathrm{ZnO}$-nanorods ${ }^{122}$. Wang et al. ${ }^{123}$ even avoided the necessity for reducing or oxidising atmospheres altogether 
by exploiting the thermally-induced transition of a layered double hydroxide to the corresponding oxide in an inert atmosphere, possibly also caused by loss of $\mathrm{OH}$ groups. This induced a similar encapsulation of Au NPs with lowered CO oxidation activity.

Changes in activity and product selectivities during $\mathrm{CO}$ hydrogenation using $\mathrm{Ni}$ / $\mathrm{Nb}_{2} \mathrm{O}_{5}$ were reported after different reduction temperatures $\left(250-450{ }^{\circ} \mathrm{C}\right)$ and related to SMSI effects ${ }^{124}$. An intermediate reduction temperature $\left(350^{\circ} \mathrm{C}\right)$ showed the highest activity $\left(3.9 \cdot 10^{-5} \mathrm{~mol}_{\mathrm{CO}} \cdot \mathrm{g}_{\mathrm{Ni}}{ }^{-1} \cdot \mathrm{s}^{-1}\right)$ and $\mathrm{C}_{5+}$-selectivity (55 wt.\%). Lower reduction temperature resulted in severe deactivation due to particle growth via nickel tetracarbonyl formation and a lower final activity $\left(2.2 \cdot 10^{-5} \mathrm{~mol}_{\mathrm{CO}} \cdot \mathrm{g}_{\mathrm{Ni}}^{-1} \cdot \mathrm{s}^{-1}\right)$. On the other hand, a higher reduction temperature $\left(450{ }^{\circ} \mathrm{C}\right)$ displayed stable performance but with a medium activity $\left(2.7 \cdot 10^{-5} \mathrm{~mol}_{\mathrm{CO}} \cdot \mathrm{g}_{\mathrm{Ni}}{ }^{-1} \cdot \mathrm{s}^{-1}\right)$ and a selectivity shift to shorter hydrocarbon products, probably due to blockage of active sites by $\mathrm{NbO}_{x}$ suboxides. Similarly, in the case of $\mathrm{Ni} / \mathrm{TiO}_{2}$ catalysts for WGS, the coverage of $\mathrm{Ni}$ nanoparticles by $\mathrm{TiO}_{\mathrm{x}}$ could be tuned via reduction temperatures between 400 and $600{ }^{\circ} \mathrm{C}^{125}$ (Figure 2.5a). The metal-support interface was maximised by starting from an NiTi-layered double hydroxide precursor. Charge transfer to interfacial $\mathrm{Ni}$, coverage of $\mathrm{Ni}$ $\mathrm{NP}$ by suboxides and the number of oxygen vacancies in $\mathrm{TiO}_{\mathrm{x}}$ all increased with higher reduction temperature. Moderate MSI after reduction at $450{ }^{\circ} \mathrm{C}$ showed the highest catalytic activity with a TOF of $3.8 \mathrm{~s}^{-1}$, about two times more active than after reduction at 400, 500 or $600{ }^{\circ} \mathrm{C}$. The high activity was attributed to the interplay between interfacial $\mathrm{Ni}^{8-}$ and oxygen vacancies. In the case of $\mathrm{Pd} / \mathrm{TiO}_{2}$ catalysts, the reduction temperature affected the coverage of $\mathrm{Pd} \mathrm{NPs}_{\text {by }} \mathrm{TiO}_{\mathrm{x}}$ species $^{48}$ (Figure $2.5 \mathrm{~b}$ ), and the amount of oxygen vacancies in $\mathrm{Pd} / \mathrm{TiO}_{2}$ used for formaldehyde oxidation ${ }^{126}$. When reduced at $450{ }^{\circ} \mathrm{C}$, more oxygen vacancies were generated, which in turn aided $\mathrm{O}_{2}$ activation and $\mathrm{H}_{2} \mathrm{O}$ dissociation to form $\mathrm{OH}$ groups and increased the formaldehyde oxidation activity 7.5 -fold. These species directly decomposed formaldehyde without the slow formation of $\mathrm{CO}$ as intermediate, as observed after reduction at $300{ }^{\circ} \mathrm{C}$.

An intermetallic nickel silicide catalyst obtained by reacting a nickel complex with silica via pyrolysis at high temperatures has been shown to be highly active for chemoselective hydrogenation of a wide variety of compounds (e.g., nitroarenes, carbonyls, nitriles, $\mathrm{N}$-heterocycles and unsaturated carbon-carbon bonds ${ }^{127}$. The researchers found that the formation of this versatile catalyst strongly depended on the pyrolysis temperature, the nitrogen-doped carbon species from the ligand for $\mathrm{Si}-\mathrm{O}$ bond reduction and the silica specific surface area. A pyrolysis temperature of $600{ }^{\circ} \mathrm{C}$ resulted in metallic nickel supported on silica and upon increasing the pyrolysis temperature to $800{ }^{\circ} \mathrm{C} \mathrm{a} \mathrm{Ni}{ }_{17} \mathrm{Si}_{3}$ phase was observed. The most active catalyst was obtained at $1000{ }^{\circ} \mathrm{C}$ with silicon-enriched phases $\mathrm{Ni}_{31} \mathrm{Si}_{12}$ and $\mathrm{Ni}_{2} \mathrm{Si}$. Additionally, coverage of metal nanoparticles by support suboxides generated at elevated temperature can steer hydrogenation selectivity, as summarised before ${ }^{128}$.

Reducing agent. The extent of MSI and in particular partial support reduction to form suboxides and oxygen vacancies depend on the overall severity of the reduction treatment. In 2014, Rui et al. ${ }^{129}$ reported that the SMSI state in $\mathrm{Pt} / \mathrm{TiO}_{2}$ could be induced at room temperature during a liquid phase reduction process using $\mathrm{NaBH}_{4}$ or formaldehyde as reducing 


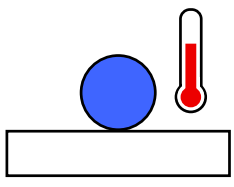

Thermal

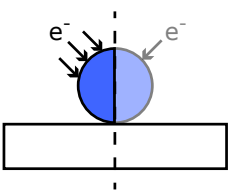

Reducing agent

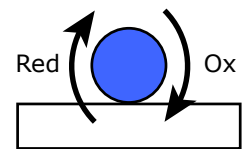

Reduction-oxidation cycles

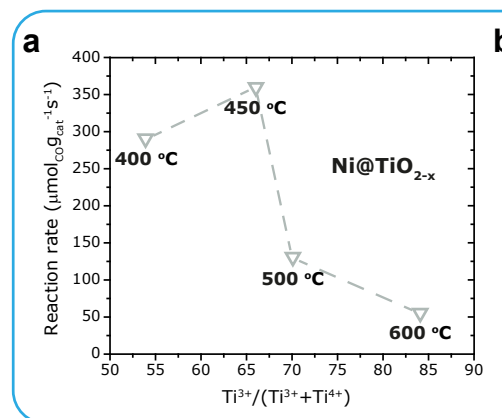

b

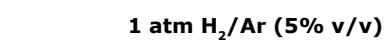

$250{ }^{\circ} \mathrm{C}$

$500{ }^{\circ} \mathrm{C}$

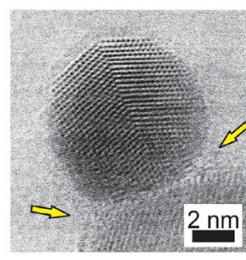

$2 \mathrm{~nm}$
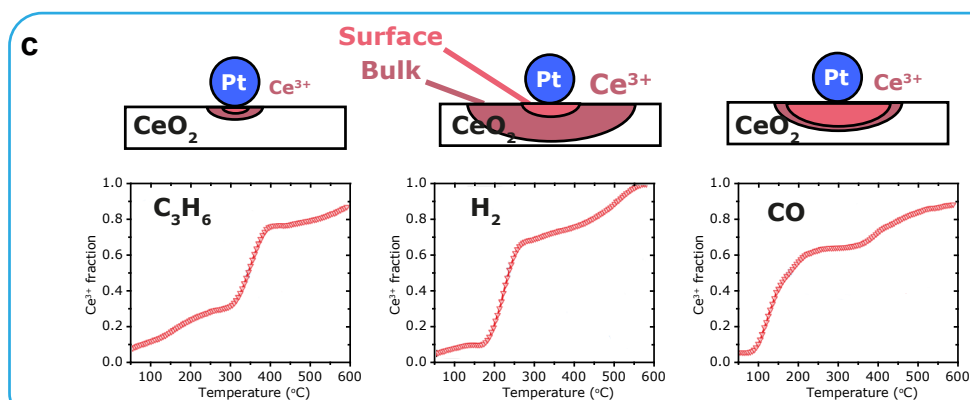

d
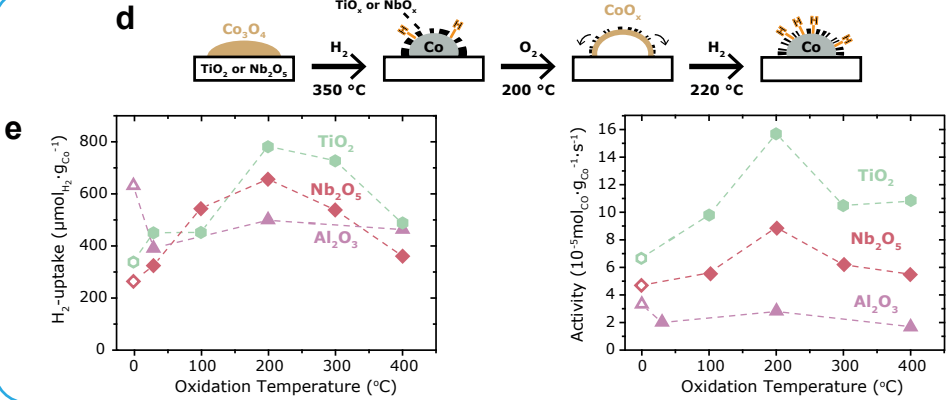

Figure 2.5 MSI tuning strategies involving treatments of supported metal catalysts based on temperature, reducing agent or reduction-oxidation cycles. a, The influence of reduction temperature of $\mathrm{Ni}_{0} \mathrm{TiO} \mathrm{x}_{\mathrm{x}}$ on $\mathrm{the} \mathrm{Ti}^{3+}$ to $\mathrm{Ti}^{4+}$ ratio and WGS reaction rate (ref. 125). b, In-situ observation of a $\mathrm{TiO}_{\mathrm{x}}$ overlayer on a Pd NP under reducing conditions at 5 vol. $\% \mathrm{H}_{2}$ in $\mathrm{Ar}, 1$ bar, 250 and $500{ }^{\circ} \mathrm{C}$ (ref. 48). c, Support reduction using different reducing agents $\left(\mathrm{C}_{3} \mathrm{H}_{6}, \mathrm{H}_{2}\right.$ or $\left.\mathrm{CO}\right)$ for $\mathrm{PtO}_{\mathrm{x}}$ on ceria in temperature-programmed experiments, as deduced from the fraction of $\mathrm{Ce}^{3+}$ obtained by Ce L3-edge XANES spectra (ref. 131). d, Schematic representation of a reduction-oxidation-reduction (ROR) treatment of cobalt supported on reducible supports. e, The effect of different oxidation $(\mathrm{O})$ temperatures in the ROR procedure on the hydrogen uptake in chemisorption experiments and Fischer-Tropsch synthesis activity of $\mathrm{Co} / \mathrm{TiO}_{2}$ (green hexagons), $\mathrm{Co} / \mathrm{Nb}_{2} \mathrm{O}_{5}$ (red diamonds) and $\mathrm{Co} / \mathrm{Al}_{2} \mathrm{O}_{3}$ (violet triangles). Singly reduced samples are indicated by open symbols (ref. 133).

agent. The SMSI state, characterised by suppressed CO chemisorption, negatively charged Pt NPs, and oxygen vacancies formation, was beneficial for toluene oxidation activity, which decreased in the order $\mathrm{NaBH}_{4}>$ formaldehyde $>\mathrm{H}_{2}$. Furthermore, the MSI effect was stronger on anatase than on rutile or P25, again highlighting the importance of the support morphology as previously discussed. 
Few systematic studies focusing on the effect of the reducing agent on MSI have been published in the meantime. A recent example includes the use of reducing agents with different reduction strengths to determine the rate of Pt-precursor reduction, which in turn regulated the association of NPs to different types of $\mathrm{N}$-functionalities in $\mathrm{N}$-doped carbon nanotubes (see Doping section) ${ }^{80}$. As a second recent example, Gänzler et al. ${ }^{130,131}$ showed that the $\mathrm{CO}$ oxidation activity of $\mathrm{Pt} \mathrm{NPs}$ supported on a $\mathrm{CeO}_{2} / \mathrm{Al}_{2} \mathrm{O}_{3}$ composite support strongly varied as a function of the reducing agent, following the order $\mathrm{CO}>\mathrm{H}_{2}>\mathrm{C}_{3} \mathrm{H}_{6}$ (Figure 2.5c) The effect of the reducing agent was ascribed to its ability to partially reduce the support. Additionally, MSI and catalytic performance could be further tuned by reduction-oxidation cycles (see next section).

Reduction-oxidation cycles. Reduction-oxidation (RO) cycles have been intensively investigated, mainly to regulate the metal NP size through re-dispersion, but also to affect MSI in various ways. Here, we will highlight several possibilities of RO for MSI tuning that were recently published.

Besides different reducing agents, Gänzler et al. ${ }^{130,131}$ applied RO cycles on a CO oxidation catalyst consisting of $\mathrm{Pt} / \mathrm{CeO}_{2} / \mathrm{Al}_{2} \mathrm{O}_{3}$ in order to control both the $\mathrm{Pt} \mathrm{NP}$ size and oxidation state, which in turn affected the reduction of $\mathrm{CeO}_{2}$ support. Metallic Pt NPs were necessary to reduce $\mathrm{CeO}_{2}$ at low temperature and the support had a crucial role in $\mathrm{CO}$ oxidation, as discussed before. $1.4 \mathrm{~nm}$ Pt NPs were identified as the optimal size, because at this size most interfacial sites were available while maintaining the Pt NPs in the active metallic state. Further RO cycles induced Pt NP growth and reduced the CO oxidation activity

Alternatively, Freakley et al. ${ }^{132}$ employed the reduction step of an RO cycle on a Pd-Sn/ $\mathrm{TiO}_{2}$ catalyst to selectively modify small Pd NPs that otherwise gave rise to side reactions. Surprisingly, the NPs were not covered by $\mathrm{TiO}_{x}$ species, but by $\mathrm{SnO}_{x}$ species, as evidenced by STEM-EELS and similarly with a Pd-Sn system supported on irreducible $\mathrm{SiO}_{2}$. The final oxidation step was necessary to generate $\mathrm{Pd}^{2+}$ ions on the larger NPs, which were less active for side reactions than metallic Pd. The investigated reaction was the direct synthesis of $\mathrm{H}_{2} \mathrm{O}_{2}$ from $\mathrm{O}_{2}$ and $\mathrm{H}_{2}$ and the selectivity is a balance between $\mathrm{H}_{2} \mathrm{O}_{2}$ production rate (hydrogenation of $\mathrm{O}_{2}$ ) and $\mathrm{H}_{2} \mathrm{O}_{2}$ decomposition rate. By covering the small NPs and having a $\mathrm{Pd}^{2+}$ containing surface on the larger NPs, the $\mathrm{H}_{2} \mathrm{O}_{2}$ decomposition was almost completely suppressed, resulting in hydrogen selectivities towards $\mathrm{H}_{2} \mathrm{O}_{2}$ of $95 \%$.

It is well established that the SMSI state is typically generated under reducing conditions and that the SMSI state can be reversed by an oxidative treatment ${ }^{48}$. In an earlier publication ${ }^{133}$, we applied this principle to enhance the FT activity of $\mathrm{Co} / \mathrm{TiO}{ }_{2}$ and $\mathrm{Co} / \mathrm{Nb}_{2} \mathrm{O}_{5}$ catalysts via a reduction-oxidation-reduction (ROR) process (Figure 2.5d). The first reduction at $350{ }^{\circ} \mathrm{C}$ fully reduced the cobalt oxide to metallic cobalt and simultaneously induced the SMSI state. Oxidation at $200{ }^{\circ} \mathrm{C}$ modified the suboxides, but did not oxidise the cobalt fully to $\mathrm{Co}_{3} \mathrm{O}_{4}$. Consequently, the second reduction could be performed at $220^{\circ} \mathrm{C}$ only, which resulted in less suboxide coverage and hence twice the accessible metallic surface area, as compared to the samples reduced at $350{ }^{\circ} \mathrm{C}$. The FT activity increased proportionally to the metallic surface area, implying that the number of active sites increased and that the TOF 
and thus the nature of the active sites remained unchanged.

Overlayer deposition. As-prepared catalysts containing NPs on a support can be covered with an overlayer of another compound and its most basic function is to stabilise the NPs via immobilisation, as was the case for a carbon ${ }^{134}$ and $\mathrm{SiO}_{2}{ }^{135}$ overlayer. In addition, in a 2D model study, a $\mathrm{Pt}(111)$ surface was covered with a thin layer of $\mathrm{TiO}_{\mathrm{x}}$ to mimic an SMSI state $^{136}$. Compared to the clean $\mathrm{Pt}(111)$ surface, the $\mathrm{TiO}_{\mathrm{x}}$ species increased $\mathrm{CO}$ oxidation activity and the effect was assigned to the formation of interfacial perimeter sites. Furthermore, Weng et al. ${ }^{137}$ deposited $\mathrm{SiO}_{2}$ over $\mathrm{Pt} / \mathrm{Al}_{2} \mathrm{O}_{3}$ and observed the formation of Brønsted acid Si-O-Al sites. The $\mathrm{SiO}_{2}$ overlayer decreased activity in cinnamaldehyde hydrogenation, possibly via site blockage by $\mathrm{SiO}_{2}$, while at the same time, selectivity towards cinnamyl alcohol increased from $25-30 \%$ to $85 \%$.

Overlayers can also be applied to create specific interfacial sites, such as $\mathrm{Cu}-\mathrm{ZrO}_{2}$ in a $\mathrm{Cu} / \mathrm{SiO}_{2}$ catalyst $^{138}$. These interface sites enhanced the intrinsic activity for ethyl acetate formation from ethanol and for methanol synthesis from $\mathrm{CO}_{2}$ by one order of magnitude. Furthermore, Moon et al. ${ }^{139}$ applied an overlayer of various reducible oxides to a $\mathrm{Pt} / \mathrm{SiO}_{2}$ cat-

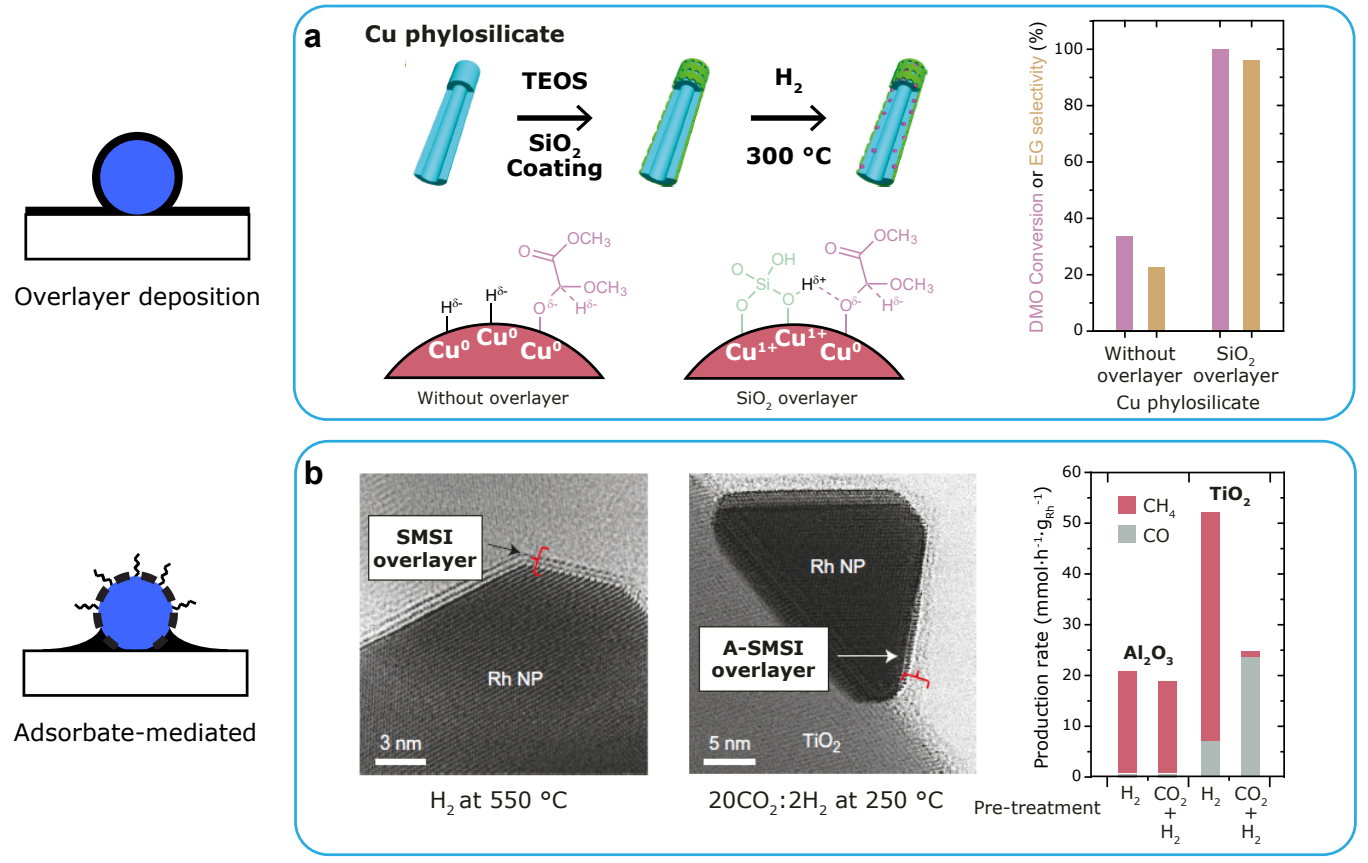

Figure 2.6 MSI tuning strategies involving overlayer deposition and adsorbate-mediated treatments of supported metal catalysts. a, Schematic representation of the effect of a silica overlayer on a copper phyllosilicate-based catalyst and the activation of dimethyl oxalate (DMO). The chart shows DMO conversion and ethylene glycol (EG) selectivity for the catalyst with and without silica overlayer (ref. 144). b, In-situ STEM observation of SMSI in $\mathrm{Rh} / \mathrm{TiO}_{2}$ after a treatment in $\mathrm{H}_{2}$ at $550{ }^{\circ} \mathrm{C}$ which induced a $\mathrm{TiO}_{\mathrm{x}}$ bilayer (SMSI overlayer) and after treatment in $20 \mathrm{CO}_{2}: 2 \mathrm{H}_{2}$ at $250{ }^{\circ} \mathrm{C}$ which induced an amorphous $\mathrm{TiO}_{\mathrm{x}}$ overlayer (A-SMSI overlayer). Production rates of $\mathrm{CH}_{4}$ (red) and $\mathrm{CO}$ (grey) are shown on the chart for Rh supported on alumina or titania after $\mathrm{H}_{2}$ or $20 \mathrm{CO}_{2}: 2 \mathrm{H}_{2}$ treatments (ref. 145). 
alyst and investigated its effect on $\mathrm{CO}$ oxidation. The activity followed the order $\mathrm{TiO}_{2}>\mathrm{CeO}_{2}$ $>\mathrm{Pt} / \mathrm{SiO}_{2}>\mathrm{Ta}_{2} \mathrm{O}_{5} \approx \mathrm{Nb}_{2} \mathrm{O}_{5}$ and the increased activity was mainly ascribed to the formation of interfacial perimeter sites between $\mathrm{Pt}$ and the $\mathrm{TiO}_{2}$ or $\mathrm{CeO}_{2}$ overlayer. In addition, the overlayer made the catalyst more resistant towards sintering of Pt NP at elevated temperature.

Yang et al. ${ }^{140}$ prepared $\mathrm{Rh} / \mathrm{SiO}_{2}$ catalysts covered with $\mathrm{TiO}_{2}$ or $\mathrm{Al}_{2} \mathrm{O}_{3}$ and applied these for $\mathrm{CO}$ hydrogenation. The $\mathrm{Al}_{2} \mathrm{O}_{3}$ overlayer decreased the activity through site blockage. The $\mathrm{TiO}_{2}$ overlayer, on the other hand, increased the intrinsic activity and selectivity towards $\mathrm{C}_{5+}$ alkanes and alkenes, while the selectivity towards higher alcohols remained unchanged. Its catalytic performance was similar to that of $\mathrm{Rh} \mathrm{NPs}_{\text {on }} \mathrm{TiO}_{2}$-coated $\mathrm{SiO}_{2}$, showing either that coverage of the NPs themselves was irrelevant for catalysis or that the system was dynamic and reached the same (SMSI) state during catalysis. The latter option can be rationalised considering that overlayer deposition can be used to create artificial support suboxide coverage on NPs, thereby mimicking an SMSI state ${ }^{141}$.

Treatment of $\mathrm{Au} / \mathrm{TiO}_{2}$ with $\mathrm{TiCl}_{3}$ at room temperature resulted in the formation of a $\mathrm{TiO}_{\mathrm{x}}$ overlayer on $\mathrm{Au}$, similar to SMSI. The $\mathrm{TiO}_{\mathrm{x}}$ overlayer increased the activity of the catalyst for $\mathrm{CO}$ oxidation (0.68 vs. $0.26 \mathrm{~mol}_{\mathrm{CO}} \cdot \mathrm{mol}_{\mathrm{Au}}{ }^{-1} \cdot \mathrm{s}^{-1}$ ) and brought about stability to the gold nanoparticles. The $\mathrm{Au}-\mathrm{TiO}_{\mathrm{x}}$ interface was identified as the active site for oxygen activation, most likely due to oxygen vacancies, which were then regenerated after reaction with CO. The suboxides, however, also donated electrons to Au resulting in $\mathrm{Au}^{\delta-}$ and decreasing $\mathrm{CO}$ adsorption. An oxidative pre-treatment increased the activity of the catalyst by removing the excess electrons in $\mathrm{Au}$, enhancing $\mathrm{CO}$ adsorption ${ }^{142}$.

Copper phyllosilicates have been employed as precursor for the formation of silica-supported metal nanoparticles upon reduction in $\mathrm{H}_{2}$, leading to high $\mathrm{Cu}$ loadings ( $\sim 40$ 50 wt.\%) with uniform distribution and particle size. The role of the generated $\mathrm{Cu}-\mathrm{SiO}_{2}$ interface in these materials has been exploited, for example, in the decomposition of methanol to hydrogen and dimethoxymethane in the liquid phase ${ }^{143}$, where $\mathrm{Cu}^{+}$and $\mathrm{Cu}-\mathrm{O}-\mathrm{Si}$ moieties were necessary for the activity and high selectivity of the catalyst. The copper-silica interface $\left(\mathrm{Cu}-\mathrm{O}-\mathrm{SiO}_{\mathrm{x}}\right)$ was recently further optimised by use of a mesoporous silica layer coating the copper phyllosilicate prior $\mathrm{H}_{2}$ activation $^{144}$ (Figure 2.6a). In ester hydrogenation, the bare $\mathrm{Cu} / \mathrm{SiO}_{2}$ obtained from copper phyllosilicate gave a TOF of $6.4 \cdot 10^{-3} \mathrm{~s}^{-1}$ and a selectivity to ethylene glycol of $23 \%$, whereas the performance of $\mathrm{Cu} / \mathrm{SiO}_{2}$ with a mesoporous silica layer increased with a TOF of $11.4 \cdot 10^{-3} \mathrm{~s}^{-1}$ and a selectivity to ethylene glycol of $96 \%$. The $\mathrm{Cu}-\mathrm{O}-\mathrm{SiO}_{\mathrm{x}}$ interface was shown to stabilise the transition state of the ester (in this case dimethyl oxalate) and to activate $\mathrm{H}_{2}$ in a heterolytic way forming $\mathrm{Cu}-\mathrm{H}^{\delta-}$ and $\mathrm{SiO}-\mathrm{H}^{\delta+}$, as previously discussed for $\mathrm{H}_{2}$ activation with nanosised non-reducible supports.

Adsorbate-mediated MSI. MSI can be tuned by adsorbing specific compounds prior to inducing the MSI state. So far, this strategy has been limited to reducible supports, because the adsorbates mainly affect the coverage of the metal NPs by support suboxides. Matsubu et al. ${ }^{145}$ recently reported this strategy for the first time. They investigated $\mathrm{Rh} / \mathrm{TiO}_{2}$ catalysts for $\mathrm{CO}_{2}$ hydrogenation and found that a treatment in $20 \% \mathrm{CO}_{2}, 2 \% \mathrm{H}_{2}, 78 \% \mathrm{He}$ atmosphere at $250{ }^{\circ} \mathrm{C}$ caused the formation of HCOx adsorbates on the Rh NPs. In the untreated 

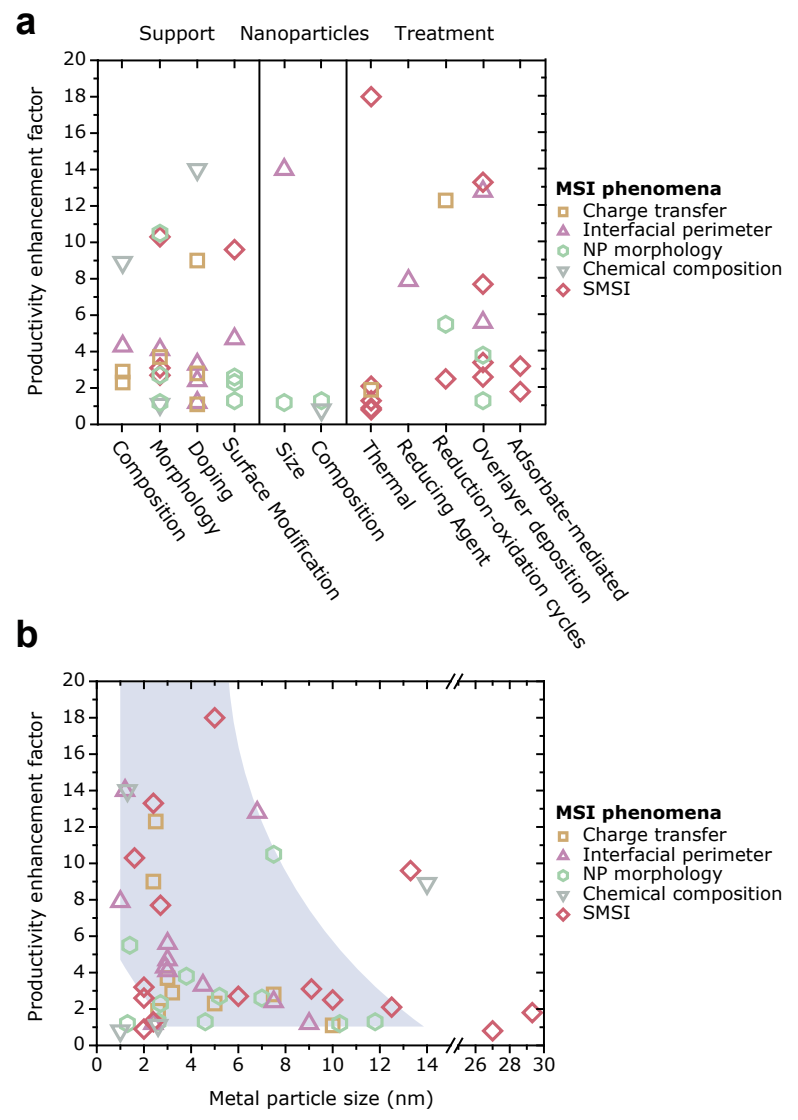

Figure 2.7 Enhancement of catalytic performance in C1 chemistry achieved through control of MSI in recent years. a, Relative differences in productivity of a desired compound for the different MSI tuning strategies grouped by general strategy (support, nanoparticle and treatment) and with different symbols indicating the main MSI phenomenon affected. Tuning strategies by modifications on the support or post-synthetic treatments have been mostly explored. b, Productivity enhancement factor as a function of metal particle size of the optimal catalyst, separated on the main MSI phenomenon affected by tuning. The grey-blue area is added as a guide to the eye and indicates the domain in which the NP size brought about the strongest productivity enhancement.

$\mathrm{Rh} / \mathrm{TiO}_{2}$ sample, a crystalline SMSI overlayer, which contained $\mathrm{Ti}^{3+}$-ions, formed during reduction at $550{ }^{\circ} \mathrm{C}$, whereas the adsorbate-mediated SMSI state, induced at only $250{ }^{\circ} \mathrm{C}$, led to an amorphous overlayer containing both $\mathrm{Ti}^{3+}$ - and $\mathrm{Ti}^{4+}$-ions (Figure 2.6b). In the adsorbate-mediated case, the support suboxides as well as the adsorbates can interact with the active sites. By covering the Rh NPs with an adsorbate-mediated SMSI overlayer, which was more stable under reaction conditions, it was possible to steer the catalyst selectivity from mainly $\mathrm{CH}_{4}$ producing (on Rh NPs) to mainly $\mathrm{CO}$ producing (on single Rh atoms). $\mathrm{Rh}$ NPs were thus more affected by the adsorbate-mediated SMSI overlayer than the single Rh atoms.

Interestingly, a similar $20 \% \mathrm{CO}_{2} / 2 \% \mathrm{H}_{2}$ pre-treatment was used by Wang et al. ${ }^{146}$ for $\mathrm{Cu} / \mathrm{CeO}_{2}$ catalysts for WGS. However, they mainly used the adsorbate-mediated SMSI 
strategy to prevent sintering of the Cu NPs and the effect on intrinsic activity was modest, although also some charge transfer from the support to the Cu NPs was inferred from XPS. This shows that the effect of such a treatment is highly dependent on the interplay between metal, support and reaction.

\subsection{Discussion}

We analysed the literature to quantify the enhancement of catalytic performance that was achieved in recent years through MSI modifications. We limited the analysis largely to $\mathrm{C} 1$ chemistry, i.e., catalytic reactions involving $\mathrm{CO}, \mathrm{CH}_{4}, \mathrm{CO}_{2}$ or methanol as the main reactant. The performance of tuned catalysts was benchmarked against a reference catalyst reported in the same paper and therefore investigated under the same conditions. Consequently, an enhancement factor for the tuned catalyst over the reference one was obtained. This approach provides a measure for the efficiency of the various MSI tuning strategies and facilitates comparison between different papers reporting a wide variety of reactions, conditions and units.

The rate of formation (productivity) of desirable products, i.e., the product of total activity and selectivity, was taken as a measure for catalytic performance. Productivity was used because this shows the combined effect of activity and selectivity changes and hence provides a more complete picture of the effect of MSI tuning than either parameter alone. Turnover frequencies or specific activities were preferred over conversions as activity descriptors, because these provide more information about intrinsic catalytic activities. Furthermore, selectivities are not relevant for certain reactions such as $\mathrm{CO}$ oxidation reactions. For these systems, $100 \%$ selectivity is assumed and productivity enhancement is essentially determined by activity differences. All analysed catalytic data and references can be found in Appendix A Table A1.

Figure 2.7a shows the productivity enhancement as a function of the different MSI tuning methods. Relative productivity enhancements up to a factor of $\sim 15$ have been obtained using various tuning methods, irrespective of which catalyst component is altered. Support modifications were effective in altering all MSI phenomena with substantial increase of the corresponding productivity. Particularly, selection of a certain support composition $^{113}$ or adding dopants to the support ${ }^{85}$ strongly improved the performance due to changes in the overall catalyst chemical composition. Treatments on the as-synthetized catalysts to tune the MSI have also proven beneficial to enhance their performance, most effort has focused on modifying the SMSI effect from which induction of this phenomenon on $\mathrm{Au}$ nanoparticles by thermal treatment ${ }^{120}$ and use of overlayer deposition of transition metal oxides ${ }^{139,140}$ led to significant catalytic enhancement. Reports involving strategies based on NP modifications to affect MSI were fewer, however an approach leading to substantially increased performance involved changing NP size which in turn improved the interfacial contribution for $\mathrm{CO}_{2}$ hydrogenation of a $\mathrm{Ru} / \mathrm{CeO}_{2}$ catalyst ${ }^{107}$.

For the enhancement of selectivity, the largest increase was reported for a treatment to modify MSI in catalysts for $\mathrm{CO}_{2}$ hydrogenation (78 \%), where preferential blockage of 
small Rh NPs or single atoms leads to a strong shift in selectivity from $\mathrm{CH}_{4}$ towards $\mathrm{CO}^{145}$. However, the strong increase in selectivity was accompanied by a decrease in activity, leading to a productivity enhancement factor of 3.2. Besides this example, selectivity increases of $20-30 \%$ are occasionally reported for various reactions. Furthermore, CO oxidation and reduction reactions were investigated most; 22 studies focused on CO oxidation and 11 on CO reduction reactions out of 50 papers analysed.

The enhancement of productivity can be correlated with metal particle size of the catalyst after MSI tuning (Figure 2.7b, dataset divided on the main MSI phenomenon that was affected). In general, the efficiency of MSI tuning rapidly decayed with increasing particle size and the highest enhancements were obtained for metal particles smaller than $4 \mathrm{~nm}$ through modification of any MSI phenomenon. The majority of studies focused on catalysts with particle sizes in the $<4 \mathrm{~nm}$ size range. For metal particles that are larger than $4 \mathrm{~nm}$, the gain in productivity as a result of MSI tuning is modest in most cases, although a few exceptions were reported. Furthermore, for these larger particles, SMSI was most often the dominant phenomenon, implying that SMSI is less affected by metal nanoparticle size. This can be rationalised by the support covering the NP and thus being in contact with a large fraction of the metal surface, regardless of particle size in the range described here.

When considering many types of catalysis, it became apparent that mainly late transition metals, starting from group 10, were involved when charge transfer between metal and support played a role in the catalysis. As for the supports, charge transfer with the metal required either conductive supports (e.g., graphite), or semi conductive supports (reducible metal oxides), often modified by dopants to increase conductivity further. Insulators (irreducible oxides) require dopants or functionalisation for charge transfer to occur on a noticeable scale ${ }^{101}$. This can be explained by a mismatch in band positions between insulating supports and the nanoparticles, i.e., the valence band of the insulator being too low in energy to affect the electronic properties of the metal NP.

Another observation is that the work on MSI modifications for electro- and photocatalysis is limited. On one hand, this might be ascribed to early development of the role MSI in these fields of catalysis and on the other hand, the range of applicable supports/metals might be more limited ${ }^{147}$. Nevertheless, we believe that the development of MSI tuning methods could be worthwhile for these applications.

Overall, MSI can improve catalytic performance roughly by one order of magnitude under industrially relevant conditions. This effect may seem modest compared to, for example, a difference of four orders of magnitude in CO hydrogenation activity that is obtained with various metals from groups 8-10 in the periodic table ${ }^{148}$. However, often the selection of the metal is fixed by selectivity considerations and MSI modification is one of the few effective tools for designing and enhancing catalyst performance. In addition, these results show that supports are more than merely an inert structural matrix and that their chemical properties can be applied to substantially improve catalytic performance. 


\section{Acknowledgements}

Shell Global Solutions, the Netherlands Association for Scientific Research (NWO) and Companhia Brasileira de Metalurgia e Mineração (CBMM) are thanked for financial support. K.P.d.J. acknowledges support from the European Research Council, EU FP7 ERC Advanced Grant no. 338846 .

\section{References}

1. Anderson, J.A. \& García, M.F. Supported Metals in Catalysis. Catalytic Science Series Volume 5, (Imperial College Press, 2005).

2. Roldan Cuenya, B. Synthesis and catalytic properties of metal nanoparticles: Size, shape, support, composition, and oxidation state effects. Thin Solid Films 518, 3127-3150 (2010).

3. Zečević, J., Vanbutsele, G., de Jong, K.P. \& Martens, J.A. Nanoscale intimacy in bifunctional catalysts for selective conversion of hydrocarbons. Nature 528, 245-248 (2015).

4. Arnal, P.M., Comotti, M. \& Schüth, F. High-temperature-stable catalysts by hollow sphere encapsulation. Angew. Chem. Int. Ed. 45, 8224-8227 (2006).

5. Pacchioni, G. \& Freund, H.-J. Controlling the charge state of supported nanoparticles in catalysis: lessons from model systems. Chem. Soc. Rev. 47, 8474-8502 (2018).

6. Farmer, J. a \& Campbell, C.T. Ceria maintains smaller metal catalyst particles by strong metal-support bonding. Science 329, 933-936 (2010).

7. Ahmadi, M., Mistry, H. \& Roldan Cuenya, B. Tailoring the catalytic properties of metal nanoparticles via support interactions. J. Phys. Chem. Lett. 7, 3519-3533 (2016).

8. Ro, I., Resasco, J. \& Christopher, P. Approaches for understanding and controlling interfacial effects in oxide-supported metal catalysts. ACS Catal. 8, 7368-7387 (2018).

9. Pan, C. J. et al. Tuning/exploiting strong metal-support interaction (SMSI) in heterogeneous catalysis. J. Taiwan Inst. Chem. Eng. 74, 154-186 (2017).

10. Fujiwara, K., Okuyama, K. \& Pratsinis, S.E. Metal-support interactions in catalysts for environmental remediation. Environ. Sci. Nano 4, 2076-2092 (2017).

11. Chen, M.S. \& Goodman, D.W. The structure of catalytically active gold on titania. Science 306, 252-255 (2004).

12. Luches, P. et al. Nature of Ag islands and nanoparticles on the CeO2(111) surface. J. Phys. Chem. C 116, 11221132 (2011).

13. Pacchioni, G. Electronic interactions and charge transfers of metal atoms and clusters on oxide surfaces. Phys. Chem. Chem. Phys. 15, 1737-1757 (2013).

14. Puigdollers, A.R., Schlexer, P., Tosoni, S. \& Pacchioni, G. Increasing oxide reducibility: The role of metal/oxide interfaces in the formation of oxygen vacancies. ACS Catal. 7, 6493-6513 (2017).

15. Molina, L.M. \& Hammer, B. Some recent theoretical advances in the understanding of the catalytic activity of Au. Appl. Catal. A Gen. 291, 21-31 (2005).

16. Zhang, B. \& Qin, Y. Interface tailoring of heterogeneous catalysts by atomic layer deposition. ACS Catal. 8, 10064-10081 (2018).

17. Lin, X. et al. Characterizing low-coordinated atoms at the periphery of MgO-supported Au islands using scanning tunneling microscopy and electronic structure calculations. Phys. Rev. B - Condens. Matter Mater. Phys. 81, 6-9 (2010).

18. Hammer, B. Special sites at noble and late transition metal catalysts. Top. Catal. 37, 3-16 (2006).

19. Farnesi Camellone, M., Negreiros Ribeiro, F., Szabová, L., Tateyama, Y. \& Fabris, S. Catalytic proton dynamics at the water/solid interface of ceria-supported Pt clusters. J. Am. Chem. Soc. 138, 11560-11567 (2016).

20. Toebes, M.L. et al. Support effects in hydrogenation of cinnamaldehyde over carbon nanofiber-supported platinum catalysts: Kinetic modeling. Chem. Eng. Sci. 60, 5682-5695 (2005).

21. Davis, S.E., Ide, M.S. \& Davis, R.J. Selective oxidation of alcohols and aldehydes over supported metal nano- 
particles. Green Chem. 15, 17-45 (2013).

22. Conner, W.C. \& Falconer, J.L. Spillover in heterogeneous catalysis. Chem. Rev. 95, 759-788 (1995).

23. Prins, R. Hydrogen spillover. Facts and fiction. Chem. Rev. 112, 2714-2738 (2012).

24. Takakusagi, S., Fukui, K.I., Tero, R., Asakura, K. \& Iwasawa, Y. First Direct visualization of spillover species emitted from Pt nanoparticles. Langmuir 26, 16392-16396 (2010).

25. Karim, W. et al. Catalyst support effects on hydrogen spillover. Nature 541, 68-71 (2017).

26. Roldan Cuenya, B. Metal nanoparticle catalysts beginning to shape-up. Acc. Chem. Res. 46, 1682-1691 (2012).

27. Frenkel, A. I. et al. Correlating particle size and shape of supported $\mathrm{Ru} / \gamma-\mathrm{Al}_{2} \mathrm{O}_{3}$ catalysts with $\mathrm{NH}_{3}$ decomposition activity .J.Am. Chem. Soc. 131, 12230-12239 (2009).

28. Henry, C. R. Morphology of supported nanoparticles. Prog. Surf. Sci. 80, 92-116 (2005).

29. Hansen, P. L.et al. Atom-resolved imaging of dynamic shape changes in supported copper nanocrystals. Science 295, 2053-2055 (2002).

30. Hemmingson, S. L. \& Campbell, C. T. Trends in adhesion energies of metal nanoparticles on oxide surfaces: Understanding support effects in catalysis and nanotechnology. ACS Nano 11, 1196-1203 (2017).

31. Ahmadi, M., Behafarid, F. \& Roldan Cuenya, B. Size-dependent adhesion energy of shape-selected Pd and Pt nanoparticles. Nanoscale 8, 11635-11641 (2016).

32. Tanase, M. et al. Interfacial bonding stabilizes rhodium and rhodium oxide nanoparticles on layered $\mathrm{Nb}$ oxide and Ta oxide supports. J. Am. Chem. Soc. 136, 5687-5696 (2014).

33. Duan, M. et al. Reconstruction of supported metal nanoparticles in reaction conditions. Angew. Chem. Int. Ed. 57, 6464-6469 (2018).

34. Lin, Y. et al. Adhesion and atomic structures of gold on ceria nanostructures: The role of surface structure and oxidation state of ceria supports. Nano Lett. 15, 5375-5381 (2015).

35. Pingel, T. N., Jørgensen, M., Yankovich, A. B., Grönbeck, H. \& Olsson, E. Influence of atomic site-specific strain on catalytic activity of supported nanoparticles. Nat. Commun. 9, 2722 (2018).

36. Shibata, N. et al. Interface structures of gold nanoparticles on $\mathrm{TiO}_{2}$ (110). Phys. Rev. Lett. 102, 136105 (2009).

37. Bartholomew, C.H. Mechanisms of catalyst deactivation. Appl. Catal. A Gen. 212, 17-60 (2001).

38. van Deelen, T. W., Nijhuis, J. J., Krans, N. A., Zečević, J. \& de Jong, K. P. Preparation of cobalt nanocrystals supported on metal oxides to study particle growth in Fischer-Tropsch catalysts. ACS Catal. 8, 10581-10589 (2018).

39. Penner, S. \& Armbrüster, M. Formation of intermetallic compounds by reactive metal- support interaction: A frequently encountered phenomenon in catalysis. ChemCatChem 7, 374-392 (2015).

40. Furukawa, S. \& Komatsu, T. Intermetallic Compounds: Promising inorganic materials for well-structured and electronically modified reaction environments for efficient catalysis. ACS Catal. 7, 735-765 (2017).

41. Zafeiratos, S., Piccinin, S. \& Teschner, D. Alloys in catalysis: phase separation and surface segregation phenomena in response to the reactive environment. Catal. Sci. Technol. 2, 1787-1801 (2012).

42. Singh, A.K. \& Xu, Q. Synergistic catalysis over bimetallic alloy nanoparticles. ChemCatChem 5, 652-676 (2013).

43. Ferrando, R., Jellinek, J. \& Johnston, R.L. Nanoalloys: From theory to applications of alloy clusters and nanoparticles. Chem. Rev. 108, 845-910 (2008).

44. Tauster, S. J., Fung, S.C . \& Garten, R. L. Strong metal-support interactions. Group 8 noble metals supported on titanium dioxide. J.Am. Chem. Soc. 100, 170-175 (1978).

45. Tauster, S.J., Fung, S.C., Baker, R.T. \& Horsley, J.A. Strong interactions in supported-metal catalysts. Science 211, 1121-1125 (1981).

46. Hernández-Cristóbal, O., Arenas-Alatorre, J., Díaz, G., Bahena, D. \& J. Yacamán, M. High resolution HAADF characterization of $\mathrm{Ir} / \mathrm{TiO}_{2}$ catalyst reduced at $500{ }^{\circ} \mathrm{C}$ : Intensity profile analysis. J. Phys. Chem. C 119, 11672 11678 (2015).

47. Willinger, M. G. et al. A case of strong metal-support interactions: Combining advanced microscopy and model systems to elucidate the atomic structure of interfaces. Angew. Chem. Int.Ed. 53, 5998-6001 (2014).

48. Zhang, S. et al. Dynamical observation and detailed description of catalysts under strong metal-support interaction. Nano Lett. 16, 4528-4534 (2016). 
49. Chen, M.S. \& Goodman, D.W. Interaction of Au with titania: the role of reduced Ti. Top. Catal. 44, 41-47 (2007).

50. Saavedra, J., Pursell, C.J. \& Chandler, B.D. CO oxidation kinetics over $\mathrm{Au} / \mathrm{TiO}_{2}$ and $\mathrm{Au} / \mathrm{Al}_{2} \mathrm{O}_{3}$ catalysts: Evidence for a common water-assisted mechanism. J. Am. Chem. Soc. 140, 3712-3723 (2018).

51. Wang, Y., Widmann, D. \& Behm, R.J. Influence of $\mathrm{TiO}_{2}$ bulk defects on $\mathrm{CO}$ adsorption and $\mathrm{CO}$ oxidation on $\mathrm{Au} / \mathrm{TiO}_{2}$ : Electronic metal-support interactions (EMSIs) in supported Au catalysts. ACS Catal. 7, 2339-2345 (2017).

52. Wang, Y. et al. The role of electronic metal-support interactions and its temperature dependence: $\mathrm{CO}$ adsorption and $\mathrm{CO}$ oxidation on $\mathrm{Au} / \mathrm{TiO}_{2}$ catalysts in the presence of $\mathrm{TiO}_{2}$ bulk defects. J. Catal.354, 46-60 (2017).

53. Kumar, G. et al. Evaluating differences in the active-site electronics of supported Au nanoparticle catalysts using Hammett and DFT studies. Nat. Chem. 10, 268-274 (2018).

54. Song, H. et al. Visible-light-mediated methane activation for steam methane reforming under mild conditions: A case study of $\mathrm{Rh} / \mathrm{TiO}_{2}$ Catalysts. ACS Catal. 8, 7556-7565 (2018).

55. Sakamoto, H. et al. Hot-electron-induced highly efficient $\mathrm{O}_{2}$ activation by $\mathrm{Pt}$ nanoparticles supported on $\mathrm{Ta}_{2} \mathrm{O}_{5}$ driven by visible light. J.Am. Chem. Soc. 137, 9324-9332 (2015).

56. Jackson, C. et al. Electronic metal-support interaction enhanced oxygen reduction activity and stability of boron carbide supported platinum. Nat. Commun. 8, 15802 (2017).

57. Irvine, J.T.S. et al. Evolution of the electrochemical interface in high-temperature fuel cells and electrolysers. Nat. Energy 1, 1-13 (2016).

58. Neagu, D., Tsekouras, G., Miller, D.N., Ménard, H. \& Irvine, J.T.S. In situ growth of nanoparticles through control of non-stoichiometry. Nat. Chem. 5,916-923 (2013).

59. Neagu, D. et al. Nano-socketed nickel particles with enhanced coking resistance grown in situ by redox exsolution. Nat.Commun. 6, 8120 (2015).

60. Gao, Y., Wang, J., Lyu, Y.-Q., Lam, K. \& Ciucci, F. In situ growth of $\mathrm{Pt}_{3} \mathrm{Ni}$ nanoparticles on an A-site deficient perovskite with enhanced activity for the oxygen reduction reaction. J. Mater. Chem. A 5, 6399-6404 (2017).

61. Huang, X., Zhao, G., Wang, G. \& Irvine, J. T. S. Synthesis and applications of nanoporous perovskite metal oxides. Chem. Sci. 9, 3623-3637 (2018).

62. Murata, K. et al. The Metal-support interaction concerning the particle size effect of $\mathrm{Pd} / \mathrm{Al}_{2} \mathrm{O}_{3}$ on methane combustion. Angew. Chem. Int. Ed. 56, 15993-15997 (2017).

63. Bertella, F., Concepción, P. \& Martínez, A. $\mathrm{TiO}_{2}$ polymorph dependent SMSI effect in Co-Ru/ $/ \mathrm{TiO}_{2}$ catalysts and its relevance to Fischer-Tropsch synthesis. Catal. Today 289, 181-191 (2017).

64. Yu, L. et al. Influence of the crystal structure of titanium oxide on the catalytic activity of $\mathrm{Rh} / \mathrm{TiO}_{2}$ in steam reforming of propane at low temperature. Chem. - A Eur.J. 24, 8742-8746 (2018).

65. Bertella, F., Concepción, P. \& Martínez, A. The impact of support surface area on the SMSI decoration effect and catalytic performance for Fischer-Tropsch synthesis of $\mathrm{Co}-\mathrm{Ru} / \mathrm{TiO}_{2}$-anatase catalysts. Catal. Today 296, $170-180$ (2017).

66. Abdel-Mageed, A.M. et al. Selective $\mathrm{CO}$ methanation on $\mathrm{Ru} / \mathrm{TiO}_{2}$ catalysts: Role and influence of metal-support interactions. ACS Catal. 5, 6753-6763 (2015).

67. Yoon, S. et al. Specific metal-support interactions between nanoparticle layers for catalysts with enhanced methanol oxidation activity. ACS Catal. 8, 5391-5398 (2018).

68. Lin, B. et al. Effect of ceria morphology on the catalytic activity of $\mathrm{Co} / \mathrm{CeO}_{2}$ catalyst for ammonia synthesis. Catal. Commun. 101, 15-19 (2017).

69. Ma, Z., Zhao, S., Pei, X., Xiong, X. \& Hu, B. New insights into the support morphology-dependent ammonia synthesis activity of $\mathrm{Ru} / \mathrm{CeO}_{2}$ catalysts. Catal. Sci. Technol. 7, 191-199 (2017).

70. Ha, H., Yoon, S., An, K. \& Kim, H. Y. Catalytic CO oxidation over Au nanoparticles supported on $\mathrm{CeO}_{2}$ nanocrystals: Effect of the $\mathrm{Au}-\mathrm{CeO}_{2}$ interface. ACS Catal. 8, 11491-11501 (2018).

71. Liu, M.-H., Chen, Y.-W., Lin, T.-S. \& Mou, C.-Y. Defective mesocrystal ZnO-supported gold catalysts: Facilitating CO oxidation via vacancy defects in ZnO. ACS Catal. 8, 6862-6869 (2018).

72. Zhu, W. et al. Taming interfacial electronic properties of platinum nanoparticles on vacancy-abundant boron 
nitride nanosheets for enhanced catalysis. Nat. Commun. 8, 15291 (2017).

73. Yan, X. et al. Nickel@Siloxene catalytic nanosheets for high-performance $\mathrm{CO}_{2}$ methanation. Nat. Commun. 10, 2608 (2019).

74. Zhang, F. et al. Tailoring the oxidation activity of Pt nanoclusters via encapsulation. ACS Catal. 5, 1381-1385 (2015).

75. Li, Z. et al. Reactive metal-support interactions at moderate temperature in two-dimensional niobium-carbide-supported platinum catalysts. Nat. Catal. 1,349-355 (2018).

76. Li, Z. et al. Two-dimensional transition metal carbides as supports for tuning the chemistry of catalytic nanoparticles. Nat.Commun. 9, 5258 (2018).

77. Shi, L., Li, Z., Dao, T.D., Nagao, T. \& Yang, Y. A synergistic interaction between isolated Au nanoparticles and oxygen vacancies in an amorphous black $\mathrm{TiO}_{2}$ nanoporous film: Toward enhanced photoelectrochemical water splitting. J. Mater. Chem. A 6, 12978-12984 (2018).

78. He, L., Weniger, F., Neumann, H. \& Beller, M. Synthesis, characterization, and application of metal nanoparticles supported on nitrogen-doped carbon: Catalysis beyond electrochemistry. Angew. Chem. Int. Ed. 55, 12582-12594 (2016).

79. Shi, R. et al. Nitrogen-doped graphene supported copper catalysts for methanol oxidative carbonylation: Enhancement of catalytic activity and stability by nitrogen species. Carbon 130, 185-195 (2018).

80. Ning, X. et al. Electron transfer dependent catalysis of Pt on N-doped carbon nanotubes: Effects of synthesis method on metal-support interaction. J. Catal. 348, 100-109 (2017).

81. Walczak, R. et al. Template- and metal-free synthesis of nitrogen-rich nanoporous "noble" carbon materials by direct pyrolysis of a preorganized hexaazatriphenylene precursor. Angew. Chem. Int. Ed. 57, 10765-10770 (2018).

82. Antonietti, M. \& Oschatz, M. The concept of "noble, heteroatom-doped carbons," their directed synthesis by electronic band control of carbonization, and applications in catalysis and energy materials. Adv. Mater. 30, 1706836 (2018).

83. Qin, Q., Heil, T., Antonietti, M. \& Oschatz, M. Single-site gold catalysts on hierarchical N-doped porous noble carbon for enhanced electrochemical reduction of nitrogen. Small Methods 2, 1800202 (2018).

84. Theofanidis, S.A. et al. Fe-containing magnesium aluminate support for stability and carbon control during methane reforming. ACS Catal. 8, 5983-5995 (2018).

85. Margossian, T. et al. Molecularly tailored nickel precursor and support yield a stable methane dry reforming catalyst with superior metal utilization. J.Am. Chem. Soc. 139, 6919-6927 (2017).

86. Horlyck, J., Lewis, S., Amal, R. \& Scott, J. The impact of La doping on dry reforming Ni-based catalysts loaded on FSP-alumina. Top. Catal. 61, 1842-1855 (2018).

87. Hsieh, B. J. et al. Platinum loaded on dual-doped $\mathrm{TiO}_{2}$ as an active and durable oxygen reduction reaction catalyst. NPG Asia Mater. 9, e403 (2017).

88. Tran, S.B.T., Choi, H.S., Oh, S.Y., Moon, S.Y. \& Park, J.Y. Iron-doped $\mathrm{ZnO}$ as a support for Pt-based catalysts to improve activity and stability: Enhancement of metal-support interaction by the doping effect. RSC Adv. 8 , 21528-21533 (2018).

89. Wang, F. et al. Enhanced catalytic performance of Ir catalysts supported on ceria-based solid solutions for methane dry reforming reaction. Catal. Today 281, 295-303 (2017).

90. Tabakova, T. et al. Structure-activity relationship in water-gas shift reaction over gold catalysts supported on Y-doped ceria. J. Rare Earths 37, 383-392 (2019).

91. Chen, P. et al. Experimental and theoretical understanding of nitrogen-doping-induced strong metal-support interactions in $\mathrm{Pd} / \mathrm{TiO}_{2}$ catalysts for nitrobenzene hydrogenation. ACS Catal. 7, 1197-1206 (2017).

92. Schumann, J. et al. Promoting strong metal support interaction: Doping $\mathrm{ZnO}$ for enhanced activity of Cu/ZnO:M (M = Al, Ga, Mg) catalysts. ACS Catal. 5, 3260-3270 (2015).

93. Chernyak, S.A. et al. Effect of Co crystallinity on $\mathrm{Co} / \mathrm{CNT}$ catalytic activity in $\mathrm{CO} / \mathrm{CO}_{2}$ hydrogenation and $\mathrm{CO}$ disproportionation. Appl. Surf. Sci. 372, 100-107 (2016).

94. Chernyak, S.A. et al. Co catalysts supported on oxidized CNTs: evolution of structure during preparation, 
reduction and catalytic test in Fischer-Tropsch synthesis. Appl. Catal. A Gen. 523, 221-229 (2016).

95. Eschemann, T.O. et al. Effect of support surface treatment on the synthesis, structure, and performance of Co/CNT Fischer-Tropsch catalysts. J. Catal. 328, 130-138 (2015).

96. Honma, T. \& Wayman, C.M. Epitaxial growth of evaporated cobalt films. J. Appl. Phys. 36, 2791-2798 (1965).

97. Rao, R.G. et al. Interfacial charge distributions in carbon-supported palladium catalysts. Nat. Commun. 8, 340 (2017).

98. Shi, W. et al. Enhanced chemoselective hydrogenation through tuning the interaction between Pt nanoparticles and carbon supports: Insights from identical location transmission electron microscopy and X-ray photoelectron spectroscopy. ACS Catal. 6, 7844-7854 (2016).

99. Donoeva, B., Masoud, N. \& De Jongh, P.E. Carbon support surface effects in the gold-catalyzed oxidation of 5-hydroxymethylfurfural. ACS Catal. 7, 4581-4591 (2017).

100. Celebi, M., Yurderi, M., Bulut, A., Kaya, M. \& Zahmakiran, M. Palladium nanoparticles supported on amine-functionalized $\mathrm{SiO}_{2}$ for the catalytic hexavalent chromium reduction. Appl.Catal.B Environ. 180, 53-64 (2016).

101. Rodríguez-Gómez, A., Platero, F., Caballero, A. \& Colón, G. Improving the direct synthesis of hydrogen peroxide from hydrogen and oxygen over Au-Pd/SBA-15 catalysts by selective functionalization. Mol. Catal. 445, $142-151$ (2018).

102. Van Den Berg, R. et al. Support functionalization to retard ostwald ripening in copper methanol synthesis catalysts. ACS Catal. 5, 4439-4448 (2015).

103. Pan, Y.X. et al. Photocatalytic $\mathrm{CO}_{2}$ reduction by carbon-coated indium-oxide nanobelts. J.Am. Chem. Soc. 139, 4123-4129 (2017).

104. Prieto, G. et al. Cobalt-catalyzed Fischer-Tropsch synthesis: Chemical nature of the oxide support as a performance descriptor. ACS Catal. 5, 3323-3335 (2015).

105. Liu, L. \& Corma, A. Metal catalysts for heterogeneous catalysis: From single atoms to nanoclusters and nanoparticles. Chem. Rev. 118, 4981-5079 (2018).

106. Lykhach, Y. et al. Counting electrons on supported nanoparticles. Nat. Mater. 15, 284-288 (2016).

107. Guo, Y. et al. Low-temperature $\mathrm{CO}_{2}$ methanation over $\mathrm{CeO}_{2}$-supported $\mathrm{Ru}$ single atoms, nanoclusters, and nanoparticles competitively tuned by strong metal-support interactions and $\mathrm{H}$-spillover effect. ACS Catal. 8, 6203-6215 (2018).

108. Yan, Y. et al. $\mathrm{Ru} / \mathrm{Al}_{2} \mathrm{O}_{3}$ catalyzed $\mathrm{CO}_{2}$ hydrogenation: Oxygen-exchange on metal-support interfaces. J. Catal. 367, 194-205 (2018).

109. Demiroglu, I. et al. Modelling free and oxide-supported nanoalloy catalysts: comparison of bulk-immiscible Pd-Ir and Au-Rh systems and influence of a $\mathrm{TiO}_{2}$ support. Faraday Discuss. 208, 53-66 (2018).

110. Piccolo, L. et al. Understanding and controlling the structure and segregation behaviour of AuRh nanocatalysts. Sci. Rep. 6, 1-8 (2016).

111. Konuspayeva, Z. et al. Au-Rh and Au-Pd nanocatalysts supported on rutile titania nanorods: Structure and chemical stability. Phys. Chem. Chem. Phys. 17, 28112-28120 (2015).

112. Han, C.W. et al. Highly stable bimetallic $\mathrm{AuIr} / \mathrm{TiO}_{2}$ catalyst: Physical origins of the intrinsic high stability against sintering. Nano Lett. 15, 8141-8147 (2015).

113. Destro, P. et al. The crucial role of the support in the transformations of bimetallic nanoparticles and catalytic performance. ACS Catal. 8, 1031-1037 (2018).

114. Seemala, B., Cai, C.M., Wyman, C.E. \& Christopher, P. Support induced control of surface composition in $\mathrm{Cu}-\mathrm{Ni} / \mathrm{TiO}_{2}$ catalysts enables high yield co-conversion of $\mathrm{HMF}$ and furfural to methylated furans. ACS Catal. 7, 4070-4082 (2017).

115. Liu, D. et al. Identifying dynamic structural changes of active sites in Pt-Ni bimetallic catalysts using multimodal approaches. ACS Catal. 8, 4120-4131 (2018).

116. Divins, N.J., Angurell, I., Escudero, C., Pérez-Dieste, V. \& Llorca, J. Influence of the support on surface rearrangements of bimetallic nanoparticles in real catalysts. Science 346, 620-623 (2014).

117. Gubó, R. et al. Variation of SMSI with the Au:Pd Ratio of Bimetallic Nanoparticles on $\mathrm{TiO}_{2}(110)$. Top. Catal. 
61, 308-317 (2018).

118. Zhan, W. et al. Surfactant-assisted stabilization of Au colloids on solids for heterogeneous catalysis. Angew. Chem. Int.Ed. 56, 4494-4498 (2017).

119. Gao, X., Liu, H., Hidajat, K. \& Kawi, S. Anti-coking $\mathrm{Ni} / \mathrm{SiO}_{2}$ catalyst for dry reforming of methane: Role of oleylamine/oleic acid organic pair. ChemCatChem 7, 4188-4196 (2015).

120. Tang, H. et al. Classical strong metal-support interactions between gold nanoparticles and titanium dioxide. Sci. Adv. 3, e1700231 (2017).

121. Tang, H. et al. Strong metal-support interactions between gold nanoparticles and nonoxides. J. Am. Chem. Soc. 138, 56-59 (2016).

122. Tang, H. et al. Oxidative strong metal-support interactions (OMSI) of supported platinum-group metal catalysts. Chem. Sci. 9, 6679-6684 (2018).

123. Wang, L. et al. Strong metal-support interactions achieved by hydroxide-to-oxide support transformation for preparation of sinter-resistant gold nanoparticle catalysts. ACS Catal. 7, 7461-7465 (2017).

124. Hernández Mejía, C., Vogt, C., Weckhuysen, B.M. \& de Jong, K.P. Stable niobia-supported nickel catalysts for the hydrogenation of carbon monoxide to hydrocarbons. Cat. Today 343, 56-62 (2020).

125. Xu, M. et al. $\mathrm{TiO}_{2-\mathrm{x}}$-modified Ni nanocatalyst with tunable metal-support interaction for water-gas-shift reaction. ACS Catal. 7, 7600-7609 (2017).

126. Li, Y. et al. High temperature reduction dramatically promotes $\mathrm{Pd} / \mathrm{TiO}_{2}$ catalyst for ambient formaldehyde oxidation. Appl. Catal. B Environ. 217, 560-569 (2017).

127. Ryabchuk, P. et al. Intermetallic nickel silicide nanocatalyst-A non-noble metal-based general hydrogenation catalyst. Sci. Adv. 4, eaat0761 (2018).

128. Serna, P. \& Corma, A. Transforming nano metal nonselective particulates into chemoselective catalysts for hydrogenation of substituted nitrobenzenes. ACS Catal. 5, 7114-7121 (2015).

129. Rui, Z., Chen, L., Chen, H. \& Ji, H. Strong metal-support interaction in $\mathrm{Pt} / \mathrm{TiO}_{2}$ induced by Mild $\mathrm{HCHO}$ and $\mathrm{NaBH}_{4}$ solution reduction and its effect on catalytic toluene combustion. Ind. Eng. Chem. Res. 53, 1587915888 (2014).

130. Gänzler, A.M. et al. Tuning the structure of platinum particles on ceria in situ for enhancing the catalytic performance of exhaust gas catalysts. Angew. Chem. Int.Ed. 56, 13078-13082 (2017).

131. Gänzler, A.M. et al. Tuning the $\mathrm{Pt} / \mathrm{CeO}_{2}$ interface by in situ variation of the Pt particle size. ACS Catal. 8, 4800-4811 (2018).

132. Freakley, S.J. et al. Palladium-tin catalysts for the direct synthesis of $\mathrm{H}_{2} \mathrm{O}_{2}$ with high selectivity. Science 351, 965-968 (2016).

133. Hernández Mejía, C., van Deelen, T.W. \& de Jong, K.P. Activity enhancement of cobalt catalysts by tuning metal-support interactions. Nat. Commun. 9, 4459 (2018).

134. Zhan, W. et al. A sacrificial coating strategy toward enhancement of metal-support interaction for ultrastable Au nanocatalysts. J.Am. Chem. Soc. 138, 16130-16139 (2016).

135. Phaahlamohlaka, T.N. et al. A sinter resistant Co Fischer-Tropsch catalyst promoted with Ru and supported on titania encapsulated by mesoporous silica. Appl. Catal. A Gen. 552, 129-137 (2018).

136. Li, H. et al. Evidence of the encapsulation model for strong metal-support interaction under oxidized conditions: A case study on $\mathrm{TiO}_{x} / \mathrm{Pt}(111)$ for $\mathrm{CO}$ oxidation by in situ wide spectral range infrared reflection adsorption spectroscopy. ACS Catal. 8, 10156-10163 (2018).

137. Weng, Z. \& Zaera, F. Sub-monolayer control of mixed-oxide support composition in catalysts via atomic layer deposition: Selective hydrogenation of cinnamaldehyde promoted by $\left(\mathrm{SiO}_{2}-\mathrm{ALD}\right)-\mathrm{Pt} / \mathrm{Al}_{2} \mathrm{O}_{3}$. ACS Catal. 8, 8513-8524 (2018).

138. Ro, I. et al. Role of the $\mathrm{Cu}-\mathrm{ZrO}_{2}$ interfacial sites for conversion of ethanol to ethyl acetate and synthesis of methanol from $\mathrm{CO}_{2}$ and $\mathrm{H}_{2}$. ACS Catal. 6, 7040-7050 (2016).

139. Moon, S.Y., Naik, B., Jung, C.-H., Qadir, K. \& Park, J.Y. Tailoring metal-oxide interfaces of oxide-encapsulated Pt/silica hybrid nanocatalysts with enhanced thermal stability. Catal. Today 265, 245-253 (2016).

140. Yang, N. \& Bent, S.F. Investigation of inherent differences between oxide supports in heterogeneous catalysis 
in the absence of structural variations. J. Catal. 351, 49-58 (2017).

141. Kennedy, R.M. et al. Replication of SMSI via ALD: $\mathrm{TiO}_{2}$ overcoats increase Pt-catalyzed acrolein hydrogenation selectivity. Catal. Letters 148, 2223-2232 (2018).

142. Zhang, J. et al. Wet-chemistry strong metal-support interactions in titania supported Au catalysts. J.Am. Chem. Soc. 141, 2975-2983 (2019).

143. Wu, L., Li, B. \& Zhao, C. Direct synthesis of hydrogen and dimethoxylmethane from methanol on copper/silica catalysts with optimal $\mathrm{Cu}^{+} / \mathrm{Cu}^{0}$ sites. ChemCatChem 10,1140-1147 (2018).

144. Xu, C. et al. Interfacing with silica boosts the catalysis of copper. Nat. Commun. 9, 3367 (2018).

145. Matsubu, J.C. et al. Adsorbate-mediated strong metal-support interactions in oxide-supported Rh catalysts. Nat. Chem. 9, 120-127 (2017).

146. Wang, X. et al. Sacrificial adsorbate strategy achieved strong metal-support interaction of stable Cu nanocatalysts. ACS Appl. Energy Mater. 1, 1408-1414 (2018).

147. Kleijn, S.E.F., Lai, S.C.S., Koper, M.T.M. \& Unwin, P.R. Electrochemistry of nanoparticles. Angew. Chem. Int.Ed. 53,3558-3586 (2014).

148. Vannice, M.A. The catalytic synthesis of hydrocarbons from $\mathrm{H}_{2} / \mathrm{CO}$ mixtures over the group VIII metals: V. The catalytic behavior of silica-supported metals. J. Catal. 50, 228-236 (1977). 



\section{Crystalline Niobia with Tailored Porosity as Support for Cobalt Catalysts for the Fischer-Tropsch Synthesis}

Structure and catalytic performance of niobia-supported cobalt catalysts were studied based on crystal phase, porosity and cobalt loading. Crystalline niobia as support proved to be a prerequisite to obtain highly active and selective Co/niobia Fischer-Tropsch catalysts, whereas amorphous niobia showed minimal activity. Crystallization changed the porous morphology of $\mathrm{Nb}_{2} \mathrm{O}_{5} \cdot n \mathrm{H}_{2} \mathrm{O}$ resulting in a dense material with low specific pore volume and specific surface area. Multiple impregnations on crystalline $\mathrm{Nb}_{2} \mathrm{O}_{5}$ were necessary to achieve cobalt loadings higher than $6 \mathrm{wt} . \%$; this led to larger cobalt particles, diminished interaction of cobalt with niobia and therefore decreased activity per unit weight of cobalt and $\mathrm{C}_{5+}$ selectivity. Carbon deposition via sucrose pyrolysis was employed in order to partly maintain the porosity during crystallization. The obtained porous crystalline niobia was used as support for cobalt catalysts with higher metal loadings. STEM-EDX mapping characterization of the catalysts provided unique information for this kind of materials, e.g. cobalt distribution and particle size. The catalysts showed high cobalt-normalized catalytic activity and $\mathrm{C}_{5+}$ selectivity for the Fischer-Tropsch synthesis under industrially relevant conditions. Moreover, higher cobalt loadings led to an increased catalyst-weight normalized catalytic activity. 


\subsection{Introduction}

Fischer-Tropsch synthesis involves the transformation of synthesis gas (a mixture of $\mathrm{H}_{2}$ and $\mathrm{CO}$ ) to chemicals and ultra-clean fuels. Particularly, cobalt-based catalysts are industrially relevant for the production of long-chain hydrocarbons $\left(\mathrm{C}_{5+}\right)$. These catalysts offer high selectivity, activity and stability, especially when promoted with noble metals and/or transition metal oxides ${ }^{1}$. Since the first reports by Schmal and coworkers ${ }^{2-4}$, cobalt supported on niobia $\left(\mathrm{Nb}_{2} \mathrm{O}_{5}\right)$ has gained considerable interest due to its notably high selectivity towards $\mathrm{C}_{5+}$. Furthermore, the $\mathrm{Co} / \mathrm{Nb}_{2} \mathrm{O}_{5}$ system shows great activity per unit weight of cobalt and markedly increases turnover frequencies upon noble metal promotion ${ }^{5-8}$.

Niobia as support has been reported to be effective for cobalt Fischer-Tropsch catalysts solely in the crystalline form. Generally, this crystalline niobia has a very low specific pore structure compared to typical Fischer-Tropsch supports (e.g. $\mathrm{SiO}_{2}$ and $\gamma-\mathrm{Al}_{2} \mathrm{O}_{3}$ ), limiting the application of high metal loadings. Therefore, crystalline niobia with higher porosity would allow higher cobalt loadings and dispersion. Several methods have been reported for the synthesis of porous $\mathrm{Nb}_{2} \mathrm{O}_{5}{ }^{9}$. However, despite the higher porosity obtained, most of these methods have basic disadvantages to be applied in large-scale support synthesis. Expensive and highly reactive precursors were involved ${ }^{10-12}$ (e.g. $\mathrm{NbCl}_{5}, \mathrm{Nb}(\mathrm{OEt})_{5}$, copolymers) or the resulting $\mathrm{Nb}_{2} \mathrm{O}_{5}$ had low crystallinity and high acidity ${ }^{13-14}$. In order to be used as FischerTropsch support material, where large quantities are necessary, a simple and efficient method is required. Contrary to the common $\mathrm{Nb}_{2} \mathrm{O}_{5}$ crystalline form, amorphous niobium oxide hydrate $\left(\mathrm{Nb}_{2} \mathrm{O}_{5} \bullet n \mathrm{H}_{2} \mathrm{O}\right)$ has a mesoporous structure with relatively high specific pore volume and specific surface area. However, due to its acidic properties, niobium oxide hydrate is reactive towards cobalt salts during catalyst preparation, leading to formation of inactive species for Fischer-Tropsch synthesis. Niobium oxide hydrate can be effectively used as precursor for niobia via thermal crystallization at temperatures greater than $500{ }^{\circ} \mathrm{C}$ as has been shown by Schmal and co-workers ${ }^{2-4}$. This thermal treatment however decreases considerably porosity and specific surface area.

Here we report the influence of niobia crystal phase, porosity and cobalt loading on the catalysts' structure and performance in Fischer-Tropsch synthesis. Sucrose impregnation, polymerization and pyrolysis over the niobium oxide hydrate surface was employed in order to maintain the porosity during crystallization. This facile method resulted in a crystalline niobia material which preserved a great fraction of the mesoporous structure of the niobium oxide hydrate. The material was used as support to prepare cobalt catalysts and tested for the Fischer-Tropsch synthesis. These catalysts showed high cobalt-specific catalytic activity and good $\mathrm{C}_{5+}$ selectivity, furthermore due to the higher cobalt loading the catalyst weightbased activity was markedly higher.

\subsection{Experimental}

Synthesis. Niobium oxide hydrate $\left(\mathrm{Nb}_{2} \mathrm{O}_{5} \cdot n \mathrm{H}_{2} \mathrm{O}, \mathrm{HY}-340, \mathrm{AD} / 4465\right)$ was obtained from Companhia Brasileira de Metalurgia e Mineração - CBMM. Thermal treatment of niobium 
oxide hydrate was performed in stagnant air, air flow or $\mathrm{N}_{2}$ flow.

Mesoporous crystalline niobia $\left(\mathrm{Nb}_{2} \mathrm{O}_{5}-\mathrm{MC}\right)$ : The support was prepared starting from niobium oxide hydrate $\left(\mathrm{Nb}_{2} \mathrm{O}_{5} \bullet n \mathrm{H}_{2} \mathrm{O}, \mathrm{HY}-340, \mathrm{AD} / 4465,75-150 \mu \mathrm{m}\right)$, which was firstly dried under dynamic vacuum. Thereafter it was impregnated with a sucrose aqueous solution $\left(0.25 \mathrm{~g} \cdot \mathrm{cm}^{-3}\right)$, using equal amounts of sucrose and $\mathrm{Nb}_{2} \mathrm{O}_{5} \cdot n \mathrm{H}_{2} \mathrm{O}(\mathrm{m} / \mathrm{m})$.

In order to polymerize and pyrolize the sucrose, the impregnated niobium oxide hydrate was heated in a tubular furnace under $\mathrm{N}_{2}$ flow at $150{ }^{\circ} \mathrm{C}$ for $2 \mathrm{~h}\left(5^{\circ} \mathrm{C} \cdot \mathrm{min}^{-1}\right)$. The sample was then heated to $600{ }^{\circ} \mathrm{C}$ for $2 \mathrm{~h}\left(20{ }^{\circ} \mathrm{C} \cdot \mathrm{min}^{-1}\right)$ under $\mathrm{N}_{2}$ flow. The obtained sample, a black uniform powder, was left to cool down to room temperature. Finally, the carbon was burned off at $400{ }^{\circ} \mathrm{C}$ for $4 \mathrm{~h}\left(5^{\circ} \mathrm{C} \cdot \mathrm{min}^{-1}\right)$ in $30 \mathrm{vol} . \% \mathrm{O}_{2} / \mathrm{N}_{2}$ flow.

The cobalt catalysts were prepared using incipient wetness impregnation of niobium oxide hydrate calcined at temperatures between $120{ }^{\circ} \mathrm{C}$ and $600{ }^{\circ} \mathrm{C}$ or $\mathrm{Nb}_{2} \mathrm{O}_{5}-\mathrm{MC}$. Prior to impregnation the supports $\left(75-150 \mu \mathrm{m}\right.$ grains) were dried under vacuum at $80{ }^{\circ} \mathrm{C}$ for $1 \mathrm{~h}$. The impregnation was performed with aqueous solution of $\mathrm{Co}\left(\mathrm{NO}_{3}\right)_{2} \cdot 6 \mathrm{H}_{2} \mathrm{O}$ (Acros, $99 \%$ ), where the concentration depended on the pore volume of the support used and the target metal loading. Multiple impregnations were necessary to achieve Co loadings larger than $6 \mathrm{wt} . \%$ for niobia with low specific pore volume. In the next step, the catalysts were dried for $12 \mathrm{~h}$ at $60{ }^{\circ} \mathrm{C}$ in stagnant air and subsequently calcined for $2 \mathrm{~h}$ at $350{ }^{\circ} \mathrm{C}\left(3{ }^{\circ} \mathrm{C} \cdot \mathrm{min}-1\right)$ in a fixed bed reactor under N2 flow. Metal loadings were defined as the mass of metallic cobalt per gram of reduced catalyst.

Characterization. Powder X-ray diffractograms were measured using a Bruker-AXS D2 Phaser X-ray diffractometer, Co-K $\alpha$ radiation $(\lambda=1.789 \AA ̊ \AA)$. For calcined catalysts $\mathrm{Co}_{3} \mathrm{O}_{4}$ crystallite size was calculated using the Scherrer equation $(\mathrm{k}=0.9)$ to the (311) diffraction line at $2 \theta=43.0^{\circ}$ or $(220)$ diffraction line at $2 \theta=36.5^{\circ}$. In situ XRD was measured using a Bruker-AXS D8 Advance X-ray diffractometer, Co-K $\alpha$ radiation $(\lambda=1.789 \AA$ A). The sample was heated to $350{ }^{\circ} \mathrm{C}\left(2 \mathrm{~h}, 5{ }^{\circ} \mathrm{C} \cdot \mathrm{min}^{-1}\right)$ in $25 \mathrm{vol} \% \mathrm{H}_{2} / \mathrm{He}$. A micromeritics TriStar 3000 apparatus was used to perform $\mathrm{N}_{2}$-physisorption at $-196{ }^{\circ} \mathrm{C}$. Prior to analysis the sample was dried at either at 120 or $200{ }^{\circ} \mathrm{C}$ for $16 \mathrm{~h}$ in $\mathrm{N}_{2}$ flow. Specific surface area was calculated using the BET theory for $\mathrm{p} / \mathrm{p}_{0}=0.06-0.25$. The pore size distribution was determined using the $\mathrm{BJH}$ theory applied to the adsorption branch. The specific mesopore volume was calculated using single point at $\mathrm{p} / \mathrm{p}_{0}=0.98$. Thermogravimetric analysis was performed using a TGA Q50 equipment, around $20 \mathrm{mg}$ of sample were placed in a platinum crucible under $60 \mathrm{~cm}^{3} \cdot \mathrm{min}^{-1}$ air flow and heated until $400{ }^{\circ} \mathrm{C}\left(15^{\circ} \mathrm{C} \cdot \mathrm{min}^{-1}\right)$ for $4 \mathrm{~h}$ thereafter heated until $1000{ }^{\circ} \mathrm{C}\left(15^{\circ} \mathrm{C} \cdot \mathrm{min}^{-1}\right), 40 \mathrm{~cm}^{3} \cdot \mathrm{min}^{-1} \mathrm{~N}_{2}$ flow was used as reference. Temperature programmed reduction (TPR) analyses were performed using a Micromeritics Autochem 2990 instrument, where $100 \mathrm{mg}$ sample were dried at $120{ }^{\circ} \mathrm{C}$ for $1 \mathrm{~h}$ in $\mathrm{Ar}$ flow followed by reduction from room temperature up to $1000{ }^{\circ} \mathrm{C}\left(10{ }^{\circ} \mathrm{C} \cdot \mathrm{min}^{-1}\right)$ in a $5 \mathrm{vol} \% \mathrm{H}_{2} / \mathrm{Ar}$ flow. Bright field transmission electron microscopy (TEM) imaging was performed using a Tecnai 12 operated at $120 \mathrm{kV}$. Scanning transmission electron microscopy (STEM-EDX) images were acquired with a Philips Tecnai-20 FEG $(200 \mathrm{kV})$ microscope equipped with an energy dispersive X-ray (EDX) and high-angle annular dark-field (HAADF) detector. 
Catalytic testing. Low pressure catalytic testing was performed in a quartz glass plug-flow reactor, typicallyloaded with $15-20 \mathrm{mg}$ catalyst $(38-150 \mu \mathrm{m})$ diluted with $200 \mathrm{mg}$ SiC. Typically, the catalysts were reduced in situ at $350{ }^{\circ} \mathrm{C}\left(5{ }^{\circ} \mathrm{C} \cdot \mathrm{min}^{-1}, 2 \mathrm{~h}\right)$ in a $20 / 40 \mathrm{~cm}^{3} \cdot \mathrm{min}^{-1} \mathrm{H}_{2} /$ Ar flow. Fischer-Tropsch catalysis was performed at $220{ }^{\circ} \mathrm{C}, 1 \mathrm{bar}, \mathrm{H}_{2} / \mathrm{CO}=2.0 \mathrm{v} / \mathrm{v}$, GHSV $=24000-48000 \mathrm{~h}^{-1}$, CO conversion $<5 \%$. C1-C18 products were analyzed by online gas chromatography (Varian 430 GC, CP sil-5 column). Activity and selectivities were reported after at least 40 hours on stream. High pressure catalytic testing was performed using an Avantium Flowrence 16 parallel, continuous flow, fixed bed reactor system. Typically, $100 \mathrm{mg}$ catalyst $(38-150 \mu \mathrm{m})$ were diluted with $300 \mathrm{mg} \mathrm{SiC}$ and loaded in a stainless-steel reactor. The catalysts were reduced in situ at atmospheric pressure in a $25 \mathrm{vol} \% \mathrm{H}_{2} / \mathrm{He}$ flow, for $8 \mathrm{~h}$ at $350{ }^{\circ} \mathrm{C}$ (heating rate of $1{ }^{\circ} \mathrm{C} \cdot \mathrm{min}^{-1}$ ). Thereafter, reactors were cooled down to $180{ }^{\circ} \mathrm{C}$ and the gas stream was switched to synthesis gas, $\mathrm{H}_{2} / \mathrm{CO}=2.0 \mathrm{v} / \mathrm{v}, \mathrm{GHSV} 4500 \mathrm{~h}^{-1}$. Reactors were pressurized to 20 bar and subsequently heated to reaction temperature $220{ }^{\circ} \mathrm{C}\left(1{ }^{\circ} \mathrm{C} \cdot \mathrm{min}^{-1}\right)$, CO conversion was maintained at $15-25 \%$. Products up to C9 were analyzed using online gas chromatography. GHSV was defined as total gas flow divided by the catalyst volume.

\subsection{Results and discussion}

\subsubsection{Niobium oxide hydrate thermal treatment}

Niobium oxide hydrate was characterized by powder X-ray diffraction (XRD) and $\mathrm{N}_{2}$-physisorption after the different thermal treatments. Niobium oxide hydrate remained amorphous after stagnant air calcination in a muffle oven up to $400{ }^{\circ} \mathrm{C}$ (Figure $3.1 \mathrm{a}$ ). Crystallization started after calcination at $500{ }^{\circ} \mathrm{C}$, transforming the material into low-crystalline pseudo-hexagonal $\mathrm{Nb}_{2} \mathrm{O}_{5}$ TT-phase. Calcination at temperatures above $600{ }^{\circ} \mathrm{C}$ led to the orthorhombic $\mathrm{Nb}_{2} \mathrm{O}_{5}$ T-phase, as indicated by the splitting of the peaks at $2 \theta=33^{\circ}$ and $42^{\circ}$. Monoclinic $\mathrm{Nb}_{2} \mathrm{O}_{5}$ phase was observed after calcination at $900{ }^{\circ} \mathrm{C}{ }^{15-17}$.

Increase in calcination temperature changed as well the niobia morphology (Figure 3.1b). Niobium oxide hydrate after drying at $120{ }^{\circ} \mathrm{C}$ had a BET specific surface area

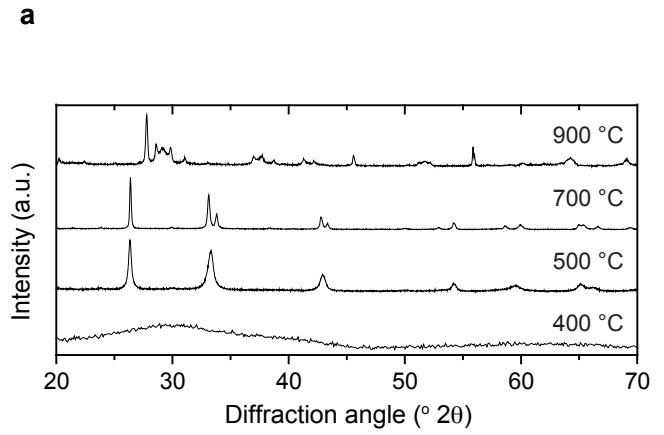

Figure 3.1 a, X-ray diffractograms for niobium oxide hydrate calcined in stagnant air at 400, 500, 700 and $900{ }^{\circ} \mathrm{C}$ b, change in specific surface area (black circles) and specific pore volume (red squares) of niobium oxide hydrate upon temperature increase. 
and specific mesopore volume of $173 \mathrm{~m}^{2} \cdot \mathrm{g}^{-1}$ and $0.19 \mathrm{~cm}^{3} \cdot \mathrm{g}^{-1}$ respectively, as determined by $\mathrm{N}_{2}$-physisorption. Upon increasing calcination temperature these values decreased. In particular, after crystallization at $600{ }^{\circ} \mathrm{C}$ the specific surface dropped to $9 \mathrm{~m}^{2} \cdot \mathrm{g}^{-1}$ and the specific mesopore volume to $0.05 \mathrm{~cm}^{3} \cdot \mathrm{g}^{-1}$.

The porosity of niobium oxide hydrate after drying at $120{ }^{\circ} \mathrm{C}$ consisted mainly of 2-5 $\mathrm{nm}$ mesopores as indicated by the hysteresis at $\mathrm{p} / \mathrm{p}_{0}=0.4-0.7$ (Figure. 3.2) and TEM images (Appendix B: Figure B1), these mesopores were maintained up to $400{ }^{\circ} \mathrm{C}$. After crystallization at $600{ }^{\circ} \mathrm{C}$ most of the mesopores had collapsed and only hysteresis at $\mathrm{p} / \mathrm{p}_{0}=0.9$ was observed, indicative for larger pores (>50 nm). These macropores originated from the $\mathrm{Nb}_{2} \mathrm{O}_{5}$ interparticle space. Table 3.1 summarizes the characterization results for the different materials.
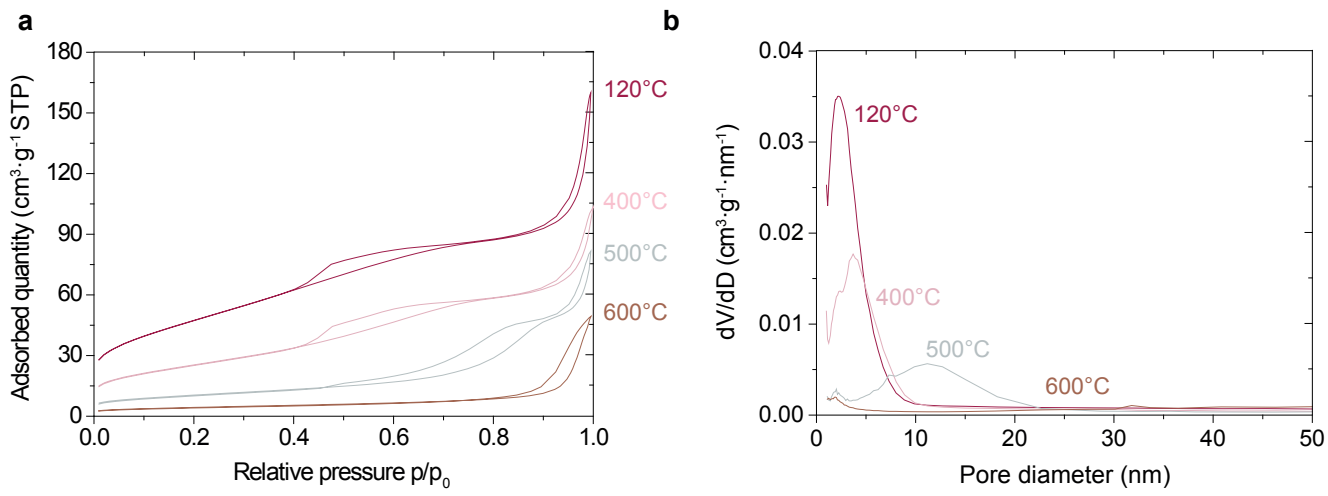

Figure 3.2 $\mathrm{N}_{2}$-physisorption isotherms (a) and pore size distributions (b) for niobium oxide hydrate treated in the temperature range 120 to $600{ }^{\circ} \mathrm{C}$.

\subsubsection{Modified niobia crystallization}

Stagnant air, air flow or $\mathrm{N}_{2}$ flow were used during niobia crystallization at $600{ }^{\circ} \mathrm{C}$ to study the effect of different gas atmospheres and hydrodynamics. For all cases, pseudo-hexagonal niobia TT-phase was obtained with BET specific surface areas of $22-25 \mathrm{~m}^{2} \cdot \mathrm{g}^{-1}$ (Table 3.1). Calcination in stagnant air led to a higher specific mesopore volume $\left(0.11 \mathrm{~cm}^{3} \cdot \mathrm{g}^{-1}\right)$ than after calcination in $\mathrm{N}_{2}$ or air flow $\left(0.06 \mathrm{~cm}^{3} \cdot \mathrm{g}^{-1}\right)$.

In order to inhibit porosity loss during crystallization, the niobium oxide hydrate pores were filled with sucrose as carbon precursor prior thermal treatment. Niobium oxide hydrate was impregnated with a sucrose solution, which polymerized by the acidic properties of the oxide and thermal treatment at $150{ }^{\circ} \mathrm{C}$. After pyrolysis and crystallization at $600{ }^{\circ} \mathrm{C}$, the obtained black powder showed the pseudo-hexagonal $\mathrm{Nb}_{2} \mathrm{O}_{5}$ TT-phase (Figure $3.3 \mathrm{a})$ and a decrease in specific mesopore volume $\left(0.08 \mathrm{~cm}^{3} \cdot \mathrm{g}^{-1}\right)$ which might indicate a blockage of the niobia pores by carbon. Thermogravimetric analysis (TGA) in air of this material shows most of the weight loss after $4 \mathrm{~h}$ at $400{ }^{\circ} \mathrm{C}$ (Apendix B: Figure B2), indicating that carbon can be effectively removed under these conditions. After carbon was burned off the obtained crystalline material has a mesopore volume of $0.16 \mathrm{~cm}^{3} \cdot \mathrm{g}^{-1}$ with a specific surface area of $56 \mathrm{~m}^{2} \cdot \mathrm{g}^{-1}$. Figure $3.3 \mathrm{~b}$ shows the pore size distribution of niobium oxide hydrate 
Table 3.1 Summary of the characterization results (XRD and $\mathrm{N}_{2}$-physisorption) for niobia after the different treatments.

\begin{tabular}{|c|c|c|c|c|}
\hline $\begin{array}{l}\text { Crystallization } \\
\text { conditions }\end{array}$ & Crystal phase & $\begin{array}{c}\text { Specific Surface } \\
\text { Area } \\
\left(\mathbf{m}^{2} \cdot \mathbf{g}^{-1}\right) \\
\end{array}$ & $\begin{array}{c}\text { Specific Mesopore } \\
\text { Volume } \\
\left(\mathrm{cm}^{3} \cdot \mathrm{g}^{-1}\right)\end{array}$ & $\begin{array}{c}\text { Pore Diameter } \\
(\mathbf{n m})\end{array}$ \\
\hline \multicolumn{5}{|c|}{ Niobium oxide hydrate thermal treatment } \\
\hline $\begin{array}{l}120^{\circ} \mathrm{C} \text {, stagnant air, } \\
\text { muffle oven }\end{array}$ & amorphous & 173 & 0.19 & $2-5$ \\
\hline $\begin{array}{l}400{ }^{\circ} \mathrm{C} \text {, stagnant air, } \\
\text { muffle oven }\end{array}$ & amorphous & 86 & 0.12 & $2-7$ \\
\hline $\begin{array}{l}600{ }^{\circ} \mathrm{C} \text {, stagnant air, } \\
\text { muffle oven }\end{array}$ & $\begin{array}{c}\text { pseudo-hexagonal } \\
\text { TT }\end{array}$ & 9 & 0.05 & $>50$ \\
\hline $\begin{array}{l}700{ }^{\circ} \mathrm{C} \text {, stagnant air, } \\
\text { muffle oven }\end{array}$ & hexagonal T & 6 & 0.01 & $>50$ \\
\hline $\begin{array}{l}900{ }^{\circ} \mathrm{C} \text {, stagnant air, } \\
\text { muffle oven }\end{array}$ & monoclinic $\mathrm{H}$ & 1 & $<0.01$ & $>50$ \\
\hline \multicolumn{5}{|c|}{ Modified niobia crystallization } \\
\hline $\begin{array}{l}600^{\circ} \mathrm{C} \text {, stagnant air, } \\
\text { quartz reactor }\end{array}$ & $\begin{array}{c}\text { pseudo-hexagonal } \\
\text { TT }\end{array}$ & 25 & 0.11 & $5-60$ \\
\hline $\begin{array}{l}600{ }^{\circ} \mathrm{C} \text {, air flow, quartz } \\
\text { reactor }\end{array}$ & $\begin{array}{c}\text { pseudo-hexagonal } \\
\text { TT }\end{array}$ & 22 & 0.06 & $5-25$ \\
\hline $\begin{array}{c}600{ }^{\circ} \mathrm{C}, \mathrm{N}_{2} \text { flow, quartz } \\
\text { reactor }\end{array}$ & $\begin{array}{c}\text { pseudo-hexagonal } \\
\text { TT }\end{array}$ & 22 & 0.06 & $5-25$ \\
\hline $\mathrm{Nb}_{2} \mathrm{O}_{5}-\mathrm{MC}$ & $\begin{array}{l}\text { pseudo-hexagonal } \\
\text { TT }\end{array}$ & 56 & 0.16 & $2-12$ \\
\hline
\end{tabular}

a

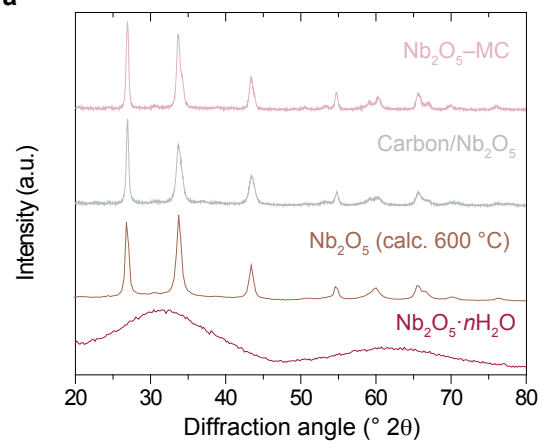

b

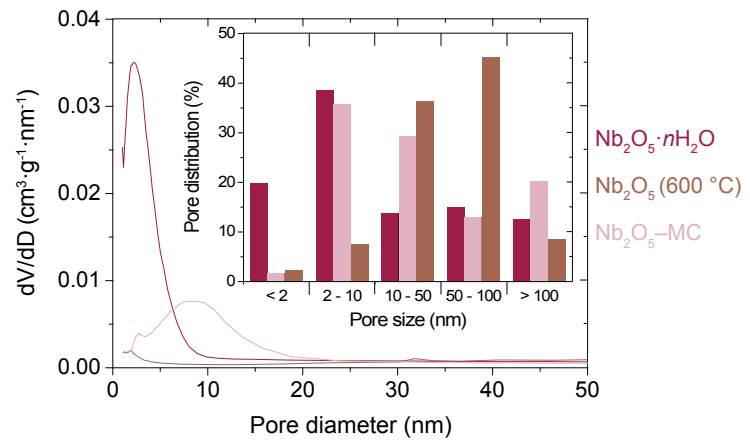

Figure 3.3 a, X-ray diffractograms for the niobium oxide hydrate (red), low pore volume niobia (brown), niobia after sucrose pyrolysis (grey) and mesoporous niobia (pink). b. Pore size distribution for the initial material (niobium oxide hydrate, red) and the crystalline materials: $\mathrm{Nb}_{2} \mathrm{O}_{5}$ calcined at $600{ }^{\circ} \mathrm{C}$ (brown) and $\mathrm{Nb}_{2} \mathrm{O}_{5}-\mathrm{MC}$ (pink).

dried at $120{ }^{\circ} \mathrm{C}$, crystallized at $600{ }^{\circ} \mathrm{C}$ and the mesoporous crystalline niobia $\left(\mathrm{Nb}_{2} \mathrm{O}_{5}-\mathrm{MC}\right)$. Despite the template used not all of the mesopores from niobium oxide hydrate could be maintained during the treatment; however, their collapse was retarded compared to normal crystallization at $600{ }^{\circ} \mathrm{C}$. Dark field STEM images of these two crystalline materials are shown in figure 3.4. Clearly the niobia crystallized at $600{ }^{\circ} \mathrm{C}$ without template has a dense structure whereas for $\mathrm{Nb}_{2} \mathrm{O}_{5}-\mathrm{MC}$ a more porous structure is observed. 

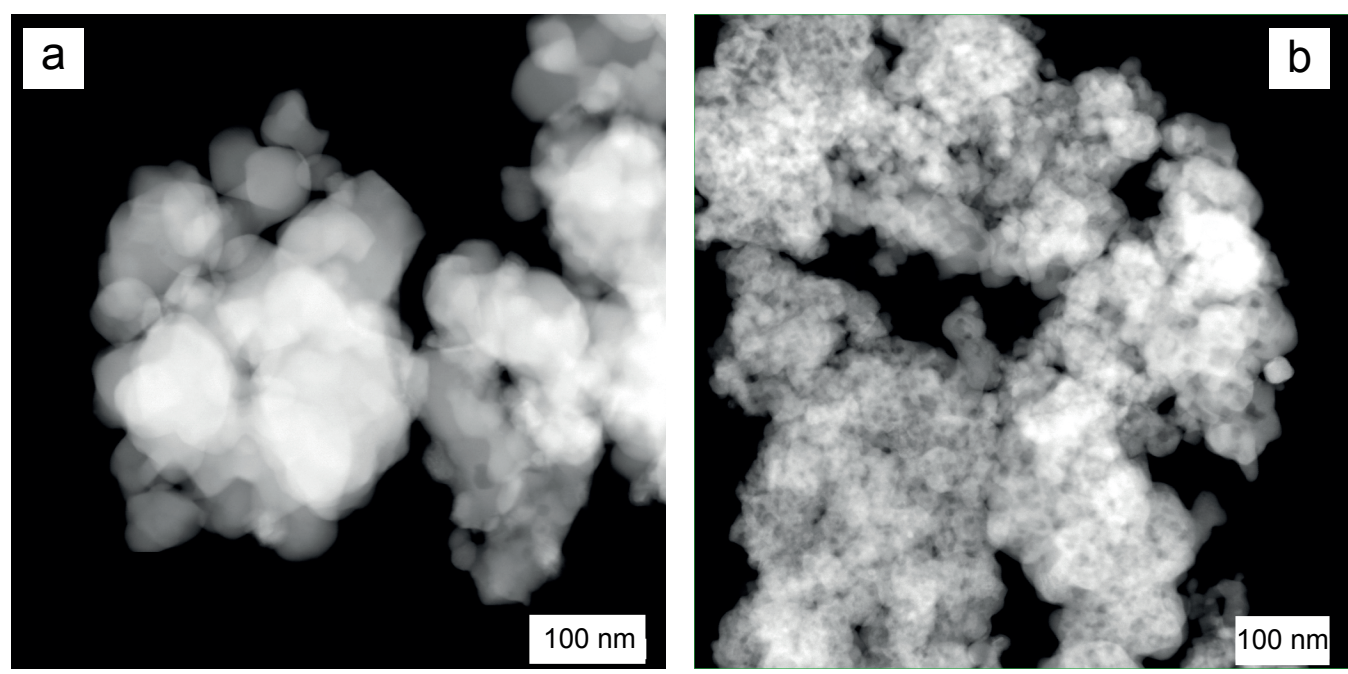

Figure 3.4 Dark field STEM images of the crystalline materials: a, dense $\mathrm{Nb}_{2} \mathrm{O}_{5}$ obtained by calcination at $600{ }^{\circ} \mathrm{C}$ and $\mathbf{b}$, porous $\mathrm{Nb}_{2} \mathrm{O}_{5}-\mathrm{MC}$ obtained by sucrose impregnation, pyrolysis and calcination

\subsubsection{Cobalt deposition}

Deposition of cobalt on the support was performed by incipient wetness impregnation method. Niobium oxide hydrate calcined at $120^{\circ} \mathrm{C}$ or $600{ }^{\circ} \mathrm{C}$ was used as support and deposition of cobalt was performed by single or multiple impregnation (4-21 Co wt.\%) followed by drying and calcination at $350{ }^{\circ} \mathrm{C}$. XRD showed no crystalline cobalt species up to $10 \mathrm{wt} . \%$ independently of the support used, i.e. amorphous or crystalline niobia. $\mathrm{Co}_{3} \mathrm{O}_{4}$ was observed only on the calcined samples with $>13$ wt.\% Co (Figure 3.5). Furthermore, samples supported on crystalline niobia were reduced in situ $\left(25 \mathrm{vol} . \% \mathrm{H}_{2} / \mathrm{He}, 350{ }^{\circ} \mathrm{C}\right)$ and still no cobalt species were observed for the low loadings (Figure 3.5b). This indicates that for low cobalt loadings poorly crystalline cobalt species, very small crystallite sizes or $\mathrm{Co}-\mathrm{Nb}$ oxide species were formed independently of the niobia pretreatment, in line with previous reports $^{18}$.

a

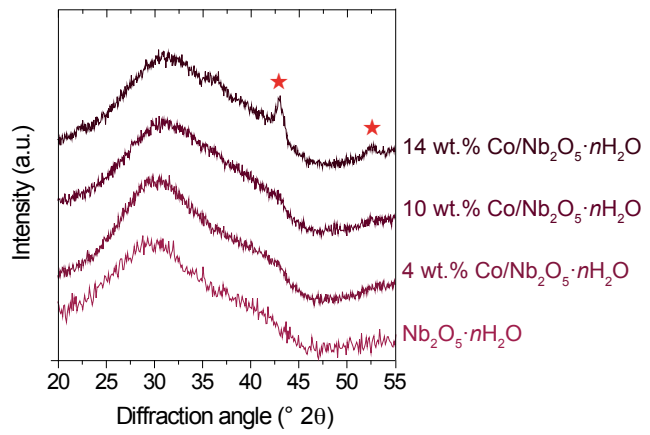

b

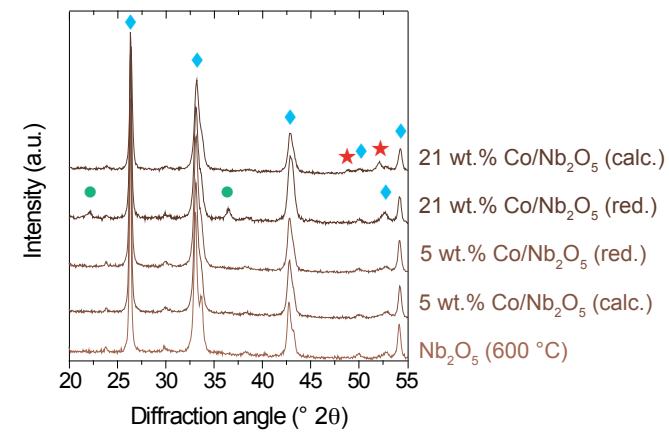

Figure 3.5 X-ray diffractograms of the calcined cobalt catalysts supported on (a) amorphous niobium oxide hydrate or $(\mathbf{b})$ crystalline niobia pretreated at $600{ }^{\circ} \mathrm{C}$. The symbols indicate diffraction peaks corresponding to $\mathrm{Co}_{3} \mathrm{O}_{4}$ $(\star), \mathrm{Nb}_{2} \mathrm{O}_{5} \mathrm{~T}$-phase $(\diamond)$ and $\mathrm{Co}^{0}(\bullet)$. 
The support used, amorphous or crystalline niobia, had a strong impact on the reduction of the cobalt species as shown by the temperature programmed reduction profiles (Figure 3.6). The reduction on crystalline niobia proceeded in two steps as previously reported: from $\mathrm{Co}_{3} \mathrm{O}_{4}$ to $\mathrm{CoO}$ and from $\mathrm{CoO}$ to metallic $\mathrm{Co}^{18-20}$. The reduction temperature is significantly lower if compared with $\gamma$-alumina- or silica-supported cobalt catalysts, therefore reduction can be effectively performed at temperatures lower than $400{ }^{\circ} \mathrm{C}$ without noble metal promotion. In contrast, cobalt supported on amorphous $\mathrm{Nb}_{2} \mathrm{O}_{5} \cdot n \mathrm{H}_{2} \mathrm{O}$ showed no distinctive reduction peaks until temperatures greater than $450{ }^{\circ} \mathrm{C}$ (Figure 3.6). A continuous $\mathrm{H}_{2}$ consumption is observed throughout temperature increase, attributed to reduction of the support. This different reduction profile can be attributed to a stronger interaction between cobalt and niobium oxide hydrate. Most likely no $\mathrm{Co}_{3} \mathrm{O}_{4}$ was formed after impregnation and calcination but rather $\mathrm{Co}-\mathrm{Nb}$ oxide species which cannot be easily reduced.

The mesoporous crystalline niobia $\left(\mathrm{Nb}_{2} \mathrm{O}_{5}-\mathrm{MC}\right)$ was used as support for 6 and 10 wt.\% Co, prepared by incipient wetness impregnation. Due to the larger specific pore volume of $\mathrm{Nb}_{2} \mathrm{O}_{5}-\mathrm{MC}$, a higher metal loading could be achieved in a single impregnation step. In general, characterization of niobia-supported catalysts using TEM in the dark or bright

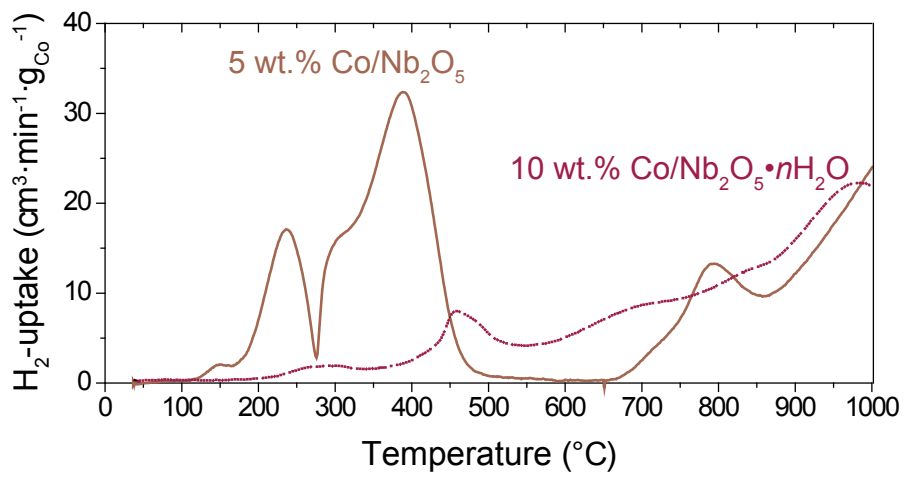

Figure 3.6 Temperature programmed reduction profiles for two catalysts after impregnation, drying and calcination: 5 wt.\% cobalt supported on crystalline niobia (treated at $600{ }^{\circ} \mathrm{C}$, brown line) and $10 \mathrm{wt} . \%$ cobalt supported on amorphous niobium oxide hydrate (treated at $120{ }^{\circ} \mathrm{C}$, red dashed line).

field has the challenge of phase distinction between $\mathrm{Co}_{3} \mathrm{O}_{4}$ and $\mathrm{Nb}_{2} \mathrm{O}_{5}-\mathrm{MC}$ due to their similar electron density. Therefore, electron microscopy combined with EDX mapping is an important and powerful technique for the characterization of this kind of materials. Figure 3.7 shows the STEM-EDX mapping images of the $\mathrm{Nb}_{2} \mathrm{O}_{5}-\mathrm{MC}$-supported catalysts and for comparison purposes a $6 \mathrm{wt} . \%$ Co supported on pretreated $\mathrm{Nb}_{2} \mathrm{O}_{5}$ at $600{ }^{\circ} \mathrm{C}$. STEM-EDX mapping images were taken after reduction at $350{ }^{\circ} \mathrm{C}$ and passivation. A comparison of the $\mathrm{Nb}_{2} \mathrm{O}_{5}-\mathrm{MC}$-supported catalysts (Figure $3.7 \mathrm{a}$ and b) shows that the $6 \mathrm{wt} . \%$ Co catalyst had smaller particles $(9.7 \pm 3.3)$ than the 10 wt.\% Co $(13.9 \pm 6.5)$, which is expected for higher metal loadings. Still these two catalysts show a smaller particle size if compared to the one supported on the dense niobia calcined at $600{ }^{\circ} \mathrm{C}(15.6 \pm 4.3$, Figure $3.7 \mathrm{c}$ and d). The porous morphology of $\mathrm{Nb}_{2} \mathrm{O}_{5}-\mathrm{MC}$ is suggested to restrict particle growth during reduction. 


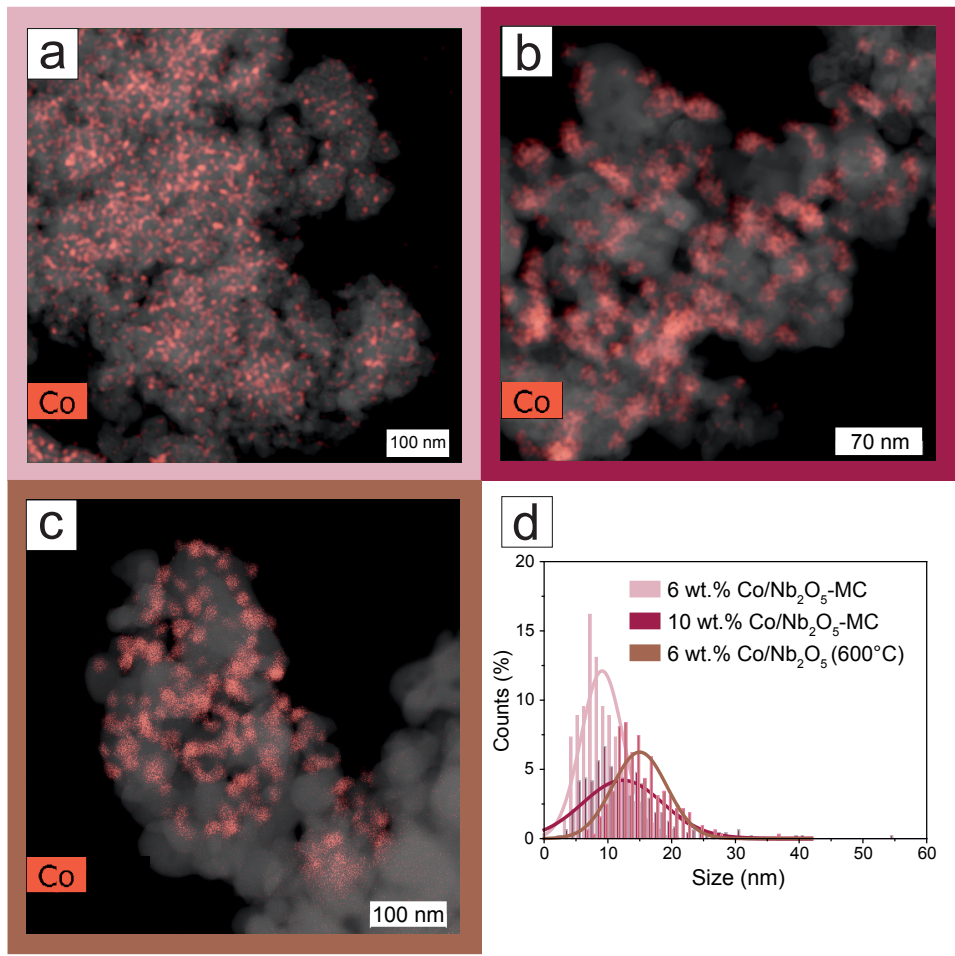

Figure 3.7 STEM-EDX mapping images of cobalt catalysts after reduction and passivation. Cobalt is shown in red and the support in grey. $\mathbf{a}, \mathrm{Nb}_{2} \mathrm{O}_{5}-\mathrm{MC}$ supported catalysts with 6 wt.\% Co and b, 10 wt.\% Co. c, 6 wt.\% Co catalyst supported on niobia pretreated at $600{ }^{\circ} \mathrm{C}$. d, Histogram from the particle size measurement.

\subsubsection{Catalytic performance}

Prepared catalysts were investigated for the Fischer-Tropsch reaction at 1 bar, $220{ }^{\circ} \mathrm{C}$ and $\mathrm{H}_{2} / \mathrm{CO}=2$ to obtain activity and selectivity data (Table 3.2). 5 wt.\% Co supported on crystalline niobia (pretreated at $600{ }^{\circ} \mathrm{C}$ ) was reduced prior to reaction conditions at $350{ }^{\circ} \mathrm{C}$, cobalt-weight normalized activity (Cobalt-Time-Yield, CTY $=3 \cdot 10^{-5} \mathrm{~mol}_{\mathrm{CO}} \mathrm{g}_{\mathrm{Co}}{ }^{-1} \mathrm{~s}^{-1}$ ) and $\mathrm{C}_{5+}$ selectivity ( $70 \mathrm{wt} . \%$ ) were observed after $40 \mathrm{~h}$ on stream similar to results observed previously for promoted $\mathrm{Co} / \mathrm{SiO}_{2}$ catalysts ${ }^{21}$. Reduction at $500{ }^{\circ} \mathrm{C}$ prior to reaction led to 10 times decrease in CTY. Since niobia is a reducible support, SMSI effects by reducing at higher temperatures are expected and have been observed previously by Silva et al. ${ }^{3}$. Catalysts supported on amorphous niobium oxide hydrate showed low catalytic activity (Table 3.2), this might be due to formation of irreducible cobalt species on this support as shown by TPR. Encapsulation of cobalt in the mesopores $(2-5 \mathrm{~nm})$ of this material during catalyst preparation or catalytic testing might have also led to inaccessibility of the active sites. The amorphous form of niobia appears too reactive thereby inhibiting activation of cobalt for the Fischer-Tropsch reaction and thus crystalline niobia is required to obtain active cobalt catalysts.

Catalysts prepared by multiple impregnations showed a decrease in CTY and $\mathrm{C}_{5+}$ selectivity by increasing the cobalt loading (Figure 3.8). Considering the low specific surface area of the support, small interparticle distance at higher cobalt loadings can lead to parti- 
Table 3.2 Summary of the catalytic results for the Fischer-Tropsch reaction at 1 or 20 bar, $220{ }^{\circ} \mathrm{C}$ and $\mathrm{H}_{2} / \mathrm{CO}=2$

\begin{tabular}{|c|c|c|c|c|}
\hline Support ${ }^{\mathrm{a}}$ & $\begin{array}{c}\text { Number of } \\
\text { Impregnations }\end{array}$ & $\begin{array}{c}\text { Co loading } \\
\text { (wt.\%) }\end{array}$ & $\begin{array}{l}\text { Cobalt-Time-Yield } \\
\left(10^{-5} \mathbf{m o l}_{\mathrm{Co}} \mathbf{g}_{\mathrm{Co}}^{-1} \mathbf{s}^{-1}\right)\end{array}$ & $\begin{array}{c}\mathrm{C}_{5^{+}} \text {selectivity } \\
\text { (wt.\%) }\end{array}$ \\
\hline $\begin{array}{c}\text { Amorphous } \\
\mathrm{Nb}_{2} \mathrm{O}_{5} \cdot n \mathrm{H}_{2} \mathrm{O}\left(120^{\circ} \mathrm{C}\right)\end{array}$ & 2 & 10 & $<0.3$ & 45 \\
\hline \multirow[t]{3}{*}{$\begin{array}{c}\text { Amorphous } \\
\mathrm{Nb}_{2} \mathrm{O}_{5} \cdot n \mathrm{H}_{2} \mathrm{O}\left(400{ }^{\circ} \mathrm{C}\right)\end{array}$} & 1 & 5 & 0.5 & 49 \\
\hline & 1 & 5 & 3.0 & 70 \\
\hline & 2 & 10 & 2.5 & 64 \\
\hline \multirow{5}{*}{$\begin{array}{l}\text { Crystalline } \mathrm{Nb}_{2} \mathrm{O}_{5} \\
\quad\left(6000^{\circ} \mathrm{C}\right)\end{array}$} & 3 & 15 & 2.2 & 60 \\
\hline & 4 & 17 & 1.5 & 55 \\
\hline & 4 & 21 & 2.1 & 42 \\
\hline & 1 & 6 & 4.5 (20 bar) & 80 (20 bar) \\
\hline & 1 & 6 & $\begin{array}{l}4.2(20 \mathrm{bar}) \\
2.1(1 \mathrm{bar})\end{array}$ & $\begin{array}{c}80 \text { (20 bar) } \\
64 \text { (1 bar })\end{array}$ \\
\hline $\mathrm{Nb}_{2} \mathrm{O}_{5}-\mathrm{MC}$ & 1 & 10 & $\begin{array}{l}3.7 \text { (20 bar }) \\
2.0(1 \mathrm{bar})\end{array}$ & $\begin{array}{l}81(20 \text { bar }) \\
65(1 \mathrm{bar})\end{array}$ \\
\hline
\end{tabular}

a. In brackets the calcination temperature of the support

b. Catalysts tested at 20 bar are indicated and the value reported is after $100 \mathrm{~h}$ TOS, if not indicated catalysts were tested at 1 bar and $40 \mathrm{~h}$ TOS.

cle growth and sintering. In a similar way, larger particles lead to a decreased $\mathrm{Co}-\mathrm{Nb}_{2} \mathrm{O}_{5}$ interface, where the chain growth probability is larger, therefore decreasing the $\mathrm{C}_{5+}$ selectivity ${ }^{5}$.

$\mathrm{Nb}_{2} \mathrm{O}_{5}-\mathrm{MC}$ supported catalysts were tested both at 1 and at 20 bar, $220{ }^{\circ} \mathrm{C}$ and $\mathrm{H}_{2} / \mathrm{CO}=2$. Results are shown on table 3.2. For comparison purposes, a 6 wt.\% cobalt catalyst with niobia treated at $600{ }^{\circ} \mathrm{C}$ as support was also tested at high pressure. The catalytic activity normalized per catalyst weight (Weight Time Yield, WTY) tested at 20 bar is shown in figure 3.9a. Clearly the $10 \mathrm{wt} . \% \mathrm{Co} / \mathrm{Nb}_{2} \mathrm{O}_{5}-\mathrm{MC}$ catalyst (red triangles) outperforms the 6 wt.\% Co catalysts because of the higher metal content. The $6 \mathrm{wt} . \% \mathrm{Co} / \mathrm{Nb}_{2} \mathrm{O}_{5}-\mathrm{MC}$ catalyst (pink circles) shows a slightly lower WTY than the $6 \mathrm{wt} . \% \mathrm{Co} / \mathrm{Nb}_{2} \mathrm{O}_{5}$ (pretreated at $600{ }^{\circ} \mathrm{C}$, brown squares) at the initial hours of the experiment, however after 70 hours on stream its steady deactivation lead to the same activity as the $\mathrm{Nb}_{2} \mathrm{O}_{5}-\mathrm{MC}$ supported catalyst. Figure $3.9 \mathrm{~b}$ shows the CTY through time on stream, the three catalysts reach virtually the same value after 100 hours on stream. The catalyst supported on $\mathrm{Nb}_{2} \mathrm{O}_{5}$ treated at $600{ }^{\circ} \mathrm{C}$ shows a more pronounced deactivation throughout time compared with the $\mathrm{Nb}_{2} \mathrm{O}_{5}-\mathrm{MC}$ supported catalysts. One of the main causes of deactivation for cobalt Fischer-Tropsch catalysts is particle sintering. It is possible to think that the porous structure of the $\mathrm{Nb}_{2} \mathrm{O}_{5}-\mathrm{MC}$ support has retarded the cobalt particles from sintering, leading to more stable catalysts during long time on stream. In contrast, the flat surface of $\mathrm{Nb}_{2} \mathrm{O}_{5}$ treated at $600{ }^{\circ} \mathrm{C}$ allows particle growth and decrease in catalytic activity with time. The three catalysts showed a similar $\mathrm{C}_{5+}$ selectivity of $\sim 80 \%$ during the catalytic experiments (Appendix B: Table B1). 


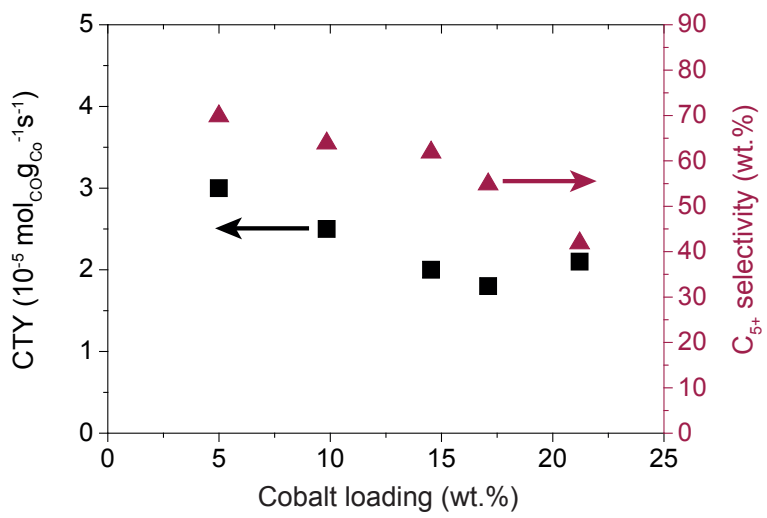

Figure 3.8 Cobalt-weight normalized activity (CTY) and $\mathrm{C}_{5+}$ selectivity for the Fischer-Tropsch reaction (1 bar, $220^{\circ} \mathrm{C}$ and $\mathrm{H}_{2} / \mathrm{CO}=2$ ). Cobalt was deposited by multiple impregnations (loadings $\geq 10 \mathrm{wt} . \%$ ) on crystalline niobia pretreated at $600{ }^{\circ} \mathrm{C}$.

a

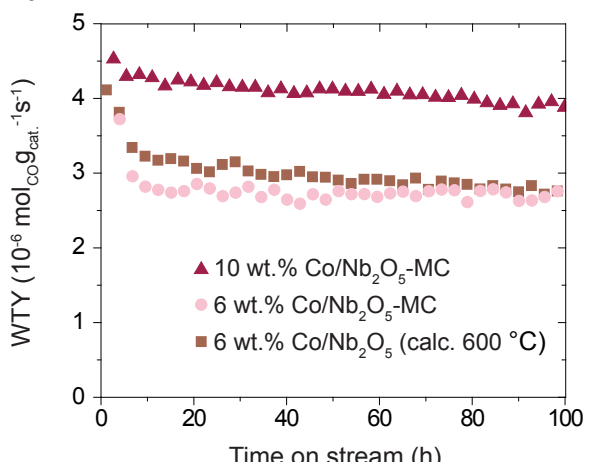

b

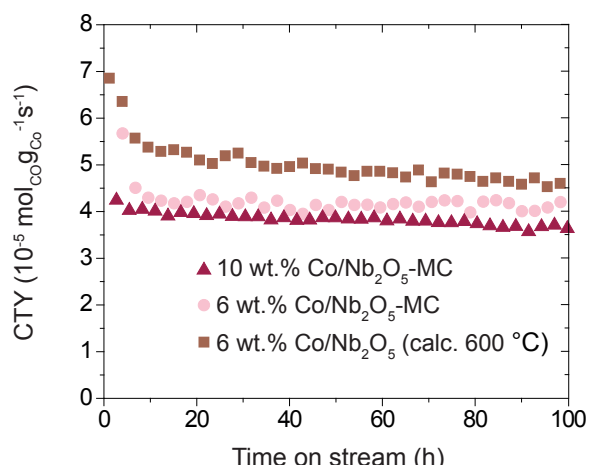

Figure 3.9 Catalytic activity up to 100 hours on stream for Co supported on crystalline niobia $\left(20\right.$ bar, $220{ }^{\circ} \mathrm{C}$ and $\mathrm{H}_{2} / \mathrm{CO}=2$ ). $\mathbf{a}$, Activity normalized per catalyst weight (Weight Time Yield, WTY) and $\mathbf{b}$, activity per unit weight of cobalt (Cobalt Time Yield, CTY).

\subsection{Conclusions}

The pore structure of amorphous niobium oxide hydrate was determined to be intricate with 2-5 nm mesopores giving rise to high specific surface and pore volume. Collapse of this pore structure during thermal treatment led to a drastic decrease in specific surface area and specific mesopore volume. For the synthesis of active cobalt Fischer-Tropsch catalysts, niobia crystallization at temperatures above $400{ }^{\circ} \mathrm{C}$ prior to cobalt deposition was found necessary to allow formation of reducible cobalt oxide species. Consequently, no activity was observed for the Fischer-Tropsch synthesis using amorphous niobia as support. Contrastingly, cobalt supported on crystalline niobia prepared by impregnation and reduced at $350{ }^{\circ} \mathrm{C}$ prior reaction conditions showed remarkably high activity per unit weight of cobalt and $\mathrm{C}_{5+}$ selectivity, previously only observed for promoted Co catalysts. Higher reduction temperature $\left(500{ }^{\circ} \mathrm{C}\right)$ significantly decreased the catalyst activity, probably due to coverage of the cobalt surface sites due to SMSI effects. The maximum cobalt loading achievable 
in a single impregnation was 6 wt. \% by using crystalline niobia as support. A decrease in activity per unit weight of cobalt was observed by increasing the cobalt loading using multiple impregnations, due to formation of larger cobalt particles and decreased interaction of cobalt with the support. Additionally, this decreased cobalt-support interaction suppressed the beneficial effect of niobia on $\mathrm{C}_{5+}$ selectivity. A facile carbon deposition method was used to restrict the collapse of the niobium oxide hydrate porous structure during crystallization. The carbon on the surface acted as structural template at the high temperatures needed to obtain crystalline niobia. The resulting crystalline niobia displayed an important fraction of the mesopores from the niobium oxide hydrate. The porous niobia was used as support to prepare cobalt catalysts and further tested in industrially relevant conditions for the Fischer-Tropsch synthesis. These catalysts proved to be highly active and selective. The porous structure allowed higher cobalt loadings leading to an increased weight-normalized catalytic activity. Furthermore, this porosity prevented the cobalt particles from sintering, resulting in very stable catalysts. STEM-EDX mapping characterization made possible to determine cobalt particle size and distribution in the catalysts, this technique demonstrated to be a powerful tool to study systems where phase distinction between its components is difficult due to similar electron density.

\section{Acknowledgments}

Companhia Brasileira de Metalurgia e Mineração - CBMM is thanked for financial support. Dr. Robson Monteiro and Mr. Rogério Ribas (CBMM) are acknowledged for useful discussions and supplying niobia. Mr. Wouter Lamme (STEM-EDX), Mr. Tom van Deelen (High pressure catalytic testing), Dr. Peter Munnik (TEM), Mrs. Marjan Versluijs-Helder (XRD), Dr. Carlo Angelici (TPR), Dr. Thomas Eschemann (TPR), Dr. Korneel Cats (TPR) and Mr. Gang Wang (TPR) are acknowledged for assistance and execution of indicated analyses. KPdeJ acknowledges the European Research Council, EU FP7 ERC Advanced Grant no. 338846 . 


\section{References}

1. Khodakov, A. Y., Chu, W. \& Fongarland, P. Advances in the Development of Novel Cobalt Fischer-Tropsch Catalysts for Synthesis of Long-Chain Hydrocarbons and Clean Fuels. Chem. Rev. 107, 1692-1744 (2007).

2. Soares, R. R., Frydman, A. \& Schmal, M. Effect of preparation method on $5 \% \mathrm{Co} / \mathrm{Nb}_{2} \mathrm{O}_{5}$ in Fischer-Tropsch Syntesis (FTS). Catal. Today 16, 361-370 (1993).

3. Silva, R. R. C. M., Schmal, M., Frety, R. \& Dalmon, J. A. Effect of the support on the fischer-tropsch synthesis with $\mathrm{Co} / \mathrm{Nb}_{2} \mathrm{O}_{5}$ catalysts. J. Chem. Soc. Faraday Trans. 89, 3975-3980 (1993).

4. Frydman, A., Soares, R. R. \& Schmal, M. High Selectivity of Diesel Fraction in Fischer-Tropsch Synthesis with $\mathrm{Co} / \mathrm{Nb}_{2} \mathrm{O}_{5}$. New Frontiers in Catalysis - Proceedings of the 10th International Congress on Catalysis $\mathbf{7 5}$, 2797-2800 (1993).

5. den Otter, J.H. \& De Jong, K. P. Highly selective and active niobia-supported cobalt catalysts for fischer-tropsch synthesis. Top. Catal. 57, 445-450 (2014).

6. den Otter, J. H., Nijveld, S. R. \& de Jong, K. P. Synergistic Promotion of $\mathrm{Co} / \mathrm{SiO}_{2}$ Fischer-Tropsch Catalysts by Niobia and Platinum. ACS Catal. 6, 1616-1623 (2016).

7. den Otter, J. H., Yoshida, H., Ledesma, C., Chen, D. \& De Jong, K. P. On the superior activity and selectivity of $\mathrm{PtCo} / \mathrm{Nb}_{2} \mathrm{O}_{5}$ Fischer Tropsch catalysts. J. Catal. 340, 270-275 (2016).

8. den Otter, J. H. Niobia-supported Cobalt Catalysts for Fischer-Tropsch Synthesis. (Utrecht University, 2016).

9. Nowak, I. \& Ziolek, M. Niobium Compounds: Preparation, Characterization, and Application in Heterogeneous Catalysis. Chem. Rev. 99, 3603-3624 (1999).

10. Chen, X. et al. Enhanced activity of mesoporous $\mathrm{Nb}_{2} \mathrm{O}_{5}$ for photocatalytic hydrogen production. Appl. Surf. Sci. 253, 8500-8506 (2007).

11. Kim, S., Jeong, I., Hwang, J., Ko, M. J. \& Lee, J. Simple synthesis of multiple length-scale structured $\mathrm{Nb}_{2} \mathrm{O}_{5}$ with functional macrodomain-integrated mesoporous frameworks. Chem. Commun. 53, 4100-4103 (2017).

12. Lee, B., Lu, D., Kondo, J. N. \& Domen, K. Three-dimensionally ordered mesoporous niobium oxide. J. Am. Chem. Soc. 124, 11256-11257 (2002).

13. Leite, E. R., Vila, C., Bettini, J. \& Longo, E. Synthesis of niobia nanocrystals with controlled morphology.J.Phys. Chem. B 110, 18088-18090 (2006).

14. Murayama, T., Chen, J., Hirata, J., Matsumoto, K. \& Ueda, W. Hydrothermal synthesis of octahedra-based layered niobium oxide and its catalytic activity as a solid acid. Catal. Sci. Technol. 4, 4250-4257 (2014).

15. Chai, S.-H., Wang, H.-P., Liang, Y. \& Xu, B.-Q. Sustainable production of acrolein: Gas-phase dehydration of glycerol over $\mathrm{Nb}_{2} \mathrm{O}_{5}$ catalyst. J. Catal. 250, 342-349 (2007).

16. Frevel, L. K. \& Rinn, H. W. Powder diffraction standards for niobium pentoxide and tantalum pentoxide. Anal. Chem. 27, 1329-1330 (1955).

17. Schäfer, H., Gruehn, R. \& Schulte, F. The modifications of niobium pentoxide. Angew. Chemie Int. Ed. 5, 40-52 (1966).

18. B. Noronha, F., A. Perez, C., Schmal, M. \& Fréty, R. Determination of cobalt species in niobia supported catalysts. Phys. Chem. Chem. Phys. 1, 2861-2867 (1999).

19. Sexton, B. A., Hughes, A. E. \& Turney, T. W. An XPS and TPR study of the reduction of promoted cobalt-kieselguhr Fischer-Tropsch catalysts. J. Catal. 97, 390-406 (1986).

20. Jacobs, G. et al. Fischer-Tropsch synthesis: Temperature programmed EXAFS/XANES investigation of the influence of support type, cobalt loading, and noble metal promoter addition to the reduction behavior of cobalt oxide particles. Appl. Catal. A Gen. 333, 177-191 (2007).

21. Den Breejen, J. P. et al. A highly active and selective manganese oxide promoted cobalt-on-silica fischer-tropsch catalyst. Top. Catal. 54, 768-777 (2011). 



\section{Activity Enhancement of Cobalt Catalysts by Tuning Metal-Support Interactions}

Interactions between metal nanoparticles and support materials can strongly influence the performance of catalysts. In particular, reducible oxidic supports can form suboxides that can decorate metal nanoparticles and enhance catalytic performance or block active sites. Therefore, tuning this metal-support interaction is essential for catalyst design. Here, we investigate reduction-oxidation-reduction (ROR) treatments as a method to affect metal-support interactions and related catalytic performance. Controlled oxidation of pre-reduced cobalt on reducible $\left(\mathrm{TiO}_{2}\right.$ and $\left.\mathrm{Nb}_{2} \mathrm{O}_{5}\right)$ and irreducible $\left(\alpha-\mathrm{Al}_{2} \mathrm{O}_{3}\right)$ supports leads to the formation of hollow cobalt oxide particles. The second reduction results in a twofold increase in cobalt surface area only on reducible oxides and proportionally enhances the cobalt-based catalytic activity during Fischer-Tropsch synthesis at industrially relevant conditions. Such activities are usually only obtained by noble metal promotion of cobalt catalysts. ROR proves an effective approach to tune the interaction between metallic nanoparticles and reducible oxidic supports, leading to improved catalytic performance.

Hernández Mejía, C.\#, van Deelen, T. W.\# \& de Jong, K. P. Activity enhancement of cobalt catalysts by tuning metal-support interactions. Nat. Commun. 9, 4459 (2018).

\# Both authors contributed equally to this manuscript. 


\subsection{Introduction}

Metal particles catalyze major chemical processes, including the synthesis of bulk chemicals and transportation fuels ${ }^{1-4}$. The catalytic reactions that are involved occur mainly at the metal surface. Therefore, the surface-to-volume ratio of these particles is typically maximized through nanosizing, leading to an adequate exposure of the active sites and efficient utilization of the metal ${ }^{5,6}$. Supports play a critical role in stabilizing the reactive nanoparticles but also in generating new interphase phenomena, such as electron transfer or shape rearrangement ${ }^{7-9}$. These phenomena can have ambivalent consequences for the catalytic performance such as promoting activity and selectivity or blocking active sites, which decreases the catalyst efficiency.

A renowned example of support effects occurs when reducible metal oxide supports $\left(\mathrm{TiO}_{2}, \mathrm{Nb}_{2} \mathrm{O}_{5}, \mathrm{CeO}_{2}\right.$, etc.) are partially reduced by hydrogen spillover from the metal nanoparticle $^{10}$, i.e. the so-called strong metal-support interaction (SMSI) ${ }^{11,12}$. As a result, suboxide species are generated from the support and these may migrate onto the metal nanoparticles surface $^{13-16}$. In the case of cobalt catalysts for the Fischer-Tropsch (FT) synthesis, i.e. the conversion of synthesis gas $\left(\mathrm{H}_{2} / \mathrm{CO}\right)$ into ultra clean fuels and chemicals, the effect of SMSI is twofold. On one hand, the cobalt catalysts benefit from the mildly Lewis acidic character of the suboxide species, as it increases the intrinsic activity (turnover frequency, TOF) and selectivity towards $\mathrm{C}_{5+}$ products $^{17,18}$. The increased TOF is believed to originate from the interface between the metal and suboxide where the CO-dissociation rate is enhanced ${ }^{19-21}$. On the other hand, the catalytic activity can be lowered by a dense overlayer of suboxide species that block the access to the active sites ${ }^{14}$. The interplay between promotion of the catalytic performance and blockage of active sites is not clear and control over the metal-support interactions may thus provide an opportunity to increase the number of accessible, promoted active sites.

The SMSI state can be reversed by oxidative treatments. However, this reversibility has been mainly studied for noble metals, while reports of base metals are scarce ${ }^{12,22-24}$. Soled et al. ${ }^{25}$ studied the impact of SMSI on $\mathrm{H}_{2}$-chemisorption for cobalt nanoparticles supported on titania. The $\mathrm{H}_{2}$-uptake was initially suppressed because of site blockage but increased significantly after a reduction-oxidation-reduction (ROR) treatment. This brought $\mathrm{H}_{2}$-chemisorption and TEM and XRD results into closer agreement, but the effect of ROR on the structure of the cobalt particles as well as its implications for catalysis remained unclear. Besides reversal of the SMSI state, ROR has been applied to regenerate deactivated catalysts through re-dispersion of the active metal ${ }^{26-29}$. The work on catalyst regeneration focused, however, on cobalt catalysts supported on irreducible oxides, such as $\mathrm{Al}_{2} \mathrm{O}_{3}$ and $\mathrm{SiO}_{2}$, in which SMSI effects do not play a role.

In this work, we investigate the possibility to tune the metal-support interactions of cobalt supported on reducible metal oxides via reduction-oxidation-reduction treatments with the aim to enhance the catalytic activity in the Fischer-Tropsch synthesis. To this end, $\mathrm{Co} / \mathrm{TiO}_{2}$ and $\mathrm{Co} / \mathrm{Nb}_{2} \mathrm{O}_{5}$ are synthesized and subjected to ROR treatments. Co on irreducible $\alpha-\mathrm{Al}_{2} \mathrm{O}_{3}$ is prepared for comparison. After the first reduction, oxidation above $100{ }^{\circ} \mathrm{C}$ 
leads to the formation of hollow cobalt oxide particles. Upon re-reduction, the $\mathrm{H}_{2}$-uptake doubles for the reducible metal oxides due to optimization of the SMSI state and not by cobalt re-dispersion, while the $\mathrm{H}_{2}$-uptake decreases for $\alpha-\mathrm{Al}_{2} \mathrm{O}_{3}$. The modified metal-support interaction on reducible supports drastically enhances the catalytic activity under industrially relevant FT conditions, effectively doubling the number of available active sites without changing their TOF. Modulation of the metal-support interaction via ROR is thus a promising strategy to boost the catalytic performance and to greatly improve the efficiency of metal catalysts supported on reducible oxides.

\subsection{Experimental}

Synthesis. The samples were synthesized by incipient wetness impregnation using aqueous cobalt nitrate solutions. The precursor solutions were prepared by dissolving appropriate amounts of cobalt nitrate hexahydrate (99+\%, Acros Organics) in Milli-Q water to obtain 6 wt.\% cobalt loading on each catalyst. The supports, $\mathrm{TiO}_{2}$ (P25, Evonik, $\mathrm{SA}_{\mathrm{BET}}$ : $50 \mathrm{~m}^{2} \cdot \mathrm{g}^{-1}$, PV: $0.30 \mathrm{~cm}^{3} \cdot \mathrm{g}^{-1}$ ), $\mathrm{Nb}_{2} \mathrm{O}_{5}$ (pseudo-hexagonal TT-phase, CBMM, SA $\mathrm{BET} \cdot 9 \mathrm{~m}^{2} \cdot \mathrm{g}^{-1}$, PV: $\left.0.06 \mathrm{~cm}^{3} \cdot \mathrm{g}^{-1}\right)$ and $\alpha-\mathrm{Al}_{2} \mathrm{O}_{3}\left(\mathrm{BASF}, \mathrm{SA}_{\mathrm{BET}}: 7 \mathrm{~m}^{2} \cdot \mathrm{g}^{-1}, \mathrm{PV}: 0.02 \mathrm{~cm}^{3} \cdot \mathrm{g}^{-1}\right)$, were sieved to a grain size of 75-150 $\mu \mathrm{m} . \mathrm{Nb}_{2} \mathrm{O}_{5}$ was obtained from amorphous niobium oxide hydrate (HY-340, $\mathrm{AD} / 4465, \mathrm{CBMM}$ ) by calcination in a muffle oven at $600{ }^{\circ} \mathrm{C}$ for $4 \mathrm{~h}$.

For a typical impregnation, $2 \mathrm{~g}$ of support was pre-dried at $80{ }^{\circ} \mathrm{C}$ for $1 \mathrm{~h}$ under vacuum. Just before the impregnation, the vacuum was released and a pore filling amount of precursor solution was added dropwise to the support under magnetic and manual stirring. In the case of $\mathrm{Co} / \mathrm{TiO}_{2}, 2 \mathrm{~g}$ of sample was dried and heat treated in fluidized bed mode in a U-shaped glass reactor following a previously reported procedure ${ }^{30}$. The sample was first dried at $80{ }^{\circ} \mathrm{C}$ for $2 \mathrm{~h}$ and heat treated directly afterwards at $250{ }^{\circ} \mathrm{C}$ for $2 \mathrm{~h}$. Both steps were performed in $1 \mathrm{~L} \cdot \mathrm{min}^{-1} \mathrm{~N}_{2}$ upward flow with a heating ramp of $2{ }^{\circ} \mathrm{C} \cdot \mathrm{min}^{-1} \cdot \mathrm{Co} / \mathrm{Nb}_{2} \mathrm{O}_{5}$ and $\mathrm{Co} / \alpha-\mathrm{Al}_{2} \mathrm{O}_{3}$ catalysts were dried for $12 \mathrm{~h}$ at $60{ }^{\circ} \mathrm{C}$ overnight in stagnant air and subsequently calcined in a fixed bed reactor under $\mathrm{N}_{2}$ flow $\left(1 \mathrm{~L} \cdot \mathrm{min}^{-1}\right)$ at $350{ }^{\circ} \mathrm{C}$ for $2 \mathrm{~h}$ with a heating ramp of $3{ }^{\circ} \mathrm{C} \cdot \mathrm{min}^{-1}$. Multiple batches of $2 \mathrm{~g}$ were mixed to obtain a substantial amount of sample. The obtained samples were pressed and sieved to a grain size of 75-150 $\mu \mathrm{m}$.

Ex situ reduction-oxidation ( $\mathrm{RO})$ treatments were performed in U-shaped glass reactors. To this end, batches of $500 \mathrm{mg}$ were first reduced at $350{ }^{\circ} \mathrm{C}$ for $2 \mathrm{~h}\left(2{ }^{\circ} \mathrm{C} \cdot \mathrm{min}^{-1}\right)$ in $120 \mathrm{~mL} \cdot \mathrm{min}^{-1}$ of $25 \mathrm{vol} . \% \mathrm{H}_{2}$ in $\mathrm{N}_{2}$ and subsequently cooled to $100{ }^{\circ} \mathrm{C}$. At this point, the reactor was flushed with $\mathrm{N}_{2}$ and cooled down further to $30{ }^{\circ} \mathrm{C}$. The oxidation step followed directly after the reduction and was performed in $95 \mathrm{~mL} \cdot \mathrm{min}^{-1}$ of $5 \mathrm{vol} . \% \mathrm{O}_{2}$ in $\mathrm{N}_{2}$ at various temperatures up to $400{ }^{\circ} \mathrm{C}$ for $2 \mathrm{~h}$ with a $2{ }^{\circ} \mathrm{C} \cdot \mathrm{min}^{-1}$ heating ramp.

Characterization. Scanning transmission electron microscopy combined with high-angle annular dark-field (STEM-HAADF) and energy-dispersive X-ray spectroscopy (EDX) analyses were performed on an FEI Talos F200X. This microscope was equipped with a high-brightness field emission gun (X-FEG) and a Super-X G2 EDX detector and operated at $200 \mathrm{kV}$. The EM samples were prepared by suspending the samples in 2-propanol $(>99.9 \%$, Sig- 
ma-Aldrich) using sonication and dropcasting the suspension on a carbon-coated $\mathrm{Cu}$ grid (200 mesh). The cobalt particle size was determined using the iTEM software and at least 200 particles were analyzed. The reduced and passivated samples were corrected for a $3 \mathrm{~nm}$ $\mathrm{CoO}$ layer and the particle surface averaged diameters $(\mathrm{D}[3,2])$ were calculated.

H2-chemisorption was measured on a Micromeritics ASAP 2020C using 200 mg of sample. The catalysts were reduced in pure $\mathrm{H}_{2}$ prior to the measurement. The pristine samples were reduced for $2 \mathrm{~h}\left(1{ }^{\circ} \mathrm{C} \cdot \mathrm{min}^{-1}\right)$ at $350{ }^{\circ} \mathrm{C}$, while the RO-samples were reduced at $220{ }^{\circ} \mathrm{C}$. After reduction, the samples were evacuated, cooled to $150{ }^{\circ} \mathrm{C}$ and analyzed at that temperature. The metallic surface area and average particle diameter were calculated assuming a cobalt cross-sectional area of $0.0662 \mathrm{~nm}^{2}$, an $\mathrm{H} /$ Co stoichiometry of 1 and spherical cobalt particles ${ }^{31}$.

Inductively coupled plasma-optical emission spectroscopy (ICP-OES) was performed on a SPECTRO ARCOS. The samples were prepared by extraction of cobalt using aqua regia.

Temperature-programmed reduction (TPR) profiles were measured using a Micromeritics Autochem 2920, equipped with a TCD detector. Typically, $100 \mathrm{mg}$ sample was reduced up to $1000{ }^{\circ} \mathrm{C}$ with $5{ }^{\circ} \mathrm{C} \cdot \mathrm{min}^{-1}$ in a flow of 5 vol. $\% \mathrm{H}_{2}$ in Ar. To determine the degree of reduction, the samples were first reduced in the TPR setup in a flow of pure $\mathrm{H}_{2}$ for $2 \mathrm{~h}$ at $350{ }^{\circ} \mathrm{C}$ or $220^{\circ} \mathrm{C}$ depending of the stage in the ROR treatment and then, the TPR profile was recorded from 50 to $800{ }^{\circ} \mathrm{C}$ in a flow of 5 vol. $\% \mathrm{H}_{2}$ in Ar. The cobalt that had not been reduced was quantified from the areas of the peaks between 250 and $700{ }^{\circ} \mathrm{C}$.

Fischer-Tropsch synthesis. The catalytic performance was measured using an Avantium Flowrence 16 parallel reactor setup. Stainless steel reactors (ID $=2 \mathrm{~mm}$ ) were loaded with 75-100 $\mathrm{mg}$ of catalyst $(75-150 \mu \mathrm{m})$ and diluted with $100 \mathrm{mg} \mathrm{SiC}(212-425 \mu \mathrm{m})$. Prior to reaction, the catalysts were reduced in situ for $8 \mathrm{~h}\left(1^{\circ} \mathrm{C} \cdot \mathrm{min}^{-1}\right)$ in $25 \mathrm{vol} . \% \mathrm{H}_{2}$ in $\mathrm{He}$ at $1 \mathrm{bar}$. The pristine samples were reduced at $350{ }^{\circ} \mathrm{C}$, while the RO-samples were reduced at $220{ }^{\circ} \mathrm{C}$. After reduction, the temperature was lowered to $180{ }^{\circ} \mathrm{C}\left(3{ }^{\circ} \mathrm{C} \cdot \mathrm{min}^{-1}\right)$ and the pressure was increased to 20 bar under $\mathrm{H}_{2}$ flow. Finally, synthesis gas with $\mathrm{H}_{2} / \mathrm{CO}=2 \mathrm{~V} / \mathrm{V}$ (5 vol.\% $\mathrm{He}$ as internal standard) was introduced and the temperature was raised to $220^{\circ} \mathrm{C}$ with $1{ }^{\circ} \mathrm{C} \cdot \mathrm{min}^{-1}$. The product stream was analyzed online with an Agilent 7890A GC. The hydrocarbon products were analyzed on an Agilent J\&W PoraBOND Q column connected to an FID. The permanent gasses were separated on a ShinCarbon ST column and quantified using a TCD.

The activity of the catalysts was expressed as CO conversion, cobalt time yield (CTY) and turnover frequency (TOF). The CO conversion was defined according to equation 1 , CTY according to equation 2 and TOF according to equation 3:

$$
\begin{array}{ll}
X_{C O}=\left(F_{C O, \text { in }}-F_{C O, \text { out }}\right) \cdot F_{C O, \text { in }}{ }^{-1} & (\text { Equation } 1) \\
\mathrm{CTY}=F_{C O, \text { in }} \cdot X_{C O} \cdot V_{m}^{-1} \cdot m_{C o}{ }^{-1} & (\text { Equation } 2) \\
\mathrm{TOF}=\mathrm{CTY} \cdot N_{A} \cdot d_{C o} \cdot \mathrm{SA}_{\mathrm{Co}}{ }^{-1} & (\text { Equation } 3)
\end{array}
$$


In these equations, $X_{C O}$ is the $\mathrm{CO}$ conversion, $F_{C O, i n}$ is the flow of $\mathrm{CO}$ into the reactor and $F_{C O, o u t}$ is the flow of $\mathrm{CO}$ in the product stream. $V_{m}$ denotes the molar volume, $m_{C o}$ the mass of cobalt in the reactor, $N_{A}$ is the Avogadro constant, $d_{C o}$ the cross-sectional area of a cobalt atom $\left(0.0662 \mathrm{~nm}^{2}\right.$ according to ref. 31$)$ and $\mathrm{SA}_{\mathrm{Co}}$ is the cobalt specific surface area as obtained by $\mathrm{H}_{2}$-chemisorption.

The selectivity towards light hydrocarbon products with carbon number $n$ (with $1 \leq$ $n \leq 4)$ was calculated as in equation 4 and the selectivity towards the heavier fraction $(n \geq$ 5) as in equation 5

$$
\begin{array}{ll}
S_{C 1-C 4}=F_{C n} \cdot n \cdot\left(F_{C O, \text { in }} \cdot X_{C O}\right)^{-1} & (\text { Equation } 4) \\
S_{C 5+}=1-S_{C 1-C 4} & (\text { Equation 5) }
\end{array}
$$

In this case, $S_{C n}$ represents the selectivity towards hydrocarbon product of a specific carbon number and $F_{C n}$ is the flow of the corresponding hydrocarbon product.

\subsection{Results and discussion}

\subsubsection{Reduction}

Cobalt particles supported on reducible oxides $\mathrm{TiO}_{2}$ and $\mathrm{Nb}_{2} \mathrm{O}_{5}$, and on irreducible oxide $\alpha-\mathrm{Al}_{2} \mathrm{O}_{3}$ were prepared by incipient wetness impregnation followed by drying and thermal treatment. The nominal cobalt loading was $6 \mathrm{wt} . \%$ and experimentally determined loadings are given in Table $\mathrm{C} 1$ (Appendix $\mathrm{C}$ ). $\mathrm{H}_{2}$-chemisorption analysis was performed on the pristine samples, which were reduced at $350{ }^{\circ} \mathrm{C}$ prior to the measurement (referred to as R-samples). After $\mathrm{H}_{2}$-chemisorption, the samples were passivated by exposure to air at room temperature and subsequently analyzed using scanning transmission electron micros-

Table 4.1 The results of cobalt particle size analyses using STEM-EDX and $\mathrm{H}_{2}$-chemisorption for the pristine

\begin{tabular}{|c|c|c|c|}
\hline Sample & $\begin{array}{c}\text { Particle diameter } \mathrm{D}[3,2]^{\mathrm{a}} \\
\pm \text { standard deviation } \\
(\mathbf{n m})\end{array}$ & $\begin{array}{c}\text { Theoretical } \mathrm{H}_{2} \text {-uptake }{ }^{\mathrm{a}} \\
\left(\mu \mathrm{mol}_{\mathrm{H} 2} \cdot \mathrm{g}_{\mathrm{Co}}^{-1}\right)\end{array}$ & $\begin{array}{c}\text { Experimental } \mathrm{H}_{2} \text {-uptake }{ }^{\mathrm{b}} \\
\left(\mu \mathrm{mol}_{\mathrm{H} 2} \cdot \mathrm{g}_{\mathrm{Co}}{ }^{-1}\right)\end{array}$ \\
\hline \multicolumn{4}{|c|}{ R-samples } \\
\hline $\mathrm{R}^{-\mathrm{TiO}_{2}}$ & $11 \pm 3.4$ & 787 & 341 \\
\hline $\mathrm{R}-\mathrm{Nb}_{2} \mathrm{O}_{5}$ & $19 \pm 10$ & 437 & 265 \\
\hline $\mathrm{R}-\mathrm{Al}_{2} \mathrm{O}_{3}$ & $13 \pm 6.5$ & 666 & 631 \\
\hline \multicolumn{4}{|c|}{ RO200R-samples } \\
\hline $\mathrm{RO}_{200 \mathrm{R}-\mathrm{TiO}_{2}}$ & $10 \pm 3.8$ & 865 & 783 \\
\hline $\mathrm{RO} 200 \mathrm{R}-\mathrm{Nb}_{2} \mathrm{O}_{5}$ & $18 \pm 7.9$ & 470 & 657 \\
\hline $\mathrm{RO} 200 \mathrm{R}-\mathrm{Al}_{2} \mathrm{O}_{3}$ & $21 \pm 11$ & 412 & 499 \\
\hline
\end{tabular}
samples after reduction at $350{ }^{\circ} \mathrm{C}$ (R-samples) and the samples after reduction at $350{ }^{\circ} \mathrm{C}$, oxidation at $200{ }^{\circ} \mathrm{C}$ and reduction at $220{ }^{\circ} \mathrm{C}$ (RO200R-samples).

a. Derived from STEM-EDX

b. Derived from $\mathrm{H}_{2}$-chemisorption 


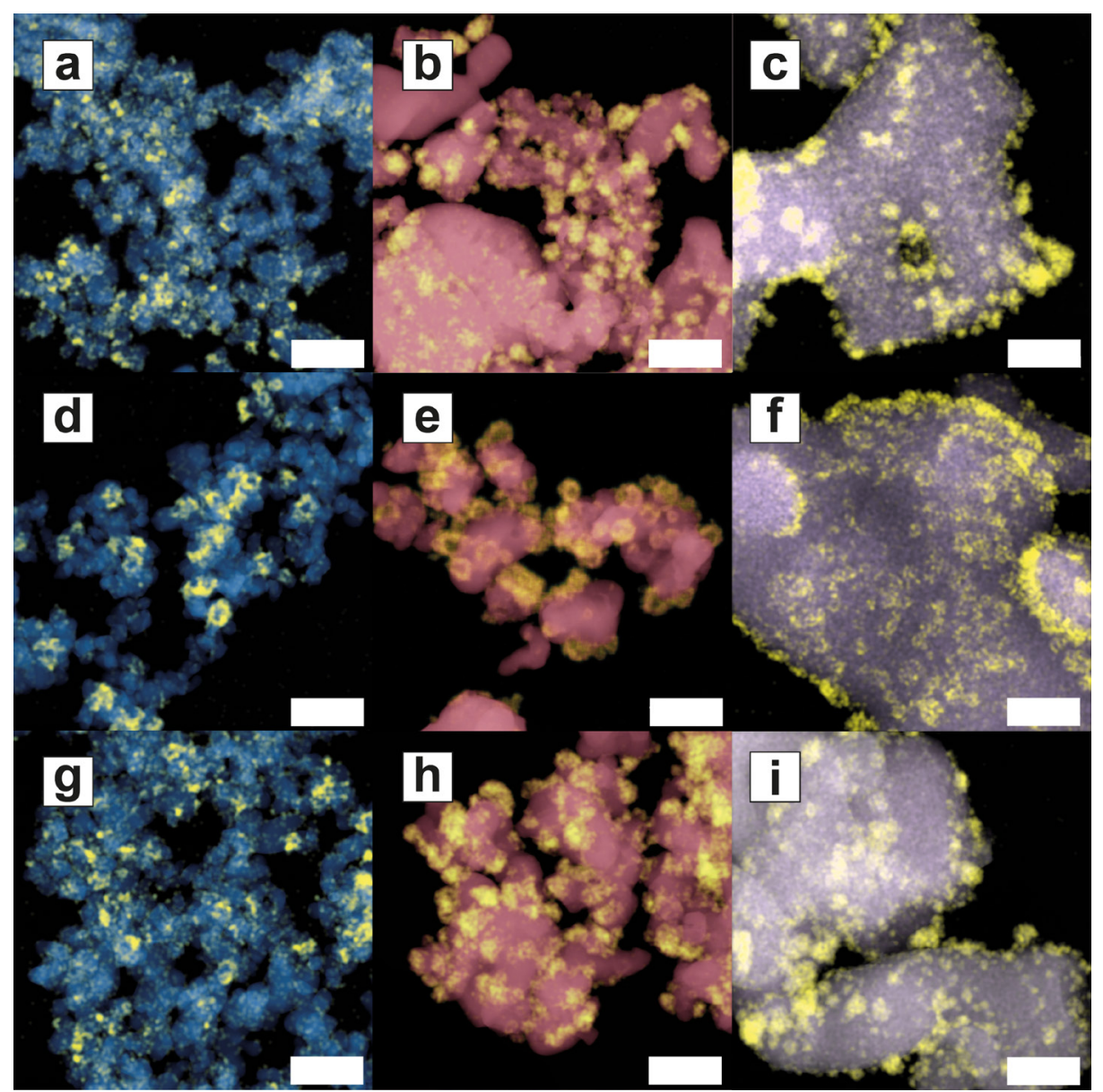

Figure 4.1 Electron microscopy images of the samples upon reduction-oxidation-reduction treatments. STEMEDX mapping of $\mathrm{Co} / \mathrm{TiO}_{2}, \mathrm{Co} / \mathrm{Nb}_{2} \mathrm{O}_{5}$ and $\mathrm{Co} / \alpha-\mathrm{Al}_{2} \mathrm{O}_{3}$ at various stages of the ROR treatment. Co is depicted in yellow, $\mathrm{Ti}$ in blue, $\mathrm{Nb}$ in red and $\mathrm{Al}$ in violet. a, b, c, Samples after reduction at $350^{\circ} \mathrm{C}$ and passivation (R-Samples); d, e, f, samples after reduction at $350{ }^{\circ} \mathrm{C}$ and oxidation at $200{ }^{\circ} \mathrm{C}$ (RO200-samples); $\mathbf{g}, \mathbf{h}, \mathbf{i}$, samples after reduction at $350{ }^{\circ} \mathrm{C}$, oxidation at $200{ }^{\circ} \mathrm{C}$ and reduction at $220^{\circ} \mathrm{C}$ (RO200R-samples) and passivation. The scale bar corresponds to $100 \mathrm{~nm}$. Additional electron microscopy results for these samples can be found in Appendix C: Figures 1-3.

copy-energy-dispersive X-ray spectroscopy (STEM-EDX, Figure 4.1a-c). The cobalt particles were rather uniformly distributed over $\mathrm{TiO}_{2}$ and $\mathrm{Nb}_{2} \mathrm{O}_{5}$ while the spatial distribution was more heterogeneous on $\alpha-\mathrm{Al}_{2} \mathrm{O}_{3}$.

$\mathrm{H}_{2}$-chemisorption and STEM-EDX results for the R-samples are given in Table 4.1. The theoretical $\mathrm{H}_{2}$-uptake was calculated for cobalt particles using the surface-average particle diameter derived from STEM-EDX images. This theoretical value was compared to the experimental uptake measured by $\mathrm{H}_{2}$-chemisorption. In the case of $\mathrm{R}^{-} \mathrm{TiO}_{2}$ and $\mathrm{R}^{-} \mathrm{Nb}_{2} \mathrm{O}_{5}$, a substantial discrepancy in $\mathrm{H}_{2}$-uptake was observed between both methodologies. This is explained by partial coverage of the metallic cobalt surface by suboxide species leading to suppressed uptake in the $\mathrm{H}_{2}$-chemisorption measurement. It is important to note that the total amount of suboxide species is probably low, because no overlayers could be detected 
with STEM-EDX nor with in situ TEM of $\mathrm{Co} / \mathrm{Nb}_{2} \mathrm{O}_{5}$ under reducing conditions in a previous study ${ }^{32}$. No large discrepancy between the theoretical and experimental $\mathrm{H}_{2}$-uptake of R- $\mathrm{Al}_{2} \mathrm{O}_{3}$ was observed, because suboxides were not formed.

\subsubsection{Reduction-oxidation}

After the first reduction treatment at $350{ }^{\circ} \mathrm{C}$, the R-samples were subjected to an oxidative treatment at temperatures varying between $30{ }^{\circ} \mathrm{C}$ and $400{ }^{\circ} \mathrm{C}$ (referred to as RO30to RO400-samples). The temperature-programmed reduction (TPR) profiles of pristine $\mathrm{Co}_{3} \mathrm{O}_{4} / \mathrm{Nb}_{2} \mathrm{O}_{5}$ and $\mathrm{RO} 30-\mathrm{Nb}_{2} \mathrm{O}_{5}$ to $\mathrm{RO} 400-\mathrm{Nb}_{2} \mathrm{O}_{5}$ are shown in Figure 4.2a. The pristine sample displayed two-step, consecutive reduction from $\mathrm{Co}_{3} \mathrm{O}_{4}$ to $\mathrm{CoO}\left(280-300{ }^{\circ} \mathrm{C}\right)$ and from $\mathrm{CoO}$ to $\mathrm{Co}\left(300-400{ }^{\circ} \mathrm{C}\right)$. Samples that had been reduced and oxidized at temperatures up to $100{ }^{\circ} \mathrm{C}$ showed only one sharp reduction peak at $230{ }^{\circ} \mathrm{C}$ corresponding to the reduction of $\mathrm{CoO}$. Therefore, the second reduction of these samples can be performed at substantially lower temperature than the first one. Based on the amount of consumed H2, we found that some metallic cobalt was still present on those samples, probably as a metallic core covered by a $\mathrm{CoO}$ layer. Further increasing the oxidation temperature to $150{ }^{\circ} \mathrm{C}$ led to broadening of the narrow peak $\left(\mathrm{RO} 150-\mathrm{Nb}_{2} \mathrm{O}_{5}\right.$ ) and eventually resulted in a two-step reduction profile, associated with the formation of $\mathrm{Co}_{3} \mathrm{O}_{4}$ during oxidation ( $\mathrm{RO} 200-\mathrm{Nb}_{2} \mathrm{O}_{5}$ ). Upon oxidation at $400{ }^{\circ} \mathrm{C}$, the reduction profile resembled that of the pristine $\mathrm{Co}_{3} \mathrm{O}_{4} / \mathrm{Nb}_{2} \mathrm{O}_{5}$ sample.

The RO-samples were characterized by STEM-EDX mapping. Samples oxidized at

a

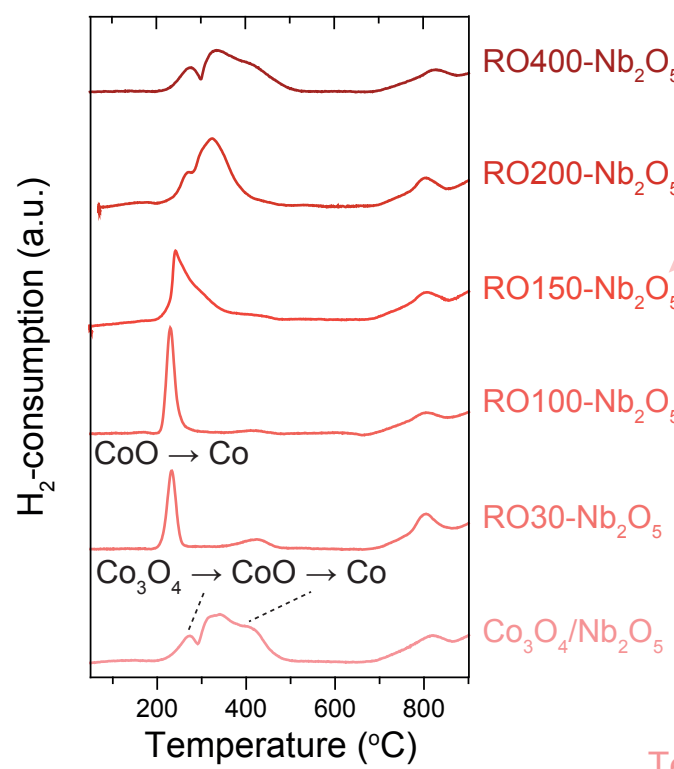

b

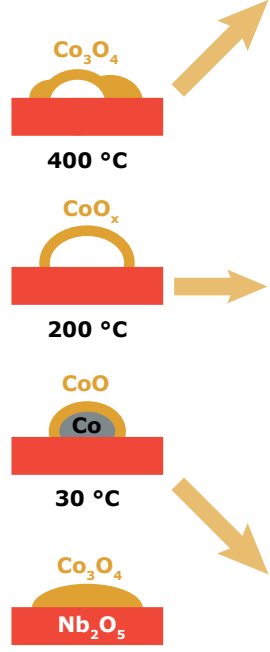

Oxidation Temperature
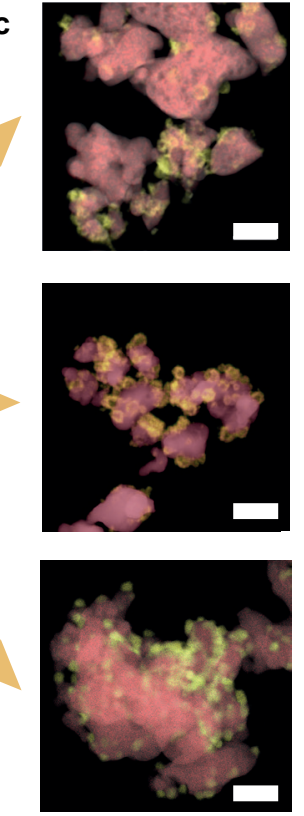

Figure 4.2 The effect of the oxidation temperature on the structure of $\mathrm{Co} / \mathrm{Nb}_{2} \mathrm{O}_{5}$. $\mathbf{a}$, Temperature-programmed reduction profiles, $\mathbf{b}$, schematic illustration and $\mathbf{c}$, STEM-EDX images of $\mathrm{Co} / \mathrm{Nb}_{2} \mathrm{O}_{5}$ after reduction and oxidation at various temperatures $\left(30-400{ }^{\circ} \mathrm{C}\right)$. Co is depicted in yellow, $\mathrm{Nb}$ in red. The scale bar corresponds to $100 \mathrm{~nm}$. 
low temperatures appeared unchanged (Figure 4.2b,c). However, at oxidation temperatures of $200{ }^{\circ} \mathrm{C}$, hollow cobalt oxide particles were observed (Figure 4.1d-f). The formation of these hollow particles was ascribed to the Kirkendall effect ${ }^{33-35}$. During oxidation, an initial oxide layer forms around the metallic particle and at higher temperature, the smaller $\mathrm{Co}^{2+}$ or $\mathrm{Co}^{3+}$ cations diffuse outwards through the oxide layer faster than the larger $\mathrm{O}^{2-}$ anions diffuse inwards, forming shells of cobalt oxide leaving behind empty cores. At an oxidation temperature of $400{ }^{\circ} \mathrm{C}$, the hollow cobalt oxide particles got distorted and agglomerated.

\subsubsection{Reduction-oxidation-reduction}

The samples after an ROR cycle were characterized by $\mathrm{H}_{2}$-chemisorption (Figure 4.3a). The second reduction of the ROR treatment was performed at $220{ }^{\circ} \mathrm{C}$, whereas the R-samples had been reduced at $350{ }^{\circ} \mathrm{C}$. For the reducible oxides, the $\mathrm{H}_{2}$-uptake significantly increased at oxidation temperatures above $100{ }^{\circ} \mathrm{C}$. In the case of $\mathrm{TiO}_{2}$, it changed from $341 \mu \mathrm{mol}_{\mathrm{H} 2} \cdot \mathrm{g}_{\mathrm{Co}}{ }^{-1}$ for $\mathrm{R}-\mathrm{TiO}_{2}$ to $783 \mu \mathrm{mol}_{\mathrm{H} 2} \cdot \mathrm{g}_{\mathrm{Co}}{ }^{-1}$ for RO200R-TiO ${ }_{2}$. Similarly, for $\mathrm{Nb}_{2} \mathrm{O}_{5}$ it

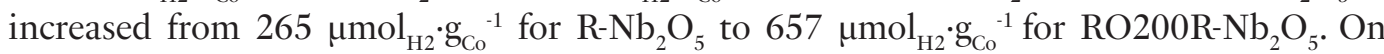
$\alpha-\mathrm{Al}_{2} \mathrm{O}_{3}$ however, a substantial decrease of $\mathrm{H}_{2}$-uptake was observed after ROR treatments. The degree of reduction (DOR) was determined by TPR directly after the last reduction for all R- and RO200R-samples and for RO400R- $\mathrm{Nb}_{2} \mathrm{O}_{5}$ (Appendix C: Figure C4 and Table C2). The DOR for the R-samples was $97-98 \%$ and decreased slightly to $84-95 \%$ after ROR. Because these changes were minor, the $\mathrm{H}_{2}$-chemisorption results were not corrected for the DOR.

The particle sizes of the RO200R-samples were investigated using STEM-EDX (Figure $4.1 \mathrm{~g}-\mathrm{i}$ ). The spatial distribution of the particles over the supports was not markedly different from that in the R-samples (Figure 4.1a-c). Furthermore, the average size of the cobalt particles was similar to that of the R-samples, despite the significantly different values obtained by $\mathrm{H}_{2}$-chemisorption (Figure $4.3 \mathrm{~b}$-d, Table 4.1 ). In fact, the theoretical $\mathrm{H}_{2}$-uptake now approached the values of the experimental $\mathrm{H}_{2}$-uptake.

On $\mathrm{TiO}_{2}$, the increase in $\mathrm{H}_{2}$-uptake with a similar average particle size implied that ROR did not induce substantial re-dispersion of cobalt. Rather, the ROR treatment resulted in a higher fraction of accessible metallic cobalt surface through a decrease of the surface coverage by suboxide species (Figure 4.3e). On $\mathrm{Nb}_{2} \mathrm{O}_{5}$, however, the situation is more complex, because the experimental $\mathrm{H}_{2}$-uptake after ROR was higher than the theoretical one. The additional $\mathrm{H}_{2}$-uptake could be rationalized in two ways. First, re-dispersion of few large cobalt particles could have formed small particles, which would be undetectable by STEMEDX. Second, hydrogen could have spilled over to $\mathrm{Nb}_{2} \mathrm{O}_{5}$, in line with the fact that $\mathrm{Nb}_{2} \mathrm{O}_{5}$ has been proven to facilitate hydrogen storage ${ }^{36,37}$. On $\alpha-\mathrm{Al}_{2} \mathrm{O}_{3}$, the same Kirkendall behavior occurred at oxidation temperatures above $100{ }^{\circ} \mathrm{C}$ (Figure $4.1 \mathrm{f}$ ), but here the $\mathrm{H}_{2}$-uptake decreased on all ROR-samples due to particle growth.

ROR has been reported to regenerate deactivated catalysts through re-dispersion of the active metal via the Kirkendall effect ${ }^{26-29}$. However, the work on catalyst regeneration focused on cobalt catalysts supported on irreducible oxides, such as $\mathrm{Al}_{2} \mathrm{O}_{3}$ and $\mathrm{SiO}_{2}$, in which SMSI effects do not play a role. Furthermore, we ascribe the absence of net re-dispersion 
a
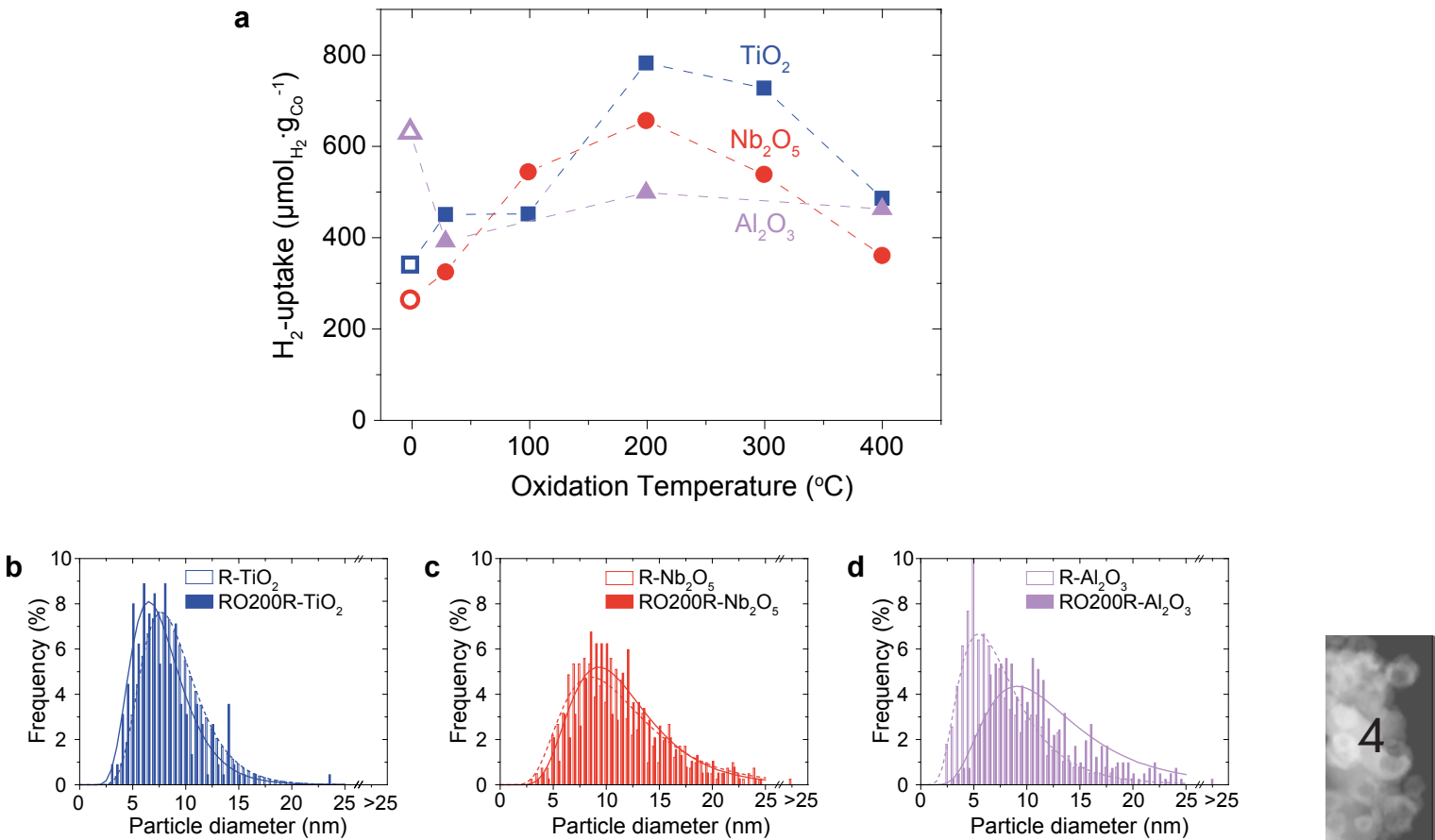

e
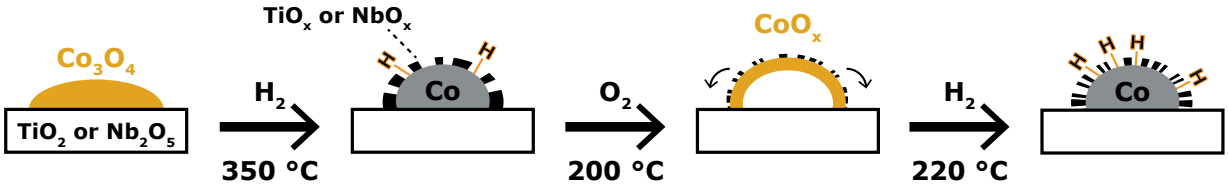

Figure 4.3 The effect of ROR treatments on the exposed cobalt surface area and particle size. a, Hydrogen uptake for $\mathrm{Co} / \mathrm{TiO}_{2}$ (blue squares), $\mathrm{Co} / \mathrm{Nb}_{2} \mathrm{O}_{5}$ (red circles) and $\mathrm{Co} / \alpha-\mathrm{Al}_{2} \mathrm{O}_{3}$ (violet triangles) after various reduction-oxidation-reduction treatments, as determined by $\mathrm{H}_{2}$-chemisorption. The results of the pristine samples after reduction at $350{ }^{\circ} \mathrm{C}$ (open symbols) are included at 0 on the x-axis. b,c,d, Particle size distributions of cobalt supported on $\mathrm{TiO}_{2}, \mathrm{Nb}_{2} \mathrm{O}_{5}$ and $\alpha-\mathrm{Al}_{2} \mathrm{O}_{3}$, respectively, after reduction at $350{ }^{\circ} \mathrm{C}$ (open bars) and after reduction at $350{ }^{\circ} \mathrm{C}$ followed by oxidation at $200{ }^{\circ} \mathrm{C}$ and reduction at $220^{\circ} \mathrm{C}$ (solid filled bars), as determined by STEM-EDX. e, Schematic illustration of the effect of the ROR treatment on cobalt supported on reducible oxides.

in our samples to different initial cobalt particle sizes. The particles in our $\mathrm{R}^{-\mathrm{TiO}_{2}}(11 \mathrm{~nm})$ and $\mathrm{R}_{-} \mathrm{Al}_{2} \mathrm{O}_{3}(13 \mathrm{~nm})$ were substantially smaller than those reported in literature $(22 \mathrm{~nm})^{29}$. According to Sadasivan et al. ${ }^{38}$, only cobalt particles above a certain critical size give rise to re-dispersion upon ROR treatments.

The trends observed with $\mathrm{H}_{2}$-chemisorption for the reducible oxides can be understood based on the previously discussed results. The Kirkendall effect was most likely key in tuning the SMSI during ROR, because at oxidation temperatures up to $100{ }^{\circ} \mathrm{C}$, where this effect was not observed, the increase in $\mathrm{H}_{2}$-uptake was minor. The $\mathrm{H}_{2}$-uptake only increased significantly when the Kirkendall effect took place. On the other side of the optimum, at an oxidation temperature of $400{ }^{\circ} \mathrm{C}$, the high temperature induced particle growth from 10 up to $15 \mathrm{~nm}$ for $\mathrm{RO} 400 \mathrm{R}-\mathrm{TiO}_{2}$, as determined using STEM-EDX (Appendix C: Figure C5). This 
reduced the metallic surface area and counteracted the positive effect of the ROR treatment on the SMSI.

Further indications for the optimization of SMSI effects through ROR were found when the second reduction was performed at a higher temperature (Figure 4.4). The $\mathrm{H}_{2}$-uptake decreased for the RO200R-TiO 2 and $\mathrm{RO} 200 \mathrm{R}-\mathrm{Nb}_{2} \mathrm{O}_{5}$ samples with increasing reduction temperature. At $350{ }^{\circ} \mathrm{C}$, the $\mathrm{H}_{2}$-uptake values returned to the values of the initial R-samples that were reduced once. Apparently, the mild temperature of the second reduction was essential to keep the concentration or mobility of the suboxide species low, while it was sufficiently high to reduce cobalt oxide to metallic cobalt. Additionally, the $\mathrm{H}_{2}$-uptakes of the R-samples at reduction temperatures of 220 and $350{ }^{\circ} \mathrm{C}$ were comparable. The substantial increase in $\mathrm{H}_{2}$-uptake for the RO200R-samples was thus not merely caused by reduction at lower temperature. In contrast, the $\mathrm{H}_{2}$-uptake of the $\mathrm{Co} / \alpha-\mathrm{Al}_{2} \mathrm{O}_{3}$ catalysts increased slightly at higher reduction temperatures.

a

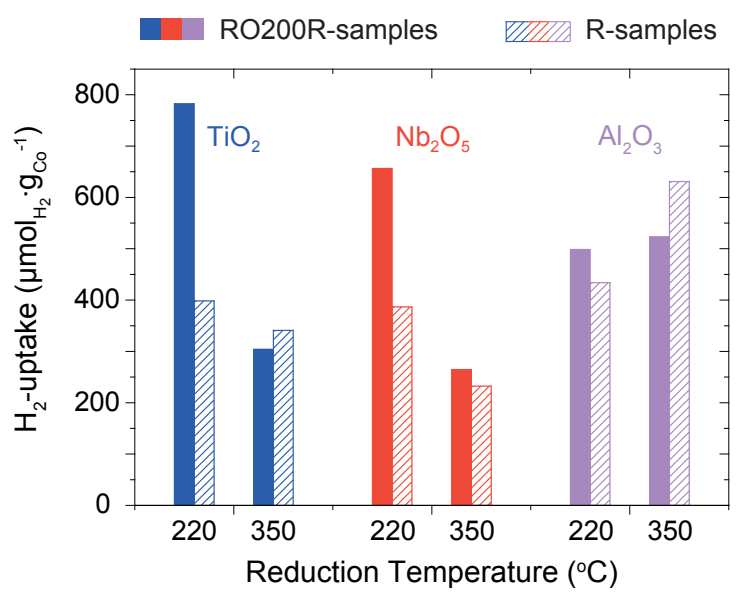

b

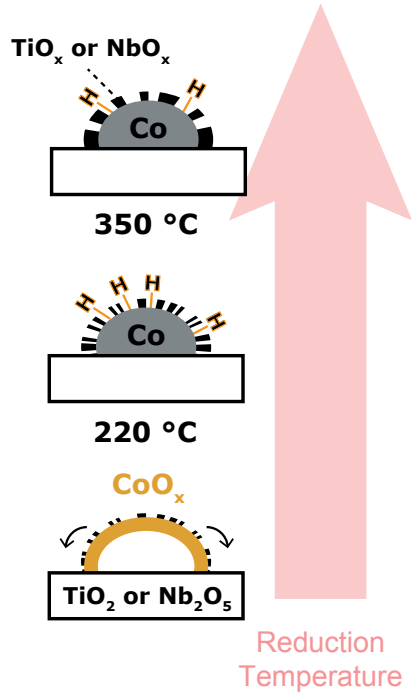

Figure 4.4 The influence of the temperature of the second reduction on the exposed cobalt surface area. a, Hydrogen uptake as a function of the second reduction temperature. Dashed bars correspond to the pristine samples after reduction at 220 or $350{ }^{\circ} \mathrm{C}$ and solid filled bars correspond to the samples after reduction at $350{ }^{\circ} \mathrm{C}$ followed by oxidation at $200^{\circ} \mathrm{C}$ and reduction at 220 or $350{ }^{\circ} \mathrm{C}$. b, Schematic illustration of the effect of the reduction temperature on catalysts supported on reducible oxides.

\subsubsection{Fischer-Tropsch synthesis}

The catalytic activity of $\mathrm{Co} / \mathrm{TiO}_{2}$ and $\mathrm{Co} / \mathrm{Nb}_{2} \mathrm{O}_{5}$ in FT after ROR followed the same trend as $\mathrm{H}_{2}$-chemisorption, i.e. increased activity with the optimum at $200{ }^{\circ} \mathrm{C}$ (Figure $4.5 \mathrm{a}$ ). Notably, the activity doubled on $\mathrm{TiO}_{2}$ and $\mathrm{Nb}_{2} \mathrm{O}_{5}$ as a result of the RO200R treatment and the enhancement was stable over at least $100 \mathrm{~h}$ time-on-stream (Appendix C: Figure 6). As expected, the activity of $\mathrm{Co} / \alpha-\mathrm{Al}_{2} \mathrm{O}_{3}$ was not enhanced, indicating that the positive effect of the ROR treatment was specific for catalysts supported on reducible oxides. The $\mathrm{C}_{5_{+}}{ }^{-}$selec- $^{-}$ tivity for all catalysts was $85-89 \%$ and did not change significantly as a result of the ROR 
a

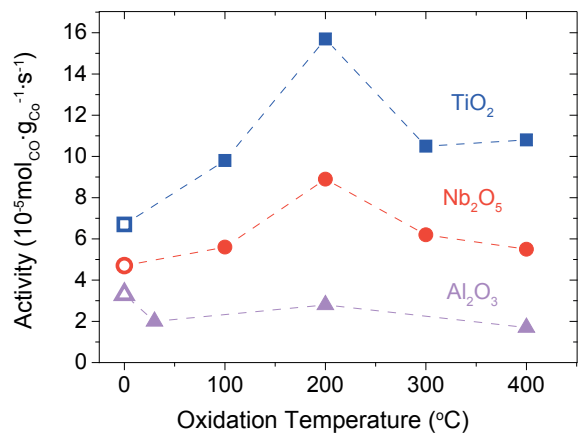

b

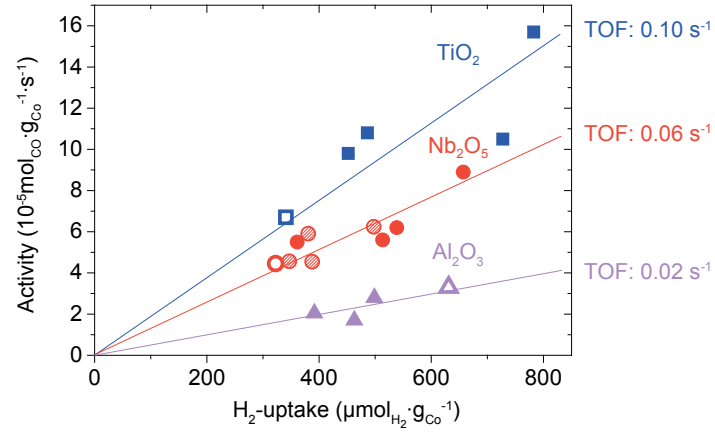

Figure 4.5 The effect of the ROR treatment on the catalytic activity in the Fischer-Tropsch synthesis. FT was performed at $20 \mathrm{bar}, 220{ }^{\circ} \mathrm{C}, \mathrm{H}_{2} / \mathrm{CO}=2 \mathrm{~V} / \mathrm{V}, \mathrm{GHSV}=1000-13000 \mathrm{~h}^{-1}$, time-on-stream $=90-100 \mathrm{~h}, \mathrm{CO}$ conv. $=15$ $34 \%\left(\mathrm{TiO}_{2}\right), 17-25 \%\left(\mathrm{Nb}_{2} \mathrm{O}_{5}\right), 8-12 \%\left(\mathrm{Al}_{2} \mathrm{O}_{3}\right)$. a, Cobalt-weight-based catalytic activity of $\mathrm{Co} / \mathrm{TiO}_{2}$ (blue squares), $\mathrm{Co} / \mathrm{Nb}_{2} \mathrm{O}_{5}$ (red circles) and $\mathrm{Co} / \mathrm{Al}_{2} \mathrm{O}_{3}$ (violet triangles) after various reduction-oxidation-reduction treatments. The activity of the pristine samples after reduction at $350{ }^{\circ} \mathrm{C}$ (R-samples, open symbols) is included at 0 on the $\mathrm{x}$-axis. $\mathbf{b}$, Cobalt-weight-based activity as a function of $\mathrm{H}_{2}$-uptake for the R-samples (open symbols) and the samples after reduction at $350{ }^{\circ} \mathrm{C}$ followed by oxidation between $30-400{ }^{\circ} \mathrm{C}$ and reduction at either $220{ }^{\circ} \mathrm{C}$ (filled symbols) or at 250 ${ }^{\circ} \mathrm{C}$ (dashed symbols); values for the turnover frequencies (TOF) have been calculated from the slopes of the lines.

treatments (Appendix C: Table C3).

The observed cobalt-weight-based activities of RO200R-TiO $2\left(16 \cdot 10^{-5} \mathrm{~mol}_{\mathrm{CO}} \cdot \mathrm{g}_{\mathrm{Co}}{ }^{-1} \cdot \mathrm{s}^{-1}\right)$ and RO200R- $\mathrm{Nb}_{2} \mathrm{O}_{5}\left(8.9 \cdot 10^{-5} \mathrm{~mol}_{\mathrm{CO}} \cdot \mathrm{g}_{\mathrm{Co}}{ }^{-1} \cdot \mathrm{s}^{-1}\right)$ are exceptionally high. Compared to literature $^{18,32,39-43}$, activities in this range are normally only achieved by promoting a cobalt-based catalyst with noble metals (Appendix C: Figure C7). Tuning of the metal-support interactions by ROR or other pretreatments might thus provide an attractive alternative to promotion with expensive and scarce noble metals.

The ROR treatments increased the catalytic activity of $\mathrm{Co} / \mathrm{TiO}_{2}$ and $\mathrm{Co} / \mathrm{Nb}_{2} \mathrm{O}_{5}$ with respect to the R-samples. The increase in activity was proportional to the H2-uptake (Figure 4.5b), indicating that the surface-specific activity or turnover frequency (TOF, based on activity and $\mathrm{H}_{2}$-chemisorption data) was constant and more surface sites with identical characteristics became available. The opposite was observed with irreducible $\alpha-\mathrm{Al}_{2} \mathrm{O}_{3}$, where the activity decreased after ROR and less surface sites were available albeit at constant TOF. Clearly, the TOF was support-dependent and increased in the order $\alpha-\mathrm{Al}_{2} \mathrm{O}_{3}<\mathrm{Nb}_{2} \mathrm{O}_{5}<\mathrm{TiO}_{2}$.

The high TOF values for the reducible oxides show that Co surface sites were promoted by $\mathrm{TiO}_{\mathrm{x}}$ or $\mathrm{NbO}_{\mathrm{x}}$ in the R- and ROR-samples. In addition, the TOF was independent of ROR, meaning that ROR did not change the nature of the promoted active sites. Therefore, the enhanced cobalt-weight-based activity of $\mathrm{Co} / \mathrm{TiO}_{2}$ and $\mathrm{Co} / \mathrm{Nb}_{2} \mathrm{O}_{5}$ implied that the number of promoted active sites increased as a result of ROR. Furthermore, the effect of the second reduction temperature on the activity is included as well in Figure $4.5 \mathrm{~b}$ for $\mathrm{Co} /$ $\mathrm{Nb}_{2} \mathrm{O}_{5}$. Reduction at $250^{\circ} \mathrm{C}$ gave only a moderate increase in $\mathrm{H}_{2}$-chemisorption and a corresponding increase in activity, while reduction at $220{ }^{\circ} \mathrm{C}$ doubled the $\mathrm{H}_{2}$-uptake and activity.

Although the TOF of cobalt catalysts has been reported to be support independ$e^{3{ }^{39,44}}$, recent publications have shown that the promoting effect of the support can be 
substantial $17,18,21,32$. This promoting effect on the TOF has been related to the Lewis acidity of the metal oxide: an increase in acidity leads to an increase in $\mathrm{TOF}^{17,18}$. The Lewis acid character of oxidic materials originates from exposed metal centers ${ }^{45}$, meaning that the structural arrangement and oxidation state of the ions will determine their acid strength ${ }^{46}$. Jeong et al. ${ }^{47}$ have recently reported an acidity scale based on the intramolecular charge transfer energy between organic molecules and several metal oxides (Appendix C: Table C4). The values reported for the supports used in our work do predict higher TOF for $\mathrm{TiO}_{2}$ and $\mathrm{Nb}_{2} \mathrm{O}_{5}$ compared to $\mathrm{Al}_{2} \mathrm{O}_{3}$, but the comparison between $\mathrm{TiO}_{2}$ and $\mathrm{Nb}_{2} \mathrm{O}_{5}$ requires further analysis. As mentioned before, Lewis acidity depends on the oxidation state of the cation, thus values for lower oxidation states in suboxides (e.g. $\mathrm{Ti}^{3+}, \mathrm{Nb}^{4+}$ or $\mathrm{Nb}^{3+}$ ) gain importance for reducible metal oxides as shown in the work of Boffa et al. ${ }^{21,48}$. Because the oxidation state and structural arrangement of the relevant suboxides are not completely established, the formal Lewis acidity remains uncertain.

\subsection{Conclusions}

In summary, reduction-oxidation-reduction (ROR) treatments were investigated as a tool to tune metal-support interactions in supported cobalt catalysts to improve their performance in the Fischer-Tropsch synthesis. Reduction of cobalt oxide supported on reducible $\left(\mathrm{TiO}_{2}\right.$ and $\left.\mathrm{Nb}_{2} \mathrm{O}_{5}\right)$ and irreducible $\left(\alpha-\mathrm{Al}_{2} \mathrm{O}_{3}\right)$ oxides followed by controlled oxidation led to hollow cobalt oxide particles via the Kirkendall effect. A second reduction resulted in a twofold increase in $\mathrm{H} 2$-uptake for the $\mathrm{TiO}_{2}$ - and $\mathrm{Nb}_{2} \mathrm{O}_{5}$-supported samples and a decrease for the $\alpha-\mathrm{Al}_{2} \mathrm{O}_{3}$-supported sample. This effect was attributed to modulation of the metal-support interactions rather than re-dispersion of the cobalt phase. The modified metal-support interactions greatly increased the catalytic activity in the Fischer-Tropsch synthesis, as the activity doubled on $\mathrm{TiO}_{2}$ and $\mathrm{Nb}_{2} \mathrm{O}_{5}$ and decreased slightly on $\alpha-\mathrm{Al}_{2} \mathrm{O}_{3}$. This increased activity was caused by more accessible cobalt surface sites as revealed by the constant turnover frequency, while preserving the full promotional effect of the $\mathrm{TiO}_{\mathrm{x}}$ or $\mathrm{NbO}_{\mathrm{x}}$ species. The more efficient utilization of the cobalt and support interphase led to exceptionally active catalysts. Tailoring of metal-support interactions via ROR treatments is thus an effective method to improve the activity of metal catalysts supported on reducible oxides.

\section{Acknowledgements}

Companhia Brasileira de Metalurgia e Mineração (CBMM), Shell Global Solutions and the Netherlands Association for Scientific Research (NWO) are thanked for financial support. K.P.d.J. acknowledges the European Research Council, EU FP7 ERC Advanced Grant no. 338846. Robson Monteiro (CBMM), Rogério Ribas (CBMM) and Peter Munnik (Shell Global Solutions) are acknowledged for useful discussions. Wouter Lamme, Jessi van der Hoeven, Nynke Krans and Mark Meijerink (STEM-EDX) and Helen de Waard (ICP-OES) are acknowledged for the measurements indicated. 


\section{References}

1. Rayment, T., Schlögl, R., Thomas, J. M. \& Ertl, G. Structure of the ammonia synthesis catalyst. Nature 315, 311-313 (1985).

2. Galvis, H. M. T. Supported Iron Nanoparticles as Catalysts for Sustainable Production of Lower Olefins. Science 835, 1-5 (2012).

3. Zečević, J., Vanbutsele, G., De Jong, K. P. \& Martens, J. A. Nanoscale intimacy in bifunctional catalysts for selective conversion of hydrocarbons. Nature 528, 245-254 (2015).

4. Behrens, M. et al. The Active Site of Methanol Synthesis over $\mathrm{Cu} / \mathrm{ZnO} / \mathrm{Al}_{2} \mathrm{O}_{3}$ Industrial Catalysts. Science 336, 893-898 (2012).

5. Campbell, C. T. The Effect of Size-Dependent Nanoparticle Energetics on Catalyst Sintering. Science 298, 811-814 (2002).

6. Munnik, P., De Jongh, P. E. \& De Jong, K. P. Recent Developments in the Synthesis of Supported Catalysts. Chem. Rev. 115, 6687-6718 (2015).

7. Lykhach, Y. et al. Counting electrons on supported nanoparticles. Nat. Mater. 15, 284 (2015).

8. Divins, N. J., Angurell, I., Escudero, C., Pérez-Dieste, V. \& Llorca, J. Influence of the support on surface rearrangements of bimetallic nanoparticles in real catalysts. Science 346, 620-623 (2014).

9. Kitano, M. et al. Ammonia synthesis using a stable electride as an electron donor and reversible hydrogen store. Nat. Chem. 4, 934-940 (2012).

10. Karim, W. et al. Catalyst support effects on hydrogen spillover. Nature 541, 68-71 (2017).

11. Tauster, S. J., Fung, S. C. \& Garten, R. L. Strong metal-support interactions. Group 8 noble metals supported on titanium dioxide. J.Am. Chem. Soc. 100, 170-175 (1978).

12. Tauster, S. J., Fung, S. C., Baker, R. T. K. \& Horsley, J. A. Strong Interactions in Supported-Metal Catalysts. Science 211, 1121 LP - 1125 (1981).

13. Matsubu, J. C. et al. Adsorbate-mediated strong metal-support interactions in oxide-supported Rh catalysts. Nat. Chem. 9, 120-127 (2017).

14. Zhang, S. et al. Dynamical Observation and Detailed Description of Catalysts under Strong Metal-Support Interaction. Nano Lett. 16, 4528-4534 (2016).

15. de la Peña O’Shea, V. A., Álvarez Galván, M. C., Platero Prats, A. E., Campos-Martin, J. M. \& Fierro, J. L. G. Direct evidence of the SMSI decoration effect: the case of $\mathrm{Co} / \mathrm{TiO}_{2}$ catalyst. Chem. Commun. 47, 7131-7133 (2011).

16. Xu, M. et al. $\mathrm{TiO}_{2-\mathrm{x}}{ }^{-}$Modified Ni Nanocatalyst with Tunable Metal-Support Interaction for Water-Gas Shift Reaction. ACS Catal. 7, 7600-7609 (2017).

17. Johnson, G. R. \& Bell, A. T. Effects of Lewis acidity of metal oxide promoters on the activity and selectivity of Co-based Fischer-Tropsch synthesis catalysts. J. Catal. 338, 250-264 (2016).

18. Prieto, G. et al. Cobalt-catalyzed Fischer-Tropsch synthesis: Chemical nature of the oxide support as a performance descriptor. ACS Catal. 5, 3323-3335 (2015).

19. Maitlis, P. M. \& Zanotti, V. The role of electrophilic species in the Fischer-Tropsch reaction. Chem. Commun. 13, 1619-1634 (2009).

20. Vannice, M. A. Hydrogenation of co and carbonyl functional groups. Catal. Today 12, 255-267 (1992).

21. Boffa, A. B., Lin, C., Bell, A. T. \& Somorjai, G. A. Lewis acidity as an explanation for oxide promotion of metals: implications of its importance and limits for catalytic reactions. Catal. Letters 27, 243-249 (1994).

22. Foger, K. Reactions of n-butane and neopentane on titania-supported iridium catalysts. J. Catal. 78, 406-418 (1982).

23. Braunschweig, E. J., Logan, A. D., Datye, A. K. \& Smith, D. J. Reversibility of strong metal-support interactions on $\mathrm{RhTiO}_{2}$.J. Catal. 118, 227-237 (1989).

24. Pan, C.-J. et al. Tuning/exploiting Strong Metal-Support Interaction (SMSI) in Heterogeneous Catalysis. J. Taiwan Inst. Chem. Eng. 74, 154-186 (2017).

25. Soled, S. L. et al. Control of metal dispersion and structure by changes in the solid-state chemistry of supported cobalt Fischer-Tropsch catalysts. Top. Catal. 26, 101-109 (2003). 
26. Weststrate, C. J. et al. Cobalt Fischer-Tropsch Catalyst Regeneration: The Crucial Role of the Kirkendall Effect for Cobalt Redispersion. Top. Catal. 54, 811-816 (2011).

27. Saib, A. M. et al. Fundamental understanding of deactivation and regeneration of cobalt Fischer-Tropsch synthesis catalysts. Catal. Today 154, 271-282 (2010).

28. Saib, A. M. et al. Fundamental Science of Cobalt Catalyst Oxidation and Reduction Applied to the Development of a Commercial Fischer-Tropsch Regeneration Process. Ind. Eng. Chem. Res. 53, 1816-1824 (2014).

29. Hauman, M. M. et al. Re-dispersion of Cobalt on a Model Fischer-Tropsch Catalyst During Reduction-Oxidation-Reduction Cycles. ChemCatChem 4, 1411-1419 (2012).

30. Eschemann, T. O. \& de Jong, K. P. Deactivation Behavior of $\mathrm{Co} / \mathrm{TiO}_{2}$ Catalysts during Fischer-Tropsch Synthesis. ACS Catal. 5, 3181-3188 (2015).

31. Reuel, R. C. \& Bartholomew, C. H. The Stoichiometries of $\mathrm{H}_{2}$ and CO Adsorptions on Cobalt: Effects of Support and Preparation. J. Catal. 85, 63-77 (1984).

32. den Otter, J. H., Yoshida, H., Ledesma, C., Chen, D. \& De Jong, K. P. On the superior activity and selectivity of $\mathrm{PtCo} / \mathrm{Nb}_{2} \mathrm{O}_{5}$ Fischer Tropsch catalysts. J. Catal. 340, 270-275 (2016).

33. Yin, Y. et al. Formation of Hollow Nanocrystals Through the Nanoscale Kirkendall Effect. Science 304, 711714 (2004).

34. Chernavskii, P. A., Pankina, G. V, Zaikovskii, V. I., Peskov, N. V \& Afanasiev, P. Formation of Hollow Spheres upon Oxidation of Supported Cobalt Nanoparticles. J. Phys. Chem. C 112, 9573-9578 (2008).

35. González-Carballo, J. M., Sadasivan, S., Landon, P. \& Tooze, R. P. Synthesis of cobalt nanodumbbells and their thermal stability under $\mathrm{H}_{2}, \mathrm{H}_{2} / \mathrm{CO}$ and $\mathrm{O}_{2}$ atmospheres. Mater. Charact. 118, 519-526 (2016).

36. Barkhordarian, G., Klassen, T. \& Bormann, R. Fast hydrogen sorption kinetics of nanocrystalline Mg using $\mathrm{Nb}_{2} \mathrm{O}_{5}$ as catalyst. Scr. Mater. 49, 213-217 (2003).

37. Dolci, F., Chio, M. Di, Baricco, M. \& Giamello, E. Niobium pentoxide as promoter in the mixed $\mathrm{MgH}_{2} / \mathrm{Nb}_{2} \mathrm{O}_{5}$ system for hydrogen storage: a multitechnique investigation of the $\mathrm{H}_{2}$ uptake. J. Mater. Sci. 42, 7180-7185 (2007).

38. Sadasivan, S., Bellabarba, R. M. \& Tooze, R. P. Size dependent reduction-oxidation-reduction behaviour of cobalt oxide nanocrystals. Nanoscale 5, 11139-11146 (2013).

39. Iglesia, E. Design, synthesis, and use of cobalt-based Fischer-Tropsch synthesis catalysts. Appl. Catal. A Gen. 161, 59-78 (1997).

40. Sun, X. et al. Manufacture of highly loaded silica-supported cobalt Fischer-Tropsch catalysts from a metal organic framework. Nat. Commun. 8, 1680 (2017).

41. Nabaho, D., Niemantsverdriet, J. W., Claeys, M. \& Steen, E. van. Hydrogen spillover in the Fischer-Tropsch synthesis: An analysis of gold as a promoter for cobalt-alumina catalysts. Catal. Today 275, 27-34 (2016).

42. Eschemann, T. O., Oenema, J. \& de Jong, K. P. Effects of noble metal promotion for $\mathrm{Co} / \mathrm{TiO}_{2}$ Fischer-Tropsch catalysts. Catal. Today 261, 60-66 (2016).

43. Lögdberg, S. et al. Effect of water on the space-time yield of different supported cobalt catalysts during Fischer-Tropsch synthesis. Appl. Catal. A Gen. 393, 109-121 (2011).

44. Iglesia, E., Soled, S. L. \& Fiato, R. A. Fischer-Tropsch synthesis on cobalt and ruthenium. Metal dispersion and support effects on reaction rate and selectivity. J. Catal. 137, 212-224 (1992).

45. Corma, A. Inorganic Solid Acids and Their Use in Acid-Catalyzed Hydrocarbon Reactions. Chem. Rev. 95, 559-614 (1995).

46. Kreissl, H. T. et al. Structural Studies of Bulk to Nanosize Niobium Oxides with Correlation to Their Acidity. J.Am. Chem. Soc. 139, 12670-12680 (2017).

47. Jeong, N. C., Lee, J. S., Tae, E. L., Lee, Y. J. \& Yoon, K. B. Acidity Scale for Metal Oxides and Sanderson's Electronegativities of Lanthanide Elements. Angew. Chemie Int. Ed. 47, 10128-10132 (2008).

48. Boffa, A., Lin, C., Bell, A. T. \& Somorjai, G. A. Promotion of $\mathrm{CO}$ and $\mathrm{CO}_{2}$ Hydrogenation over Rh by Metal Oxides: The Influence of Oxide Lewis Acidity and Reducibility. J. Catal. 149, 149-158 (1994). 


\section{5 \\ Cobalt-Nickel Nanoparticles Supported on Reducible Oxides as Fischer-Tropsch Catalysts}

Efficient and more sustainable production of transportation fuels is key to fulfill the ever-increasing global demand. In order to achieve this, progress in the development of highly active and selective catalysts is fundamental. The combination of bimetallic nanoparticles and reactive support materials offers unique and complex interactions that can be exploited for improved catalyst performance. Here, we report on cobalt-nickel nanoparticles on reducible metal oxides as support material for enhanced performance in the Fischer-Tropsch synthesis. For this, different cobalt to nickel ratios $(\mathrm{Ni} /(\mathrm{Ni}+\mathrm{Co}): 0.0,0.25$, $0.50,0.75$ or 1.0 at/at) supported on reducible $\left(\mathrm{TiO}_{2}\right.$ and $\left.\mathrm{Nb}_{2} \mathrm{O}_{5}\right)$ or non-reducible $\left(\alpha-\mathrm{Al}_{2} \mathrm{O}_{3}\right)$ oxides were studied. At 1 bar, Co-Ni nanoparticles supported on $\mathrm{TiO}_{2}$ and $\mathrm{Nb}_{2} \mathrm{O}_{5}$ showed stable catalytic performance, high activities and remarkably high selectivities for long-chain hydrocarbons $\left(\mathrm{C}_{5}, \sim 80 \mathrm{wt} . \%\right)$. In contrast, catalysts supported on $\alpha-\mathrm{Al}_{2} \mathrm{O}_{3}$ independently of the metal composition showed lower activities, high methane production and considerable deactivation throughout the experiment. At 20 bar, the combination of cobalt and nickel supported on reducible oxides allowed for 25 to $50 \%$ cobalt substitution by nickel with increased Fischer-Tropsch activity and without sacrificing much $\mathrm{C}_{5_{+}}$selectivity. STEM-EDX and IR of adsorbed $\mathrm{CO}$ pointed to a cobalt enrichment of the nanoparticle's surface and a weaker adsorption of $\mathrm{CO}$ in Co-Ni supported on $\mathrm{TiO}_{2}$ and $\mathrm{Nb}_{2} \mathrm{O}_{5}$ and not on $\alpha-\mathrm{Al}_{2} \mathrm{O}_{3}$, modifying the rate determining step and the catalytic performance. Overall, we show the strong effect and potential of reducible metal oxides as support materials for bimetallic nanoparticles for enhanced catalytic performance. 


\subsection{Introduction}

The increasing demand for transportation fuels has stimulated the diversification of their sources and encouraged research towards efficient production ${ }^{1,2}$. Liquid fuels in particular have been widely employed due to their high energy density and convenience to handle ${ }^{3}$. Fuels produced from processes such as gas-to-liquids (GTL) or coal-to-liquids (CTL) have emerged as an attractive alternative to the traditional fuels derived from crude oil. The GTL and CTL processes allow feedstock diversification and generate ultra-clean fuels. A crucial step in GTL and CTL is the catalytic transformation of synthesis gas (a mixture of carbon monoxide and hydrogen) to hydrocarbons, also known as the Fischer-Tropsch (FT) synthesis. The competitiveness of FT, and therefore the GTL and CTL processes, heavily rely on highly productive and stable catalysts. Finding materials with improved FT catalytic performance is highly desirable.

The FT synthesis is a complex reaction that is typically catalyzed by late-transition metals in the metallic or carbidic form. Current research has shown that the rate-controlling step in such catalytic surfaces need a balance between CO dissociation, water removal, chain growth and chain-growth termination for an optimal FT perfomrance ${ }^{4-6}$. However, no single metal surface displays these characteristics concurrently ${ }^{4}$. Bimetallic systems hold potential to bring about unique catalytic properties distinct from those of the individual metals ${ }^{7-10}$.

Nowadays, cobalt-based FT catalysts are employed in GTL due to their selectivity towards long-chain hydrocarbons $\left(\mathrm{C}_{5+}\right)$, low water-gas-shift activity, stable performance and $\operatorname{costs}^{11,12}$. Considering these characteristics, iron, nickel or copper are potential candidates to form bimetallic catalysts with cobalt. Taking into account the industrial FT conditions, that is temperatures between $200-250{ }^{\circ} \mathrm{C}$ and pressures $10-40$ bar, $\mathrm{CO}$ dissociation on copper is not favored and thus $\mathrm{Co}-\mathrm{Cu}$ systems can be employed for the synthesis of alcohols ${ }^{13-15}$. Iron under FT conditions often favors the formation of iron carbide that might lead to segregation in Co-Fe systems and loss of possible bimetallic synergy ${ }^{16,17}$. Finally, nickel can readily dissociate $\mathrm{CO}$ and form stable Co-Ni alloys, making it an attractive option. However, the risks exist of lower $\mathrm{C}_{5+}$ selectivity due to high hydrogenation activity and concomitant methane production and decreased stability due to formation of volatile nickel tetracarbony ${ }^{18}$. Indeed, in most previous reports a compromise between activity and $\mathrm{C}_{5+}$ selectivity has been observed for Co-Ni-based FT catalysts, although a common feature has been the utilization of non-reducible supports, such as silica, alumina or zirconia ${ }^{19-24}$. Early work of Arai et al. ${ }^{25-28}$ has shown that the nature of the support has important consequences for the FT performance of Co-Ni catalysts; they observed differences in catalytic performance from supports with contrasting electronegativities but similar performance of reducible and non-reducible supports.

The interaction between metal nanoparticles and the support has become a prominent tool in the design of catalysts with enhanced performance ${ }^{29,30}$. For bimetallic nanoparticles, the interaction with the support can as well lead to various and usually complex phenomena that strongly affect their catalytic performance ${ }^{31-35}$. The understanding of such interactions is often difficult. One of the phenomena that arises from the interaction of 
mono- and bimetallic nanoparticles supported on reducible metal oxides (e.g. $\mathrm{TiO}_{2}, \mathrm{Nb}_{2} \mathrm{O}_{5}$, $\mathrm{CeO}_{2}$, etc.) is the so-called strong metal-support interaction (SMSI) ${ }^{36,37}$. This phenomenon takes place upon partial reduction of the support at the periphery of the metal nanoparticle, leading to the generation of mobile suboxide species (e.g. $\mathrm{TiO}_{x}, \mathrm{NbO}_{\mathrm{x}}$ ) that partially cover the surface of the metal nanoparticle. In FT, reducible oxidic supports have a major influence on the catalyst performance ${ }^{38,39}$. The mild Lewis acidity of the suboxides is known to promote the intrinsic surface-specific catalytic activity (turnover frequency, TOF) and selectivity towards $\mathrm{C}_{5+}$ products $^{40}$. The increased TOF is believed to originate at the interphase between the suboxides and the metal where an enhanced $\mathrm{CO}$ adsorption and rate of hydrogenation occurs ${ }^{41,42}$. Tuning this interaction can lead for instance to cobalt-based catalysts with enhanced FT activities ${ }^{43}$ and in the case of nickel-based catalysts, SMSI can be employed to suppress the formation of nickel tetracarbonyl and enhance the selectivity towards longer-hydrocarbons ${ }^{44,45}$. Hence, improvement can be achieved by careful selection of the components in the Co-Ni catalytic system, particularly of the support material.

In this research, we investigated the effect of cobalt substitution by nickel on supported FT catalysts and the influence of the support nature on the catalytic behavior of the metals. Several characterization techniques, in particular IR spectroscopy of adsorbed $\mathrm{CO}$, were employed to elucidate the effect of combining cobalt and nickel on the different supports. At 1 bar, the Co-Ni samples displayed increased activities and $\mathrm{C}_{5_{+}}$selectivities, up to doubling the activity compared to the monometallic catalysts. Contrastingly, $\alpha-\mathrm{Al}_{2} \mathrm{O}_{3}$-supported catalysts had for all Co-Ni compositions lower metal-normalized activities and higher selectivities towards methane. Moreover, these catalysts deactivated severely throughout the experiment in contrast to the more stable $\mathrm{TiO}_{2}$ - and $\mathrm{Nb}_{2} \mathrm{O}_{5}$-supported catalysts. Increasing synthesis gas pressure to 20 bar benefited the activity and selectivity of the samples supported on reducible oxides with high cobalt content, and with similar $\mathrm{C}_{5+}$ selectivities as the monometallic cobalt-based catalysts. Reducible oxides used as support material strongly modified the reactivity of alloys, opening new possibilities for more efficient catalysts in general.

\subsection{Experimental}

Synthesis. Niobia $\left(\mathrm{Nb}_{2} \mathrm{O}_{5}\right)$ and titania $\left(\mathrm{TiO}_{2}\right)$ were employed as reducible supports. $\mathrm{Nb}_{2} \mathrm{O}_{5}$ was obtained by crystallization of niobium oxide hydrate $\left(\mathrm{Nb}_{2} \mathrm{O}_{5} \cdot n \mathrm{H}_{2} \mathrm{O}, \mathrm{HY}-340, \mathrm{AD} / 4465\right.$ provided by Companhia Brasileira de Metalurgia e Mineração - CBMM). Crystallization was carried out in stagnant air at $600{ }^{\circ} \mathrm{C}\left(5^{\circ} \mathrm{C} \cdot \mathrm{min}^{-1}, 4 \mathrm{~h}\right)$. The obtained $\mathrm{Nb}_{2} \mathrm{O}_{5}$ had a pseudo-hexagonal TT-phase, a specific surface area of $9 \mathrm{~m}^{2} \cdot \mathrm{g}^{-1}$ and a specific mesopore volume of $0.05 \mathrm{~cm}^{3} \cdot \mathrm{g}^{-1}$. $\mathrm{TiO}_{2}$ had a rutile phase, a specific surface area of $11 \mathrm{~m}^{2} \cdot \mathrm{g}^{-1}$ and a specific mesopore volume of $0.04 \mathrm{~cm}^{3} \cdot \mathrm{g}^{-1}$. Alpha-alumina $\left(\alpha-\mathrm{Al}_{2} \mathrm{O}_{3}\right)$ was employed as non-reducible support and supplied by BASF in the form of extrudates. The $\alpha-\mathrm{Al}_{2} \mathrm{O}_{3}$ consisted of only alpha-phase with specific surface area of $7 \mathrm{~m}^{2} \cdot \mathrm{g}^{-1}$ and specific mesopore volume of $0.02 \mathrm{~cm}^{3} \cdot \mathrm{g}^{-1}$. Support materials were crushed and sieved $(75-150 \mu \mathrm{m}$ grains) prior to catalyst preparation.

The supported metal catalysts were prepared using the incipient wetness impreg- 
nation method. First, $2.0 \mathrm{~g}$ of support material were dried under vacuum at $80{ }^{\circ} \mathrm{C}$ for $1 \mathrm{~h}$, thereafter the impregnation was performed at room temperature with a $4.2 \mathrm{M}$ aqueous solution with the appropriate cobalt-nickel ratio. The aqueous solutions were prepared using $\mathrm{Ni}\left(\mathrm{NO}_{3}\right)_{2} \cdot 6 \mathrm{H}_{2} \mathrm{O}$ (Acros, 99+\%) and/or $\mathrm{Co}\left(\mathrm{NO}_{3}\right)_{2} \cdot 6 \mathrm{H}_{2} \mathrm{O}$ (Acros, 99+\%) in Milli-Q water. After impregnation, the materials were dried at $60{ }^{\circ} \mathrm{C}\left(5^{\circ} \mathrm{C} \cdot \mathrm{min}^{-1}, 2 \mathrm{~h}\right)$ in a fixed bed reactor under $\mathrm{N}_{2}$ flow and subsequently calcined at $350{ }^{\circ} \mathrm{C}\left(3{ }^{\circ} \mathrm{C} \cdot \mathrm{min}^{-1}, 2 \mathrm{~h}\right)$. Metal loadings were defined as the total mass of metallic $\mathrm{Ni}$ and/or Co per gram of reduced catalyst, resulting in total metal loadings of 6 - 8 wt.\% (Appendix D: Table D1). The total metal loading per support was chosen in order to maintain similar metal loadings per unit surface area within all the samples. In this way, the metal distribution over the different supports is expected to be similar. The metal composition is expressed as $\mathrm{Ni} /(\mathrm{Ni}+\mathrm{Co})$ atomic ratio and the ratios studied were: $0.0,0.25,0.5,0.75$ and 1.0 at/at.

Characterization. Temperature programmed reduction (TPR) analyses were performed using a Micromeritics Autochem 2990 instrument, where typically $50 \mathrm{mg}$ of sample (75 - $150 \mu \mathrm{m}$ grains) were dried at $120{ }^{\circ} \mathrm{C}$ for $1 \mathrm{~h}$ in Ar flow followed by reduction from room temperature up to $600{ }^{\circ} \mathrm{C}\left(5{ }^{\circ} \mathrm{C} \cdot \mathrm{min}^{-1}\right)$ in a $5 \mathrm{vol} . \% \mathrm{H}_{2} / \mathrm{Ar}$ flow.

Bright field transmission electron microscopy (TEM) and dark field scanning transmission electron microscopy (STEM-EDX) images were acquired at a FEI Talos F200X microscope operated at $200 \mathrm{kV}$ equipped with 4 energy dispersive X-ray (EDX) detectors, a high-angle annular dark-field (HAADF) and a bright field detector. The reduced and subsequently passivated samples for the microscopy analysis were prepared by suspending the catalysts in 2-propanol (>99.9\%, Sigma-Aldrich) using sonication and drop casting the suspension on a Cu TEM grid (200 mesh copper (100), Formvar/carbon film). The metal particle size measurements and Co-Ni distribution cross-section analyses were carried out using the Image ${ }^{46}$ software by analyzing at least 500 particles. Particle surface average diameters or Sauter mean $(\mathrm{D}[3,2])$ were then calculated and corrected for a $2 \mathrm{~nm}$ oxide shell. The theoretical $\mathrm{H}_{2}$-uptake $\left(\mu \mathrm{mol}_{\mathrm{H} 2} \cdot \mathrm{g}_{\mathrm{Metal}}{ }^{-1}\right)$ was calculated by first obtaining the specific metallic surface area $\left(\mathrm{SA}_{\text {metal }}, \mathrm{m}^{2} \cdot \mathrm{g}^{-1}\right.$ metal $)$ from $\mathrm{D}[3,2](\mathrm{nm})$ from TEM and assuming hemispherical particles:

$$
\mathrm{SA}_{\text {metal }}=6 \cdot\left(10^{6} \rho \cdot 10^{-9} \mathrm{D}[3,2]\right)^{-1}
$$

Where $\rho$ is the density $\left(8.9 \mathrm{~g} \cdot \mathrm{cm}^{-3}\right)$ for cobalt and nickel. Then, assuming an average metal cross-sectional area of $0.0656 \mathrm{~nm}^{2}$, a metal to $\mathrm{H}$ stoichiometry of 1 and $\mathrm{N}_{\mathrm{A}}=6.0221 \mathrm{X} 10^{23} \mathrm{~mol}^{-1}$ :

$$
\text { Theoretical } \mathrm{H}_{2} \text {-uptake }=\mathrm{SA}_{\text {metal }} \cdot\left(2 \cdot N_{A} \cdot 10^{-18} \text { metal cross-section area }\right)^{-1}
$$

$\mathrm{H}_{2}$-chemisorption was measured on a Micromeritics ASAP 2020C using $100 \mathrm{mg}$ of sample. Prior to the measurement, the sample was reduced in pure $\mathrm{H} 2$ at $350{ }^{\circ} \mathrm{C}\left(5^{\circ} \mathrm{C} \cdot \mathrm{min}^{-1}\right.$, $2 \mathrm{~h}$ ). The sample was then evacuated, cooled to $150{ }^{\circ} \mathrm{C}$ and $\mathrm{H}_{2}$-chemisorption was measured at that temperature. Inductively coupled plasma-optical emission spectroscopy (ICP-OES) was performed on a SPECTRO ARCOS in order to establish the cobalt to nickel ratio before 
and after catalysis; samples were extracted using aqua regia.

Fourier transform infrared (FT-IR) spectroscopy measurements were carried out in a PerkinElmer 2000 instrument, in a specially designed cell fitted with $\mathrm{CaF}_{2}$ windows. Self-supported catalyst wafers were prepared by applying on a powdered sample a force of $4000 \mathrm{~kg}$ for $20 \mathrm{~s}$, yielding a wafer of $1 \mathrm{~cm}$ diameter, and $<1 \mathrm{~mm}$ thickness. Before dosing CO, the wafer sample was placed in the FTIR cell and reduced using a flow of pure hydrogen at $350{ }^{\circ} \mathrm{C}\left(5^{\circ} \mathrm{C} \cdot \mathrm{min}^{-1}, 2 \mathrm{~h}\right)$, then at the same temperature the hydrogen flow was stopped and evacuated to $\sim 10^{-5}$ mbar. Thereafter the sample was cooled down to $220{ }^{\circ} \mathrm{C}$ under dynamic vacuum and left for one hour. A 10 vol.\% CO in He mixture was slowly introduced into the cell until the pressure reached $\sim 10^{-4}$ mbar and allowed to equilibrate for 5 minutes to collect the spectrum. $\mathrm{CO} / \mathrm{He}$ mixture was slowly further introduced to reach various pressures up to 1 bar and spectra were measured at these different pressures after equilibration for 5 minutes before each measurement. For treatment of the data, the measured spectra were normalized by the total available metal sites per sample as obtained from $\mathrm{H}_{2}$-chemisorption. Areas resulting from the deconvolution in the bimetallic samples were normalized to the area of the corresponding monometallic sample.

Fischer-Tropsch synthesis. The low-pressure catalytic performance was assessed in a quartz glass plug-flow reactor, loaded with $\sim 20 \mathrm{mg}$ catalyst $(38-150 \mu \mathrm{m})$ diluted with $\sim 200 \mathrm{mg} \mathrm{SiC}$ $(212-425 \mu \mathrm{m})$. Catalysts were reduced in situ at $350{ }^{\circ} \mathrm{C}\left(5{ }^{\circ} \mathrm{C} \cdot \mathrm{min}^{-1}, 2 \mathrm{~h}\right)$ in an $\mathrm{Ar} / \mathrm{H}_{2}=2 \mathrm{v} / \mathrm{v}$ flow $\left(\mathrm{GHSV}=60000 \mathrm{~h}^{-1}\right)$ at 1 bar. After reduction, the sample was cooled down to $220{ }^{\circ} \mathrm{C}$ and once the temperature was reached the gas composition was changed to synthesis gas $\left(\mathrm{H}_{2} /\right.$ $\mathrm{CO}=2 \mathrm{v} / \mathrm{v}, \mathrm{GHSV}=20000 \mathrm{~h}^{-1}$ ) maintaining 1 bar total pressure. CO conversion was below 5 $\%$ and the reaction was carried out for 40 h. C1-C18 products were analyzed by online gas chromatography (Varian 430 GC, CP sil-5 column). After reaction, the synthesis gas flow was changed for argon and the reactor was cooled down to room temperature.

The high-pressure catalytic performance was measured using an Avantium Flowrence 16 parallel reactor setup. Stainless steel reactors $(\mathrm{ID}=2 \mathrm{~mm}$ ) were loaded with $50-100 \mathrm{mg}$ of catalyst $(38-150 \mu \mathrm{m})$ and diluted with $200 \mathrm{mg}$ of $\mathrm{SiC}(212-425 \mu \mathrm{m})$. Prior to reaction, the catalysts were reduced in-situ at $350{ }^{\circ} \mathrm{C}\left(1{ }^{\circ} \mathrm{C} \cdot \mathrm{min}^{-1}, 8 \mathrm{~h}\right)$ in $25 \mathrm{vol} . \% \mathrm{H}_{2}$ in $\mathrm{He}$ at 1 bar. After reduction, the temperature was lowered to $220{ }^{\circ} \mathrm{C}, 240{ }^{\circ} \mathrm{C}$ or $260{ }^{\circ} \mathrm{C}\left(3{ }^{\circ} \mathrm{C} \cdot \mathrm{min}^{-1}\right)$ and the pressure was increased to 20 bar under $\mathrm{H}_{2}$ flow. Synthesis gas $\left(\mathrm{H}_{2} / \mathrm{CO}=2 \mathrm{v} / \mathrm{v}, 5 \mathrm{vol}\right.$.\% He as internal standard) was then introduced. The product stream was analyzed online with an Agilent 7890A GC, hydrocarbon products were analyzed on an Agilent J\&W PoraBOND Q column connected to an FID and the permanent gases were separated on a ShinCarbon ST column and quantified using a TCD.

\subsection{Results and discussion}

\subsubsection{Catalysts characterization}

After calcination, samples were characterized by temperature programmed reduction (TPR) under hydrogen flow and the corresponding reduction profiles are shown in 
Figure 5.1. Samples containing only cobalt $(\mathrm{Ni} /(\mathrm{Ni}+\mathrm{Co})=0.0$ at/at $)$ show two distinctive $\mathrm{H}_{2}$-uptake peaks, the first one corresponds to the reduction of $\mathrm{Co}_{3} \mathrm{O}_{4}$ to $\mathrm{CoO}$ and the second one to the reduction of $\mathrm{CoO}$ to metallic cobalt. For the reducible supports (Figure 5.1a and b), the first reduction event appears at $\sim 250{ }^{\circ} \mathrm{C}$ and the second one shows two overlapping peaks which finalize at temperatures around $400-500{ }^{\circ} \mathrm{C}$. The alumina-supported sample shows a first reduction event at $225{ }^{\circ} \mathrm{C}$ and reduction is complete at $350{ }^{\circ} \mathrm{C}$ (Figure $5.1 \mathrm{c}$ ). Partial replacement of cobalt with nickel $(\mathrm{Ni} /(\mathrm{Ni}+\mathrm{Co})=0.25,0.5$ and 0.75 at/at $)$ shifted the reduction profiles to lower temperatures, which indicates an influence of the presence of nickel on the cobalt oxide reduction. This influence was more pronounced on the reducible supports than on the non-reducible support. The lowest reduction temperature for the supported cobalt-nickel oxides was observed for the $\mathrm{Ni} /(\mathrm{Ni}+\mathrm{Co})=0.75$ at/at sample in the case of the reducible supports and 0.5 at/at for the non-reducible support. Moreover, the intensity of the first reduction step decreased gradually when increasing the cobalt substitution, likely due to the decreased amount of $\mathrm{Co}^{3+}$ species. Total substitution of cobalt by nickel $(\mathrm{Ni} /(\mathrm{Ni}+\mathrm{Co})=1.0 \mathrm{at} / \mathrm{at})$ showed a slight increase of the temperatures in the reduction profile of nickel oxide to metallic nickel compared to the bimetallic samples.

Quantification from the reduction profiles revealed a decrease in the molar ratio of $\mathrm{H}_{2}$-consumption to metal loading upon replacement of cobalt with nickel (Appendix D: Table D1). For the three supports, monometallic cobalt samples had an $\mathrm{H}_{2} /$ Co molar ratio of 1.4 , closely corresponding to a 1.3 ratio expected for the full reduction of $\mathrm{Co}_{3} \mathrm{O}_{4}$ to metallic $\mathrm{Co}$, and monometallic nickel samples had an $\mathrm{H}_{2} / \mathrm{Ni}$ molar ratio of 1.0, which corresponds to the reduction of $\mathrm{NiO}$ to $\mathrm{Ni}$. The bimetallic samples showed intermediate values, indicative of a mix of $\mathrm{Co}^{3+}, \mathrm{Co}^{2+}$ and $\mathrm{Ni}^{2+}$ species. Overall, the mixed cobalt and nickel oxides formed after co-impregnation and subsequent calcination displayed lower reduction temperatures than the monometallic samples, particularly in the case of the samples supported on reducible oxides.
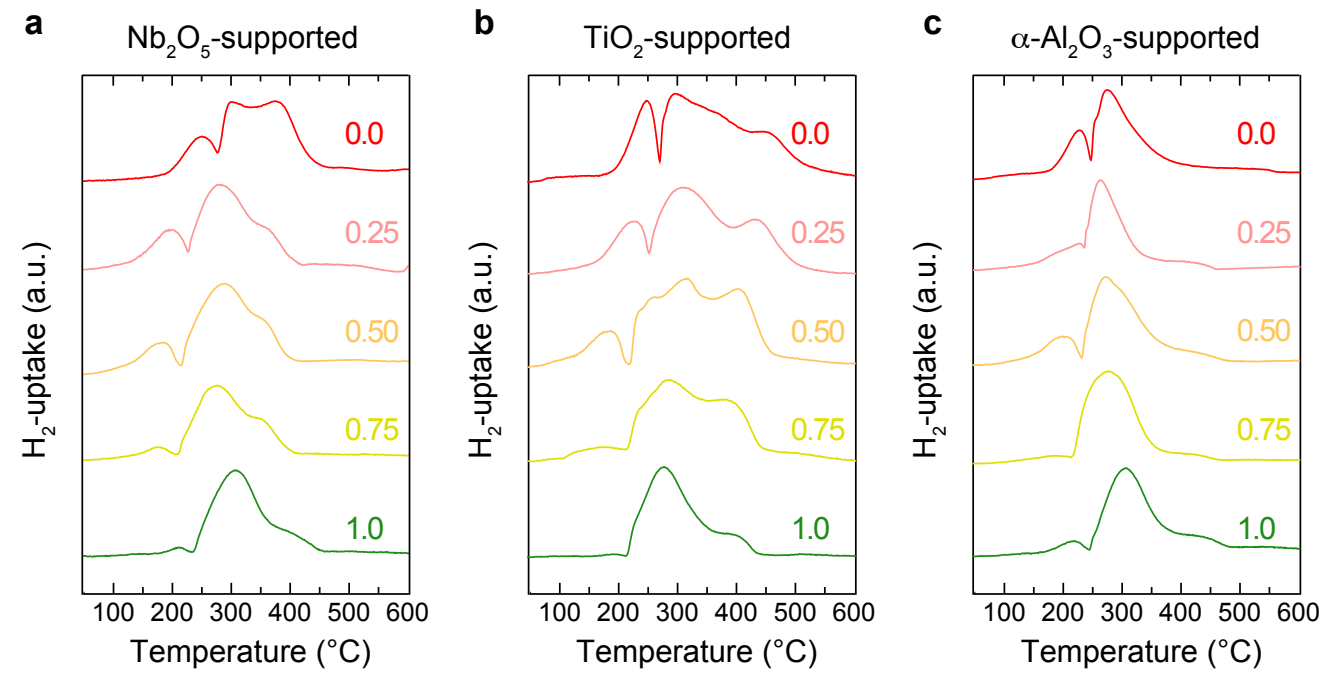

Figure 5.1 Temperature Programmed Reduction (TPR) profiles of the Co-Ni oxide samples supported on niobia (a), titania (b) or $\alpha$-alumina (c). The metal composition $\mathrm{Ni} /(\mathrm{Ni}+\mathrm{Co})$ at/at is indicated for each profile. 
Based on the TPR results, samples were treated under hydrogen flow at $350{ }^{\circ} \mathrm{C}$ to reduce the cobalt and nickel oxides to the metallic form and thereafter $\mathrm{H}_{2}$-chemisorption measurements were carried out. Hydrogen uptake results indicate that gradual replacement of cobalt with nickel increased the adsorption of hydrogen (Table 5.1), suggesting an increased metal dispersion over the support. The effect seemed more pronounced for the $\alpha$-alumina-supported samples. After the experiments, samples were exposed to air at room temperature, analyzed by scanning transmission electron microscopy (STEM) and their metal particles sizes (D[3,2]) were determined (Table 5.1). STEM analyses revealed a gradual decrease in particle size when cobalt was substituted by nickel for all three supports. Figure 5.2 shows a more uniform distribution of the metal nanoparticles over $\mathrm{Nb}_{2} \mathrm{O}_{5}$ facilitated seemingly by the presence of nickel. The smallest particles were obtained at intermediate Co-Ni compositions, i.e., at $\mathrm{Ni} /(\mathrm{Ni}+\mathrm{Co})$ of 0.5 at/at for $\mathrm{TiO}_{2}$ and 0.75 at/at for $\mathrm{Nb}_{2} \mathrm{O}_{5}$ and $\alpha-\mathrm{Al}_{2} \mathrm{O}_{3}$. Thus, metal nanoparticle dispersion on the oxidic supports was enhanced by addition of nickel, as suggested by the H2-chemisorption measurements and in accordance with previous reports ${ }^{20,47}$.

Theoretical hydrogen uptake was calculated using the corresponding STEM-derived particle sizes (Table 5.1). A comparison between theoretical $\mathrm{H}_{2}$-uptake and experimental $\mathrm{H}_{2}$-uptake, obtained from $\mathrm{H}_{2}$-chemisorption measurements, shows significant discrepancies for the niobia- and titania-supported samples (Table 5.1 and Appendix D: Figure D1a and b). The differences are larger for the niobia-supported samples than for the titania-supported ones and increase with increasing nickel content in the samples. Since $\mathrm{Nb}_{2} \mathrm{O}_{5}$ and

Table 5.1 Summary of the experimental $\mathrm{H}_{2}$-uptake determined by $\mathrm{H}_{2}$-chemisorption measurements and STEM-derived particle diameter $(\mathrm{D}[3,2])$ of the samples after the chemisorption experiments with the corresponding theoretical $\mathrm{H}_{2}$-uptake based on the particle diameter from STEM.

\begin{tabular}{|c|c|c|c|c|}
\hline Support & $\begin{array}{c}\mathbf{N i} /(\mathbf{N i}+\mathbf{C o}) \\
(\mathbf{a t} / \mathbf{a t})\end{array}$ & $\begin{array}{c}\text { Experimental } \\
\mathbf{H}_{2} \text {-uptake } \\
\left(\mu \mathrm{mol}_{\mathrm{H} 2} \cdot \mathrm{g}_{\text {Metal }}^{-1}\right) \\
\end{array}$ & $\begin{array}{c}\text { Particle diameter } \\
\text { D[3,2] } \\
(\mathbf{n m}) \\
\end{array}$ & $\begin{array}{c}\text { Theoretical } \\
\mathrm{H}_{2} \text {-uptake } \\
\left(\mu \mathrm{mol}_{\mathrm{H} 2} \cdot \mathrm{g}_{\text {Metal }}^{-1}\right) \\
\end{array}$ \\
\hline \multirow{5}{*}{$\mathrm{Nb}_{2} \mathrm{O}_{5}$} & 0.0 & 320 & 17 & 491 \\
\hline & 0.25 & 441 & 13 & 658 \\
\hline & 0.50 & 452 & 10 & 813 \\
\hline & 0.75 & 482 & 9 & 912 \\
\hline & 1.0 & 362 & 10 & 873 \\
\hline \multirow{5}{*}{$\mathrm{TiO}_{2}$} & 0.0 & 464 & 15 & 569 \\
\hline & 0.25 & 573 & 12 & 700 \\
\hline & 0.50 & 647 & 9 & 908 \\
\hline & 0.75 & 622 & 10 & 899 \\
\hline & 1.0 & 621 & 10 & 857 \\
\hline \multirow{5}{*}{$\alpha-\mathrm{Al}_{2} \mathrm{O}_{3}$} & 0.0 & 610 & 13 & 657 \\
\hline & 0.25 & 731 & 11 & 799 \\
\hline & 0.50 & 888 & 9 & 967 \\
\hline & 0.75 & 1101 & 8 & 1115 \\
\hline & 1.0 & 1056 & 9 & 949 \\
\hline
\end{tabular}




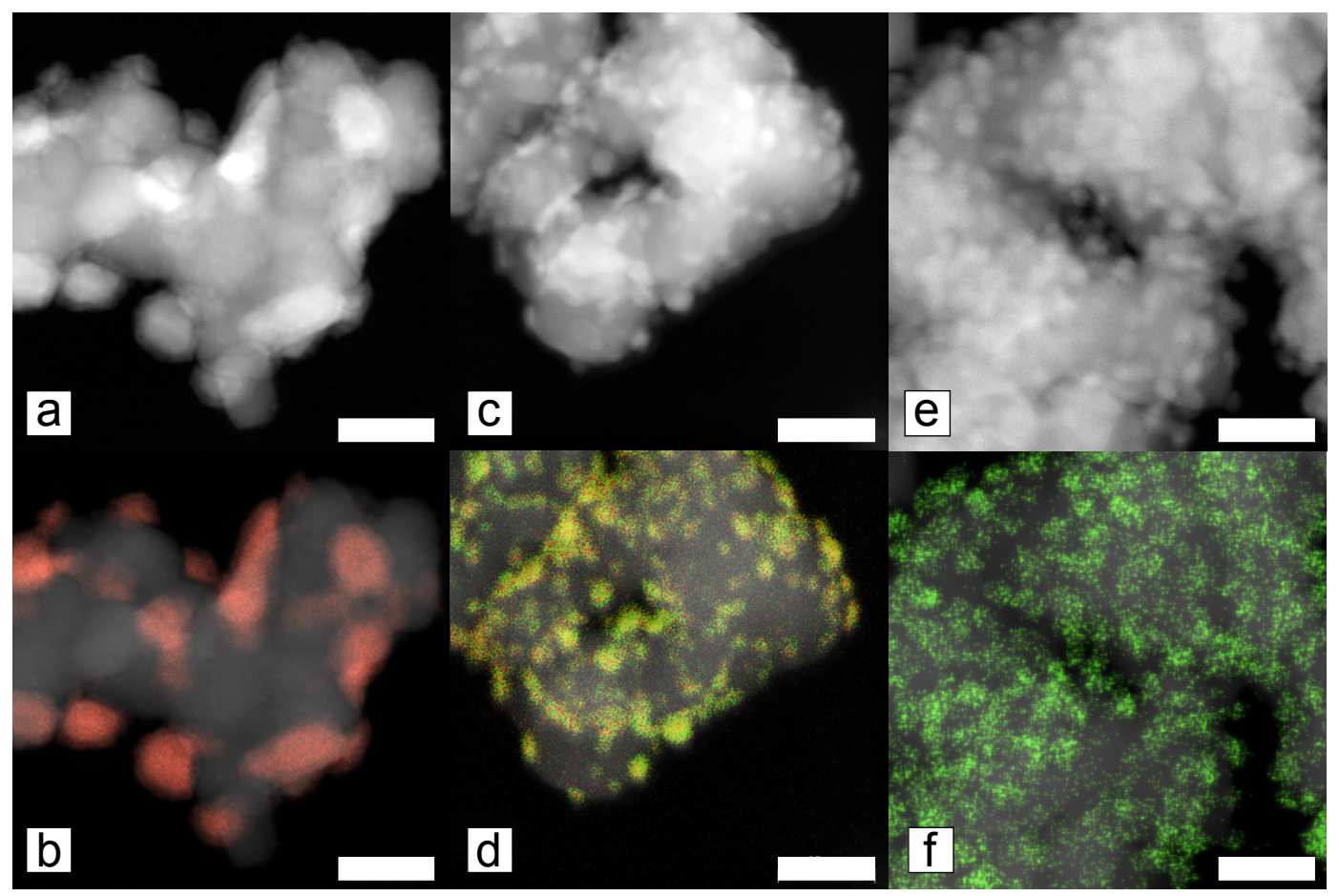

Figure 5.2 STEM-EDX of monometallic cobalt ( $\mathbf{a}$ and $\mathbf{b}$ ), bimetallic cobalt-nickel (c and d, nominal $\mathrm{Ni} /(\mathrm{Ni}+\mathrm{Co})=0.50$ at/at) and monometallic nickel (e and $\mathbf{f})$ samples supported on niobia after reduction at $350{ }^{\circ} \mathrm{C}$ and passivation at room temperature. $\mathbf{a}, \mathbf{c}$ and e show the dark-field STEM images and $\mathbf{b}, \mathbf{d}$ and $\mathbf{f}$ the same darkfield images overlapped with the corresponding EDX maps for cobalt (shown in red) and nickel (shown in green), the scale bars represent $40 \mathrm{~nm}$.

$\mathrm{TiO}_{2}$ are both reducible oxides, the discrepancies are ascribed to the strong metal-support interaction (SMSI) effect, which means that suboxides from the support generated upon reduction treatment partially cover the metallic nanoparticles, thus decreasing the available metallic surface area ${ }^{36,48}$. The niobia-supported nanoparticles were more strongly affected by this than the titania-supported ones. Moreover, the increasing discrepancies with increasing $\mathrm{Ni}$ content may point to stronger susceptibility to SMSI for Ni than for Co, or relate to the decrease in particle size ${ }^{49}$. In contrast, the samples supported on $\alpha-\mathrm{Al}_{2} \mathrm{O}_{3}$, which is a non-reducible support and hence does not display the SMSI effect, showed similar values for theoretical and experimental hydrogen-uptake (Table 5.1 and Appendix D: Figure D1c).

Characterization of metal nanoparticles supported on transition metal oxides by STEM in dark-field or bright-field is difficult due to the similar transition metal atomic number and material density, respectively, of each component (Figure $5.2 \mathrm{a}, \mathrm{c}$ and e). Moreover, supported bimetallic nanoparticles pose a challenge to discern the distribution of the individual elements. EDX mapping combined with STEM has therefore become a powerful tool to better study these material ${ }^{50}$. STEM-EDX of the bimetallic samples after reduction at $350{ }^{\circ} \mathrm{C}$ and passivation at room temperature showed that, independently of the metal composition, nickel associated with cobalt (Figures 5.2d and Appendix D: Figure D2a-c), 
however cobalt was sometimes found without nickel, being more pronounced for the samples with more cobalt $(\mathrm{Ni} /(\mathrm{Ni}+\mathrm{Co})=0.25$ at/at $)$. This is better visible at higher magnification as shown in Appendix D: Figure D3a. For the nanoparticles containing both metals, a cross-section analysis of several particles (e.g. Appendix D: Figures D4 and D5) confirmed a homogeneous distribution of cobalt and nickel, implying the formation of a uniform alloy after reduction at $350{ }^{\circ} \mathrm{C}$ and passivation. Similar observations were made for the titaniaand alumina-supported samples (Appendix D: Figures D6 and D7).

Further characterization by FT-IR spectroscopy with $\mathrm{CO}$ as a probe molecule was carried out in order to examine the electronic and structural surface properties of the metals and alloys. After reduction at $350{ }^{\circ} \mathrm{C}$ under hydrogen flow of the self-supported catalyst wafer and cooling down to $220^{\circ} \mathrm{C}$ under ultra-high vacuum, $\mathrm{CO}$ was dosed from $1 \cdot 10^{-4}$ to 100 mbar. Figure D8 in Appendix D shows the spectra in the frequency region between 2250 and $1550 \mathrm{~cm}^{-1}$ for various Co-Ni compositions supported on niobia, titania and $\alpha$-alumina at increasing CO pressures. Examples of the spectra of the niobia-, titania- and $\alpha$-alumina-supported samples at $1 \cdot 10^{-1}$ mbar CO pressure are as well shown in Figure 5.3. For the monometallic cobalt samples $(\mathrm{Ni} /(\mathrm{Ni}+\mathrm{Co})=0.0 \mathrm{at} / \mathrm{at})$, a single narrow band is observed at low pressures around $1980 \mathrm{~cm}^{-1}$, increasing in intensity upon higher CO pressure, due to higher CO coverages. A second broad band around $1800 \mathrm{~cm}^{-1}$ appears at $\mathrm{P}_{C O}=1 \cdot 10^{-2} \mathrm{mbar}$. According to literature, the narrow band at high wavenumbers can be ascribed to linearly adsorbed $\mathrm{CO}$ and the broad band at lower wavenumbers to $\mathrm{CO}$ adsorbed in bridged mode ${ }^{51-}$ ${ }^{54}$. At intermediate pressures $\left(\mathrm{P}_{\mathrm{CO}}=1 \mathrm{mbar}\right)$, a new band next to the linearly adsorbed $\mathrm{CO}$
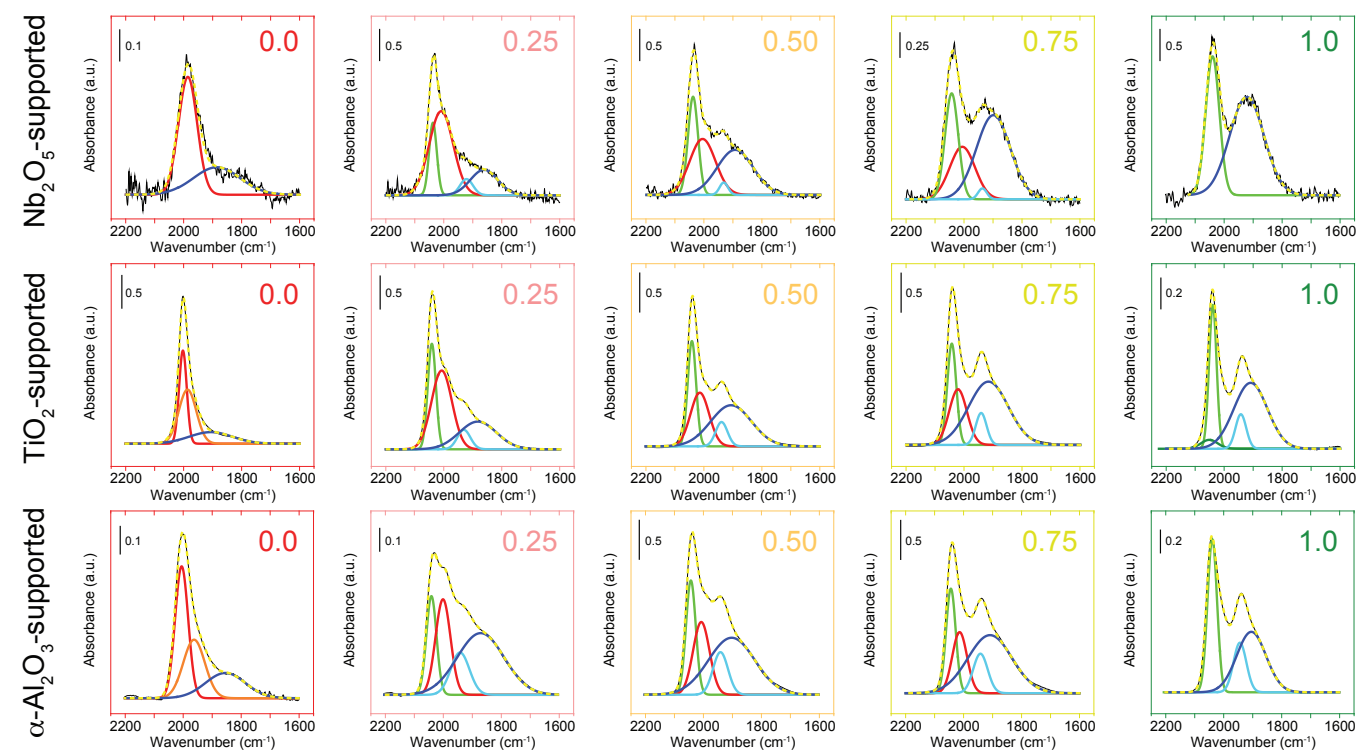

Figure 5.3 Deconvoluted CO-FTIR spectra of the niobia-, titania- and $\alpha$-alumina-supported samples at $0.1 \mathrm{mbar}$ $\mathrm{CO}$ pressure and at $220{ }^{\circ} \mathrm{C}$. The corresponding $\mathrm{Ni} /(\mathrm{Ni}+\mathrm{Co})$ composition is indicated for each spectrum. Spectra are plotted with a black line and curves from the deconvolution correspond to $\mathrm{CO}$ linearly adsorbed on cobalt (red and orange), $\mathrm{CO}$ linearly adsorbed on nickel (green), $\mathrm{CO}$ adsorbed on bridged mode (light and dark blue) and the resulting curve (dashed yellow). 
band appeared around $2060 \mathrm{~cm}^{-1}$, being more clear for the cobalt supported on titania sample. This new band might correspond to CO adsorbed on cobalt in close contact with the support, with a more electropositive character $\left(\mathrm{Co}^{\mathrm{d}+}\right)$ due to the presence of oxygen at the interface, as previously reported ${ }^{51,55,56}$.

For the monometallic nickel samples $(\mathrm{Ni} /(\mathrm{Ni}+\mathrm{Co})=1.0$ at/at $)$ on the other hand, a narrow band $\left(\sim 2020 \mathrm{~cm}^{-1}\right)$ and a broad band $\left(\sim 1850 \mathrm{~cm}^{-1}\right)$ are already observed at the lowest $\mathrm{CO}$ pressure. Again, the high wavenumber band can be ascribed to $\mathrm{CO}$ adsorbed in linear mode and the lower wavenumber band to bridged $\mathrm{CO}$ on nickel ${ }^{57-59}$. Ni appears to favor a CO coordination in bridged mode at low CO surface coverages in line with the appearance of the low-frequency band for nickel at low pressures, in contrast to the cobalt samples. The low work function of nickel and higher valence-electron band occupation result in an interaction with CO dominated by $2 \pi^{*}$ back-donation that favors a bridged coordination ${ }^{60}$. An increased intensity and shift to higher wavenumbers is observed for both bands upon increasing the CO pressure, for the linear-CO band to $2070 \mathrm{~cm}^{-1}$ and for the bridge-CO band to $\sim 1920 \mathrm{~cm}^{-1}$ together with the appearance of a shoulder at slightly higher wavenumbers. Bands corresponding to subcarbonyl species $\mathrm{Ni}(\mathrm{CO})_{\mathrm{x}}(\mathrm{x}=2,3)$, precursors of volatile nickel tetracarbonyl at 2075-2090 $\mathrm{cm}^{-1}$ according to literature ${ }^{59,61,62}$, were not observed at the highest pressure in this set of experiments $\left(\mathrm{P}_{\mathrm{CO}}=100 \mathrm{mbar}\right)$. Thus, loss of nickel during the CO-FTIR measurements is not expected. In the case of the Co-Ni samples various bands emerge upon $\mathrm{CO}$ adsorption consisting of a combination of bands from the ones observed for the monometallic samples. Likewise, the bands increased in intensity and shifted to higher frequencies upon increasing the $\mathrm{CO}$ pressure.

Deconvolution of the spectra for all Co-Ni compositions supported on niobia, titania and $\alpha$-alumina at 0.1 mbar CO pressure can be found in Figure 5.3. In order to distinguish between the cobalt and the nickel contributions in the spectra of the bimetallic samples the analysis focused on the linear-CO bands, since the bands corresponding to $\mathrm{CO}$ adsorbed in bridge mode were too broad and difficult to assign. The low-pressure spectra were used because at 1 mbar and higher CO pressures the cobalt and nickel contributions overlapped (Appendix D: Figure D8). Moreover, the low CO pressures and relative high temperature of the samples $\left(220{ }^{\circ} \mathrm{C}\right)$ prevent dipole-dipole coupling between adsorbed CO molecules which can influence the $\mathrm{CO}$ vibration frequency ${ }^{63}$. The spectra and corresponding deconvolution at CO pressures lower than 1 mbar can be found in Appendix D: Figures D9 and D10 for niobia- and $\alpha$-alumina-supported samples. For the bimetallic samples it is possible to distinguish the linear-CO contributions from cobalt (red) and nickel (green). Therefore, the ratio of these areas was used to qualitatively correlate to the surface composition upon interaction with CO. Figure 5.4 shows the change in ratio of the area for cobalt to the area for nickel as a function of CO pressure for samples supported on niobia or alumina. At a CO pressure of 0.001 mbar the ratio was already different for both support materials, the surface composition for the $\alpha-\mathrm{Al}_{2} \mathrm{O}_{3}$-supported samples seems to be rather independent of the overall composition, whereas for the $\mathrm{Nb}_{2} \mathrm{O}_{5}$-supported samples their surface composition was more affected by the overall composition. Furthermore, upon increasing the $\mathrm{CO}$ pressure the change in area ratio behaved remarkably differently for each support, for 
the $\mathrm{Nb}_{2} \mathrm{O}_{5}$-supported samples it increased, meaning a more Co-rich surface, while for the $\alpha-\mathrm{Al}_{2} \mathrm{O}_{3}$-supported ones it decreased meaning a tendency towards a Ni-rich surface. Reported heats of adsorption for CO on Co and on Ni show similar values ${ }^{64-69}$, therefore, a preferred Co or Ni surface segregation upon contact with $\mathrm{CO}$ is not expected, indicating in our case that the metal-support interaction is affecting the surface composition of the nanoparticles.

Also changes in frequency were observed for the linear-CO bands as a consequence of Co-Ni composition on the three different supports. Figure D11 in Appendix D shows the wavenumber at maximum absorbance as a function of metal composition for the linear-CO band on cobalt and on nickel at 0.1 mbar. For the band corresponding to $\mathrm{CO}$ adsorbed on cobalt, substitution of cobalt by nickel led to a marked increase in the wavenumber. This increase in the $\mathrm{C}-\mathrm{O}$ stretching frequency corresponds to a stronger $\mathrm{C}$-O bond, due to less back-donation from cobalt in the CO $2 \pi$-antibonding orbitals. The change in wavenumber for the band corresponding to $\mathrm{CO}$ adsorbed on Ni was less pronounced. The observed wavenumber shifts can then point to a change in the electron density of $\mathrm{Ni}$ and in particular Co in the bimetallic samples, indicative of a close Co-Ni contact likely due to formation of alloyed nanoparticles ${ }^{57,70,71}$.
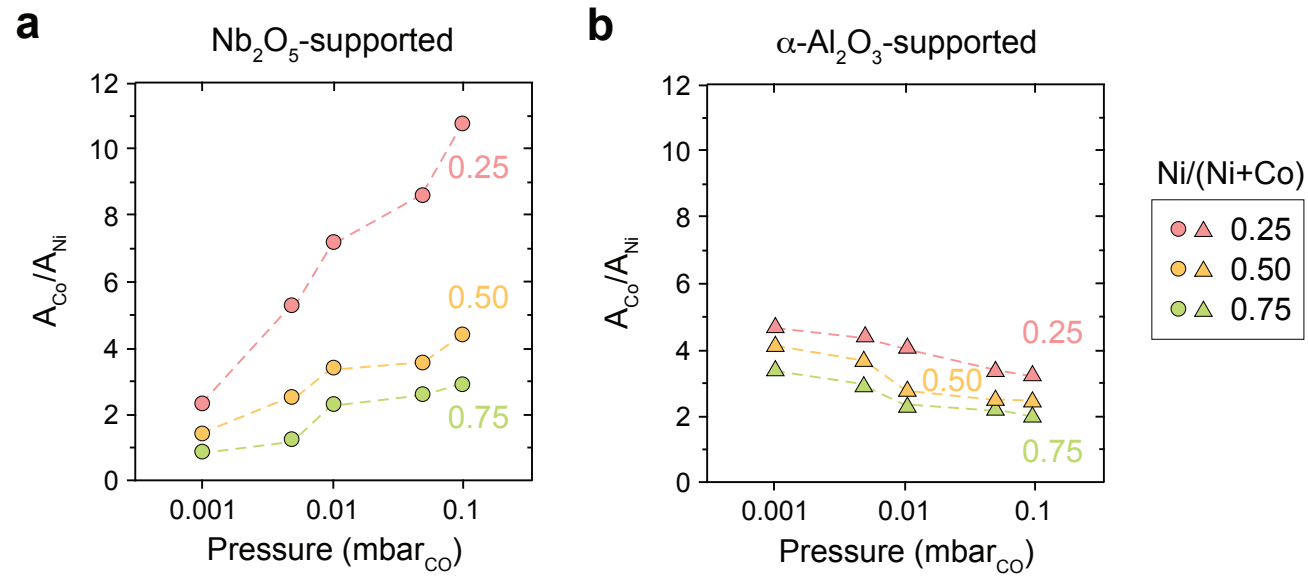

Figure 5.4 Ratio of the IR band areas of linearly adsorbed CO on cobalt and nickel as a function of CO pressure for bimetallic nanoparticles supported on $\mathrm{Nb}_{2} \mathrm{O}_{5}(\mathbf{a})$ and $\alpha-\mathrm{Al}_{2} \mathrm{O}_{3}(\mathbf{b})$. Measurements were carried out at $220{ }^{\circ} \mathrm{C}$.

\subsubsection{Fischer-Tropsch synthesis}

The catalysts FT performance was studied at 1 bar total pressure $\left(\mathrm{H}_{2} / \mathrm{CO}=2 \mathrm{v} / \mathrm{v}\right)$ and $220{ }^{\circ} \mathrm{C}$ after in-situ reduction at $350{ }^{\circ} \mathrm{C}$ for $2 \mathrm{~h}$. Figure 5.5 shows a summary of the catalytic performance after $40 \mathrm{~h}$-on-stream and comprehensive data can be found in Appendix D, Table D2. The metal-normalized catalytic activity of the titania- and niobia-supported catalysts proved markedly higher than the activity of the $\alpha$-alumina-supported samples for all metal compositions (Figure 5.5a). Furthermore, a large increase in activity is observed for the Co-Ni catalysts supported on reducible oxides with increasing nickel content, reaching the highest activity at $\mathrm{Ni} /(\mathrm{Ni}+\mathrm{Co})=0.75$ at/at. On the other hand, samples supported on $\alpha$-alumina showed little change upon cobalt substitution by nickel, with a slightly lower 
a
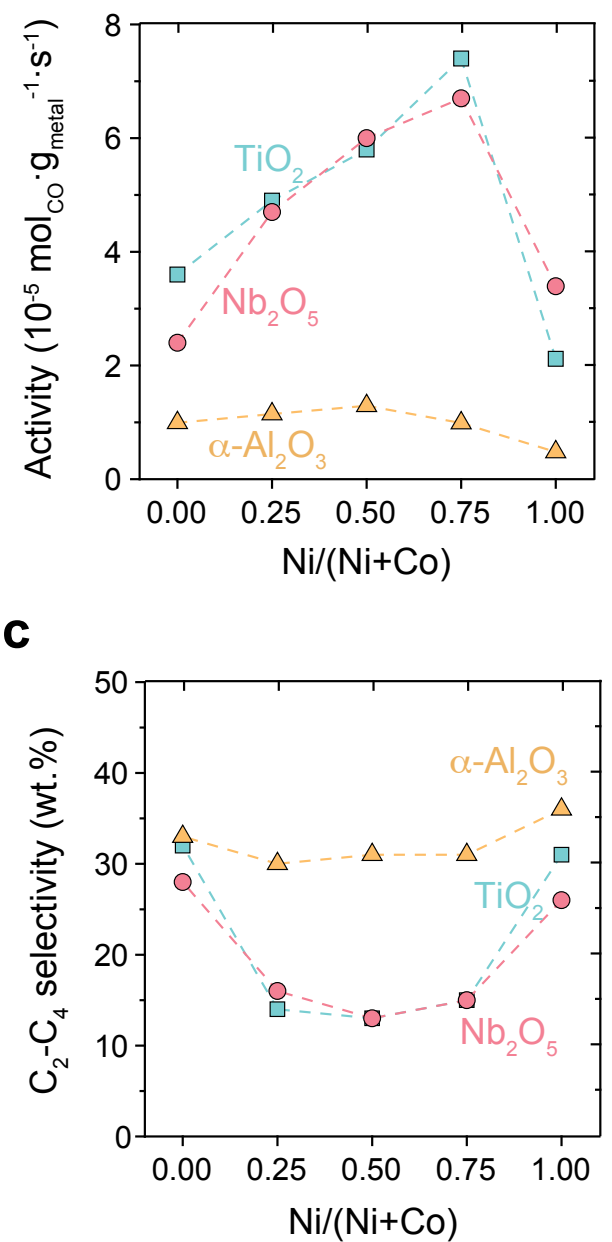

b

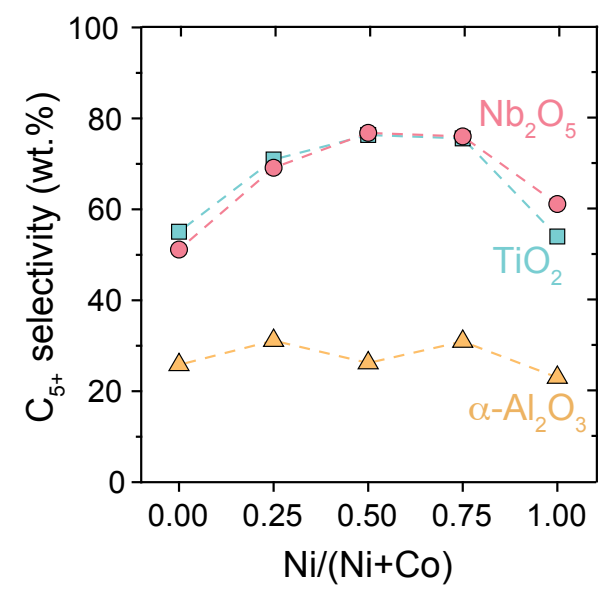

d

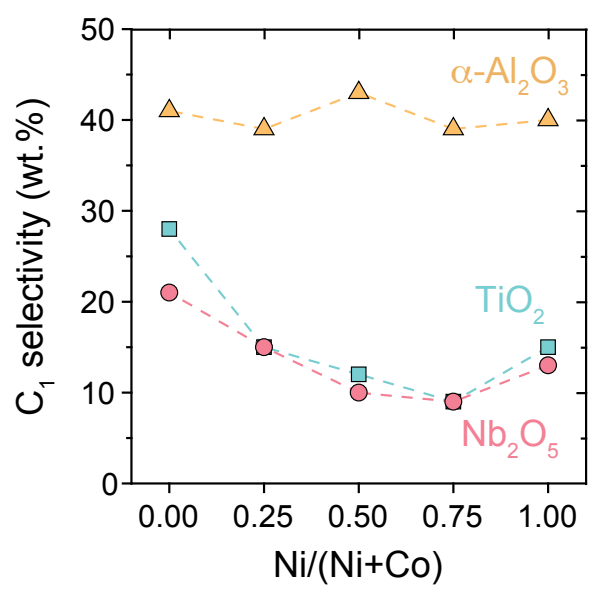

Figure 5.5 Summary of the catalytic performance after 40 h-on-stream at 1 bar $\left(\mathrm{H}_{2} / \mathrm{CO}=2 \mathrm{v} / \mathrm{v}\right)$ and $220{ }^{\circ} \mathrm{C}$ for samples with various cobalt to nickel ratios supported on reducible $\left(\mathrm{Nb}_{2} \mathrm{O}_{5}\right.$ and $\left.\mathrm{TiO}_{2}\right)$ and non-reducible $\left(\alpha-\mathrm{Al}_{2} \mathrm{O}_{3}\right)$ oxides. a, Activity normalized by total metal weight loading of bi- and monometallic catalysts supported on reducible and non-reducible oxides. The corresponding selectivities for $\mathrm{C}_{5+}, \mathrm{C}_{2}-\mathrm{C}_{4}$, and $\mathrm{C}_{1}$ products are shown in $\mathbf{b}, \mathbf{c}$ and d respectively.

activity for the nickel-rich samples $(\mathrm{Ni} /(\mathrm{Ni}+\mathrm{Co})=0.75$ and 1.0 at/at $)$. Turnover-frequencies (TOFs) followed a similar trend (Appendix D: Table D2), in which cobalt substitution by nickel for titania- and niobia-supported catalysts led to higher TOFs, whereas $\alpha$-alumina-supported catalysts displayed lower TOFs upon addition of nickel. The selectivities of the catalysts were strongly influenced by the nature of the support and the composition of supported metals (Figure 5.5b-d). Long-chain hydrocarbons $\left(\mathrm{C}_{5+}\right)$ selectivities surprisingly reached values of around $80 \mathrm{wt} . \%$ for the intermediate $\mathrm{Co}-\mathrm{Ni}$ samples supported on reducible supports, despite the low pressure applied (Figure 5.5b). In turn, $\mathrm{C}_{1}$ and $\mathrm{C}_{2}-\mathrm{C}_{4}$ selectivities were lower in these samples than for the monometallic ones (Figure 5.5c and 
d). In stark contrast, $\alpha$-alumina-supported samples showed low $\mathrm{C}_{5+}$ and high $\mathrm{C}_{1}$ and $\mathrm{C}_{2}-\mathrm{C}_{4}$ selectivities for all metal compositions. Independently of the nanoparticles' composition selectivities did not change. Therefore, the exceptionally high $\mathrm{C}_{5+}$ selectivities and activities of the catalysts supported on reducible oxides emerged from a combination of nanoparticle composition and nature of the support.

In contrast to our observations, similar FT performance on reducible and non-reducible supports previously reported in the literature ${ }^{27}$ might originate from the pre-treatment employed, consisting there of a pre-reduction at $400{ }^{\circ} \mathrm{C}$, likely followed by exposure to air and reduction prior catalysis at $250^{\circ} \mathrm{C}$. These conditions might generate, besides Co-Ni segregation ${ }^{72}$, less suboxides from the reducible supports since the SMSI effect is sensible to reduction temperature and oxidative conditions ${ }^{36,43,73}$. In turn, a decrease of the promotional catalytic effect might have resulted in a similar performance to the non-reducible-supported catalysts.

The enhanced catalytic performance of the bimetallic catalysts supported on reducible oxides can be better understood when considering the observations by CO-FTIR. First, the interaction with $\mathrm{CO}$ led to nanoparticles with a surface enriched in cobalt when supported on reducible oxides and not on the non-reducible oxide (Figure 5.4). High initial FT activities have been previously observed when bimetallic nanoparticles have been prepared by sequential impregnation forcing a cobalt-enriched surface, in contrast to the samples with a nickel-enriched surface or the monometallic ones ${ }^{20}$. Second, we have identified a relationship between the wavenumber of maximum absorbance of linear-CO on cobalt and the corresponding TOF based on the experimental $\mathrm{H}_{2}$-uptake (Figure 5.6 and Appendix D: Table D3). The set of samples supported on alpha-alumina showed high TOFs as well as low wavenumber values, indicating a stronger $\mathrm{CO}$ adsorption to the metal surface and a weaker $\mathrm{C}-\mathrm{O}$ bond. Thus, higher TOFs here are tentatively ascribed to faster $\mathrm{CO}$ dissociation, proposed to be the rate determining step for the alpha-alumina-supported samples. This is in agreement with the work of Filot et al. ${ }^{4}$, where in their model $\mathrm{Co} / \alpha-\mathrm{Al}_{2} \mathrm{O}_{3}$ would fall between a regime controlled by the rate of $\mathrm{CO}$ dissociation and oxygen removal and addition of nickel (a less oxophilic metal) might move the rate-controlling step away from the oxygen removal regime to the one controlled by $\mathrm{CO}$ dissociation. That results in a carbon coverage and concomitant high methane selectivity characteristic of nickel catalysts ${ }^{74}$. In the case of the titania- and niobia-supported samples, a reverse trend was observed, i.e. higher TOFs coincide with higher wavenumbers of adsorbed CO. We propose that CO here is weakly bonded to the metal surface, allowing a closer to optimal surface hydrogen coverage ${ }^{4,28,75}$. In contrast to the alpha-alumina catalysts, $\mathrm{CO}$ dissociation is no longer the rate determining step for reducible supports, but more likely the hydrogenation of surface carbon. Similar to $\mathrm{MnO}$ on cobalt ${ }^{76-79}, \mathrm{NbO}_{\mathrm{x}}$ and $\mathrm{TiO}_{\mathrm{x}}$ suboxides on the Co-Ni surface might generate active sites with altered effects on the FT mechanism and more specifically accelerate $\mathrm{CO}$ dissociation. Following the model of Filot et al. ${ }^{4}, \mathrm{Co}-\mathrm{Ni}$ on reducible supports then diverges from the regime controlled by $\mathrm{CO}$ dissociation towards a regime closer to an optimal balance between $\mathrm{CO}$ dissociation, carbon hydrogenation and oxygen removal, similar to Ru.

Additionally, the stability of the catalysts was influenced by the support. Figure 5.7 


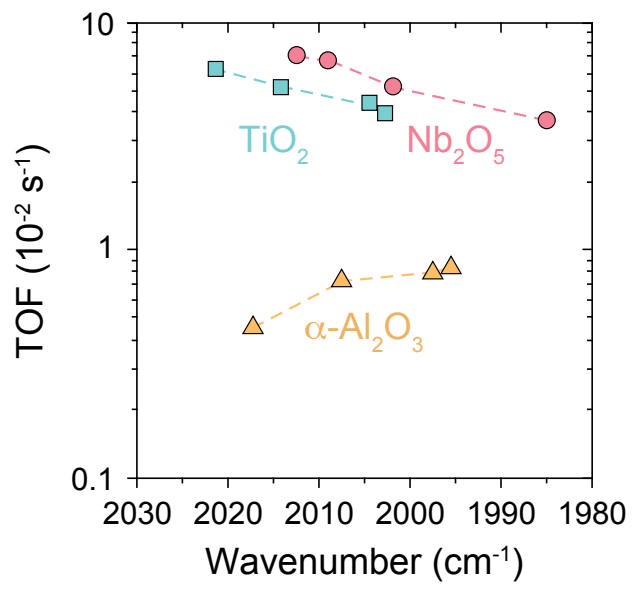

Figure 5.6 Relationship between turn-over-frequency (TOF) and wavenumber of linear-CO on cobalt $\left(\mathrm{P}_{\mathrm{CO}}=0.1 \mathrm{mbar}\right)$ for the Co- and CoNi-based catalysts supported on titania, niobia and alpha-alumina. TOFs were obtained based on the experimental $\mathrm{H}_{2}$-uptake derived from $\mathrm{H}_{2}$-chemisorption and catalytic activity at 40 h-onstream $\left(1 \mathrm{bar}, \mathrm{H}_{2} / \mathrm{CO}=2 \mathrm{v} / \mathrm{v}\right.$ and $220{ }^{\circ} \mathrm{C}$, Table S3).

shows the relative change in activity during reaction for the different metal compositions supported on niobia, titania and alpha-alumina (a, $\mathbf{b}$ and $\mathbf{c}$, respectively). Catalysts containing cobalt and nickel supported on niobia or titania showed similar activity loss as the samples containing only cobalt ( $20-25 \%)$, however, the largest activity loss was observed for catalysts containing only nickel, $35 \%$ for $\mathrm{Nb}_{2} \mathrm{O}_{5}$ and $55 \%$ for $\mathrm{TiO}_{2}$. For the $\alpha-\mathrm{Al}_{2} \mathrm{O}_{3}$-supported catalysts the activity loss increased with increasing nickel content relative to cobalt, with the monometallic cobalt sample being the most stable ( $25 \%$ activity loss) and the monometallic nickel one the least (60\% activity loss). Activity loss in nickel-based catalysts under these conditions is often driven by a decrease of nickel specific surface area due to formation and diffusion of volatile nickel tetracarbonyl from small to large nanoparticles and leading to overall particle growth ${ }^{80,81}$. Nickel carbonyl formation can be avoided by alloying nickel with another metal or by the SMSI effect with a reducible oxide as support ${ }^{44,45,82,83}$. This rationalizes the stability of the Co-Ni samples supported on niobia and titania. However, for
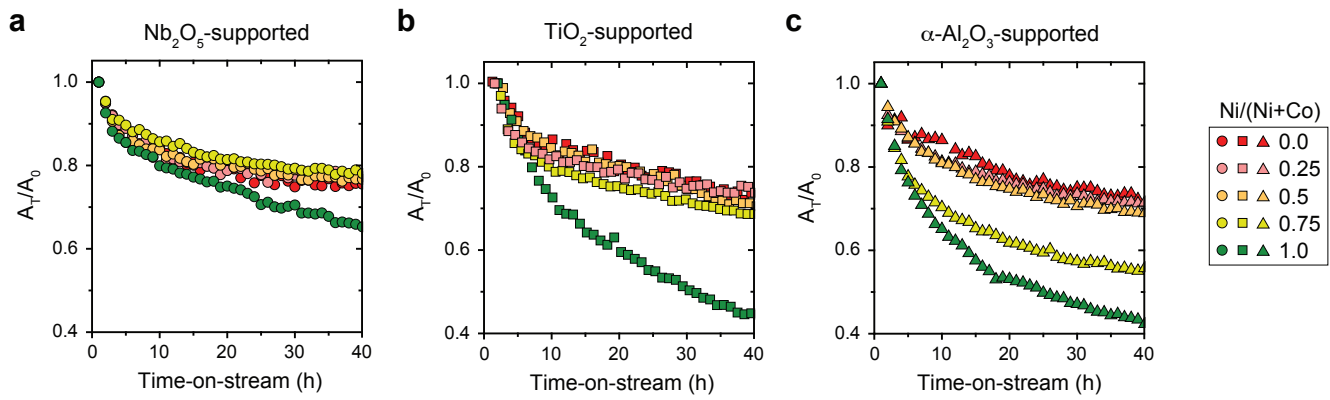

Figure 5.7 Relative change in catalytic activity throughout time for samples supported on niobia (a), titania (b) and alpha-alumina (c). Reaction conditions: 1 bar $\left(\mathrm{H}_{2} / \mathrm{CO}=2 \mathrm{v} / \mathrm{v}\right), 220^{\circ} \mathrm{C}$ and $40 \mathrm{~h}$-on-stream. Samples were reduced in-situ under hydrogen flow at $350{ }^{\circ} \mathrm{C}\left(5^{\circ} \mathrm{C} \cdot \mathrm{min}^{-1}, 2 \mathrm{~h}\right)$ prior to reaction. 
the monometallic nickel samples supported on reducible oxides a reduction temperature of $350{ }^{\circ} \mathrm{C}$ prior reaction most likely is not high enough to induce a SMSI state capable of completely hampering nickel tetracarbonyl formation ${ }^{45}$, and thus the activity loss.

STEM-EDX of the used niobia-supported Co-Ni catalysts revealed minor changes on the particle size and metal distribution compared to the freshly reduced samples (Appendix D: Figure D2d-f). In the case of the alumina-based catalyst, STEM-EDX of the sample with composition $\mathrm{Ni} /(\mathrm{Ni}+\mathrm{Co})=0.50$ at/at (Appendix D: Figure D6d) showed substantial particle growth, $9 \mathrm{~nm}$ for the freshly reduced sample against $32 \mathrm{~nm}$ for the sample after FT, and areas with non-uniform cobalt and nickel distribution. The extensive particle growth most likely originated from nickel carbonyl formation and diffusion, leading subsequently to a decrease in the catalytic activity. Metal quantification by EDX and ICP analyses showed that the amount of nickel before and after reaction conditions had not changed (Appendix D: Table D4). This suggests that despite the possible formation of $\mathrm{Ni}(\mathrm{CO})_{4}$ the conditions (pressure, time, etc.) were not severe enough to remove a measurable quantity of nickel from the catalyst bed at atmospheric pressure, in agreement with previous research ${ }^{81}$.

Overall, the catalytic performance results at 1 bar show that the combination of reducible oxides as support material together with bimetallic cobalt-nickel nanoparticles have the potential of highly active, selective and stable Fischer-Tropsch catalysts. Therefore, we focused on these samples and the monometallic cobalt ones $(\mathrm{Ni} /(\mathrm{Ni}+\mathrm{Co})=0.0,0.25,0.50$ and $0.75 \mathrm{at} / \mathrm{at}$ ) to evaluate their catalytic performance at higher pressures. Due to the likely formation of volatile nickel tetracarbonyl already at 1 bar for samples containing only nickel $(\mathrm{Ni} /(\mathrm{Ni}+\mathrm{Co})=1.0$ at/at $)$ and $\alpha-\mathrm{Al}_{2} \mathrm{O}_{3}$-supported samples containing nickel, experiments at higher pressures were not carried out for these samples to avoid the risk of nickel loss from the catalysts.

The high-pressure Fischer-Tropsch catalytic performance was studied at $220{ }^{\circ} \mathrm{C}$ and $20 \mathrm{bar}\left(\mathrm{H}_{2} / \mathrm{CO}=2 \mathrm{v} / \mathrm{v}\right)$ for $100 \mathrm{~h}$-on-stream. The catalytic activity through time is shown in Figure 5.8 for the titania- and niobia-supported catalysts ( $\mathbf{a}$ and $\mathbf{b}$ respectively). Increase in the reaction pressure to 20 bar largely improved the activity of the monometallic and cobalt-rich samples. Particularly samples containing $25 \%$ nickel $(\mathrm{Ni} /(\mathrm{Ni}+\mathrm{Co})=0.25$ at/at $)$ had an activation period during the first hours of the experiment resulting eventually in the highest metal-normalized activities and turnover-frequencies of the set of samples. Comprehensive data after $100 \mathrm{~h}$-on-stream can be found in Appendix D: Table D2. Similar activation of bimetallic Co-Ni catalysts for FT has been previously observed and attributed to partial segregation of the metals during reaction ${ }^{24}$. Replacement of $50 \%$ cobalt by nickel $(\mathrm{Ni} /(\mathrm{Ni}+\mathrm{Co})=0.50 \mathrm{at} / \mathrm{at})$ showed similar activities as the cobalt-based catalysts. However, the nickel-rich samples $(\mathrm{Ni} /(\mathrm{Ni}+\mathrm{Co})=0.75$ at $/$ at $)$ did not show an increase in activity by increasing the reaction pressure and thus became the less active catalysts under these conditions.

Selectivity trends were similar for both support materials, the main changes were observed throughout the reaction depending on the Co-Ni composition (Figure 5.9). Cobalt-rich catalysts showed increased $\mathrm{C}_{5+}$ selectivities upon pressure increase. $\mathrm{Ni} /(\mathrm{Ni}+\mathrm{Co})=0.0$ and 0.25 at/at samples presented the highest $\mathrm{C}_{5_{+}}$selectivities with $83 \%$ for $\mathrm{TiO}_{2}$ and $86 \%$ for $\mathrm{Nb}_{2} \mathrm{O}_{5}$ (Figure 5.9a and d, respectively). $\mathrm{C}_{2}-\mathrm{C}_{4}$ selectivity increased with increasing nickel 

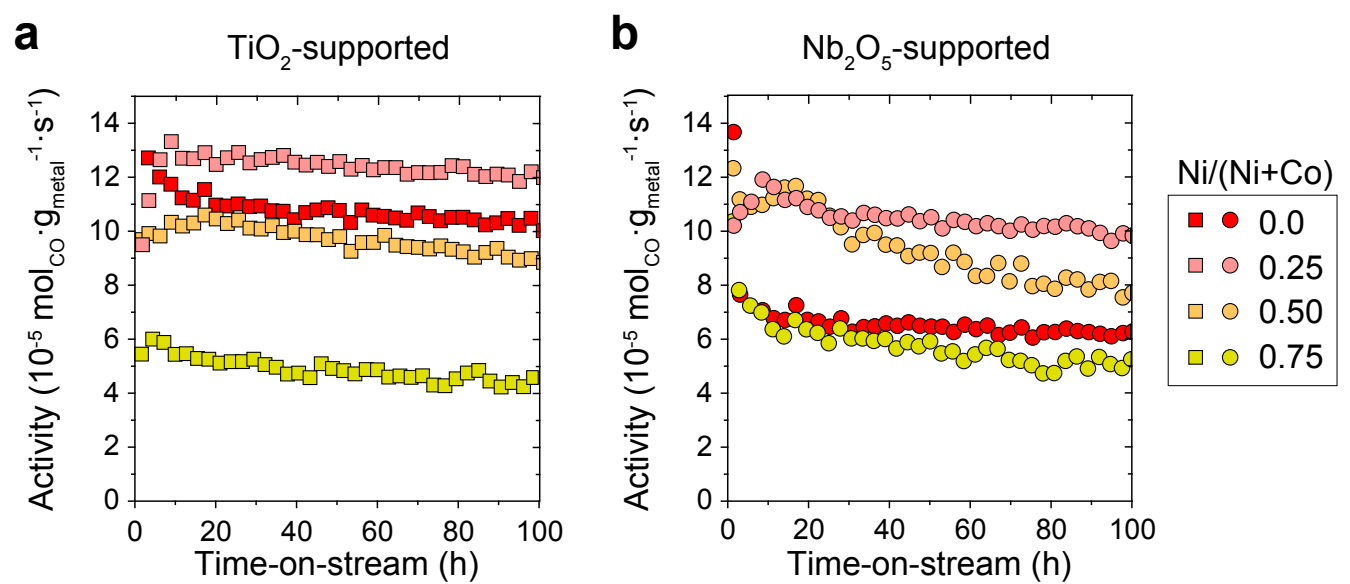

Figure 5.8 Metal weight-normalized catalytic activity against time-on-stream for cobalt and cobalt-nickel catalysts supported on titania (a) and on niobia (b). Prior to reaction conditions, samples were reduced in-situ at $350{ }^{\circ} \mathrm{C}$ in $25 \mathrm{vol} \% \mathrm{H}_{2}$ in $\mathrm{He}$ at 1 bar. Reaction conditions: $220{ }^{\circ} \mathrm{C}, 20$ bar and $\mathrm{H}_{2} / \mathrm{CO}=2 \mathrm{v} / \mathrm{v}$.

content (Figure 5.9b and e). During the first $20 \mathrm{~h}$ on stream a sharp decrease in $\mathrm{C}_{2}-\mathrm{C}_{4}$ selectivity was observed for all nickel-containing catalysts. At the same time, these samples also showed an initial increase in $\mathrm{C}_{5+}$ selectivity during the first $10 \mathrm{~h}$ on stream. $\mathrm{C}_{1}$ selectivities were relatively low for all samples, but no clear trend with nickel content was found (Figure 5.9c and $\mathbf{f}$ ). All samples showed an increase in $\mathrm{C}_{1}$ selectivity at the beginning of the experiment, however for the bimetallic samples this increase took around $40 \mathrm{~h}$-on-stream to reach stable values whereas for the monometallic samples occurred during the first 10 h-on-stream.

When compared to cobalt-nickel supported on non-reducible oxides from literature, the activity of the niobia- and titania-supported catalysts proved superior at similar reaction conditions, while maintaining similar $\mathrm{C}_{5+}$ selectivities (Appendix D: Figure D12 and Table D5). Hence, the promotional effect of reducible oxides on Co-Ni nanoparticles was maintained at high pressures.

STEM-EDX of the used Co-Ni catalysts supported on niobia showed a quite uniform composition in the metal nanoparticles, some particle growth and some areas of the support depleted of nanoparticles (Appendix D: Figure D2g-i). For the Co-rich sample, nanoparticles containing only cobalt, that were observed after reduction and after low-pressure catalysis (Appendix D: Figure D3), were no longer observed; all nanoparticles contained both cobalt and nickel. Similar changes were observed in the titania-supported $\mathrm{Ni} /(\mathrm{Ni}+\mathrm{Co})=0.50$ at $/ \mathrm{at}$ catalyst (Appendix D: Figure D7). Furthermore, some nanoparticles in the sample with highest initial nickel content $(\mathrm{Ni} /(\mathrm{Ni}+\mathrm{Co})=0.75$ at/at $)$ supported on niobia showed a surface enriched with cobalt, confirmed by a cross section of the Co-Ni distribution (Appendix D: Figure D13). The rearrangement of the metals might originate from a structure change during the high-pressure conditions ${ }^{84,85}$, a faster oxidation of cobalt when exposed to air after the experiment accompanied by the Kirkerdall effect ${ }^{72,86,87}$ or nickel interparticle transport related to the high CO partial pressure ${ }^{88,89}$. Quantification of the EDX maps for various sam- 
ples revealed even a loss in nickel relative to the cobalt content confirmed by ICP (Appendix D: Table D4). Despite the loss of nickel, Co-Ni catalysts compared to the monometallic cobalt showed similar $\mathrm{C}_{5+}$ selectivities and higher Fischer-Tropsch activities for the samples $\mathrm{Ni}$ / $(\mathrm{Ni}+\mathrm{Co})=0.25$ at/at supported on titania and $\mathrm{Ni} /(\mathrm{Ni}+\mathrm{Co})=0.25$ and 0.50 at/at supported on niobia.

The set of samples was additionally studied at higher temperatures, namely 240 and $260{ }^{\circ} \mathrm{C}$, and $20 \mathrm{bar}$, since reducible supports have shown potential for operating at high temperatures without sacrificing $\mathrm{C}_{5+}$ selectivity ${ }^{90}$. Figures D14 and D15 in Appendix D show a summary of the catalytic performance after $100 \mathrm{~h}$-on-stream, 20 bar and $220-260{ }^{\circ} \mathrm{C}$ (the exact values can be found in Appendix D: Table D2). A temperature increase magnified the

a

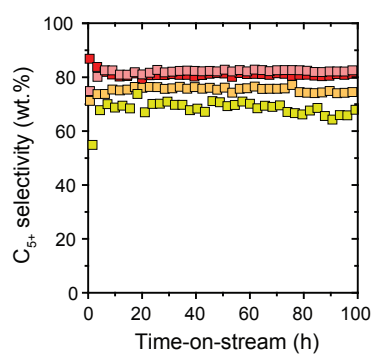

d

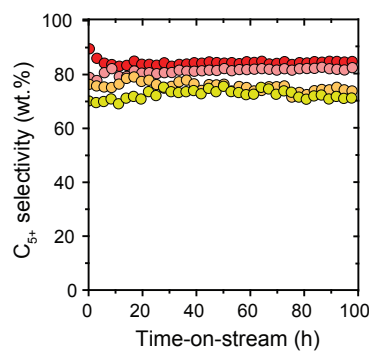

b

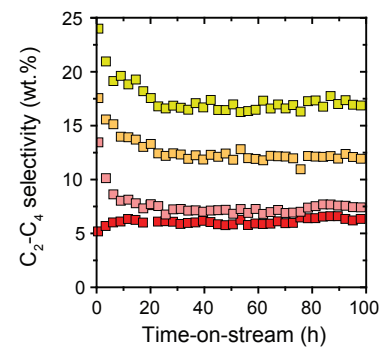

e

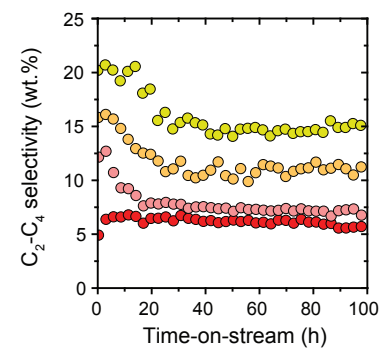

C

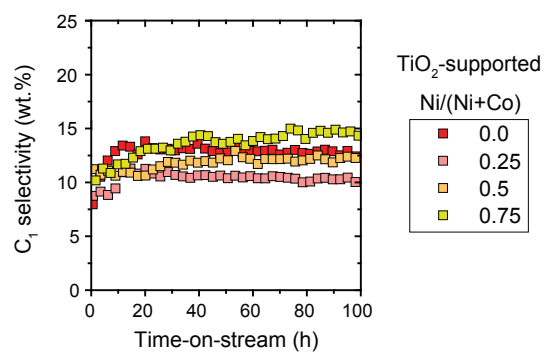

f

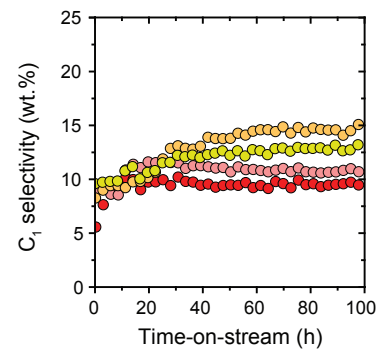

$\mathrm{Nb}_{2} \mathrm{O}_{5}$-supported

$\mathrm{Ni} /(\mathrm{Ni}+\mathrm{Co})$

- 0.0

0.25

$\circ 0.5$

$\circ \quad 0.75$

Figure 5.9 Selectivities against time-on-stream for catalysts supported on $\mathrm{TiO}_{2}(\mathbf{a}, \mathbf{b}$ and $\mathbf{c})$ and $\mathrm{Nb}_{2} \mathrm{O}_{5}(\mathbf{d}, \mathrm{e}, \mathbf{f})$. Selectivities are divided in $\mathrm{C}_{5+}(\mathbf{a}$ and $\mathbf{d}), \mathrm{C}_{2}-\mathrm{C}_{4}(\mathbf{b}$ and $\mathbf{e})$ and $\mathrm{C}_{1}(\mathbf{c}$ and $\mathbf{f})$. Prior to reaction, samples were reduced in-situ at $350{ }^{\circ} \mathrm{C}\left(1{ }^{\circ} \mathrm{C} \cdot \mathrm{min}^{-1}, 8 \mathrm{~h}\right)$ in $25 \mathrm{vol} . \% \mathrm{H}_{2}$ in He at 1 bar. Reaction conditions: $220{ }^{\circ} \mathrm{C}, 20 \mathrm{bar}$ and $\mathrm{H}_{2} / \mathrm{CO}=2 \mathrm{v} / \mathrm{v}$.

activity trends already observed at $220{ }^{\circ} \mathrm{C}$, in the order $0.25>0.50>0.0>0.75$ at/at for the niobia-supported samples and $0.25>0.0>0.50>0.75$ at/at for the titania-supported samples. More surprisingly, selectivity trends drastically changed with the increase in reaction temperature. For both titania- and niobia-supported samples the increase in temperature resulted in a notorious increase in $\mathrm{C}_{1}$ and $\mathrm{C}_{2}-\mathrm{C}_{4}$ products at the expense of $\mathrm{C}_{5+}$ ones (Appendix D: Figures D14 and D15 b, c and d). This behavior attenuated upon increasing the nickel content, thus the monometallic cobalt catalysts showed the largest increase in $\mathrm{C}_{1}$ and $\mathrm{C}_{2}-\mathrm{C}_{4}$ selectivities whereas the nickel-rich catalyst $(\mathrm{Ni} /(\mathrm{Ni}+\mathrm{Co})=0.75$ at $/$ at $)$ had an almost unchanged selectivity upon increasing the reaction temperature. The selectivity trends observed at $220{ }^{\circ} \mathrm{C}$ had practically inverted at $260{ }^{\circ} \mathrm{C}$. 
Apparent activation energies were derived from the catalytic activities at temperatures of $220-260{ }^{\circ} \mathrm{C}$ and plotted as a function of $\mathrm{Ni} /(\mathrm{Ni}+\mathrm{Co})$ for both supports (Figure 5.9). At high nickel content $(\mathrm{Ni} /(\mathrm{Ni}+\mathrm{Co})=0.75$ at/at $)$ the activation energy had increased compared to the monometallic cobalt catalysts on both supports. A substitution of $50 \%$ of the cobalt by nickel displayed similar activation energy as for the cobalt-only catalysts. Finally, substitution of cobalt by $25 \%$ nickel decreased the activation energy, indicating that up to a certain nickel concentration, it functioned as a promoter, which was also reflected by increased turnover frequencies.

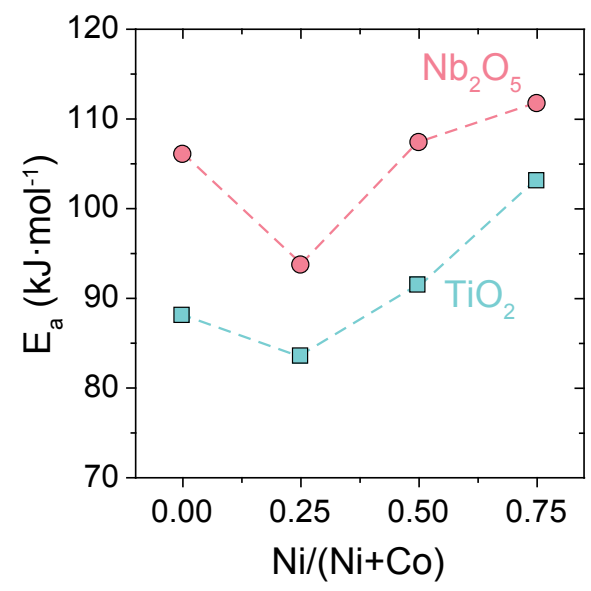

Figure 5.9 Apparent activation energies for catalysts with different cobalt to nickel ratios supported on titania (blue squares) and niobia (red circles). Apparent activation energies were obtained from the slopes of the Arrhenius equation in the linear form (Figure S18), reaction conditions: 20 bar, $\mathrm{H}_{2} / \mathrm{CO}=2 \mathrm{v} / \mathrm{v}$, after $100 \mathrm{~h}$-on-stream and temperatures of 220,240 and $260{ }^{\circ} \mathrm{C}$.

\subsection{Conclusions}

Bimetallic Co-Ni nanoparticles supported on reducible $\left(\mathrm{TiO}_{2}\right.$ and $\left.\mathrm{Nb}_{2} \mathrm{O}_{5}\right)$ and non-reducible $\left(\alpha-\mathrm{Al}_{2} \mathrm{O}_{3}\right)$ oxides were synthesized and characterized, and their catalytic performance in the Fischer Tropsch (FT) synthesis was evaluated. Samples were prepared by co-impregnation of aqueous solutions with varying cobalt to nickel atomic ratio. After calcination, samples were characterized by TPR where a shift towards lower temperatures in the reduction profiles of the bimetallic samples was observed, in comparison to the monometallic samples, indicative of a close interaction between the cobalt and nickel oxides. TEM of the reduced samples revealed that gradual substitution of cobalt by nickel led to a decrease in nanoparticle size on all support materials. However, comparison of the theoretical and experimental $\mathrm{H}_{2}$-uptakes (derived from TEM and $\mathrm{H}_{2}$-chemisorption, respectively) showed a discrepancy for the samples supported on reducible oxides, which was ascribed to the SMSI effect. Whereas the samples supported on the non-reducible support did not show this difference. STEM-EDX analysis of the reduced and passivated catalysts demonstrated 
that while nickel was always found together with cobalt, cobalt could be found without nickel. Nanoparticles containing both metals showed a uniform Co-Ni distribution. Moreover, CO-FTIR results suggested that for the reducible supports, the metal nanoparticles likely underwent a cobalt-enrichment at their surface upon increasing the CO pressure, while the nanoparticles supported on alumina did not. This indicated that the surface composition of the nanoparticles was affected by the metal-support interaction.

The low-pressure catalytic performance showed substantially higher activities, $\mathrm{C}_{5+}$ selectivities and stabilities for the bimetallic nanoparticles supported on reducible oxides. In contrast, the alumina-based catalysts showed low activities and $\mathrm{C}_{5+}$ selectivities independently of the Co-Ni composition and, moreover, a continuous loss of activity. The marked difference in catalytic performance was tentatively coined to a shift of the rate determining step, as derived from the trend between TOF and CO-FTIR. For Co-Ni supported on reducible oxides, a weaker adsorption of $\mathrm{CO}$ was inferred, which improves $\mathrm{H}$ adsorption and the catalytic activity. The catalytic performances of the samples supported on reducible supports were also studied at 20 bar and various temperatures. At $220{ }^{\circ} \mathrm{C}$, the cobalt-rich samples benefited from the increase in pressure resulting in high activity and $\mathrm{C}_{5+}$ selectivities. However, higher reaction temperatures inverted the selectivity trend. Yet, a comparison to non-reducible-supported catalysts from the literature showed the promotional effect of reducible oxides on bimetallic nanoparticles. $25 \%$ substitution of cobalt by nickel led to lower apparent activation energy values, implying that nickel acted as promotor in these samples. In summary, we showed that the combination of cobalt and nickel supported on reducible oxides allowed for increased FT performance. Reducible oxides used as support material strongly modify the reactivity of bimetallic nanoparticles thus opening up avenues to arrive at more efficient catalysts.

\section{Acknowledgements}

Companhia Brasileira de Metalurgia e Mineração (CBMM) is thanked for financial support. KPdJ acknowledges support from the European Research Council, EU FP7 ERC Advanced Grant no. 338846. JvdH and PdJ acknowledge funding from the European Research Council (ERC) under the European Union's Horizon 2020 research and innovation programme (ERC-2014-CoG No 648991). Mrs. Savannah Turner (Utrecht University) is acknowledged for performing TEM measurements. Mr. Miguel Rivera-Torrente, Mrs. Zanoni Silvia and Mr. Herrick Schaink (Utrecht University) are thanked for their assistance and support during the CO-FTIR measurements. Mr. Lennart Weber and Mr. Tom W. van Deelen (Utrecht University) are thanked for their support during the catalytic performance and fruitful discussions throughout the project. 


\section{References}

1. Chu, S. \& Majumdar, A. Opportunities and challenges for a sustainable energy future. Nature 488, 294-303 (2012).

2. Staples, M. D., Malina, R. \& Barrett, S. R. H. The limits of bioenergy for mitigating global life-cycle greenhouse gas emissions from fossil fuels. Nat. Energy 2, 1-8 (2017).

3. Armstrong, R. C. et al. The frontiers of energy. Nat. Energy 1, 15020 (2016).

4. Filot, I. A. W., Van Santen, R. A. \& Hensen, E. J. M. The optimally performing Fischer-Tropsch catalyst. Angew. Chemie - Int.Ed. 53, 12746-12750 (2014).

5. Chen, W., Filot, I. A. W., Pestman, R. \& Hensen, E. J. M. Mechanism of Cobalt-Catalyzed CO Hydrogenation: 2. Fischer-Tropsch Synthesis. ACS Catal. 7, 8061-8071 (2017).

6. Van Santen, R. A., Markvoort, A. J., Ghouri, M. M., Hilbers, P. A. J. \& Hensen, E. J. M. Monomer formation model versus chain growth model of the Fischer-Tropsch reaction. J. Phys. Chem. C 117, 4488-4504 (2013).

7. Besenbacher, F. et al. Design of a surface alloy catalyst for steam reforming. Science 279, 1913-1915 (1998).

8. Ferrando, R., Jellinek, J. \& Johnston, R. L. Nanoalloys: From theory to applications of alloy clusters and nanoparticles. Chem. Rev. 108, 845-910 (2008).

9. Calderone, V. R., Shiju, N. R., Ferré, D. C. \& Rothenberg, G. Bimetallic catalysts for the Fischer-Tropsch reaction. Green Chem. 13, 1950-1959 (2011).

10. Jacobsen, C. J. H. et al. Catalyst design by interpolation in the periodic table: Bimetallic ammonia synthesis catalysts. J.Am. Chem. Soc. 123, 8404-8405 (2001).

11. Dry, M. E. The Fischer-Tropsch process: 1950-2000. Catal. Today 71, 227-241 (2002).

12. Cheng, K. et al. Advances in catalysis for syngas conversion to hydrocarbons. Adv. Catal. 60, 125-208 (2017).

13. Pan, W. X., Cao, R. \& Griffin, G. L. Direct alcohol synthesis using copper/cobalt catalysts. J. Catal. 114, 447-456 (1988).

14. Prieto, G. et al. Design and synthesis of copper-cobalt catalysts for the selective conversion of synthesis gas to ethanol and higher alcohols. Angew. Chemie - Int. Ed. 53, 6397-6401 (2014).

15. Xiang, Y., Barbosa, R., Li, X. \& Kruse, N. Ternary cobalt-copper-niobium catalysts for the selective CO hydrogenation to higher alcohols. ACS Catal. 5, 2929-2934 (2015).

16. Calderone, V. R. et al. De novo design of nanostructured iron-cobalt fischer-tropsch catalysts. Angew. Chemie Int.Ed. 52, 4397-4401 (2013).

17. Griboval-Constant, A., Butel, A., Ordomsky, V. V., Chernavskii, P. A. \& Khodakov, A. Y. Cobalt and iron species in alumina supported bimetallic catalysts for Fischer-Tropsch reaction. Appl. Catal. A Gen. 481, 116-126 (2014).

18. Enger, B. C. \& Holmen, A. Nickel and Fischer-Tropsch synthesis. Catal. Rev. - Sci. Eng. 54, 437-488 (2012).

19. Ishihara, T. et al. Effect of alloying on $\mathrm{CO}$ hydrogenation activity over $\mathrm{SiO}_{2}$-supported CoNi alloy catalysts. $J$. Catal. 136, 232-241 (1992).

20. Shimura, K., Miyazawa, T., Hanaoka, T. \& Hirata, S. Fischer-Tropsch synthesis over alumina supported bimetallic Co-Ni catalyst: Effect of impregnation sequence and solution. J.Mol. Catal. A Chem. 407, 15-24 (2015).

21. Das, P. C., Pradhan, N. C., Dalai, A. K. \& Bakshi, N. N. Carbon monoxide hydrogenation over zirconia supported Ni and Co-Ni bimetallic catalysts. Catal. Letters 98, 153-160 (2004).

22. Razzaq, R. et al. Catalytic methanation of $\mathrm{CO}$ and $\mathrm{CO}_{2}$ in coke oven gas over $\mathrm{Ni}-\mathrm{Co} / \mathrm{ZrO}_{2}-\mathrm{CeO}_{2}$. Ind. Eng. Chem. Res. 52, 2247-2256 (2013).

23. van Helden, P. et al. Cobalt-nickel bimetallic Fischer-Tropsch catalysts: A combined theoretical and experimental approach. Catal. Today 342, 88-98 (2020).

24. Rytter, E., Skagseth, T. H., Eri, S. \& Sjåstad, A. O. Cobalt fischer-tropsch catalysts using nickel promoter as a rhenium substitute to suppress deactivation. Ind. Eng. Chem. Res. 49, 4140-4148 (2010).

25. Arai, H., Mitsuishi, K. \& Seiyama, T. $\mathrm{TiO}_{2}$-supported $\mathrm{Fe}-\mathrm{Co}, \mathrm{Co}-\mathrm{Ni}$, and $\mathrm{Ni}-\mathrm{Fe}$ alloy catalysts for Fischer-Tropsch synthesis. Chem. Lett. 13, 1291-1294 (1984).

26. Ishihara, T., Eg, K. \& Arai, H. Hydrogenation of carbon monoxide over $\mathrm{SiO}_{2}$-supported Fe-Co, Co-Ni and Ni-Fe bimetallic catalysts. Appl. Catal. 30, 225-238 (1987).

27. Ishihara, T., Horiuchi, N., Eguchi, K. \& Arai, H. The effect of supports on the activity and selectivity of CoNi 
alloy catalysts for CO hydrogenation. J. Catal. 130, 202-211 (1991).

28. Ishihara, T., Eguchi, K. \& Arai, H. Importance of surface hydrogen concentration in enhancing activity of CoNi alloy catalyst for CO hydrogenation. J. Mol. Catal. 72, 253-261 (1992).

29. van Deelen, T. W., Hernández Mejía, C. \& de Jong, K. P. Control of metal-support interactions in heterogeneous catalysts to enhance activity and selectivity. Nat. Catal. 2, 955-970 (2019).

30. Roldan Cuenya, B. Synthesis and catalytic properties of metal nanoparticles: Size, shape, support, composition, and oxidation state effects. Thin Solid Films 518,3127-3150 (2010).

31. Divins, N. J., Angurell, I., Escudero, C., Pérez-Dieste, V. \& Llorca, J. Influence of the support on surface rearrangements of bimetallic nanoparticles in real catalysts. Science 346, 620-623 (2014).

32. Han, C.W. et al. Highly stable bimetallic AuIr/TiO 2 catalyst: Physical origins of the intrinsic high stability against sintering. Nano Lett. 15, 8141-8147 (2015).

33. Destro, P. et al. The crucial role of the support in the transformations of bimetallic nanoparticles and catalytic performance. ACS Catal. 8, 1031-1037 (2018).

34. Gubó, R. et al. Variation of SMSI with the Au:Pd Ratio of Bimetallic Nanoparticles on $\mathrm{TiO}_{2}(110)$. Top. Catal. 61,308-317 (2018).

35. Mouaddib, N., Perrichon, V. \& Primet, M. Bulk and surface characterization of supported cobalt-copper catalysts active in CO hydrocondensation. J. Chem. Soc. Faraday Trans. 1 Phys. Chem. Condens. Phases 85, 3413-3424 (1989).

36. Tauster, S. J., Fung, S. C. \& Garten, R. L. Strong metal-support interactions. Group 8 noble metals supported on titanium dioxide. J.Am. Chem. Soc. 100, 170-175 (1978).

37. Tauster, S. J. Strong metal-support interactions. Acc. Chem. Res. 20,389-394 (1987).

38. Reuel, R. C. \& Bartholomew, C. H. Effects of support and dispersion on the CO hydrogenation activity/selectivity properties of cobalt. J. Catal. 85, 78-88 (1984).

39. Johnson, G. R. \& Bell, A. T. Effects of Lewis acidity of metal oxide promoters on the activity and selectivity of Co-based Fischer-Tropsch synthesis catalysts. J. Catal. 338, 250-264 (2016).

40. Prieto, G. et al. Cobalt-catalyzed Fischer-Tropsch synthesis: Chemical nature of the oxide support as a performance descriptor. ACS Catal. 5, 3323-3335 (2015).

41. Boffa, A. B., Lin, C., Bell, A. T. \& Somorjai, G. A. Lewis acidity as an explanation for oxide promotion of metals: implications of its importance and limits for catalytic reactions. Catal. Letters 27, 243-249 (1994).

42. Maitlis, P. M. \& Zanotti, V. The role of electrophilic species in the Fischer-Tropsch reaction. Chem. Commun. 13, 1619-1634 (2009).

43. Hernández Mejía, C., van Deelen, T. W. \& de Jong, K. P. Activity enhancement of cobalt catalysts by tuning metal-support interactions. Nat. Commun. 9,4459 (2018).

44. Vannice, M. A. \& Garten, R. L. Metal-support effects on the activity and selectivity of Ni catalysts in $\mathrm{CO} / \mathrm{H}_{2}$ synthesis reactions. J. Catal. 56, 236-248 (1979).

45. Hernández Mejía, C., Vogt, C., Weckhuysen, B. M. \& De Jong, K. P. Stable niobia-supported nickel catalysts for the hydrogenation of carbon monoxide to hydrocarbons. Catal. Today 343, 56-62 (2020).

46. Schindelin, J. et al. Fiji: An open-source platform for biological-image analysis. Nat. Methods 9, 676-682 (2012).

47. Voss, G. J. B., Fløystad, J. B., Voronov, A. \& Rønning, M. The state of nickel as promotor in cobalt FischerTropsch synthesis catalysts. Top. Catal. 58, 896-904 (2015).

48. Tauster, S. J. \& Fung, S. C. Strong metal-support interactions: Occurrence among the binary oxides of groups IIA-VB. J. Catal. 55, 29-35 (1978).

49. Lögdberg, $S$. et al. Further insights into methane and higher hydrocarbons formation over cobalt-based catalysts with $\gamma-\mathrm{Al}_{2} \mathrm{O}_{3}, \alpha-\mathrm{Al}_{2} \mathrm{O}_{3}$ and $\mathrm{TiO}_{2}$ as support materials. J. Catal. 352, 515-531 (2017).

50. Van Der Hoeven, J. E. S. et al. In situ observation of atomic redistribution in alloying gold-silver nanorods. ACS Nano 12, 8467-8476 (2018).

51. Ansorge, J. \& Förster, H. Transient ir spectroscopic investigation of surface-carbonyl formation on a supported cobalt catalyst. J. Catal. 68, 182-185 (1981).

52. Lapidus, A. et al. Hydrocarbon synthesis from carbon monoxide and hydrogen on impregnated cobalt cata- 
lysts Part I. Physico-chemical properties of 10\% cobalt/alumina and 10\% cobalt/silica. Appl. Catal. $73,65-81$ (1991).

53. Beitel, G. A., Laskov, A., Oosterbeek, H. \& Kuipers, E. W. Polarization modulation infrared reflection absorption spectroscopy of CO adsorption on $\mathrm{Co}(0001)$ under a high-pressure regime. J. Phys. Chem. 100, 12494 12502 (1996).

54. Sun, S., Tsubaki, N. \& Fujimoto, K. The reaction performances and characterization of Fischer-Tropsch synthesis $\mathrm{Co} / \mathrm{SiO}_{2}$ catalysts prepared from mixed cobalt salts. Appl. Catal. A Gen. 202, 121-131 (2000).

55. Prieto, G., Martínez, A., Concepción, P. \& Moreno-Tost, R. Cobalt particle size effects in Fischer-Tropsch synthesis: structural and in situ spectroscopic characterisation on reverse micelle-synthesised Co/ITQ-2 model catalysts. J. Catal. 266, 129-144 (2009).

56. Kadinov, G., Bonev, C., Todorova, S. \& Palazov, A. IR spectroscopy study of CO adsorption and of the interaction between CO and hydrogen on alumina-supported cobalt. J. Chem. Soc. - Faraday Trans. 94, 3027-3031 (1998).

57. Dalmon, J. A., Primet, M., Martin, G. A. \& Imelik, B. Magnetic and infrared study of CO chemisorption on silica supported nickel-copper alloys. Surf. Sci. 50, 95-108 (1975).

58. Trenary, M., Uram, K. J. \& Yates, J. T. An infrared reflection-absorption study of CO chemisorbed on clean and sulfided $\mathrm{Ni}(111)$ - evidence for local surface interactions. Surf. Sci. 157, 512-538 (1985).

59. Agnelli, M., Swaan, H. M., Marquez-Alvarez, C., Martin, G. A. \& Mirodatos, C. CO hydrogenation on a nickel catalyst: II. A mechanistic study by transient kinetics and infrared spectroscopy. J. Catal. 175, 117-128 (1998).

60. Van Santen, R. A. Coordination of carbon monoxide to transition-metal surfaces. J. Chem. Soc., Faraday Trans. 1 83, 1915-1934 (1987).

61. Mihaylov, M., Hadjiivanov, K. \& Knözinger, H. Formation of $\mathrm{Ni}(\mathrm{CO})_{4}$ during the interaction between $\mathrm{CO}$ and silica-supported nickel catalyst: an FTIR spectroscopic study. Catal. Letters 76, 59-63 (2001).

62. Jensen, M. B. et al. FT-IR characterization of supported Ni-catalysts: Influence of different supports on the metal phase properties. Catal. Today 197, 38-49 (2012).

63. Primet, M. Electronic transfer and ligand effects in the infrared spectra of adsorbed carbon monoxide.J.Catal. 88, 273-282 (1984).

64. Toyoshima, I. \& Somorjai, G. A. Heats of chemisorption of $\mathrm{O}_{2}, \mathrm{H}_{2}, \mathrm{CO}, \mathrm{CO}_{2}$, and $\mathrm{N}_{2}$ on polycrystalline and single crystal transition metal surfaces. Catal. Rev. Sci. Eng. 19, 105-159 (1979).

65. Bridge, M.E., Comrie, C. M. \& Lambert, R. M. Chemisorption studies on cobalt single crystal surfaces. Surf. Sci. 67, 393-404 (1977).

66. Brennan, D. \& Hayes, F. H. The Adsorption of carbon monoxide on evaporated metal films. Philos. Trans. R. Soc. A Math. Phys. Eng. Sci. 258, 347-373 (1965).

67. Bonzel, H. P. \& Krebs, H. J. Surface science approach to heterogeneous catalysis: CO hydrogenation on transition metals. Surf. Sci. 117, 639-658 (1982).

68. Abild-Pedersen, F. \& Andersson, M. P. CO adsorption energies on metals with correction for high coordination adsorption sites - A density functional study. Surf. Sci. 601, 1747-1753 (2007).

69. Miyazaki, E. Chemisorption of diatomic molecules $\left(\mathrm{H}_{2}, \mathrm{~N}_{2}, \mathrm{CO}\right)$ on transition d-metals. J. Catal. 65, 84-94 (1980).

70. Blyholder, G. Molecular Orbital View of Chemisorbed Carbon Monoxide. J. Phys. Chem. 68, 2772-2777 (1964).

71. Bailliard-Letournel, R. M., Gomez Cobo, A. J., Mirodatos, C., Primet, M. \& Dalmon, J. A. About the nature of the Co-Cu interaction in Co-based catalysts for higher alcohols synthesis. Catal. Letters 2, 149-156 (1989).

72. Law, Y. T., Dintzer, T. \& Zafeiratos, S. Surface oxidation of NiCo alloy: A comparative X-ray photoelectron spectroscopy study in a wide pressure range. Appl. Surf. Sci. 258, 1480- 1487 (2011).

73. Braunschweig, E. J., Logan, A. D., Datye, A. K. \& Smith, D. J. Reversibility of strong metal-support interactions on $\mathrm{RhTiO}_{2}$. J. Catal. 118, 227-237 (1989).

74. Sehested, J., Dahl, S., Jacobsen, J. \& Rostrup-Nielsen, J. R. Methanation of CO over nickel: Mechanism and kinetics at high $\mathrm{H}_{2} / \mathrm{CO}$ ratios. J. Phys. Chem. B 109, 2432-2438 (2005).

75. Weststrate, C. J. \& Niemantsverdriet, J. W. Understanding FTS selectivity: The crucial role of surface hydrogen. 
Faraday Discuss. 197, 101-116 (2017).

76. Dinse, A., Aigner, M., Ulbrich, M., Johnson, G. R. \& Bell, A. T. Effects of Mn promotion on the activity and selectivity of $\mathrm{Co} / \mathrm{SiO}_{2}$ for Fischer-Tropsch synthesis. J. Catal. 288, 104-114 (2012).

77. Johnson, G. R., Werner, S. \& Bell, A. T. An investigation into the effects of Mn promotion on the activity and selectivity of $\mathrm{Co} / \mathrm{SiO}_{2}$ for Fischer-Tropsch synthesis: Evidence for enhanced $\mathrm{CO}$ adsorption and dissociation. ACS Catal. 5, 5888-5903 (2015).

78. Pedersen, E. Ø., Svenum, I. H. \& Blekkan, E. A. Mn promoted Co catalysts for Fischer-Tropsch production of light olefins - An experimental and theoretical study. J. Catal. 361, 23-32 (2018).

79. Athariboroujeny, M. et al. Competing Mechanisms in CO Hydrogenation over Co-MnO Catalysts. ACS Catal. 9, 5603-5612 (2019).

80. Mirodatos, C., Praliaud, H. \& Primet, M. Deactivation of nickel-based catalysts during CO methanation and disproportionation. J. Catal. 107, 275-287 (1987).

81. Munnik, P., Velthoen, M. E. Z., De Jongh, P. E., De Jong, K. P. \& Gommes, C. J. Nanoparticle growth in supported nickel catalysts during methanation reaction - Larger is better. Angew. Chemie - Int. Ed. 53, 9493-9497 (2014).

82. Pereira, E. B. \& Martin, G. A. Alcohol synthesis from syngas over nickel catalysts: Effect of copper and lithium addition. Appl. Catal. A, Gen. 103, 291-309 (1993).

83. Agnelli, M. \& Mirodatos, C. CO hydrogenation on nickel-based catalysts: Effects of copper addition. J. Catal. 192, 204-214 (2000).

84. Zegkinoglou, I. et al. Surface segregation in $\mathrm{CuNi}$ nanoparticle catalysts during $\mathrm{CO}_{2}$ hydrogenation: The role of CO in the reactant mixture. J. Phys. Chem.C 123, 8421-8428 (2019).

85. Zafeiratos, S., Piccinin, S. \& Teschner, D. Alloys in catalysis: phase separation and surface segregation phenomena in response to the reactive environment. Catal. Sci. Technol. 2, 1787-1801 (2012).

86. Carenco, S. et al. Synthesis and structural evolution of nickel-cobalt nanoparticles under $\mathrm{H}_{2}$ and $\mathrm{CO}_{2}$. Small 11,3045-3053 (2015).

87. Yin, Y. et al. Formation of Hollow Nanocrystals Through the Nanoscale Kirkendall Effect. Science 304, 711714 (2004).

88. Shen, W. M., Dumesic, J. A. \& Hill, C. G. Criteria for stable Ni particle size under methanation reaction conditions: Nickel transport and particle size growth via nickel carbonyl. J. Catal. 68, 152-165 (1981).

89. Goldberger, W. M. \& Othmer, D. F. Kinetics of nickel carbonyl formation. Ind. Eng. Chem. Process Des. Dev. 2, 202-209 (1963).

90. den Otter,J.H. \& De Jong, K.P. Highly selective and active niobia-supported cobalt catalysts for Fischer-Tropsch synthesis. Top. Catal. 57, 445-450 (2014). 



\section{Stable Niobia-Supported Nickel Catalysts for the Hydrogenation of Carbon Monoxide to Hydrocarbons}

Stability of metal nanoparticles under reaction conditions is crucial in many catalytic processes. Nickel-based catalysts often encounter severe particle growth in the presence of carbon monoxide due to the formation and migration of nickel carbonyl. In this research, we showed that the reduction temperature of nickel oxide supported on niobia $\left(\mathrm{Nb}_{2} \mathrm{O}_{5}\right)$ influenced the stability of the resulting nickel catalyst during subsequent carbon monoxide hydrogenation. Low reduction temperatures resulted in high initial nickel-normalized activity towards long-chain hydrocarbons $\left(\mathrm{C}_{5+}\right)$, but fast deactivation throughout the experiment. High reduction temperatures led to a shift in product distribution towards shorter hydrocarbons and a decreased initial nickel-normalized activity, while during the first hours of the experiment an increase in turnover frequency and nickel-normalized activity was observed, resulting eventually in a stable catalytic performance. Electron microscopy analysis revealed extensive particle growth after catalysis when the catalyst had been reduced at low temperatures and no significant changes in particle size when reduced at high temperatures. By use of in-situ FT-IR spectroscopy, nickel subcarbonyl species which are precursors of volatile nickel tetracarbonyl were detected on $\mathrm{Ni} / \mathrm{Nb}_{2} \mathrm{O}_{5}$ after low temperature reduction and exposure to CO, but not after high temperature reduction. Hence, particle growth is explained by the formation and diffusion of nickel carbonyl and subsequent Ostwald ripening, that leads to larger nickel particles with concomitant decrease in nickel-normalized activity. The stability of the catalyst reduced at high temperature was linked to the formation of niobium suboxides and their partial coverage of the nickel particles limiting the formation of nickel carbonyl and slowing down particle growth. 


\subsection{Introduction}

Metal nanoparticles are commonly used to catalyze many chemical processes ${ }^{1}$. Since catalytic reactions occur at the metal surface, the high surface-area-to-volume-ratio of a nanoparticle provides an effective number of active sites per weight of metal in the overall catalyst. One of the biggest challenges for any catalytic system is to maintain this maximum amount of active sites throughout the lifespan of a solid catalyst ${ }^{2}$. Particularly in the case of metal nanoparticles, their growth is a prevailing phenomenon in which the efficient utilization of the metal in a catalyst is compromised, usually leading to a detriment in catalytic performance $^{3-5}$. In order to stabilize the nanoparticles and prevent their growth, these are typically dispersed over a support material. The nature of the support is crucial in delivering this stability and offers an opportunity to develop improved solid catalysts.

Reducible oxides used as support material display characteristic interactions with metal nanoparticles. During reductive conditions, one effect that arises is coverage of the nanoparticles by in-situ generated suboxides from the support ${ }^{6,7}$, the so called Strong Metal-Support Interaction (SMSI) ${ }^{8,9}$. This effect can modify the available metal surface area, the electronic state of the metal and the particle shape ${ }^{10-12}$. An interesting example is the substantial change in reactivity of nickel during carbon monoxide hydrogenation: nickel supported on non-reducible oxides (e.g. $\mathrm{Al}_{2} \mathrm{O}_{3}, \mathrm{SiO}_{2}$ ) selectively hydrogenates carbon monoxide to methane, whereas when supported on reducible oxides like $\mathrm{TiO}_{2}$ or $\mathrm{Nb}_{2} \mathrm{O}_{5}$ the product distribution shifts towards heavier hydrocarbons ${ }^{13-17}$. Furthermore, previous reports have suggested that reducible supports can also deliver unique stability to nickel-based catalysts ${ }^{13,18}$.

The interest to achieve stable nickel-based systems in the presence of carbon monoxide arises from the extensive utilization of nickel catalysts in reactions involving carbon monoxide as reactant, intermediate or product ${ }^{19-23}$ and the poor stability of nickel in the presence of carbon monoxide at low temperature ${ }^{24,25}$. Deactivation of nickel-based catalysts during carbon monoxide hydrogenation proceeds most often through particle growth by the formation and diffusion of volatile nickel carbonyl ${ }^{25-27}$. This phenomenon is a classic example of Ostwald ripening, where species containing metal atoms, in this case nickel carbonyl, diffuse from smaller towards larger nanoparticles leading to metal sintering ${ }^{28,29}$. In order to prevent this, the reaction is typically operated at high temperatures and low CO pressures, since these conditions disfavor the formation of nickel carbony $1^{24,26,30}$. However, such conditions compromise the product selectivity mainly towards methane and therefore hamper the application of nickel catalysts for the synthesis of more commercially attractive products, such as long-chain hydrocarbons $\left(\mathrm{C}_{5+}\right)$ or olefins ${ }^{31,32}$. Alternative strategies to inhibit the formation of nickel carbonyl in these catalysts have been explored in literature, for instance, by alloying nickel with copper ${ }^{33,34}$ or by depositing nickel on titania, a reducible support ${ }^{13}$.

Here, we studied the effect of SMSI in nickel supported on niobia for the hydrogenation of carbon monoxide. For this, different reduction temperatures $\left(250-450{ }^{\circ} \mathrm{C}\right)$ on $\mathrm{NiO} / \mathrm{Nb}_{2} \mathrm{O}_{5}$ were used prior to $\mathrm{H}_{2}$-chemisorption, in order to determine the extent of SMSI, and prior to $\mathrm{CO}$ hydrogenation. $\mathrm{H}_{2}$-uptake suppression was observed when increasing 
the reduction temperature which is characteristic of the SMSI effect. Simultaneously, an increase in reduction temperature led to a decrease in nickel-based catalytic activity, however stable catalytic performance was gained in return with high selectivity for long-chain hydrocarbons. $\mathrm{Ni} / \mathrm{Nb}_{2} \mathrm{O}_{5}$ showed higher turnover frequency and $\mathrm{C}_{5+}$ selectivity compared to nickel supported on a non-reducible support $\left(\alpha-\mathrm{Al}_{2} \mathrm{O}_{3}\right)$. The overall results obtained pointed out to an inhibition of nickel carbonyl formation by SMSI in $\mathrm{Ni} / \mathrm{Nb}_{2} \mathrm{O}_{5}$, leading to a stable supported nickel catalyst for CO hydrogenation.

\subsection{Experimental}

Synthesis. Niobium oxide $\left(\mathrm{Nb}_{2} \mathrm{O}_{5}\right)$ was used as support and obtained by crystallization of niobium oxide hydrate $\left(\mathrm{Nb}_{2} \mathrm{O}_{5} \cdot n \mathrm{H}_{2} \mathrm{O}, \mathrm{HY}-340, \mathrm{AD} / 4465\right)$, which was provided by Companhia Brasileira de Metalurgia e Mineração - CBMM. The crystallization was carried out in stagnant air at $600{ }^{\circ} \mathrm{C}$ during $4 \mathrm{~h}$ with a ramp of $5^{\circ} \mathrm{C} \cdot \mathrm{min}^{-1}$. The obtained $\mathrm{Nb}_{2} \mathrm{O}_{5}$ had a pseudo-hexagonal TT-phase, a specific surface area of $9 \mathrm{~m}^{2} \cdot \mathrm{g}^{-1}$ and a specific mesopore volume of $0.05 \mathrm{~cm}^{3} \cdot \mathrm{g}^{-1}$.

A nickel supported on niobia catalyst was prepared using the incipient wetness impregnation method. Prior to impregnation the support $(75-150 \mu \mathrm{m}$ grains $)$ was dried under vacuum at $80{ }^{\circ} \mathrm{C}$ for $1 \mathrm{~h}$, thereafter the impregnation was performed at room temperature with a $4.2 \mathrm{M}$ aqueous solution of $\mathrm{Ni}\left(\mathrm{NO}_{3}\right)_{2} \cdot 6 \mathrm{H}_{2} \mathrm{O}$ (Acros, $99 \%$ ) for a $6 \mathrm{wt}$ \% $\mathrm{Ni}$. In the next step, the catalyst was dried for $1 \mathrm{~h}$ at $60{ }^{\circ} \mathrm{C}$ in in a fixed bed reactor under $\mathrm{N}_{2}$ flow and subsequently in the same reactor and gas flow calcined for $2 \mathrm{~h}$ at $350{ }^{\circ} \mathrm{C}\left(3{ }^{\circ} \mathrm{C} \cdot \mathrm{min}^{-1}\right)$. Nickel supported on $\alpha$-alumina (BASF) was prepared in the same way. Metal loadings were defined as the mass of metallic Ni per gram of reduced catalyst.

Characterization. Temperature programmed reduction (TPR) analyses were performed using a Micromeritics Autochem 2990 instrument, where $100 \mathrm{mg}$ sample was dried at $120{ }^{\circ} \mathrm{C}$ for $1 \mathrm{~h}$ in Ar flow followed by reduction from room temperature up to 700 or $1000{ }^{\circ} \mathrm{C}$ $\left(5^{\circ} \mathrm{C} \cdot \mathrm{min}^{-1}\right)$ in a $5 \mathrm{vol} \% \mathrm{H}_{2} /$ Ar flow. Powder X-ray diffractograms were measured using a Bruker-AXS D2 Phaser X-ray diffractometer, Co-Ka radiation $(\lambda=1.789 \AA$ ).

Bright field transmission electron microscopy (TEM) and Scanning transmission electron microscopy (STEM-EDX) images were acquired with a Philips Tecnai-20 FEG (200 $\mathrm{kV}$ ) microscope equipped with an energy dispersive X-ray (EDX) and high-angle annular dark-field (HAADF) detector. The reduced and subsequently passivated samples for the microscopy analysis were prepared by suspending the catalysts in 2-propanol $(>99.9 \%$, Sigma-Aldrich) using sonication and dropcasting the suspension on a carbon-coated $\mathrm{Cu}$ grid (200 mesh). The nickel particle size was determined using the iTEM software by analyzing at least 500 particles. Particle surface average diameters or Sauter mean (D[3,2]) were then calculated and corrected for a $2 \mathrm{~nm} \mathrm{NiO}$ shell ${ }^{35}$.

$\mathrm{H}_{2}$-chemisorption was measured on a Micromeritics ASAP 2020C using $\sim 100 \mathrm{mg}$ of sample. Prior to the measurement, the calcined catalyst was reduced in $\mathrm{H}_{2}$ flow at different temperatures during $2 \mathrm{~h}\left(5^{\circ} \mathrm{C} \cdot \mathrm{min}^{-1}\right)$. The sample was then evacuated, cooled to $150{ }^{\circ} \mathrm{C}$ and 
$\mathrm{H}_{2}$-chemisorption was measured at that temperature.

Inductively coupled plasma-optical emission spectroscopy (ICP-OES) was performed on a SPECTRO ARCOS in order to establish the nickel content before and after catalysis; samples were extracted using aqua regia.

Fourier-transform Infrared (FT-IR) spectroscopy measurements were carried out in a Specac "High Temperature High Pressure" transmission FT-IR cell. A self-supported catalyst wafer was prepared by applying on a sample a force of $4000 \mathrm{~kg}$ for $20 \mathrm{~s}$, yielding a wafer of $16 \mathrm{~mm}$ diameter, and $<1 \mathrm{~mm}$ thickness. Catalyst wafers were reduced in-situ, each at different temperatures of 250,350 and $450{ }^{\circ} \mathrm{C}\left(\mathrm{N}_{2} / \mathrm{H}_{2}=2 \mathrm{v} / \mathrm{v}\right.$; both Linde, 5.0). Subsequently, a sample was cooled down to $230{ }^{\circ} \mathrm{C}$ flushed with 5.0 purity $\mathrm{N}_{2}$ for $10 \mathrm{~min}$, after which flowing $\mathrm{CO}$ (Linde, 5.0) was added with a ratio $\mathrm{N}_{2} / \mathrm{CO}=2 \mathrm{v} / \mathrm{v}$ at 1 bar total pressure. Due to low photon-transmittance of the $\mathrm{Nb}_{2} \mathrm{O}_{5}$-supported $\mathrm{Ni}$ catalyst, 256 spectra were averaged to improve signal-to-noise. Spectra were recorded with a resolution of $4 \mathrm{~cm}^{-1}$.

Catalytic performance. Catalytic performance was carried out in a quartz glass plug-flow reactor, loaded with $15-20 \mathrm{mg}$ catalyst $(38-150 \mu \mathrm{m})$ diluted with $\sim 200 \mathrm{mg}$ SiC. Catalysts were reduced in situ at 250,350 or $450{ }^{\circ} \mathrm{C}\left(5{ }^{\circ} \mathrm{C} \cdot \mathrm{min}^{-1}, 2 \mathrm{~h}\right)$ in an $\mathrm{Ar} / \mathrm{H} 2=2.0 \mathrm{v} / \mathrm{v}$ flow $\left(\mathrm{GHSV}=190000 \mathrm{~h}^{-1}\right)$. After reduction, $\mathrm{CO}$ hydrogenation was performed at $230{ }^{\circ} \mathrm{C}, 1 \mathrm{bar}$, $\mathrm{H}_{2} / \mathrm{CO}=2.0 \mathrm{v} / \mathrm{v}, \mathrm{GHSV}=28000 \mathrm{~h}^{-1}$ and $\mathrm{CO}$ conversion $<5 \%$. Reaction was carried out for $90 \mathrm{~h}$. Finally, the $\mathrm{CO}$ flow was stopped and the $\mathrm{H}_{2}$ flow and temperature were kept for one hour in order to remove remaining hydrocarbons for further analysis of the catalyst. C1-C18 products were analyzed by online gas chromatography (Varian 430 GC, CP sil-5 column). the corresponding hydrocarbon product.

\subsection{Results and discussion}

\subsubsection{Reduction temperature}

A nickel supported on niobia catalyst was synthetized by incipient wetness impregnation method. After subsequent drying and calcination, the nickel content was determined by ICP-OES, being 5.6 $\pm 0.1 \mathrm{wt} . \%$. Nickel supported on $\alpha$-alumina was also synthetized as comparative system, with a nickel content of $5.5 \pm 0.1 \mathrm{wt} . \%$ as determined by ICP-OES. Temperature programed reduction was carried out on the support $\left(\mathrm{Nb}_{2} \mathrm{O}_{5}\right)$, the calcined $\mathrm{NiO} / \mathrm{Nb}_{2} \mathrm{O}_{5}$ and $\mathrm{NiO} / \alpha-\mathrm{Al}_{2} \mathrm{O}_{3}$ samples. The corresponding reduction profiles for the niobia-based samples are shown in figure 6.1. $\mathrm{Nb}_{2} \mathrm{O}_{5}$ showed a gradual consumption of hydrogen starting at $600{ }^{\circ} \mathrm{C}$ and a maximum consumption rate at $940{ }^{\circ} \mathrm{C}$. The hydrogen consumption was assigned to the reduction of the $\mathrm{Nb}_{2} \mathrm{O}_{5}$ surface to $\mathrm{NbO}_{2}$, along with the change in color of the sample to deep indigo, characteristic of $\mathrm{Nb}^{4+}$ ions ${ }^{36,37}$. The reduction profile for the $\mathrm{NiO} / \mathrm{Nb}_{2} \mathrm{O}_{5}$ sample showed a small hydrogen consumption signal at $200{ }^{\circ} \mathrm{C}$ which might be attributed to the reduction of $\mathrm{Ni}^{3+}$. The main hydrogen consumption between 230 and $430{ }^{\circ} \mathrm{C}$ was attributed to the reduction of $\mathrm{NiO}$ to metallic $\mathrm{Ni}^{38,39}$. Hydrogen consumption continued above $700{ }^{\circ} \mathrm{C}$ related to reduction of $\mathrm{Nb}_{2} \mathrm{O}_{5}$, catalyzed by the metallic nickel ${ }^{37}$. The consumption peak at $780{ }^{\circ} \mathrm{C}$ might correspond to the initial reduction of the support 
surface $\left(\mathrm{Nb}_{2} \mathrm{O}_{5}\right.$ to $\left.\mathrm{NbO}_{2}\right)$ and further consumption above $810{ }^{\circ} \mathrm{C}$ to the reduction of bulk $\mathrm{Nb}_{2} \mathrm{O}_{5}$ and possibly subsequent reduction of $\mathrm{NbO}_{2}$ to $\mathrm{Nb}_{2} \mathrm{O}_{3}$. Nickel oxide supported on $\alpha-\mathrm{Al}_{2} \mathrm{O}_{3}$ showed a similar reduction profile to the niobia-based sample (Appendix E: Figure E1), with a small hydrogen consumption signal at $220{ }^{\circ} \mathrm{C}$ ascribed to $\mathrm{Ni}^{3+}$ reduction and a main signal between 250 and $450{ }^{\circ} \mathrm{C}$ for $\mathrm{NiO}$ reduction to $\mathrm{Ni}$. For both $\mathrm{Nb}_{2} \mathrm{O}_{5}-$ and $\alpha-\mathrm{Al}_{2} \mathrm{O}_{3}$-supported samples, the total hydrogen consumption below $450{ }^{\circ} \mathrm{C}$ corresponded to the complete reduction of all nickel oxide to metallic nickel.

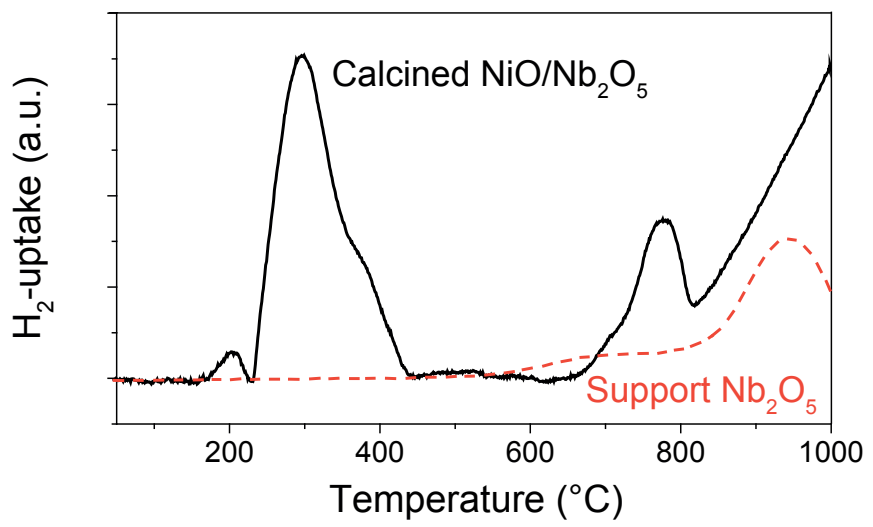

Figure 6.1 $\mathrm{H}_{2}$ temperature programmed reduction profile of the $\mathrm{Nb}_{2} \mathrm{O}_{5}$ support (red dashed line) and of the calcined $\mathrm{NiO} / \mathrm{Nb}_{2} \mathrm{O}_{5}$ sample (black line).

Based on the $\mathrm{NiO} / \mathrm{Nb}_{2} \mathrm{O}_{5} \mathrm{TPR}$ profile, four different reduction temperatures, namely 250, 350 and $450{ }^{\circ} \mathrm{C}$, were chosen to study their effect on CO hydrogenation. The degree of reduction for the low temperatures $\left(250\right.$ and $\left.350{ }^{\circ} \mathrm{C}\right)$ was calculated by measuring TPR of $\mathrm{NiO} / \mathrm{Nb}_{2} \mathrm{O}_{5}$ with an additional dwell step of $2 \mathrm{~h}$ at 250 or at $350{ }^{\circ} \mathrm{C}$. The isothermal step at $250{ }^{\circ} \mathrm{C}$ resulted in two main distinctive signals in hydrogen uptake for the reduction of nickel oxide (Appendix E: Figure E2a). The first one was observed by reaching $250{ }^{\circ} \mathrm{C}$ with a sharp increase in hydrogen uptake which gradually decreased back to the baseline throughout the $2 \mathrm{~h}$ at $250{ }^{\circ} \mathrm{C}$. Based on the hydrogen uptake the degree of reduction at this temperature was $58 \%$. The second main hydrogen uptake signal was observed after the isothermal

Table 6.1 $\mathrm{H}_{2}$-uptake for $\mathrm{Ni} / \mathrm{Nb}_{2} \mathrm{O}_{5}$ at different reduction temperatures measured by chemisorption.

\begin{tabular}{|c|c|c|c|c|c|}
\hline \multirow[b]{2}{*}{ Support } & \multirow[b]{2}{*}{$\begin{array}{c}\text { Reduction } \\
\text { temperature } \\
\left({ }^{\circ} \mathrm{C}\right)\end{array}$} & \multicolumn{2}{|c|}{$\mathbf{H}_{2}$-chemisorption } & \multicolumn{2}{|c|}{ TEM } \\
\hline & & $\begin{array}{c}\text { Experimental } \\
\mathbf{H}_{2} \text {-uptake } \\
\left(\mu \mathrm{mol}_{\mathrm{H} 2} \cdot \mathrm{g}_{\mathrm{Ni}}{ }^{-1}\right)\end{array}$ & $\begin{array}{c}\text { Particle size } \\
(\mathbf{n m})\end{array}$ & $\begin{array}{c}\text { Particle size } \\
\text { D }[3,2] \\
(\mathbf{n m})\end{array}$ & $\begin{array}{c}\text { Theoretical } \\
\mathrm{H}_{2} \text {-uptake } \\
\left(\mu \mathrm{mol}_{\mathrm{H} 2} \cdot \mathrm{g}_{\mathrm{Ni}}^{-1}\right)\end{array}$ \\
\hline \multirow{3}{*}{$\mathrm{Nb}_{2} \mathrm{O}_{5}$} & 250 & 936 & 10 & 12 & 716 \\
\hline & 350 & 626 & 15 & 12 & 740 \\
\hline & 450 & 16 & 539 & 11 & 785 \\
\hline \multirow{2}{*}{$\alpha-\mathrm{Al}_{2} \mathrm{O}_{3}$} & 350 & 1328 & 6 & 9 & 955 \\
\hline & 450 & 1078 & 8 & 12 & 716 \\
\hline
\end{tabular}


step with a maximum at $360{ }^{\circ} \mathrm{C}(\mathrm{t}=200 \mathrm{~min})$, this indicates that temperatures higher than $250{ }^{\circ} \mathrm{C}$ are necessary to completely reduce the nickel oxide to metallic nickel. The hydrogen uptake observed at $360^{\circ} \mathrm{C}$ might relate to the observed shoulder at the same temperature in Figure 6.1, which might correspond to the reduction of nickel oxide species with a stronger interaction with the support. The TPR profile with an isotherm step at $350{ }^{\circ} \mathrm{C}$ (Appendix $\mathrm{E}$ : Figure E2b) showed a main hydrogen uptake signal which corresponded to a degree of reduction of $96 \%$, indicating that most of the nickel oxide is reduced to metallic nickel at $350{ }^{\circ} \mathrm{C}$.

Table 6.1 shows the hydrogen uptake determined by $\mathrm{H}_{2}$-chemisorption for $\mathrm{Ni} / \mathrm{Nb}_{2} \mathrm{O}_{5}$ and $\mathrm{Ni} / \alpha-\mathrm{Al}_{2} \mathrm{O}_{3}$ after reduction at different temperatures. An increase of the reduction temperature resulted in a decrease in hydrogen uptake for $\mathrm{Ni} / \mathrm{Nb}_{2} \mathrm{O}_{5}$, resulting in an apparent increase in the derived particle size. This suppression of hydrogen chemisorption by reducible oxidic supports, the so called strong metal-support interaction (SMSI) effect, is a well-documented phenomenon attributed to coverage of the metal nanoparticles by suboxides from the support upon reductive conditions $s^{6,8}$. The degree of coverage by the suboxides

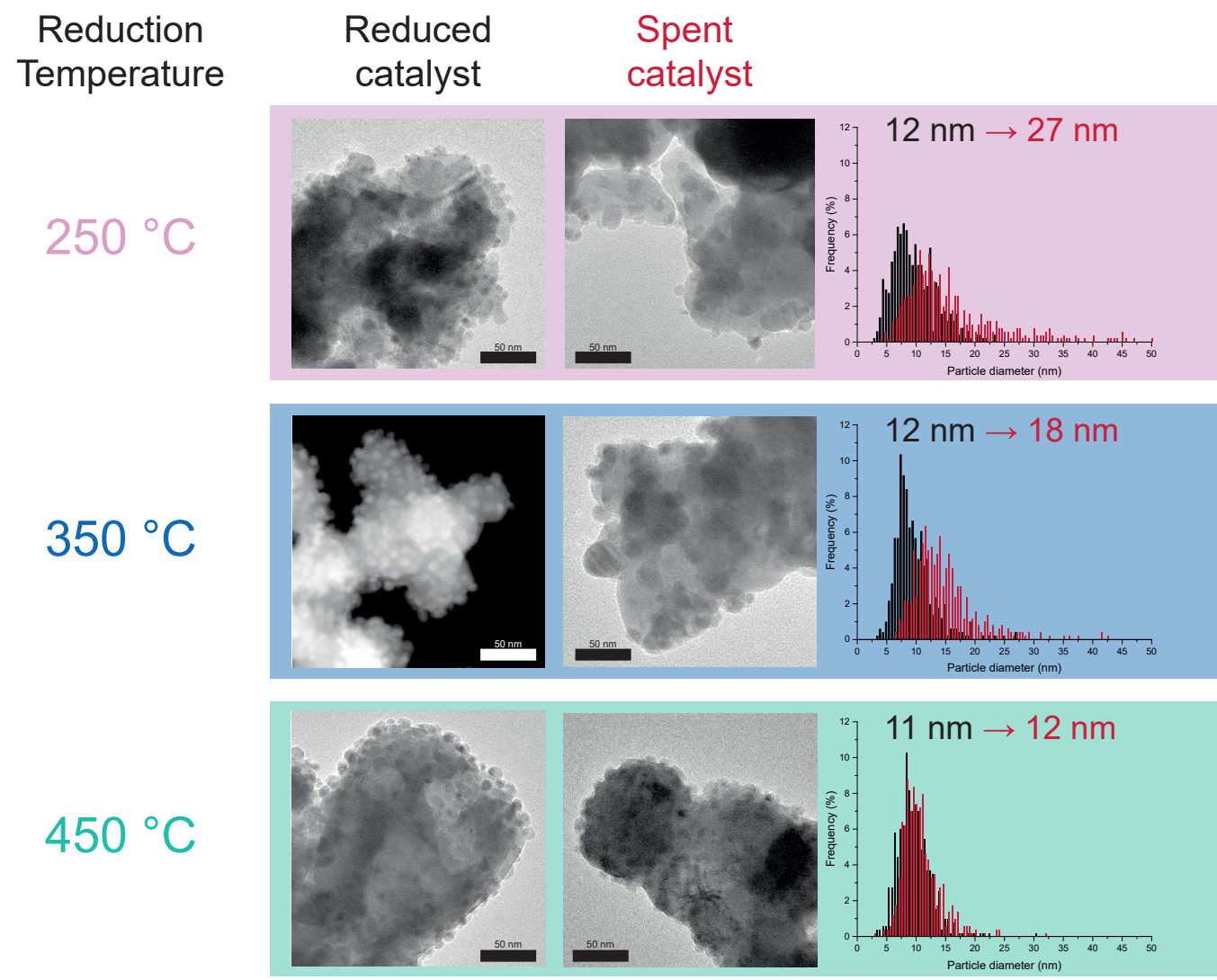

Figure 6.2 TEM images of the $\mathrm{Ni} / \mathrm{Nb}_{2} \mathrm{O}_{5}$ catalyst after reduction at different temperatures and passivation (denoted as reduced) and after catalysis (denoted as spent). The corresponding histograms show the particle size distribution for the 'reduced' (black bars) and 'spent' (red bars) with their corresponding surface-average particle sizes. 
is a temperature-dependent phenomenon, in which higher reduction temperatures enhance the mobility of these species and coverage of the nanoparticles ${ }^{40}$. Powder X-ray diffraction (Appendix E: Figure E3) neither showed the formation of new crystalline species (e.g. nickel niobates) nor provided indications of SMSI after reduction of $\mathrm{Ni} / \mathrm{Nb}_{2} \mathrm{O}_{5}$. Reduction at $250{ }^{\circ} \mathrm{C}$ showed a substantial hydrogen uptake even though nickel oxide was not completely reduced at $250{ }^{\circ} \mathrm{C}$ as shown by the TPR results, indicating that most of the particles' surface consisted of metallic nickel. The $\mathrm{Ni} / \alpha-\mathrm{Al}_{2} \mathrm{O}_{3}$ sample showed also a decreased in the hydrogen uptake upon increasing the reduction temperature, however this decrease was not as severe as the one observed for $\mathrm{Ni} / \mathrm{Nb}_{2} \mathrm{O}_{5}$.

After the chemisorption measurement and exposure to air at room temperature, the samples were analyzed by TEM (Figure 6.2 and Appendix E: Figure E4). TEM images showed for all $\mathrm{Ni} / \mathrm{Nb}_{2} \mathrm{O}_{5}$ samples a uniform distribution of nickel nanoparticles over the niobia. Furthermore, a similar nickel particle size $(\sim 12 \mathrm{~nm})$ was determined based on TEM as shown in Table 6.1, indicating no significant effect of the reduction temperature on the nickel particle size and confirming that the suppressed hydrogen chemisorption results related to the SMSI effect. In the case of the $\mathrm{Ni} / \alpha-\mathrm{Al}_{2} \mathrm{O}_{3}$ sample, TEM images (Appendix E: Figure E4) revealed a slight increase in particle size upon increasing the reduction temperature, in line with the results obtained from hydrogen chemisorption. The discrepancy observed here between the experimental and theoretical $\mathrm{H}_{2}$-uptake can be explained by the more significant impact of larger particles when determining the $\mathrm{D}[3,2]$ value, a surface-based diameter. Since a considerable amount of very small nanoparticles would not be detected by TEM.

\subsubsection{CO hydrogenation}

The catalytic performance of the $\mathrm{Ni} / \mathrm{Nb}_{2} \mathrm{O}_{5}$ and $\mathrm{Ni} / \alpha-\mathrm{Al}_{2} \mathrm{O}_{3}$ catalysts was evaluated by varying the reduction temperature similar to the $\mathrm{H}_{2}$-chemisorption experiments and a summary of the results is shown in Table 6.2. Nickel-normalized catalytic activity (Nickel Time Yield, NTY) plotted against time-on-stream (TOS) up to $90 \mathrm{~h}$ is shown in figure 6.3. The

Table 6.2 Summary of the catalytic performance for the $\mathrm{Ni} / \mathrm{Nb}_{2} \mathrm{O}_{5}$ and $\mathrm{Ni} / \alpha-\mathrm{Al}_{2} \mathrm{O}_{3}$ catalysts. Reaction conditions: $230{ }^{\circ} \mathrm{C}, 1 \mathrm{bar}, \mathrm{H}_{2} / \mathrm{CO}=2.0 \mathrm{v} / \mathrm{v}, \mathrm{GHSV}=28000 \mathrm{~h}^{-1}$ and $\mathrm{CO}$ conversion $<5 \%$.

\begin{tabular}{|c|c|c|c|c|c|c|c|c|c|c|c|}
\hline \multirow[t]{2}{*}{ Support } & \multirow[t]{2}{*}{$\begin{array}{c}\begin{array}{c}\text { Reduction } \\
\text { temperature }\end{array} \\
\left({ }^{\circ} \mathbf{C}\right) \\
\end{array}$} & \multicolumn{2}{|c|}{$\begin{array}{l}\text { Nickel-Time- } \\
\text { Yield } \\
\left(10^{-5} \text { mol }_{\mathrm{Cog}_{\mathrm{Ni}}}{ }^{-1} \mathbf{s}^{-1}\right) \\
\end{array}$} & \multicolumn{2}{|c|}{$\begin{array}{c}\text { TOF } \\
\left(10^{-3} s^{-1}\right) \\
\end{array}$} & \multirow{2}{*}{$\begin{array}{l}\mathbf{T O F}_{\text {app }}^{\mathbf{b}} \\
\left(\mathbf{1 0}^{-3} \mathbf{s}^{-\mathbf{1}}\right) \\
\mathrm{TOS}=0 \mathrm{~h}\end{array}$} & \multicolumn{3}{|c|}{$\begin{array}{c}\text { Selectivity }^{\mathrm{c}} \\
\text { (wt.\%) }\end{array}$} & \multirow[t]{2}{*}{$\alpha^{\mathrm{d}}$} & \multirow[t]{2}{*}{$\begin{array}{l}\text { Olefin/ } \\
\text { Parffin }^{\mathrm{e}}\end{array}$} \\
\hline & & $\mathrm{TOS}=01$ & $\mathrm{SS}=90$ & $\mathrm{OS}=0$ & $\mathrm{OS}=90 \mathrm{~h}$ & & $\mathrm{C}_{1}$ & $\mathrm{C}_{2-4}$ & $\mathrm{C}_{5+}$ & & \\
\hline \multirow{3}{*}{$\mathrm{Nb}_{2} \mathrm{O}_{5}$} & 250 & 7.9 & 2.2 & 46 & 39 & 42 & 18 & 33 & 49 & 0.65 & 0.9 \\
\hline & 350 & 7.1 & 3.9 & 45 & 42 & 59 & 15 & 30 & 55 & 0.70 & 1.0 \\
\hline & 450 & 1.6 & 2.7 & 11 & 20 & 605 & 22 & 45 & 33 & 0.58 & 1.6 \\
\hline \multirow{2}{*}{$\alpha-\mathrm{Al}_{2} \mathrm{O}_{3}$} & 350 & 2.0 & 0.6 & 11 & 10 & 8 & 54 & 35 & 11 & 0.46 & 0.8 \\
\hline & 450 & 1.7 & 0.5 & 12 & 8 & 8 & 55 & 35 & 10 & 0.45 & 0.9 \\
\hline
\end{tabular}

a. Based on TEM particle size distribution in fresh (for TOS $=0 \mathrm{~h}$ ) and spent (for TOS $=90 \mathrm{~h}$ ) catalyst.

b. Based on $\mathrm{H}_{2}$-chemisorption of fresh catalyst.

c. Selectivity is reported at TOS $=90 \mathrm{~h}$ and up to $\mathrm{C} 18$.

d. Values were determined for $\mathrm{C} 1-\mathrm{C} 11$ concentration values.

e. Molar ratios determined for C4-C7. 


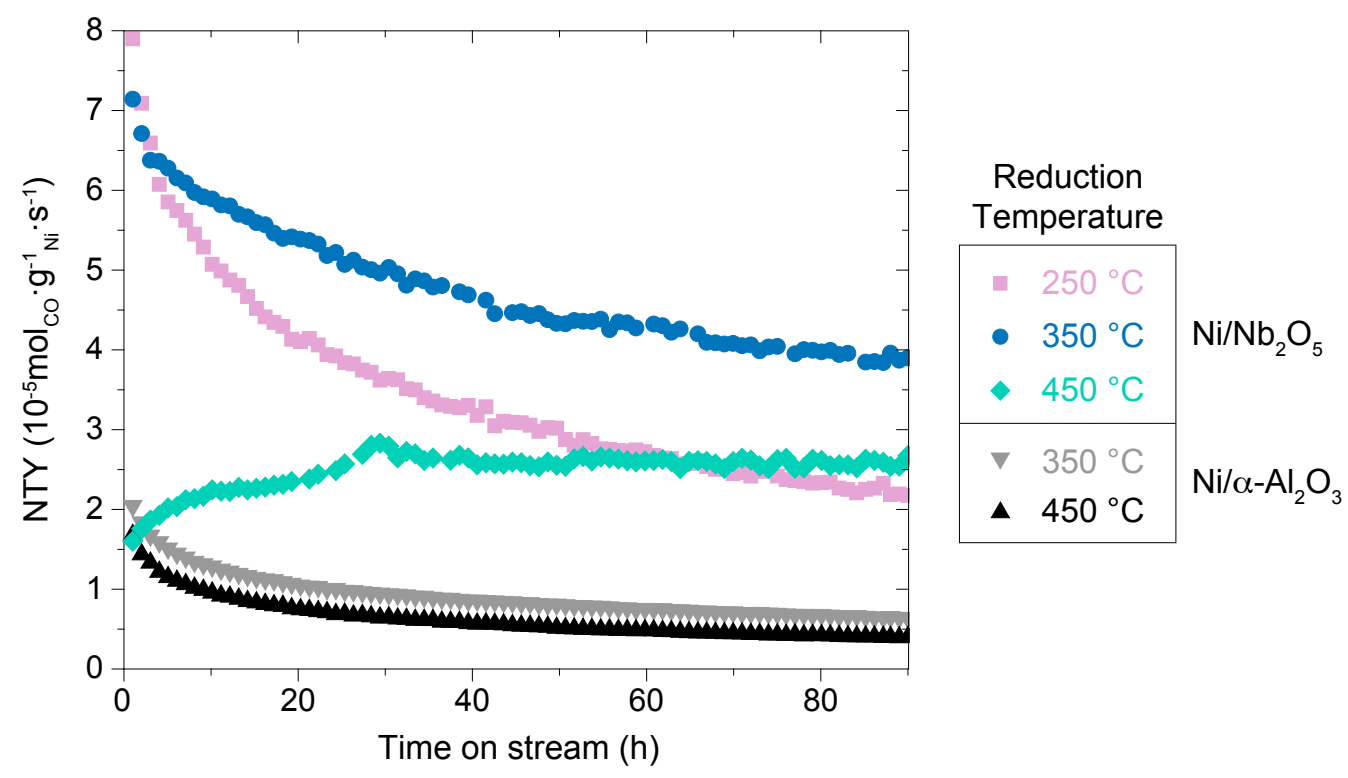

Figure 6.3 Nickel-Time-Yield (NTY) plotted against time-on-stream for $\mathrm{Ni} / \mathrm{Nb}_{2} \mathrm{O}_{5}$ reduced at different temperatures prior to reaction. In-situ reduction: $1 \mathrm{bar}, \mathrm{Ar} / \mathrm{H}_{2}=2 \mathrm{v} / \mathrm{v}, \mathrm{GHSV}=190000 \mathrm{~h}^{-1}, \mathrm{~T}=250{ }^{\circ} \mathrm{C}$ (pink $\square$ ), $350{ }^{\circ} \mathrm{C}$ (blue $\bullet$, grey $\boldsymbol{\nabla}$ ) or $450{ }^{\circ} \mathrm{C}$ (green $\bullet$, black $\boldsymbol{\Delta}$ ). Reaction conditions: 1 bar, $\mathrm{H}_{2} / \mathrm{CO}=2 \mathrm{v} / \mathrm{v}, \mathrm{GHSV}=28000 \mathrm{~h}^{-1}, \mathrm{~T}=230{ }^{\circ} \mathrm{C}$, CO conversion: $1-4 \%$.

initial NTY $\left(\right.$ TOS $=0$ ) showed consistency with the $\mathrm{H}_{2}$-chemisorption results, i.e. reduction at low temperatures for the niobia-supported sample displayed high $\mathrm{H}_{2}$-uptake along with markedly high initial NTY whereas an increase of the reduction temperature led to a suppression of the $\mathrm{H}_{2}$-uptake and a decrease in the initial NTY. However, the decrease in initial NTY is not proportional to the decrease in $\mathrm{H}_{2}$-uptake for unknown reasons. The stability throughout time significantly varied for each reduction temperature. Reduction at $250{ }^{\circ} \mathrm{C}$ led to severe deactivation, down to $70 \%$ loss in NTY at TOS $=90 \mathrm{~h}$. A less pronounced deactivation was observed when the reduction temperature was increased to $350{ }^{\circ} \mathrm{C}$ with only $40 \%$ loss in NTY, however the catalyst did not reach steady state during the experiment due to continuous deactivation. In stark contrast, reduction at $450{ }^{\circ} \mathrm{C}$ showed a catalytic performance, with a low initial NTY which increased during the first $30 \mathrm{~h}$ of the reaction followed by a stable conversion until the end of the experiment. This might indicate a partial recover of the available metallic surface area during reaction conditions, which has been associated in literature to re-oxidation of the suboxides (e.g. $\mathrm{NbO}_{\mathrm{x}}$ ) by water produced during reaction, hence modifying the SMSI effect ${ }^{41}$.

Contrary to the $\mathrm{Ni} / \mathrm{Nb}_{2} \mathrm{O}_{5}$ sample, the reduction temperature had a minor effect on the catalytic performance of the $\mathrm{Ni} / \alpha-\mathrm{Al}_{2} \mathrm{O}_{3}$ as shown in figure 6.3 . Reduction at $350{ }^{\circ} \mathrm{C}$ led to a small increase in NTY than when reduced at $450{ }^{\circ} \mathrm{C}$ at the beginning of the experiment, this difference originated from their different initial particle size as revealed by their same initial turnover frequencies (TOF). Their prevalent decrease in NTY during the experiment resulted in almost similar NTY values at TOS $=90 \mathrm{~h}$. The niobia-supported sample showed 
independently of the reduction temperature higher NTY values than the alumina-supported sample at the end of the experiment. The nickel content was determined after catalysis by ICP-OES showing no metal loss during the experiment for all samples.

The promotional effect of niobia was maintained in all cases as shown by the TOFs compared to $\mathrm{Ni} / \alpha-\mathrm{Al}_{2} \mathrm{O}_{3}$, determined either by particle size distribution from TEM or $\mathrm{H}_{2}$-chemisorption (Table 6.2). Initial TOFs based on TEM particle size distributions showed the highest values for $\mathrm{Ni} / \mathrm{Nb}_{2} \mathrm{O}_{5}$ reduced at low temperatures $\left(250\right.$ and $\left.350{ }^{\circ} \mathrm{C}\right)$ and decreased when increasing the reduction temperature to $450{ }^{\circ} \mathrm{C}$. The inverse trend was observed for the apparent initial TOFs based on chemisorption results (TOF ${ }_{\text {app }}$, Table 6.2); an increase in reduction temperature led to a substantial increase in $\mathrm{TOF}_{\text {app }}$ due to the hydrogen chemisorption suppression by SMSI (vide supra). However, the nickel surface under reaction conditions is expected to change and therefore these TOFs are indicated as 'apparent'. Interestingly, $\mathrm{Ni} / \mathrm{Nb}_{2} \mathrm{O}_{5}$ reduced at $250{ }^{\circ} \mathrm{C}$ shows consistent values for both initial TOFs indicating that coverage of the nickel nanoparticles by suboxides from the support has not taken place at this temperature. Consequently, the resulting high TOF might originate from the interphase of the nickel nanoparticles and the support. For $\mathrm{Ni} / \alpha-\mathrm{Al}_{2} \mathrm{O}_{3}$, the apparent TOFs and TOFs based on TEM have the same values and SMSI does not play a role in this catalyst system.

The change in reduction temperature additionally influenced the selectivity of the nioba-supported catalyst, as shown with the Anderson-Schulz-Flory (ASF) product distribution plot in figure 6.4 and in table 6.2. For all reduction temperatures, niobia-supported catalysts showed higher selectivity towards long-chain hydrocarbons when compared to the

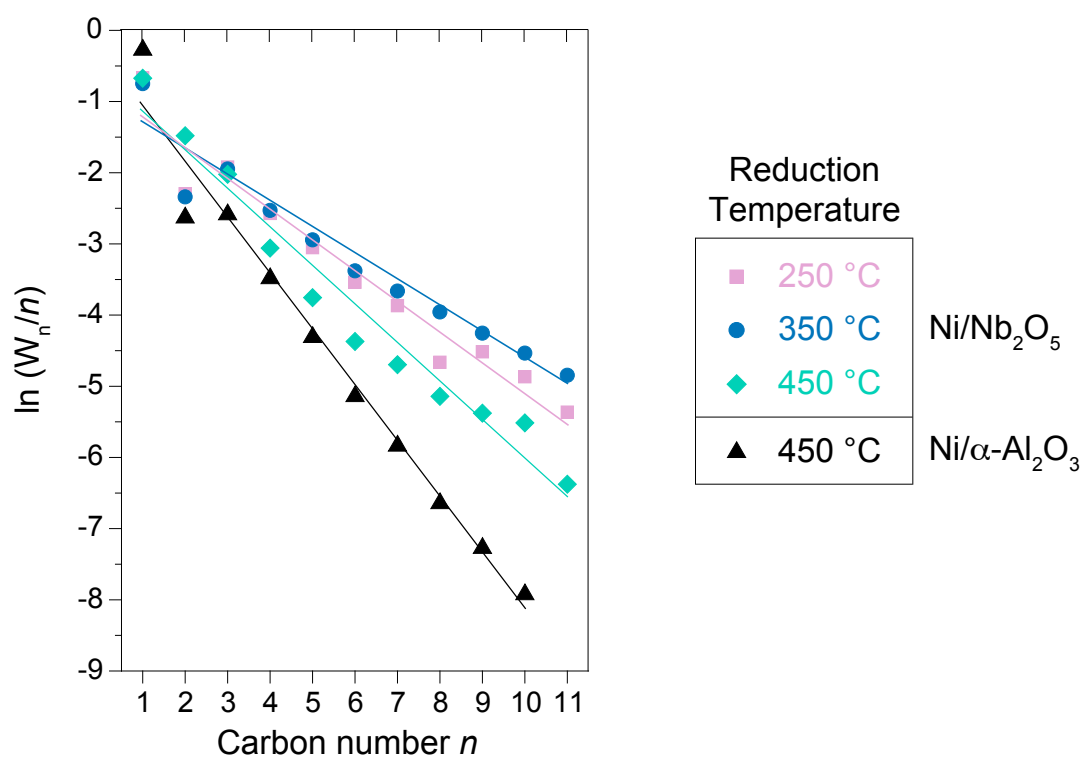

Figure 6.4 Anderson-Schulz-Flory-plot (ASF-plot) at TOS $=90 \mathrm{~h}$ for $\mathrm{Ni} / \mathrm{Nb}_{2} \mathrm{O}_{5}$ after different reduction temperatures and for the $\mathrm{Ni} / \alpha-\mathrm{Al}_{2} \mathrm{O}_{3}$ reference catalyst. $\mathrm{W}_{\mathrm{n}}=$ weight fraction of olefins plus paraffins of given carbon number $n$ in total hydrocarbon products. 
alumina-supported catalyst. At TOS $=90 \mathrm{~h}$, the catalyst reduced at $350{ }^{\circ} \mathrm{C}$ had the highest $\alpha$ value, with the highest selectivity to $\mathrm{C}_{5+}$ products, followed by the reduction temperature at $250{ }^{\circ} \mathrm{C}$. Reduction at $450{ }^{\circ} \mathrm{C}$ led to a shift in product distribution to shorter hydrocarbons and therefore a smaller $\alpha$ value. Suppressed olefin to paraffin ratio was observed for the catalyst reduced at 250 or $350{ }^{\circ} \mathrm{C}$, which has been attributed in the case of cobalt-based catalysts to re-adsorption of olefins to the metal surface to further increase chain-growth ${ }^{42,43}$. However, reduction at $450{ }^{\circ} \mathrm{C}$ did not show this behavior, instead a slight increase in the olefin selectivity was observed, as shown in table 6.2. Re-adsorption of olefins could be hindered on the metal surface, shifting the selectivity to shorter hydrocarbons. On the other hand, $\mathrm{Ni} / \alpha-\mathrm{Al}_{2} \mathrm{O}_{3}$ showed the lowest $\alpha$ value, a high selectivity for methane and to a lesser extent for $\mathrm{C}_{2}$ to $\mathrm{C}_{10}$ products for both reduction temperatures. The formation of $\mathrm{C}_{2+}$ products in this case might be due to some small nickel metal nanoparticles $(<3 \mathrm{~nm})$ found in this catalyst (Appendix E: Figure E4), which agrees with previous research reports ${ }^{44}$.

\subsubsection{SMSI and nickel carbonyl formation}

The $\mathrm{Ni} / \mathrm{Nb}_{2} \mathrm{O}_{5}$ samples after catalysis were analyzed by TEM and the results are shown in figure 6.2. Significant changes for the nickel nanoparticles were observed for the spent catalyst reduced at $250{ }^{\circ} \mathrm{C}$ : broadened particle size distribution and increased average particle size (12 nm to $27 \mathrm{~nm}$ ) were observed. Likewise, large particles were observed for the spent catalyst after reduction at $350{ }^{\circ} \mathrm{C}$ leading to a particle mean size of $18 \mathrm{~nm}$. The observed nickel particle growth agreed with the stability of the catalyst during reaction; where reduction at $250{ }^{\circ} \mathrm{C}$ led to the severest deactivation and the most pronounced particle growth, increase of the reduction temperature to $350{ }^{\circ} \mathrm{C}$ attenuated the particle growth and diminished the deactivation rate. The resulting particle sizes and catalytic activity at TOS $=90 \mathrm{~h}$ led to similar TOFs for both reduction temperatures when compared to initial TOFs (Table 6.2). This is an indication that the decrease in NTY was mainly due to particle growth. The slight decrease in TOF might relate to carbon deposition over the nickel surface. In a similar way, TEM of the spent $\mathrm{Ni} / \alpha-\mathrm{Al}_{2} \mathrm{O}_{3}$ catalysts revealed a substantial increase in nickel particle size (Appendix E: Figure E5), indicating that the decrease in NTY originated mainly from particle growth. Particle growth for nickel-based catalysts under these reaction conditions most likely occurs via Ostwald ripening by the formation of $\mathrm{Ni}(\mathrm{CO})_{4}$ ${ }^{25-27}$. In contrast, the nickel particles remained well distributed over the support for the $\mathrm{Ni} /$ $\mathrm{Nb}_{2} \mathrm{O}_{5}$ sample reduced at $450{ }^{\circ} \mathrm{C}$. No significant change in particle size was observed after catalysis, with a final mean particle size of $12 \mathrm{~nm}$. Therefore, the increase in CO conversion during the first hours of the experiment means that sites more active became available and thus the TOF almost doubled (Table 6.2). These results suggest that SMSI inhibited the formation of $\mathrm{Ni}(\mathrm{CO})_{4}$ on a $\mathrm{Nb}_{2} \mathrm{O}_{5}$ support leading to a more stable catalyst. $\mathrm{Ni}(\mathrm{CO})_{4}$ formation rate has been reported to depend on the nickel surface morphology with particularly low coordinated $\mathrm{Ni}$ atoms readily reacting to form carbonyls ${ }^{45,46}$, thus $\mathrm{NbO}_{\mathrm{x}}$ species might be responsible for blocking or modifying the electron density of these sites.

Fourier-Transform Infrared (FT-IR) spectroscopy was used to study the differences for the sample reduced at 250,350 and $450{ }^{\circ} \mathrm{C}$ in their tendencies to form nickel carbonyl. 


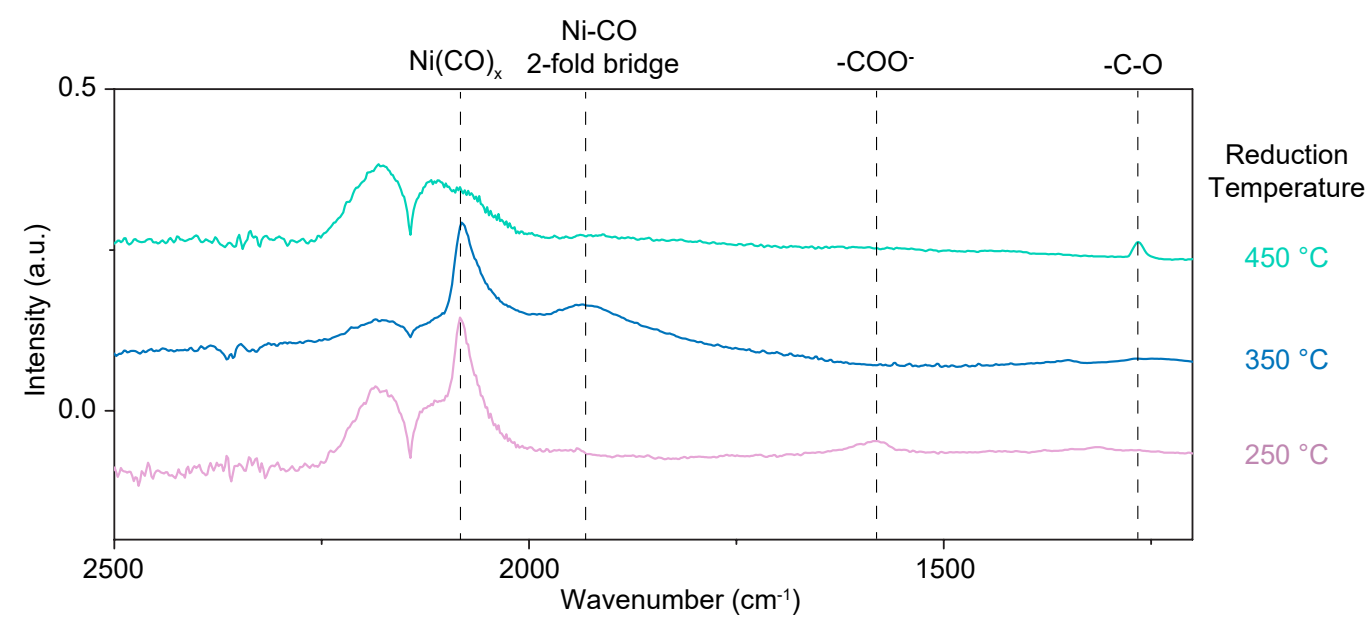

Figure 6.5 FT-IR spectra under $\mathrm{CO}$ atmosphere of $\mathrm{Ni} / \mathrm{Nb}_{2} \mathrm{O}_{5}$ after reduction at 250,350 or $450{ }^{\circ} \mathrm{C}$.

In-situ reduction of the wafer was carried out at these three different temperatures. Thereafter FT-IR spectra were recorded at $230{ }^{\circ} \mathrm{C}$ under atmospheric pressure of $\mathrm{CO} / \mathrm{N}_{2}=2 \mathrm{v} / \mathrm{v}$ flow (Figure 6.5). Interestingly, a pronounced sharp band at $2080 \mathrm{~cm}^{-1} \mathrm{can}$ be observed when the sample was reduced at $250{ }^{\circ} \mathrm{C}$. This band is ascribed to subcarbonyl $\mathrm{Ni}(\mathrm{CO})_{\mathrm{x}}(\mathrm{x}=2,3)$ species, precursors of $\mathrm{Ni}(\mathrm{CO})_{4}$, in accordance with literature ${ }^{46-48}$. These species were also detected for the catalyst reduced at $350{ }^{\circ} \mathrm{C}$ and in both cases the band disappeared after flushing with $\mathrm{N}_{2}$. In contrast, reduction at $450{ }^{\circ} \mathrm{C}$ did not give rise to this subcarbonyl $\mathrm{Ni}(\mathrm{CO})_{\mathrm{x}}$ band. These results show that there is a reduction temperature dependency in nickel carbonyl formation. Lower reduction temperatures thus most likely led to rapid deactivation during $\mathrm{CO}$ hydrogenation due to $\mathrm{Ni}$ particle growth via the formation and diffusion of $\mathrm{Ni}(\mathrm{CO})_{4}$ originated from the detected $\mathrm{Ni}(\mathrm{CO})_{x}$ species. High reduction temperature showed stable catalytic activity (Figure 6.3), suggesting that the SMSI effect suppressed the formation of $\mathrm{Ni}(\mathrm{CO})_{x}$ species and hence $\mathrm{Ni}(\mathrm{CO})_{4}$, avoiding the diffusion of nickel over the support.

Furthermore, the FT-IR spectra plotted in Figure 6.5 show that the degree of CO activation in the adsorbed state is affected by the reduction temperature. That is, a reduction at $250{ }^{\circ} \mathrm{C}$ shows a large contribution of $\mathrm{Ni}(\mathrm{CO})_{\mathrm{x}}$ at $2090 \mathrm{~cm}^{-1}$ corresponding to the strongest carbon-oxygen bond based on the relatively high wavenumber of this band. A band at $1580 \mathrm{~cm}^{-1}$ is also observed which is attributed to carboxylate-type species, these may have originated from the oxidation of $\mathrm{CO}$ by the remaining $\mathrm{NiO}$ in this sample as shown by the TPR results. For a slightly higher reduction temperature $\left(350{ }^{\circ} \mathrm{C}\right)$ besides the band at $2090 \mathrm{~cm}^{-1}$, a broad peak at around $1960 \mathrm{~cm}^{-1}$ is observed, which is ascribed to $\mathrm{C}=\mathrm{O}$ adsorbed in a 2 -fold bridge position ${ }^{49,50}$. At the highest reduction temperature (i.e., $450{ }^{\circ} \mathrm{C}$ ) a small peak at $\sim 1266 \mathrm{~cm}^{-1}$ appears, which can be ascribed to the weakest CO bond ${ }^{51}$, or lowest wavenumber observed in this set of experiments.

Two effects of the SMSI can explain the inhibition of nickel carbonyl formation. On one hand, $\mathrm{NbO}_{\mathrm{x}}$ suboxides might physically block the more reactive low-coordinated $\mathrm{Ni}$ atoms on the surface of the nanoparticles, preventing the formation of subcarbonyl $\mathrm{Ni}(\mathrm{CO})_{\mathrm{x}}$ 
species. A similar effect has been shown in literature by addition of alkali metals or sulfur to nickel-based catalysts ${ }^{52,53}$. On the other hand, the suboxides partially covering the nickel nanoparticle's surface are capable of transferring electrons to the nickel ${ }^{54-56}$. In this case, $\mathrm{Nb}^{4+}$ or $\mathrm{Nb}^{3+}$ in the $\mathrm{NbO}_{\mathrm{x}}$ suboxides might transfer electron density to the metallic nickel, resulting in electron-rich $\mathrm{Ni}^{\delta-}$ atoms at the surface. Upon $\mathrm{CO}$ chemisorption at the nickel surface, $\mathrm{Ni}^{\delta}$ increases the back-donation to the $\mathrm{CO} 2 \pi^{*}$ antibonding orbital weakening the $\mathrm{C}-\mathrm{O}$ bond, as suggested by FT-IR, and thus avoiding the formation of $\mathrm{Ni}(\mathrm{CO})_{\mathrm{x}}$ species. Furthermore, an electron-rich metallic surface could hinder the re-adsorption of electron-rich molecules, explaining the increased olefin to paraffin ratios when the catalyst was reduced at high temperatures.

\subsection{Conclusions}

The effect of different reduction temperatures was studied for nickel nanoparticles supported on niobia. An increase of the reduction temperature led to $\mathrm{H}_{2}$-chemisorption suppression, a typical phenomenon caused by reducible oxidic supports in which suboxides from the support cover partially the metal nanoparticles. The initial nickel-based catalytic activity was in line with the chemisorption results where high $\mathrm{H}_{2}$-uptake corresponded to high initial CO conversion. However, low reduction temperatures turned into a fast deactivation due to nickel particle growth as shown by TEM, whereas a high reduction temperature led to stable catalytic performance and no significant particle growth. Interestingly, reduction of the niobia-supported catalyst at high temperature brought about an activation period during the first hours under reaction conditions followed by stable nickel-based activity. FT-IR measurements of $\mathrm{CO}$ adsorbed on $\mathrm{Ni} / \mathrm{Nb}_{2} \mathrm{O}_{5}$ showed that nickel subcarbonyls readily formed after low but not after high reduction temperature. This could explain the particle growth involving the formation and diffusion of nickel tetracarbonyl, which formed from the detected nickel subcarbonyls. The inhibition of nickel tetracarbonyl formation after high temperature reduction is associated to the presence of suboxide species over the nickel surface, by either physically blocking exposed low-coordination nickel atoms, or by enhancing the electron density on the nickel surface and facilitating C-O bond rupture instead of nickel tetracarbonyl formation. The reduction treatment had a strong influence in the product distribution, where the highest selectivity towards $\mathrm{C}_{5+}$ was obtained after reduction at $350{ }^{\circ} \mathrm{C}$, while a further increase of the reduction temperature shifted the product distribution towards lighter products. Finally, the promotional effect of reducible oxides, such as niobia, in CO hydrogenation was clearly shown since independently of the reduction temperature nickel supported on niobia showed higher nickel-based activity, TOF and $\mathrm{C}_{5+}$ selectivity compared to nickel supported on $\alpha$-alumina, a non-reducible support. We have shown that niobia used as support material offers the possibility to make stable nickel-based catalysts for CO hydrogenation with tunable product spectrum. 


\section{Acknowledgments}

Companhia Brasileira de Metalurgia e Mineração (CBMM) is thanked for financial support of this research. Dr. Robson Monteiro and Mr. Rogério Ribas (CBMM) are acknowledged for useful discussions and supplying the niobia support. Mr. Wouter Lamme (Utrecht University, UU), Mrs. Petra Keijzer (UU) and Mrs. Savannah Turner (UU) are acknowledged for performing TEM measurements. KPdJ acknowledges the European Research Council (ERC) for a EU FP7 ERC Advanced Grant no. 338846.

\section{References}

1. Munnik, P., De Jongh, P. E. \& De Jong, K. P. Recent developments in the synthesis of supported catalysts. Chem. Rev. 115, 6687-6718 (2015).

2. Bartholomew, C. H. Mechanisms of catalyst deactivation. Appl. Catal. A Gen. 212, 17-60 (2001).

3. Goodman, E. D., Schwalbe, J. A. \& Cargnello, M. Mechanistic understanding and the rational design of sinter-resistant heterogeneous catalysts. ACS Catal. 7, 7156-7173 (2017).

4. Prieto, G., Zečević, J., Friedrich, H., De Jong, K. P. \& De Jongh, P. E. Towards stable catalysts by controlling collective properties of supported metal nanoparticles. Nat. Mater. 12,34-39 (2013).

5. Pompe, C. E., Slagter, M., de Jongh, P. E. \& de Jong, K. P. Impact of heterogeneities in silica-supported copper catalysts on their stability for methanol synthesis. J. Catal.365, 1-9 (2018).

6. Resasco, D. E. \& Haller, G. L. A model of metal-oxide support interaction for Rh on $\mathrm{TiO}_{2}$.J. Catal. 82, 279-288 (1983).

7. Shi, X. Y. et al. Real-space observation of strong metal-support interaction: State-of-the-art and what's the next. J.Microsc. 262, 203-215 (2016).

8. Tauster, S. J., Fung, S. C. \& Garten, R. L. Strong metal-support interactions. Group 8 noble metals supported on titanium dioxide. J.Am. Chem. Soc. 100, 170-175 (1978).

9. Tauster, S. J. Strong metal-support interactions. Acc. Chem. Res. 20, 389-394 (1987).

10. Newton, M. A. Dynamic adsorbate/reaction induced structural change of supported metal nanoparticles: heterogeneous catalysis and beyond. Chem. Soc. Rev. 37, 2644 (2008).

11. Zhang, S. et al. Dynamical observation and detailed description of catalysts under strong metal-support interaction. Nano Lett. 16, 4528-4534 (2016).

12. Lykhach, Y. et al. Counting electrons on supported nanoparticles. Nat. Mater. 15, 284 (2015).

13. Vannice, M. A. \& Garten, R. L. Metal-support effects on the activity and selectivity of Ni catalysts in $\mathrm{CO} / \mathrm{H}_{2}$ synthesis reactions. J. Catal. 56, 236-248 (1979).

14. van de Loosdrecht, J., van der Kraan, A. M., van Dillen, A. J. \& Geus, J. W. Metal-support interaction: Titania-supported and silica-supported nickel catalysts. J. Catal. 170, 217-226 (1997).

15. Ko, E. I., Hupp, J. M. \& Wagner, N. J. Ethane hydrogenolysis and carbon monoxide hydrogenation over niobia-supported nickel catalysts: A hierarchy to rank strong metal-support interaction. J. Catal. 86, 315-327 (1984).

16. Ko, E. I., Hupp, J. M. \& Wagner, N. J. Activity and selectivity of a niobia $\left(\mathrm{Nb}_{2} \mathrm{O}_{5}\right)$-supported nickel catalyst in CO hydrogenation. J. Chem. Soc., Chem. Commun. 0,94-95 (1983).

17. Raupp, G. B. \& Dumesic, J. A. Effects of titania on the coadsorption of $\mathrm{H}_{2}$ and CO on nickel surfaces: Consequences for understanding methanation over titania-supported nickel catalysts. J. Catal. 96, 597-612 (1985).

18. Lin, Y., Zhu, Y., Pan, X. \& Bao, X. Modulating the methanation activity of $\mathrm{Ni}$ by the crystal phase of $\mathrm{TiO}_{2}$. Catal. Sci. Technol. 7, 2813-2818 (2017).

19. Shan, S. et al. Atomic-structural synergy for catalytic CO oxidation over palladium-nickel nanoalloys. J.Am. Chem. Soc. 136, 7140-7151 (2014).

20. Li, Y., Fu, Q. \& Flytzani-Stephanopoulos, M. Low-temperature water-gas shift reaction over $\mathrm{Cu}$ - and Ni-loaded cerium oxide catalysts. Appl. Catal. B Environ. 27, 179-191 (2000). 
21. Vogt, C. et al. Unravelling structure sensitivity in $\mathrm{CO}_{2}$ hydrogenation over nickel. Nat. Catal. 1, 127-134 (2018).

22. Foppa, L. et al. Contrasting the role of $\mathrm{Ni} / \mathrm{Al}_{2} \mathrm{O}_{3}$ interfaces in water-gas shift and dry reforming of methane. J.Am. Chem. Soc. 139, 17128-17139 (2017).

23. Li, Z., Mo, L., Kathiraser, Y. \& Kawi, S. Yolk-satellite-shell structured $\mathrm{Ni}-Y$ olk@ $\mathrm{Ni} @ S i O_{2}$ nanocomposite: Superb catalyst toward methane $\mathrm{CO}_{2}$ reforming reaction. ACS Catal. 4, 1526-1536 (2014).

24. Shen, W. M., Dumesic, J. A. \& Hill, C. G. Criteria for stable Ni particle size under methanation reaction conditions: Nickel transport and particle size growth via nickel carbonyl. J. Catal. 68, 152-165 (1981).

25. Mirodatos, C., Praliaud, H. \& Primet, M. Deactivation of nickel-based catalysts during CO methanation and disproportionation. J. Catal. 107, 275-287 (1987).

26. Agnelli, M., Kolb, M. \& Mirodatos, C. CO hydrogenation on a nickel catalyst I. Kinetics and modeling of a low temperature sintering process. J. Catal. 148, 9-21 (1994).

27. Munnik, P., Velthoen, M. E. Z., De Jongh, P. E., De Jong, K. P. \& Gommes, C. J. Nanoparticle growth in supported nickel catalysts during methanation reaction - Larger is better. Angew. Chemie - Int. Ed. 53, 9493-9497 (2014).

28. Cao, A. \& Lu, R. Stabilizing metal nanoparticles for heterogeneous catalysis. Phys. Chem. Chem. Phys. 12, 13499-13510 (2010).

29. Hansen, T. W., Delariva, A. T., Challa, S. R. \& Datye, A. K. Sintering of catalytic nanoparticles: Particle migration or ostwald ripening ? Acc. Chem. Res. 46, 1720-1730 (2013).

30. Goldberger, W. M. \& Othmer, D. F. Kinetics of nickel carbonyl formation. Ind. Eng. Chem. Process Des. Dev. 2, 202-209 (1963).

31. Enger, B. C. \& Holmen, A. Nickel and Fischer-Tropsch synthesis. Catal. Rev. 54, 437-488 (2012).

32. Dry, M. E. The Fischer-Tropsch process: 1950-2000. Catal. Today 71, 227-241 (2002).

33. Agnelli, M. \& Mirodatos, C. CO hydrogenation on nickel-based catalysts: Effects of copper addition. J. Catal. 192, 204-214 (2000).

34. Pereira, E. B. \& Martin, G. A. Alcohol synthesis from syngas over nickel-catalysts - Effect of copper and lithium addition. Appl. Catal. a-General 103, 291-309 (1993).

35. Zacharaki, E. et al. From Colloidal monodisperse nickel nanoparticles to well-defined $\mathrm{Ni} / \mathrm{Al}_{2} \mathrm{O}_{3}$ model catalysts. Langmuir 33, 9836-9843 (2017).

36. Schäfer, H., Gruehn, R. \& Schulte, F. The modifications of niobium pentoxide. Angew. Chemie Int. Ed. 5, 40-52 (1966).

37. Forghany, S. K. E. \& Anderson, J. S. Reduction and polymorphic transformation of $\mathrm{B}-\mathrm{Nb}_{2} \mathrm{O}_{5}$. J. Chem. Soc, Dalt. Trans. 1 255-261 (1981).

38. Lensveld, D. J., Mesu, J. G., van Dillen, A. J. \& de Jong, K. P. Synthesis and characterisation of MCM-41 supported nickel oxide catalysts. Micropor. Mesopor. Mat. 44-45, 401-407 (2001).

39. Mile, B., Stirling, D.,Zammitt, M. A., Lovell, A. \& Webb, M. TPR studies of the effects of preparation conditions on supported nickel catalysts. J.Mol. Catal. 62, 179-198 (1990).

40. Hernández Mejía, C., van Deelen, T. W. \& de Jong, K. P. Activity enhancement of cobalt catalysts by tuning metal-support interactions. Nat. Commun. 9, 4459 (2018).

41. Deleitenburg, C. \& Trovarelli, A. Metal-support interactions in $\mathrm{Rh} / \mathrm{CeO}{ }_{2}, \mathrm{Rh} / \mathrm{TiO}_{2}$, and $\mathrm{Rh} / \mathrm{Nb}_{2} \mathrm{O}_{5}$ catalysts as inferred from $\mathrm{CO}_{2}$ methanation activity. J. Catal. 156, 171-174 (1995).

42. Komaya,T.\& Bell,A.T.Estimates of rate coefficients for elementary processes occurring during Fischer-Tropsch synthesis over $\mathrm{Ru} / \mathrm{TiO}_{2}$. J. Catal. 146, (1994).

43. Iglesia, E., Reyes, S. C. \& Madon, R. J. Transport-enhanced $\alpha$-olefin readsorption pathways in Ru-catalyzed hydrocarbon synthesis. J. Catal. 129, 238-256 (1991).

44. Bartholomew, C. H., Pannell, R. B. \& Butler, J. L. Support and crystallite size effects in CO hydrogenation on nickel. J. Catal. 65, 335-347 (1980).

45. De Groot, P., Coulon, M. \& Dransfeld, $\mathrm{K} . \mathrm{Ni}(\mathrm{CO})_{4}$ formation on single Ni crystals: Reaction kinetics and observation of surface facetting induced by the reaction. Surf. Sci. 94, 204-220 (1980).

46. Agnelli, M., Swaan, H. M., Marquez-Alvarez, C., Martin, G. A. \& Mirodatos, C. CO hydrogenation on a nickel 
catalyst. J. Catal. 175, 117-128 (1998).

47. Blackmond, D. G. \& Ko, E. I. Structural sensitivity of $\mathrm{CO}$ adsorption and $\mathrm{H}_{2} / \mathrm{CO}$ coadsorption on $\mathrm{Ni} / \mathrm{SiO}_{2}$ catalysts. J. Catal. 96, 210-221 (1985).

48. Mihaylov, M., Hadjiivanov, K. \& Knözinger, H. Formation of $\mathrm{Ni}(\mathrm{CO})_{4}$ during the interaction between $\mathrm{CO}$ and silica-Supported nickel catalyst: an FTIR spectroscopic study. Catal. Letters 76, 59-63 (2001).

49. Courtois, M. \& Teichner, S. J. Infrared studies of $\mathrm{CO}, \mathrm{O}_{2}$ and $\mathrm{CO}_{2}$ gases and their interaction products, chemically adsorbed on nickel oxide. J. Catal. 135, 121-135 (1962).

50. Trenary, M., Uram, K. J. \& Yates, J. T. An infrared reflection-absorption study of CO chemisorbed on clean and sulfided $\mathrm{Ni}(111)$ - evidence for local surface interactions. Surf. Sci. 157, 512-538 (1985).

51. Socrates, G. Infrared and Raman Characteristic Group Frequencies: Tables and Charts (third edition), John Wiley and Sons, Ltd, Chichester (2001).

52. Ang, M. L. et al. Highly active $\mathrm{Ni} / \mathrm{xNa} / \mathrm{CeO}_{2}$ Catalyst for the water gas shift reaction: Effect of sodium on methane suppression. ACS Catal. 4, 3237-3248 (2014).

53. Bengaard, H. S. et al. Steam reforming and graphite formation on Ni catalysts. J. Catal. 209, 365-384 (2002).

54. Kao, C. C., Tsai, S. C., Bahl, M. K., Chung, Y. W. \& Lo, W. J. Electronic properties, structure and temperature-dependent composition of nickel deposited on rutile titanium dioxide (110) surfaces. Surf. Sci. 95, 1-14 (1980).

55. Wang, W. et al. Strong metal-support interactions between $\mathrm{Ni}$ and $\mathrm{ZnO}$ particles and their effect on the methanation performance of Ni/ZnO. Catal. Sci. Technol. 7, 4413-4421 (2017).

56. Xu, M. et al. $\mathrm{TiO}_{2-\mathrm{x}}$-modified Ni nanocatalyst with tunable metal-support interaction for water-gas-shift reaction. ACS Catal. 7, 7600-7609 (2017). 



\section{Niobium-based Solid Acids in Combination with a Methanol Synthesis Catalyst for the Direct Production of Dimethyl Ether from Synthesis Gas}

The production of dimethyl ether as compared to methanol from synthesis gas allows for increased conversions in a single pass. A challenge in this process is the combination of methanol synthesis and dehydration functionalities in a single catalyst without mutual negative interference of their performances. Here, we studied the use of hydrated niobium pentoxide $\left(\mathrm{Nb}_{2} \mathrm{O}_{5} \cdot n \mathrm{H}_{2} \mathrm{O}\right)$ and niobium phosphate $\left(\mathrm{NbOPO}_{4}\right)$ in combination with a copper-based methanol synthesis catalyst in the direct synthesis of DME while gamma-alumina $\left(\gamma-\mathrm{Al}_{2} \mathrm{O}_{3}\right)$ was used as a reference material. The three solid acids combined with the copper-based catalyst proved active and selective in the production of DME, however all of them showed some degree of deactivation throughout the reaction. Characterization of the used catalysts pointed out that while the $\gamma-\mathrm{Al}_{2} \mathrm{O}_{3}$-based mixture deactivated most likely due to coke deposition on the alumina and structural changes in the methanol synthesis catalysts, the $\mathrm{Nb}_{2} \mathrm{O}_{5} \cdot n \mathrm{H}_{2} \mathrm{O}$ and $\mathrm{NbOPO}_{4}$-based catalysts lost activity probably as a result of copper migration from the methanol synthesis catalyst to the acid component. In view of the high volume-based activity of the Nb-based solid acids it is concluded that these are promising components for the direct catalytic conversion of synthesis gas to DME.

Hernández Mejía, C., Verbart, D. M. A. \& de Jong, K. P. Niobium-based solid acids in combination with a methanol synthesis catalyst for the direct production of dimethyl ether from synthesis gas. Catal. Today, accepted. 


\subsection{Introduction}

Synthesis gas, a mixture of hydrogen and carbon monoxide, is a versatile feedstock for the production of various chemicals and fuels. The conversion of synthesis gas to a desired product relies substantially on the catalyst employed. Whereas a primary hydrogenation function, typically a late-transition metal, can selectively produce chemicals such as alcohols, olefins or paraffins, addition of a second catalyst can be employed to couple reactions and expand the diversity of products ${ }^{1,2}$. Ideally, both functionalities in a catalyst mixture should result solely in a positive synergetic performance, which is feasible by selecting the appropriate chemical properties and an optimal degree of intimacy ${ }^{3-6}$. However, achieving the ideal composition without negative interferences remains a challenge in these multifunctional catalytic systems.

Dimethyl ether (DME) is commonly utilized in the aerosol industry as propellant and in the chemical industry as methylating agent, and it has shown potential in the production of bulk chemicals such as olefins, aromatics and acetic acid ${ }^{7-10}$. Moreover, DME has attracted interest during the last decades as a clean fuel owing to its similar physicochemical properties to LPG and low particulate emissions ${ }^{11-15}$. DME can be directly produced by coupling the synthesis of methanol from synthesis gas with the dehydration of methanol to DME. Haldor Topsøe initially recognized the industrial advantages of combining both reactions in a single process, showing that the direct production of DME from synthesis gas could improve energy efficiencies and reduce capital costs ${ }^{13,14,16}$. Figure 7.1 shows the rele-

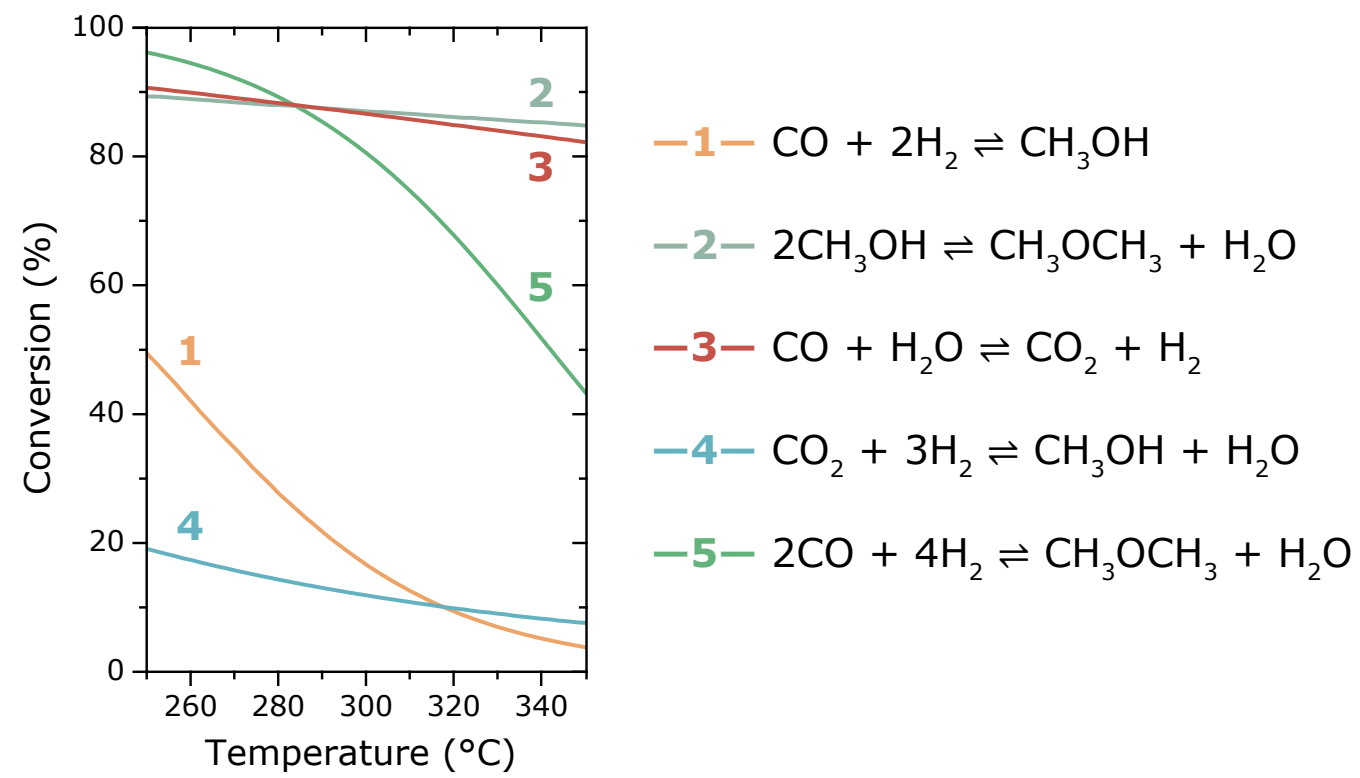

Figure 7.1 Thermodynamic equilibrium for stoichiometric quantities of reactants for the individual reactions involved in the synthesis of DME. Calculations were performed using the HSC software from Outotec, 7 .14 in the temperature range from $250-350{ }^{\circ} \mathrm{C}$, considering all species in the gas phase and 40 bar total pressure. Conversion refers to that of $\mathrm{CO}$ (eq. 1, 3 and 5), $\mathrm{CO}_{2}$ (eq. 4) or methanol (eq. 2). 
vant reaction equations for the synthesis of DME and their corresponding thermodynamic equilibria. While methanol formation from synthesis gas is an equilibrium-limited reaction (Figure 7.1, eq. 1), in-situ conversion of methanol towards DME shifts this equilibrium towards higher conversions in a single pass, a benefit of combining both reactions (Figure 7.1, eq. 2 and 5). The additional water formed during the dehydration can bring about the watergas-shift reaction, in which $\mathrm{H}_{2} \mathrm{O}$ and $\mathrm{CO}$ react to form $\mathrm{CO}_{2}$ and $\mathrm{H}_{2}$ (Figure 7.1, eq. 3). This can be beneficial when using hydrogen-deficient synthesis gas but also the presence of $\mathrm{CO}_{2}$ can enhance the synthesis of methano ${ }^{17}$ (Figure 7.1, eq. 4). However, an excess of water can further boost the water-gas-shift reaction at the expense of methanol synthesis decreasing the DME yield of the catalyst ${ }^{18}$. Water can also lead to detrimental effects on the catalysts' structure, such as sintering or poisoning of active sites, resulting in an accelerated deactiva$\operatorname{tion}^{18,19}$. The direct synthesis of DME from synthesis gas is therefore a clear example of the advantages and challenges in bifunctional catalysis ${ }^{20,21}$.

Currently, the most efficient methanol synthesis catalysts are copper-based and hence widely used in industry ${ }^{22}$. Methanol synthesis is an exothermic reaction and it is accompanied with a volumetric contraction, the preferred reaction conditions are therefore low temperatures and high pressures according to Le Chatelier's principle (Figure 7.1, eq. 1). Thus, methanol synthesis catalysts are typically operated at pressures between $30-50$ bar and temperatures in the range of $220-300{ }^{\circ} \mathrm{C}$, such conditions result in methanol selectivity greater than $99 \%$ and reduced formation of by-products ${ }^{23,24}$. Furthermore, it is well known that methanol can be synthetized from $\mathrm{CO}_{2}$-enriched synthesis gas (Figure 7.1, eq. 4),

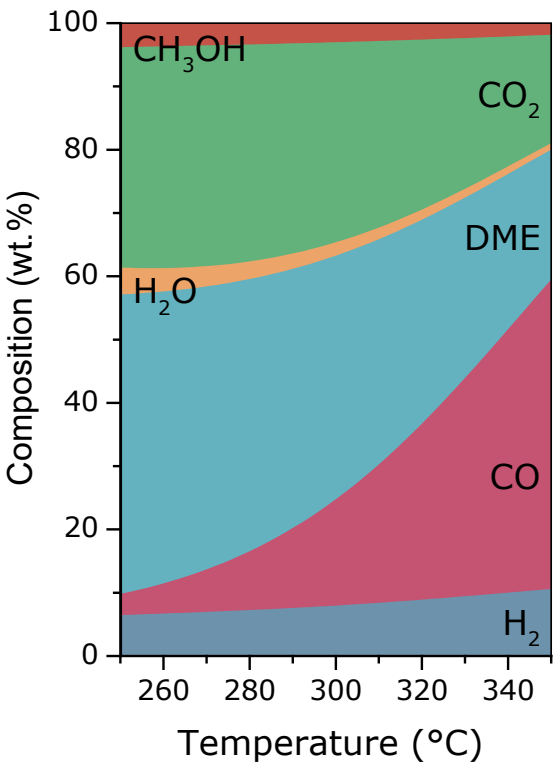

Figure 7.2 Equilibrium composition of species involved in the direct synthesis of DME as a function of temperature at 40 bar. The thermodynamic calculation was carried out considering all species in the gas phase, a synthesis gas composition of $\mathrm{H}_{2}: \mathrm{CO}=2 \mathrm{v} / \mathrm{v}$ and DME, methanol, water and $\mathrm{CO}_{2}$ as possible species. The HSC software from Outotec (v 7.14) was used to perform the calculation. 
making it a target for research on $\mathrm{CO}_{2}$ utilization ${ }^{25,26}$. Methanol dehydration to form DME (Figure 7.1, eq. 2) is also an exothermic process and can be performed at relatively low temperatures $\left(150-300{ }^{\circ} \mathrm{C}\right)$. Thus, the similarity of the process conditions makes it possible to operate methanol synthesis and DME production in a single reactor. The synergy generated by introducing the methanol dehydration reaction leads to a significant increase in CO conversion per pass (Figure 7.1, eq 5), this in marked contrast to the two-step process in which methanol is produced separately, stored and further converted to DME. The resulting equilibrium composition as a function of temperature for the direct DME synthesis is shown in figure 7.2, when considering the presence of $\mathrm{CO}, \mathrm{H}_{2}$, methanol, DME, $\mathrm{CO}_{2}$ and $\mathrm{H}_{2} \mathrm{O}$ at 40 bar total pressure. It is possible to observe that DME is favored as the main product at temperatures below $300{ }^{\circ} \mathrm{C}$, and the other molecules can be recycled to produce more DME.

Methanol dehydration can be catalyzed by Brønsted as well as Lewis acid sites and the most studied solid acids for this reaction are $\gamma-\mathrm{Al}_{2} \mathrm{O}_{3}$ and zeolites ${ }^{20,21,27,28}$. Too strong acid sites and high temperatures can favor the further dehydration of DME to olefins and hydrocarbons ${ }^{29}$, compromising the selectivity of the catalyst. This is the case for most zeolites, which contain strong acid sites favoring DME dehydration at the required temperatures for methanol synthesis ${ }^{30}$. Even though various strategies exist to tune the zeolites' acidity ${ }^{31,32}$, their microporous structure can restrain the diffusion of methanol, DME and hydrocarbons leading to further polymerization reactions and coke formation, inactivating and blocking the active sites ${ }^{33} \cdot \gamma-\mathrm{Al}_{2} \mathrm{O}_{3}$ on the other hand, possesses milder acid sites, mainly of the Lewis type, making it more selective for DME and used for industrial catalysts ${ }^{13,34,35}$. Nonetheless, competitive adsorption of water as well as crystal phase transformation aided by steam make $\gamma-\mathrm{Al}_{2} \mathrm{O}_{3}$ sensitive to the formed water during dehydration and thus diminishes its catalytic activity ${ }^{34,36,37}$.

Hydrated niobium pentoxide $\left(\mathrm{Nb}_{2} \mathrm{O}_{5} \cdot n \mathrm{H}_{2} \mathrm{O}\right)$ and niobium phosphate $\left(\mathrm{NbOPO}_{4}\right)$ are interesting solid acids, possessing both Brønsted and Lewis acid sites, which have shown exceptional catalytic performance for various acid-catalyzed reactions ${ }^{38-40}$. Contrary to many solid acids, these materials are capable of maintaining high catalytic activity and stability when water is involved. This resistance to water poisoning has been reported to originate from Lewis acid sites, in this case coordinatively unsaturated $\mathrm{Nb}^{5+}$ cations in $\mathrm{NbO}_{4}$ tetrahedral arrangements, capable of forming active $\mathrm{NbO}_{4}-\mathrm{H}_{2} \mathrm{O}$ adducts that preserve an effective positive charge ${ }^{41-43}$. Thus, niobium-based materials have raised the research interest as stable solid acids for hydration and dehydration reactions. Several studies have reported the application of niobium-based and niobium-modified materials for the dehydration of methanol to form $\mathrm{DME}^{44-46}$ and for the direct synthesis of DME from synthesis gas ${ }^{47,48}$. These studies have shown the potential of niobium-based materials as active and selective catalysts for the synthesis of DME, however little attention has been paid to their stability.

In this research we studied the catalytic performance of $\mathrm{Nb}_{2} \mathrm{O}_{5} \bullet n \mathrm{H}_{2} \mathrm{O}$ and $\mathrm{NbOPO}_{4}$ acting as solid acids in concert with a Cu-based catalyst in the direct synthesis of DME from synthesis gas. Particularly, this research focused on the stability of such materials under industrially relevant conditions (40 bar total pressure and 260 or $280{ }^{\circ} \mathrm{C}$ ). For this end, we worked with physical mixtures composed of a commercial methanol synthesis catalyst and 
a solid acid, $\mathrm{Nb}_{2} \mathrm{O}_{5} \cdot n \mathrm{H}_{2} \mathrm{O}, \mathrm{NbOPO}_{4}$ or $\gamma-\mathrm{Al}_{2} \mathrm{O}_{3}$, which was used as reference material. The mixtures of the niobium-based solid acids showed comparable activity and DME selectivity than the gamma-alumina one, while all catalysts showed deactivation throughout the reaction. Characterization of the used materials indicated that migration of copper from the methanol synthesis catalyst to the niobium-based materials contributed to the loss in methanol and DME production, whereas in the case of the gamma-alumina mixtures, coke deposition on the alumina and structural alteration of the copper-based catalyst were the main causes of deactivation.

\subsection{Experimental}

Materials. Hydrated niobium pentoxide $\left(\mathrm{Nb}_{2} \mathrm{O}_{5} \cdot n \mathrm{H}_{2} \mathrm{O}, \mathrm{HY}-340\right)$ and niobium phosphate $\left(\mathrm{NbOPO}_{4}\right)$ were provided by Companhia Brasileira de Metalurgia e Mineração - CBMM. The gamma-alumina $\left(\gamma-\mathrm{Al}_{2} \mathrm{O}_{3}\right)$ was obtained from BASF as extrudates (Al-3992E1/8”), which were grinded and sieved after thermal treatment. Thermal treatment of the solid acids was performed in stagnant air at different temperatures in all cases for $4 \mathrm{~h}$ with a ramp of $5{ }^{\circ} \mathrm{C} \cdot \mathrm{min}^{-1}$. Thereafter, the materials were sieved in a $38-75 \mu \mathrm{m}$ fraction. The methanol synthesis catalyst employed was obtained from Alfa Aesar (I06Z036), with a reported composition of $10.1 \% \mathrm{Al}_{2} \mathrm{O}_{3}, 63.5 \% \mathrm{CuO}, 24.7 \% \mathrm{ZnO}$ and $1.3 \% \mathrm{MgO}$. The catalyst pellets were grinded and sieved in a $75-150 \mu \mathrm{m}$ fraction.

The bulk density of the sieved solid acids and methanol synthesis catalyst was determined by using a $200 \mu \mathrm{L}$ spoon. The corresponding mass was measured by weighting the volume of material obtained with the spoon. This was repeated for five times and the average of weights was used to calculate the density (Table 7.1).

The physical mixtures for the direct synthesis of DME were prepared by weighting the desired amount of methanol synthesis catalyst and solid acid, mixed with $200 \mathrm{mg}$ of $\mathrm{SiC}(212-425 \mu \mathrm{m})$ and loaded in the reactor. For the experiment in stacked-bed configuration, an amount of solid acid fixed to have the same amount of acid sites per reactor $\left(6 \cdot 10^{-3} \mathrm{mmol}_{\mathrm{NH} 3}\right.$ at $260{ }^{\circ} \mathrm{C}$ and $3 \cdot 10^{-3} \mathrm{mmol}_{\mathrm{NH} 3}$ at $280{ }^{\circ} \mathrm{C}$ from ammonia TPD) was mixed with $\sim 60 \mathrm{mg} \mathrm{SiC}(212-425 \mu \mathrm{m})$ and placed downstream of the methanol synthesis catalyst with $\sim 40 \mathrm{mg}$ of $\mathrm{SiC}(212-425 \mu \mathrm{m})$ separating both catalysts beds. Around $20 \mathrm{mg}$ of copper-based methanol synthesis catalyst were used for the experiments at $260{ }^{\circ} \mathrm{C}$ and around $10 \mathrm{mg}$ for the experiments at $280{ }^{\circ} \mathrm{C}$, diluted with $\sim 60 \mathrm{mg}$ of $\mathrm{SiC}(212-425 \mu \mathrm{m})$.

Characterization. Powder X-ray diffractograms of passivated samples were measured using a Bruker-AXS D2 Phaser X-ray diffractometer, Co-K $\alpha$ radiation $(\lambda=1.7903 \AA$ ) with a $1.0 \mathrm{~mm}$ fixed slit. Reduced Cu-based methanol synthesis catalyst $\left(25 \mathrm{vol} \% \mathrm{H}_{2} / \mathrm{N}_{2}\right.$ flow, $2 \mathrm{~h}$ at $250{ }^{\circ} \mathrm{C}$, heating rate of $5{ }^{\circ} \mathrm{C} \cdot \mathrm{min}^{-1}$ ) was placed in an air-tight sample holder and diffraction patterns were recorded on a Bruker D8 advance, equipped with a variable slit and $\mathrm{Co}-\mathrm{K} \alpha$ radiation $(\lambda=1.7903 \AA)$. Patterns were compared with the PDF-4+-database. Cu crystallite size was calculated using the Scherrer equation $(\mathrm{k}=0.94)$ to the $(111)$ diffraction line at $2 \theta=50.7^{\circ}$, with the Fityk 1.3.1 software ${ }^{49}$. 
A micromeritics TriStar 3000 apparatus was used to perform $\mathrm{N}_{2}$-physisorption at $-196{ }^{\circ} \mathrm{C}$. Prior to analysis the samples were dried at $200{ }^{\circ} \mathrm{C}$ for $16 \mathrm{~h}$ in $\mathrm{N}_{2}$ flow. Specific surface area was calculated using the BET theory for $\mathrm{p} / \mathrm{p}_{0}=0.06-0.25$. The pore size distribution was determined using the $\mathrm{BJH}$ theory applied to the adsorption branch. The specific mesopore volume was calculated using single point at $\mathrm{p} / \mathrm{p}_{0}=0.98$.

Thermogravimetric measurements were performed using a Perkin Elmer TGA8000, hyphenated with a Hiden HPR-20 mass spectrometer. The experiments took place under an oxidizing flow composed of $20 \mathrm{vol} . \% \mathrm{O}_{2} / \mathrm{Ar}$. First, the temperature of the sample was held at $30{ }^{\circ} \mathrm{C}$ for $5 \mathrm{~min}$. and thereafter heated to $800{ }^{\circ} \mathrm{C}$ at $10{ }^{\circ} \mathrm{C} \cdot \mathrm{min}^{-1}$. The mass spectrometer was used to monitor carbon dioxide $(\mathrm{m} / \mathrm{z}=44)$ and water $(\mathrm{m} / \mathrm{z}=18)$ throughout the experiment.

Ammonia temperature programmed desorption $\left(\mathrm{NH}_{3} \mathrm{TPD}\right)$ analyses were performed using a Micromeritics AutoChem 2990 instrument equipped with a TCD detector. Typically, $100 \mathrm{mg}$ of sample were dried in a He flow at the corresponding calcination temperature for each sample. The samples were then cooled to $100{ }^{\circ} \mathrm{C}$ in a He flow, followed by pulses of $10 \mathrm{vol} \% \mathrm{NH}_{3} / \mathrm{He}$ until saturation was reached. The temperature $\left(100{ }^{\circ} \mathrm{C}\right)$ and $\mathrm{He}$ flow were maintained for $1 \mathrm{~h}$. Thereafter, the sample was heated under He flow to $400{ }^{\circ} \mathrm{C}\left(\mathrm{Nb}_{2} \mathrm{O}_{5} \cdot n \mathrm{H}_{2} \mathrm{O}\right.$ and $\left.\mathrm{NbOPO}_{4}\right)$ or $600{ }^{\circ} \mathrm{C}\left(\gamma-\mathrm{Al}_{2} \mathrm{O}_{3}\right)$ at a rate of $10{ }^{\circ} \mathrm{C} \cdot \mathrm{min}^{-1}$, the desorption of ammonia was monitored by the TCD detector. NH3-TPD profiles can be found in Appendix F: Figure F1.

FTIR spectroscopy of adsorbed pyridine was carried out using a Bruker Vertex 70v spectrometer. Each sample was pressed into a self-supporting wafer (diameter $13 \mathrm{~mm}$ ) and placed in an environmental transmittance IR cell. Samples were first pre-treated under dynamic vacuum $\left(\sim 10^{-6} \mathrm{mbar}\right)$ at their corresponding calcination temperature $(300,400$ or $\left.500{ }^{\circ} \mathrm{C}, 10{ }^{\circ} \mathrm{C} \cdot \mathrm{min}^{-1}\right)$, thereafter the sample was cooled down to room temperature and exposed to an excess of pyridine. Then, dynamic vacuum $\left(\sim 10^{-6} \mathrm{mbar}\right)$ was applied to the sample and heated to $150{ }^{\circ} \mathrm{C}$ for $1 \mathrm{~h}$. Spectra were recorded in the $4000-1000 \mathrm{~cm}^{-1}$ range. The quantitative determination of Lewis and Brønsted acid sites was made using the bands at 1448 and $1540 \mathrm{~cm}^{-1}$ following the procedure reported in ref 50 .

Scanning transmission electron microscopy (STEM) images were acquired with a FEI Talos F200X microscope operated at $200 \mathrm{kV}$ equipped with 4 energy dispersive X-ray (EDX) detectors, a high-angle annular dark-field (HAADF) and a bright field detector. Samples were prepared by dipping the Au sample grid into the used catalyst.

Catalytic performance. The catalytic performance was evaluated using an Avantium Flowrence 16 parallel, continuous flow, fixed bed reactor system. The catalysts were reduced in-situ at atmospheric pressure in a $25 \mathrm{vol} \% \mathrm{H}_{2} / \mathrm{He}$ flow, for $2 \mathrm{~h}$ at $250{ }^{\circ} \mathrm{C}$ (heating rate of $\left.5{ }^{\circ} \mathrm{C} \cdot \mathrm{min}-1\right)$, this in order to activate the methanol synthesis catalyst by reducing the copper oxide to metallic copper. Thereafter, the gas stream was switched to $\mathrm{H}_{2} / \mathrm{CO}=2.0 \mathrm{v} / \mathrm{v}$, with different GHSV depending on the catalyst. Reactors were pressurized to 40 bar and subsequently heated to reaction temperature 260 or $280{ }^{\circ} \mathrm{C}\left(1{ }^{\circ} \mathrm{C} \cdot \mathrm{min}^{-1}\right)$. Products were analyzed using an on-line three-channel gas chromatograph (GC, Agilent 7890B). Hydrogen, carbon monoxide, helium, nitrogen and carbon dioxide were separated on a MolSieve 5A column ( $2.4 \mathrm{~m}, 1 / 8$ inch inner diameter) and quantified using a thermal conductivity detector. Meth- 
anol, dimethyl ether and $\mathrm{C}_{1}-\mathrm{C}_{4}$ hydrocarbons were separated using a GS-GasPro column (GS-Gaspro $30 \mathrm{~m}$ x $0.32 \mathrm{~mm}$ ID) and a HP-Innowax column (6 m, $0.32 \mathrm{~mm}$ ID) and analyzed by flame ionization detectors. The integrated peak areas were used to determine the gas phase composition, with $\mathrm{He}$ as the internal standard. Selectivities reported here were based on carbon atoms $(\% \mathrm{C})$ within hydrocarbon formed and excluding $\mathrm{CO}_{2}$. All experiments showed a selectivity of $\sim 26 \%$ for $\mathrm{CO}_{2}$, which is in the range of the thermodynamic equilibrium. Gas-Hourly-Space-Velocities (GHSV) were defined as total gas flow divided by the total catalyst volume.

\subsection{Results and discussion}

\subsubsection{Structural, textural and acidic properties of the solid acids}

$\mathrm{Nb}_{2} \mathrm{O}_{5} \cdot n \mathrm{H}_{2} \mathrm{O}$ and $\mathrm{NbOPO}_{4}$ are known to have various crystal structures and metastable polymorphs depending on the thermal treatment to which they have been exposed ${ }^{51,52}$. In general, crystallization in these materials occurs around $500{ }^{\circ} \mathrm{C}$ for $\mathrm{Nb}_{2} \mathrm{O}_{5} \cdot n \mathrm{H}_{2} \mathrm{O}$ and $800{ }^{\circ} \mathrm{C}$ for $\mathrm{NbOPO}_{4}$, when treated below these temperatures both remain amorphous ${ }^{40,53,54}$. Powder $\mathrm{X}$-ray diffraction (XRD) patterns in figure 7.3a and b show that effectively after calcination at 200 or $400{ }^{\circ} \mathrm{C}$ for $\mathrm{Nb}_{2} \mathrm{O}_{5} \bullet n \mathrm{H}_{2} \mathrm{O}$ and 200,400 or $600{ }^{\circ} \mathrm{C}$ for $\mathrm{NbOPO}_{4}$, both materials did not show sharp diffraction signals but broad scattered diffraction patterns characteristic of a largely amorphous structure. Higher calcination temperatures induced crystallization. An increase of the temperature treatment is also accompanied by a loss in specific surface area as previously reported for niobium pentoxide ${ }^{54,55}$. This was the same case for niobium phosphate as shown by the results obtained from $\mathrm{N}_{2}$-physisorption for samples calcined at different temperatures (Figure 7.3c). Previous reports have shown that the decrease of surface area occurs together with a decrease of the concentration and strength of acid sites ${ }^{42,53,56}$.

a

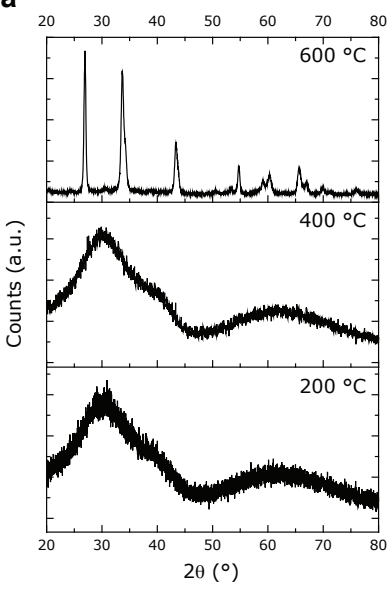

b

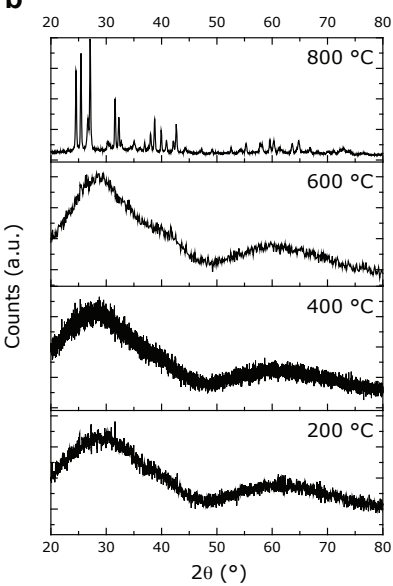

C

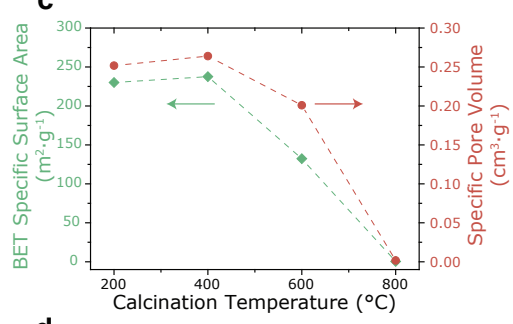

d

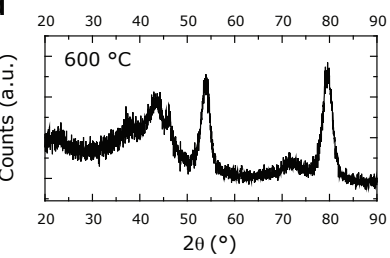

Figure 7.3 a, $\mathbf{b}$ and $\mathbf{d}$ XRD patterns of the materials after calcination at different temperatures indicated on each diffractogram. Diffractograms of $\mathrm{Nb}_{2} \mathrm{O}_{5} \cdot n \mathrm{H}_{2} \mathrm{O}(\mathbf{a}), \mathrm{NbOPO}_{4}(\mathbf{b})$ and $\gamma-\mathrm{Al}_{2} \mathrm{O}_{3}(\mathbf{d})$. c , Change in specific surface area (green diamonds) and specific pore volume (red circles) for $\mathrm{NbOPO}_{4}$ as a function of calcination temperature. Data obtained from $\mathrm{N}_{2}$-physisorption. 
Table 7.1 Summary of the properties of the solid acids.

\begin{tabular}{|c|c|c|c|c|c|c|c|}
\hline \multirow[t]{2}{*}{ Solid acid } & \multirow{2}{*}{$\begin{array}{c}\text { Bulk } \\
\text { density } \\
\left(\mathrm{g} \cdot \mathrm{mL}^{-1}\right)\end{array}$} & \multirow{2}{*}{$\begin{array}{c}\text { Specific } \\
\text { Surface } \\
\text { Area }^{\mathrm{a}} \\
\\
\left(\mathrm{m}^{2} \cdot \mathrm{g}^{-1}\right)\end{array}$} & \multicolumn{2}{|c|}{$\mathbf{N H}_{3}$-uptake } & \multirow{2}{*}{$\begin{array}{c}\text { Acid sites } \\
\text { surface } \\
\text { concentration } \\
\left(\mathrm{mmol}_{\mathrm{NH} 3} \cdot \mathbf{m}^{-2}\right)\end{array}$} & \multicolumn{2}{|c|}{$\begin{array}{c}\text { Lewis/ } \\
\text { Brønsted acid } \\
\text { sites ratio }^{c}\end{array}$} \\
\hline & & & $\left(\mathbf{m m o l}_{\mathrm{NH} 3} \cdot \mathbf{g}^{-1}\right)$ & $\left(\mathbf{m m o l}_{\mathrm{NH} 3} \cdot \mathbf{m L}^{-1}\right)$ & & $\begin{array}{l}\text { Pre-treated } \\
\text { at } 300{ }^{\circ} \mathrm{C}\end{array}$ & $\begin{array}{c}\text { Pre-treated } \\
\text { at } 400{ }^{\circ} \mathrm{C}\end{array}$ \\
\hline $\mathrm{Nb}_{2} \mathrm{O}_{5} \cdot n \mathrm{H}_{2} \mathrm{O}$ & 0.78 & 92 & 0.31 & 0.24 & 0.0034 & 0.9 & 1.4 \\
\hline $\mathrm{NbOPO}_{4}$ & 0.90 & 238 & 0.60 & 0.54 & 0.0025 & 0.5 & 0.7 \\
\hline$\gamma-\mathrm{Al}_{2} \mathrm{O}_{3}$ & 0.53 & 190 & 0.62 & 0.33 & 0.0033 & - & - \\
\hline
\end{tabular}

a. Determined by $\mathrm{N}_{2}$-physisorption.

b. Determined by $\mathrm{NH}_{3}$-TPD after pretreatment at $400{ }^{\circ} \mathrm{C}$ for $\mathrm{Nb}_{2} \mathrm{O}_{5} \cdot n \mathrm{H}_{2} \mathrm{O}$ and $\mathrm{NbOPO}_{4}$ and at $600{ }^{\circ} \mathrm{C}$ for $\gamma$ - $\mathrm{Al}_{2} \mathrm{O}_{3}$.

c. Determined by FT-IR with pyridine as probe molecule.

Therefore, in order to maintain the acidic properties of both materials and considering the optimal reaction temperature for the direct synthesis of DME $\left(250-300{ }^{\circ} \mathrm{C}\right)$, a calcination temperature of $400{ }^{\circ} \mathrm{C}\left(4 \mathrm{~h}, 5{ }^{\circ} \mathrm{C} \cdot \mathrm{min}^{-1}\right)$ was selected as pre-treatment for both materials. $\gamma-\mathrm{Al}_{2} \mathrm{O}_{3}$ was calcined at $600{ }^{\circ} \mathrm{C}$ to ensure the gamma phase (Figure $7.3 \mathrm{~d}$ ). Table $7.1 \mathrm{sum}$ marizes the characterization results for $\mathrm{Nb}_{2} \mathrm{O}_{5} \cdot n \mathrm{H}_{2} \mathrm{O}, \mathrm{NbOPO}_{4}$ and $\gamma-\mathrm{Al}_{2} \mathrm{O}_{3}$ obtained from $\mathrm{N}_{2}$-physisorption, $\mathrm{NH}_{3}$-temperature programmed desorption $\left(\mathrm{NH}_{3}\right.$-TPD) and FT-IR with pyridine as probe molecule.

The interaction of pyridine with the surface of the solid acids was used to assess the nature of such acid sites. The FT-IR spectra region between $1700-1400 \mathrm{~cm}^{-1}$ shows the vibrations of pyridine interacting with a solid $\operatorname{acid}^{57-60}$ and employed to determine the ratio of Lewis and Brønsted acid sites (Table 7.1). The corresponding spectra are shown in figure F2 Appendix F, in which IR bands can be observed at 1446 and $1606 \mathrm{~cm}^{-1}$ corresponding to pyridine coordinated to Lewis acid sites (highlighted in green), whereas IR bands corresponding to pyridinium ion on Brønsted acid sites are observed at $\sim 1639$ and $1540 \mathrm{~cm}^{-1}$ (highlighted in red). Additionally, a common IR band for both sites is observed at $1489 \mathrm{~cm}^{-1}$ (highlighted in yellow). $\mathrm{Nb}_{2} \mathrm{O}_{5} \cdot n \mathrm{H}_{2} \mathrm{O}$ and $\mathrm{NbOPO}_{4}$ show bands corresponding to both Lewis and Brønsted acid sites, however $\mathrm{NbOPO}_{4}$ compared to $\mathrm{Nb}_{2} \mathrm{O}_{5} \cdot n \mathrm{H}_{2} \mathrm{O}$ shows more intense bands at $\sim 1639$ and $1540 \mathrm{~cm}^{-1}$ (more pyridinium ion on Brønsted acid sites) and a lower ratio of Lewis to Brønsted acid sites. The $\gamma-\mathrm{Al}_{2} \mathrm{O}_{3}$ sample displayed only bands at $\sim 1446$ and $1606 \mathrm{~cm}^{-1}$ and not at $\sim 1639$ and $1540 \mathrm{~cm}^{-1}$, an indication that mainly Lewis acid sites are present on the surface of the alumina and no strong Brønsted acid sites to form pyridinium ions. Spectra for $\mathrm{Nb}_{2} \mathrm{O}_{5} \bullet n \mathrm{H}_{2} \mathrm{O}$ and $\mathrm{NbOPO}_{4}$ pretreated at $300{ }^{\circ} \mathrm{C}$ are also included in figure F2 Appendix F. For both materials it can be observed that an increment of the pre-treatment temperature from 300 to $400{ }^{\circ} \mathrm{C}$ increased the relative intensity of the band at $\sim 1446$ $\mathrm{cm}^{-1}$ and decreased the one at $\sim 1540 \mathrm{~cm}^{-1}$, therefore the Lewis to Brønsted acid sites ratio increased which is consistent with previous reports ${ }^{53,55,61}$. In summary, the two niobium-based solid acids presented both Lewis and Brønsted acid sites, $\mathrm{NbOPO}_{4}$ with more Brønsted acid sites compared to $\mathrm{Nb}_{2} \mathrm{O}_{5} \bullet n \mathrm{H}_{2} \mathrm{O}$, and $\gamma-\mathrm{Al}_{2} \mathrm{O}_{3}$ showed mainly Lewis acid sites. Both types of acids can catalyze de dehydration of methanol, however differences in their catalytic performance can be expected due to their distinct mechanisms for DME formation ${ }^{62-64}$. 


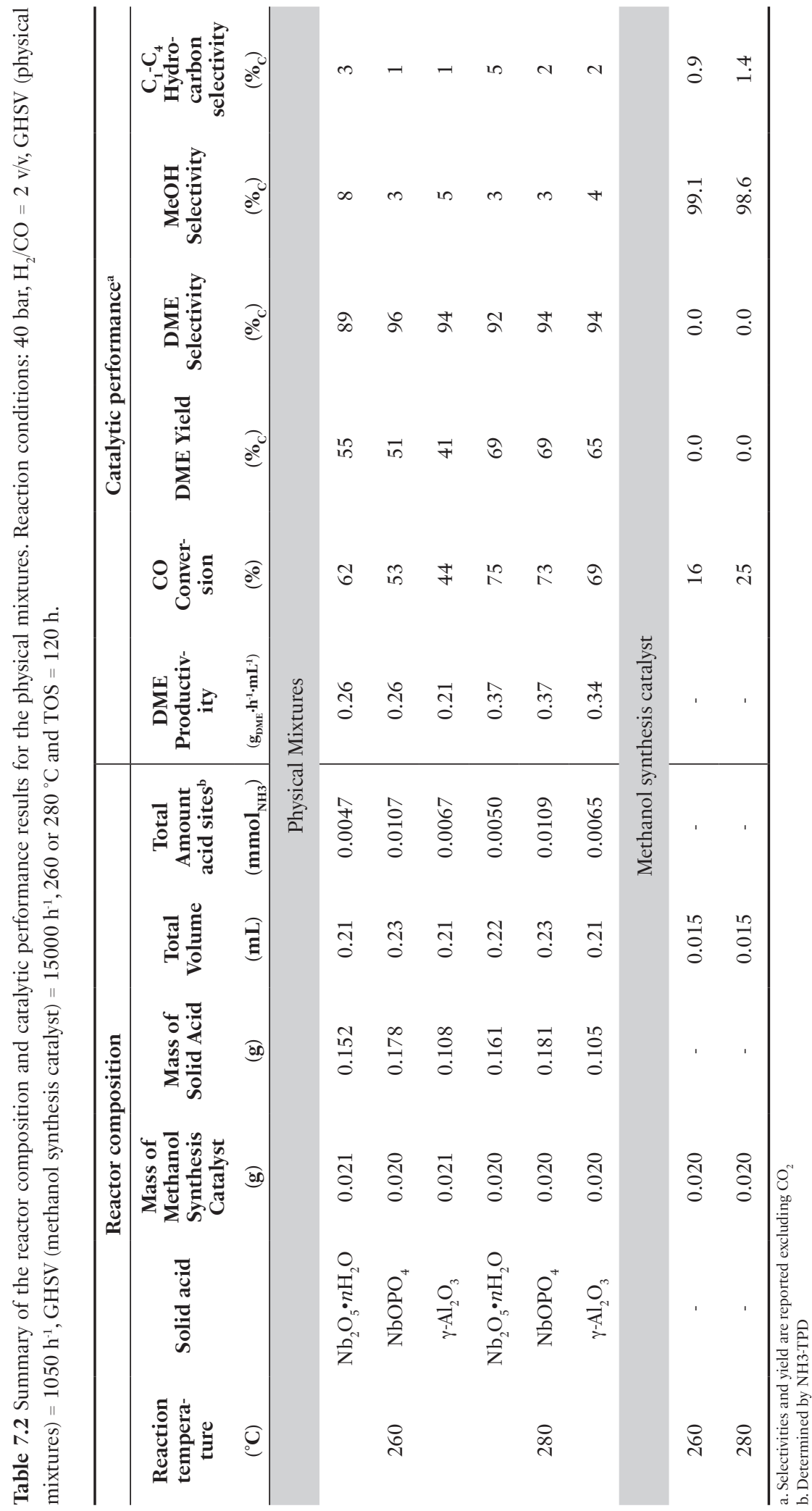




\subsubsection{Catalytic performance}

The catalytic performance of the three solid acids was evaluated by preparing physical mixtures with a copper-based methanol synthesis catalyst. These physical mixtures were made by mechanically mixing the $20 \mathrm{mg}$ of copper-based methanol synthesis catalyst (sieve fraction $75-150 \mu \mathrm{m}$ ) and $\sim 0.2 \mathrm{~mL}$ of the solid acid (sieve fraction $38-75 \mu \mathrm{m}$ ), 1:13 v/v $\mathrm{Cu}$-based catalyst to solid acid. Therefore, each reactor contained similar volumes of catalyst and hence similar Gas-Hourly-Space-Velocities (GHSV). The exact compositions and the corresponding results of the catalytic performance for all physical mixtures can be found in Table 7.2.

DME synthesis was carried out with an $\mathrm{H}_{2}$ to $\mathrm{CO}$ ratio of 2, at 40 bar and for $120 \mathrm{~h}$. The performance was evaluated at 260 or $280^{\circ} \mathrm{C}$, since it has been reported ${ }^{65}$ that water poisoning on $\gamma-\mathrm{Al}_{2} \mathrm{O}_{3}$ was avoided by raising the reaction temperature above $270{ }^{\circ} \mathrm{C}$. A reaction temperature of $280{ }^{\circ} \mathrm{C}$ might then diminish the detrimental effects of water on the solid acids. The physical mixtures in all cases triple the $\mathrm{CO}$ conversion for both temperatures compared to the Cu-based catalyst only (Table 7.2). This increase in conversion by the addition of the solid acid to the copper-based catalyst originates by two effects: first, the conversion of methanol to form DME shifts the equilibrium to higher CO conversions and second, water formed from the DME synthesis enables the water-gas-shift reaction, producing $\mathrm{CO}_{2}$ (observed as one of the products) which accelerates methanol production (Figure 7.1).

Addition of any of the solid acids to the methanol synthesis catalyst effectively changed the selectivity from almost exclusively methanol to mainly DME. Particularly $\mathrm{NbOPO}_{4}$ and $\gamma-\mathrm{Al}_{2} \mathrm{O}_{3}$ showed the highest DME selectivities, the rest of the products consisted of methanol and a small fraction of $\mathrm{C}_{1}-\mathrm{C}_{4}$ hydrocarbons, mainly $\mathrm{CH}_{4}$ and $\mathrm{C}_{2} \mathrm{H}_{6}$ and in a lesser amount $\mathrm{C}_{2} \mathrm{H}_{4}, \mathrm{C}_{3} \mathrm{H}_{6}, \mathrm{C}_{3} \mathrm{H}_{8}, \mathrm{C}_{4} \mathrm{H}_{8}$ and $\mathrm{C}_{4} \mathrm{H}_{10}$. The reported selectivities exclude $\mathrm{CO}_{2}$ since in an in-
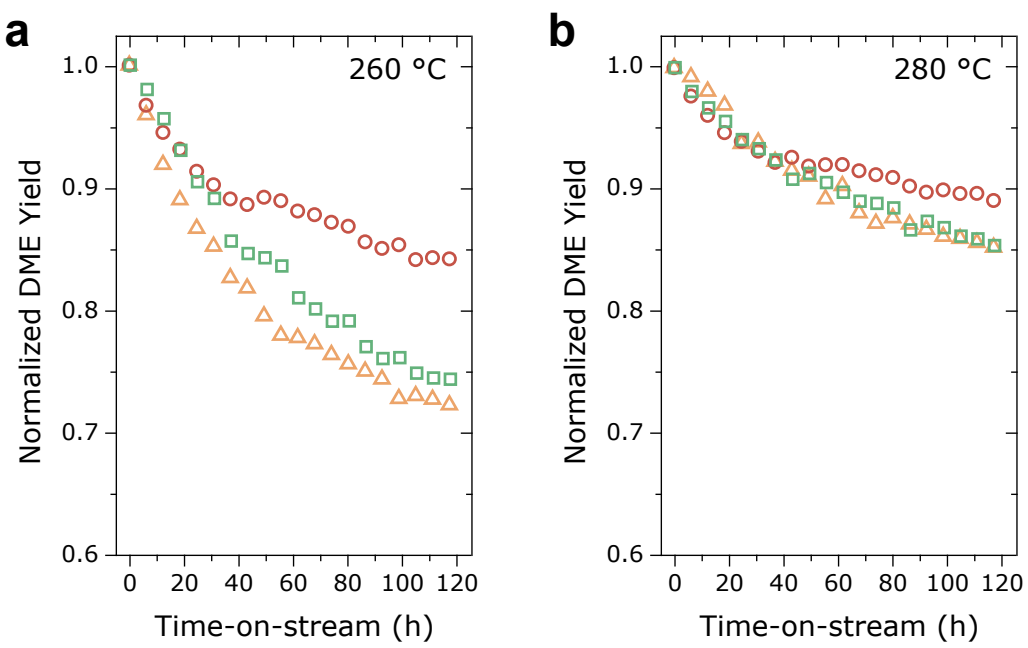

Solid Acid

$\circ \mathrm{Nb}_{2} \mathrm{O}_{5} \cdot n \mathrm{H}_{2} \mathrm{O}$
$\square \mathrm{NbOPO}_{4}$
$\triangle \gamma-\mathrm{Al}_{2} \mathrm{O}_{3}$

Figure 7.4 Normalized DME yield as a function of time-on-stream at $260{ }^{\circ} \mathrm{C}(\mathbf{a})$ or $280{ }^{\circ} \mathrm{C}$ (b) for the physical mixtures composed of $20 \mathrm{mg}$ of copper-based methanol synthesis catalyst and $\sim 0.2 \mathrm{~mL}$ of solid acid. Reaction conditions: $40 \mathrm{bar}, \mathrm{H}_{2} / \mathrm{CO}=2 \mathrm{v} / \mathrm{v}$ and initial $\mathrm{CO}$ conversion between 61 and $71 \%$ at $260{ }^{\circ} \mathrm{C}$ and between 79 and $82 \%$ at $280{ }^{\circ} \mathrm{C}$. 
dustrial process it can be recycled with the unconverted synthesis gas to form more DME. On the other hand, the formation of hydrocarbons constitutes a loss of available carbon to further form methanol or DME and thus undesired in this process.

An increase of the reaction temperature from 260 to $280{ }^{\circ} \mathrm{C}$ increased the activity in all cases but also in the case of $\mathrm{Nb}_{2} \mathrm{O}_{5} \cdot n \mathrm{H}_{2} \mathrm{O}$ improved the DME selectivity while decreasing the methanol selectivity. An increase in methanol dehydration activity to DME in this temperature range has been previously observed for $\mathrm{Nb}_{2} \mathrm{O}_{5} \cdot n \mathrm{H}_{2} \mathrm{O}^{44}$, which is also observed in this study. Volume-based DME productivity was higher for the physical mixtures containing niobium-based acids compared to the $\gamma-\mathrm{Al}_{2} \mathrm{O}_{3}$-based mixtures, due to the high density of the niobium materials. Furthermore, the mixtures with $\mathrm{Nb}_{2} \mathrm{O}_{5} \bullet n \mathrm{H}_{2} \mathrm{O}$ and $\mathrm{NbOPO}_{4}$ also showed a higher yield towards DME.

The relative change in DME yield through time is shown in figure 7.4 for the different physical mixtures. $\mathrm{NbOPO}_{4}$ and $\gamma-\mathrm{Al}_{2} \mathrm{O}_{3}$ showed similar trends in relative DME yield, losing $\sim 30 \%$ at $260{ }^{\circ} \mathrm{C}$ and $\sim 15 \%$ at $280{ }^{\circ} \mathrm{C}$, while $\mathrm{Nb}_{2} \mathrm{O}_{5} \cdot n \mathrm{H}_{2} \mathrm{O}$ lost $\sim 15 \%$ at $260{ }^{\circ} \mathrm{C}$ and $\sim 10$ $\%$ at $280{ }^{\circ} \mathrm{C}$.

As previously mentioned, formation of hydrocarbons constitutes undesired products for this reaction. The change in hydrocarbons selectivity through time is shown in figure 7.5 for the different physical mixtures and the methanol synthesis catalyst, in all cases a slight increase in the selectivity to hydrocarbons was observed during the experiment. At a reaction temperature of $260{ }^{\circ} \mathrm{C}$, the mixtures containing $\mathrm{NbOPO}_{4}$ and $\gamma-\mathrm{Al}_{2} \mathrm{O}_{3}$ had similar selectivities as the methanol synthesis catalyst throughout the experiment (Figure 7.5a), an indication that these products might have mainly originated from the copper-based catalyst. The $\mathrm{Nb}_{2} \mathrm{O}_{5} \cdot n \mathrm{H}_{2} \mathrm{O}$-based mixture however showed an increased hydrocarbon selectivity compared to the other catalysts, particularly at the first hours of the experiment.
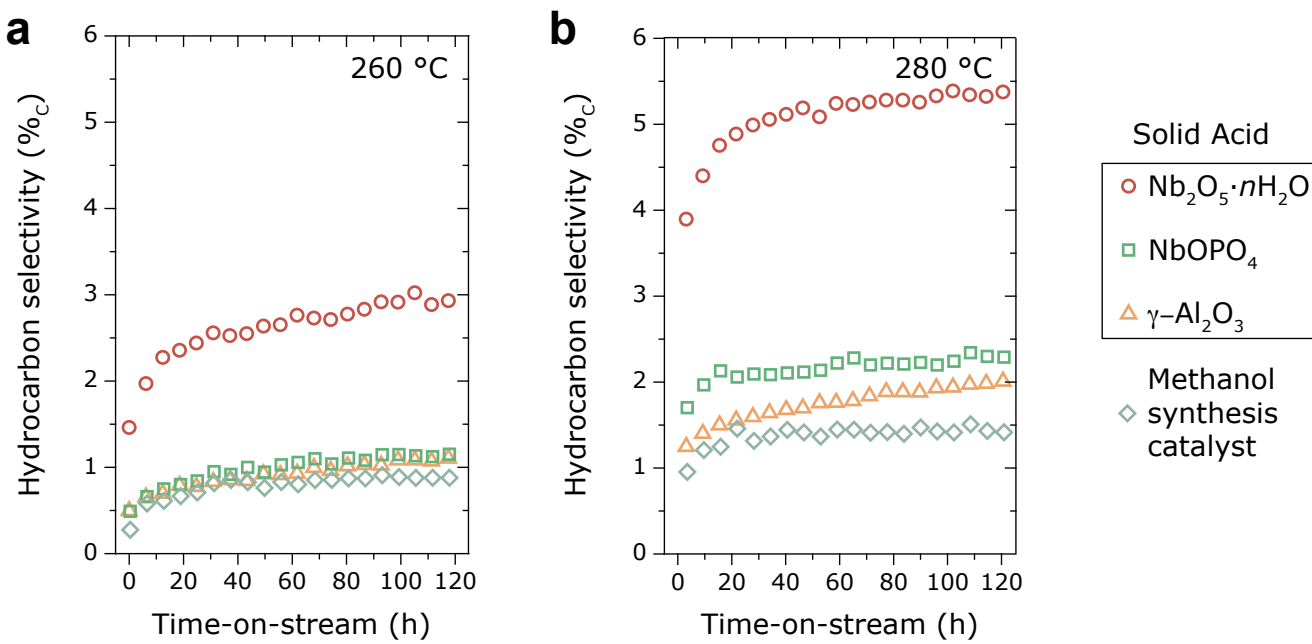

Figure 7.5 Hydrocarbon selectivity, comprising $\mathrm{C}_{1}$ to $\mathrm{C}_{4}$ products, as a function of time-on-stream at $260{ }^{\circ} \mathrm{C}(\mathbf{a})$ or $280{ }^{\circ} \mathrm{C}$ (b) for the physical mixtures composed of $20 \mathrm{mg}$ of copper-based methanol synthesis catalyst and $0.2 \mathrm{~mL}$ of solid acid and of only the methanol synthesis catalyst (grey diamonds). Reaction conditions: 40 bar, $\mathrm{H}_{2} / \mathrm{CO}=2 \mathrm{v} / \mathrm{v}$. 
An increase of the reaction temperature to $280{ }^{\circ} \mathrm{C}$ increased also the selectivity to hydrocarbons for all catalysts (Figure 7.5b), although in different proportion for each of them. The methanol synthesis catalysts showed a constant selectivity after $20 \mathrm{~h}$ on stream resulting in $1.4 \%$ hydrocarbons at the end of the experiment, $0.5 \%$ more than at a reaction temperature of $260{ }^{\circ} \mathrm{C}$. The hydrocarbon selectivities for the physical mixtures containing $\mathrm{NbOPO}_{4}$ and $\gamma-\mathrm{Al}_{2} \mathrm{O}_{3}$ were around $2 \% \mathrm{C}$ at the end of the experiment, however their increase throughout the experiment was markedly different. While the $\mathrm{NbOPO}_{4}$-based catalyst showed a less pronounced increase in hydrocarbon selectivity after $20 \mathrm{~h}$ on stream, the $\gamma-\mathrm{Al}_{2} \mathrm{O}_{3}$-based catalyst showed a continuous increase throughout the experiment. The $\mathrm{Nb}_{2} \mathrm{O}_{5} \cdot n \mathrm{H}_{2} \mathrm{O}$-based mixture showed also at $280{ }^{\circ} \mathrm{C}$ the highest hydrocarbon selectivity. Hydrocarbon formation at $280{ }^{\circ} \mathrm{C}$ seemed to originate for all physical mixtures not only from the methanol synthesis catalysts but also from the addition of the solid acid.

The catalytic performance of the materials was further evaluated in a stacked-bed configuration, with the solid acid downstream of the methanol synthesis catalyst, this to further understand the synergy between the methanol synthesis catalyst and the solid acids. Table 7.3 summarize the results for this experiment, the amount of solid acid was adjusted to have same amount of acid sites per reactor. Contrary to the physical mixtures, the CO conversion in this case was limited by the methanol synthesis catalyst and thus no major differences in conversion were observed within reactors. $\mathrm{CO}_{2}$ was not detected as a product since the copper-based catalyst was not exposed to the water formed from the dehydration of methanol and then the water-gas-shift reaction did not take place. Throughout the experiment, reactors with stacked-bed showed a decrease in activity similar to only the methanol synthesis catalyst at both reaction temperatures (Appendix F: Figure F3a and b), implying that the activity loss originated mainly from the methanol synthesis catalyst and not the solid acids at these reaction conditions. The product distribution changed by addition of the solid acid downstream of the methanol synthesis catalyst, by forming DME at the expense of methanol. At both reaction temperatures, $\gamma-\mathrm{Al}_{2} \mathrm{O}_{3}$ showed the highest selectivity for DME, followed by $\mathrm{NbOPO}_{4}$ and finally $\mathrm{Nb}_{2} \mathrm{O}_{5} \cdot n \mathrm{H}_{2} \mathrm{O}$. The differences in DME selectivity might be explained by the dissimilar densities and acid sites concentrations of each solid acid. Increasing the amount of $\mathrm{Nb}_{2} \mathrm{O}_{5} \cdot n \mathrm{H}_{2} \mathrm{O}$, the solid acid with the lowest concentration of acid sites per volume, indeed resulted in an increase in the DME selectivity (Table 7.3, second line).

In contrast to the physical mixtures, the hydrocarbon selectivities of the reactors with solid acid and of only the methanol synthesis catalyst were similar throughout the experiment and increased to similar values by increasing reaction temperature (Appendix F Figure F3c and d). The close contact of the methanol synthesis and dehydration functionalities in the physical mixtures, contrary to the stacked-bed configuration, could be then linked to the additional formation of hydrocarbons.

\subsubsection{Characterization of the used catalysts}

In order to further understand the reason behind deactivation in the physical mixtures, the used catalysts were separated by sieving them into the Cu-based methanol synthe- 


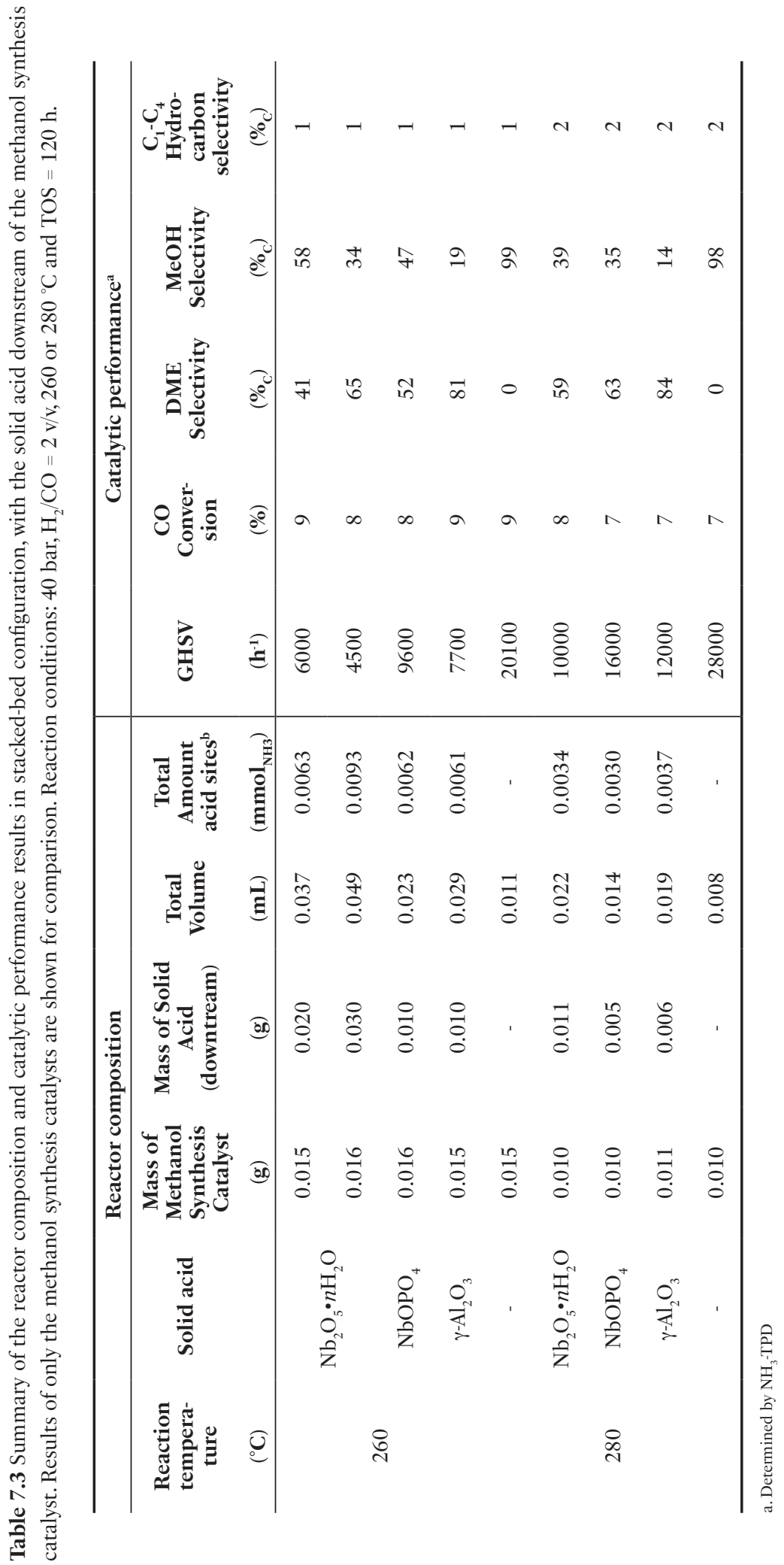


sis catalyst and the solid acid components. XRD patterns of the used solid acids (Appendix F: Figure F4) did not show significant changes in comparison to the diffractograms of the materials before reaction. The niobium-based materials maintained an amorphous structure while the alumina remained in the gamma phase. Thus, a change in the crystal phase of the solid acid did not occur during the reaction despite the high water partial pressures and the deactivation of the catalysts is not explained by this ${ }^{37}$. XRD characterization of their used $\mathrm{Cu}$-based methanol synthesis catalyst showed growth of the $\mathrm{Cu}$ crystallite size in all cases (Appendix F: Figure F5 and Table F1), particularly after the reaction at $280^{\circ} \mathrm{C}$. The actual crystallite size of the used catalysts might be slightly larger since these samples were passivated in air and part of the exposed copper most likely has been oxidized. Solely the $\mathrm{Cu}$-based catalyst without solid acid after reaction showed a $\mathrm{Cu}$ crystallite size of $7.1 \mathrm{~nm}$ at $260{ }^{\circ} \mathrm{C}$ and of $7.6 \mathrm{~nm}$ at $280{ }^{\circ} \mathrm{C}$ compared to the reduced catalyst $(6.6 \mathrm{~nm})$. The Cu-based catalyst in the physical mixtures with the different solid acids displayed a larger crystallite growth compared to the catalyst without solid acid. However, the crystallite size variations within them could not be correlated to their deactivation trends.

Thus, only copper growth cannot explain the differences observed in loss of activity for the different physical mixtures. Besides metal growth, other structural changes aided by the presence of water could have taken place in the catalyst. Phenomena in the methanol synthesis catalyst such as re-crystallization of the $\mathrm{ZnO}$ or oxidation of the copper surface are relevant in the deactivation of the catalyst ${ }^{66,67}$. Here it was not possible to clearly observe

a

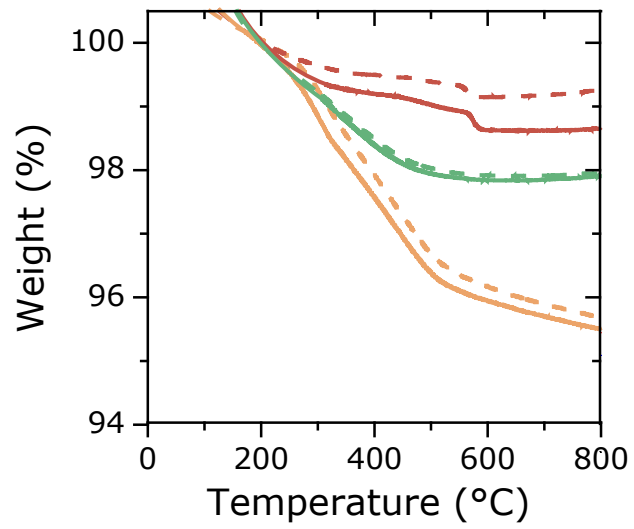

Solid acid

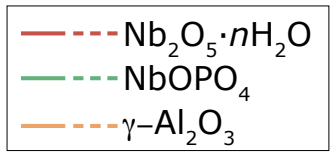

b
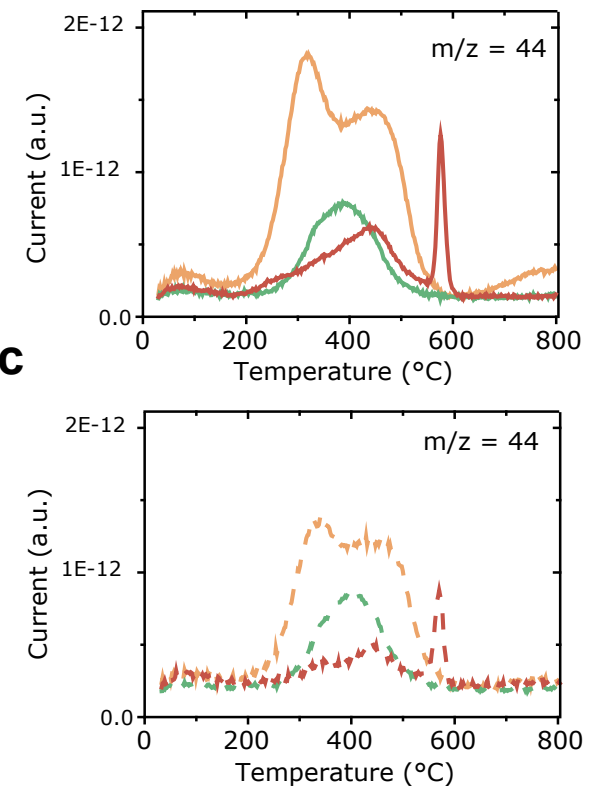

Figure 7.6 a, Thermogravimetric analysis plotted in weight percentage as a function of temperature, for the solid acids after reaction at $260{ }^{\circ} \mathrm{C}$ (solid lines) or $280{ }^{\circ} \mathrm{C}$ (dashed lines). The weight is normalized to the weight at $\mathrm{T}=$ $200{ }^{\circ} \mathrm{C}$, temperature in which $\mathrm{CO} 2(\mathrm{~m} / \mathrm{z}=44)$ started to be detected by mass spectrometry as shown in plot ' $\mathbf{b}$ ' for samples after reaction at $260{ }^{\circ} \mathrm{C}$ and plot 'c' at $280^{\circ} \mathrm{C}$. 

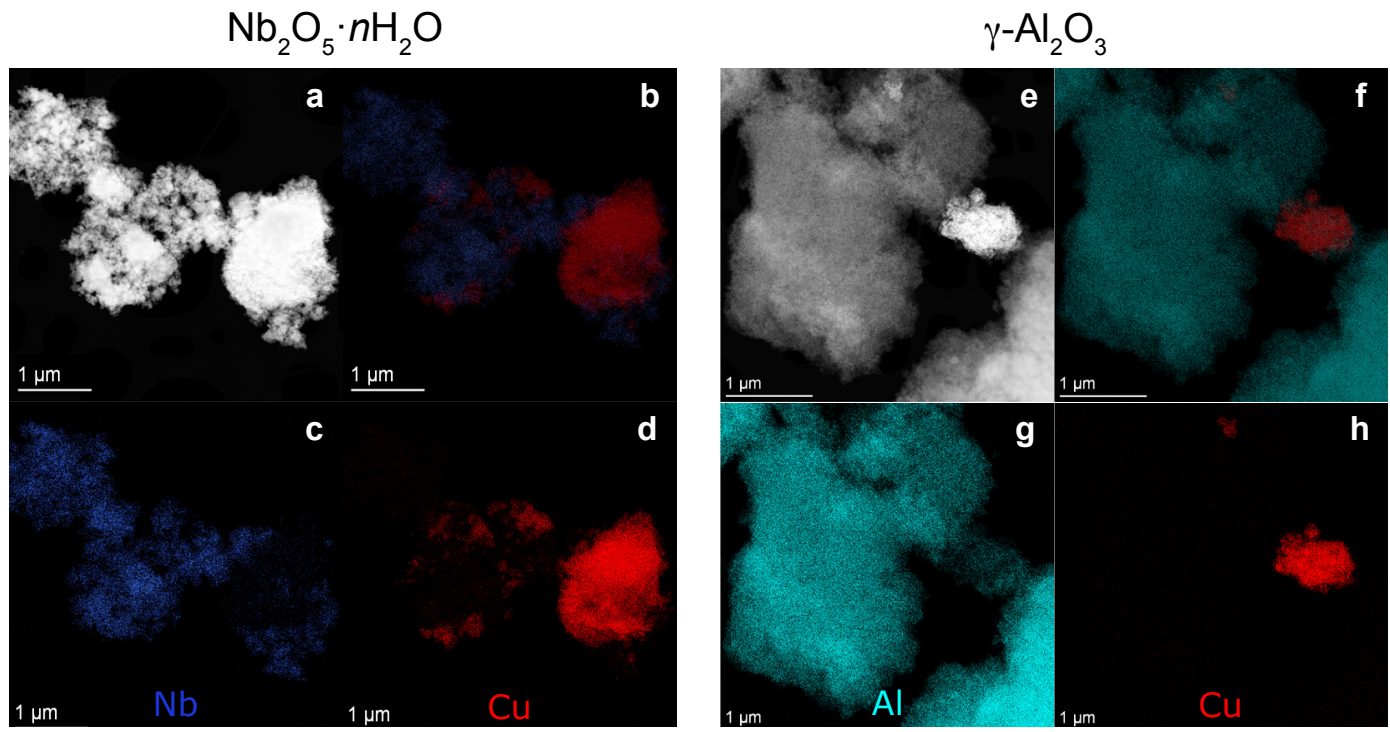

Figure 7.7 STEM-EDX characterization results for the used mixtures of copper-based catalyst with $\mathrm{Nb}_{2} \mathrm{O}_{5} \cdot n \mathrm{H}_{2} \mathrm{O}$ (a-d) or $\gamma-\mathrm{Al}_{2} \mathrm{O}_{3}$ (e-h). a, Dark-field image for the $\mathrm{Nb}_{2} \mathrm{O}_{5} \cdot n \mathrm{H}_{2} \mathrm{O}$-based mixture. b, Overlap of the EDX-maps for $\mathrm{Nb}$ (blue) and $\mathrm{Cu}$ (red). The corresponding niobium and copper maps are shown in $\mathbf{c}$ and $\mathbf{d}$ respectively. e, Dark-field image for the $\gamma$ - $\mathrm{Al}_{2} \mathrm{O}_{3}$-based mixture. f, overlap of the EDX-maps for $\mathrm{Al}$ (light blue) and $\mathrm{Cu}$ (red). The corresponding aluminum and copper maps are shown in $\mathbf{g}$ and $\mathbf{h}$ respectively.

such fine changes for all catalysts, only the $\mathrm{Cu}$-based catalyst in the mixture with $\gamma-\mathrm{Al}_{2} \mathrm{O}_{3}$ after $280{ }^{\circ} \mathrm{C}$ reaction temperature (Appendix F: Figure F5j) showed a sharp diffraction peak at $2 \theta=40.7^{\circ}$. This diffraction can correspond to the $\mathrm{ZnO}(002)$ reflection (PDF 00-003-0752), characteristic of $\mathrm{ZnO}$ nanowires ${ }^{68,69}$. Deterioration of the methanol synthesis catalyst during the reaction can then hamper the CO conversion and further DME formation.

The used solid acids were also characterized by thermogravimetric analysis in an oxidative atmosphere and monitored by MS in order to determine if deactivation might relate to coke deposition (Figure 7.6). At temperatures below $200{ }^{\circ} \mathrm{C}$ the weight loss corresponded to the elimination of adsorbed water. Above $200{ }^{\circ} \mathrm{C}$ the weight loss was accompanied by the detection of $\mathrm{CO}_{2}(\mathrm{~m} / \mathrm{z}=44$, Figure $7.6 \mathrm{~b}$ and $\mathrm{c})$, which most likely corresponded to burning of deposited coke. The change in weight was therefore normalized to the weight at $200{ }^{\circ} \mathrm{C}$ and weight loss was more pronounced for $\gamma-\mathrm{Al}_{2} \mathrm{O}_{3}\left(\sim 4 \%_{\mathrm{w}}\right)$, followed by $\mathrm{NbOPO}_{4}\left(\sim 2 \%_{\mathrm{w}}\right)$ and $\mathrm{Nb}_{2} \mathrm{O}_{5} \cdot n \mathrm{H}_{2} \mathrm{O}\left(\sim 1 \%{ }_{\mathrm{w}}\right)$. No marked difference in mass loss was observed when the catalysts had a reaction temperature at either 260 or $280{ }^{\circ} \mathrm{C}$. Coke formation in solid acids can originate from accumulation and side reactions of methoxy groups ${ }^{70}$ (intermediate species for methanol dehydration) and even though weak acid sites typically show less tendency of coke formation $^{30}$, still constitutes a relevant source of deactivation ${ }^{71,72}$.

Scanning transmission electron microscopy with energy dispersive X-ray spectra mapping (STEM-EDX) was used to characterize the used mixtures and the used solid acids after reaction at $260{ }^{\circ} \mathrm{C}$. Figure 7.7 shows the dark-field images and EDX elemental maps for the mixtures composed of the Cu-based catalyst and $\mathrm{Nb}_{2} \mathrm{O}_{5} \bullet n \mathrm{H}_{2} \mathrm{O}$ (left) or $\gamma-\mathrm{Al}_{2} \mathrm{O}_{3}$ (right). The 
EDX maps show the signal for $\mathrm{Nb}$ in dark blue, for $\mathrm{Al}$ in light blue and for $\mathrm{Cu}$ in red, $\mathrm{Zn}$ in all cases was found together with $\mathrm{Cu}$ so its EDX maps are not presented here for simplicity. In the case of $\mathrm{Nb}_{2} \mathrm{O}_{5} \cdot n \mathrm{H}_{2} \mathrm{O}$ is possible to observe that $\mathrm{Nb}$ and $\mathrm{Cu}$ in some areas are very close together and even showing some overlap. On the left side of the EDX maps it seems that $\mathrm{Cu}$ is dispersed on the niobium oxide and on the right side the big copper particle seems to be covered with some niobium oxide. For $\gamma-\mathrm{Al}_{2} \mathrm{O}_{3}$, the areas corresponding to $\mathrm{Al}$ and $\mathrm{Cu}$ are also close together but they seem to be more localized, is possible to observe an overlap in the particle on the right side of the $\mathrm{Cu}$ with $\mathrm{Al}$ because the methanol synthesis catalyst also contains alumina, however the big particles with $\mathrm{Al}$ which correspond to $\gamma-\mathrm{Al}_{2} \mathrm{O}_{3}$ do not show an overlap with the $\mathrm{Cu}$ signal. It has been previously shown that migration of ions in bifunctional systems occurs, leading to a deterioration of the catalytic performance with time ${ }^{4}$. The overlap in $\mathrm{Cu}$ and $\mathrm{Nb}$ signal might be an indication that metals from the methanol synthesis catalyst might have migrated to the $\mathrm{Nb}_{2} \mathrm{O}_{5} \bullet n \mathrm{H}_{2} \mathrm{O}$ during the reaction, compromising the performance of both the methanol synthesis catalyst and the solid acid. Moreover, this close contact of the copper and acid functionality might have had a relationship with the increased hydrocarbon selectivity of the physical mixtures via methoxy migration and decomposition ${ }^{73,74}$.

EDX maps of only the used solid acids (Appendix F: Figure F6) showed a uniform overlap of $\mathrm{Cu}$ and $\mathrm{Nb}$ for $\mathrm{NbOPO}_{4}$ and $\mathrm{Nb}_{2} \mathrm{O}_{5} \cdot n \mathrm{H}_{2} \mathrm{O}$, an indication that the copper might be homogenously distributed over the surface of these solid acids after reaction. The $\mathrm{Cu}-\mathrm{K} \alpha$ signal of the corresponding spectra was more intense for $\mathrm{NbOPO}_{4}$ than for $\mathrm{Nb}_{2} \mathrm{O}_{5} \bullet n \mathrm{H}_{2} \mathrm{O}$ or $\gamma-\mathrm{Al}_{2} \mathrm{O}_{3}$. Furthermore, the niobium-based materials had a green grayish color after reaction, an indication of a copper compound on their surface, whereas the alumina remained white. Migration of copper to the surface of the niobium-based materials could have been aided by the presence of Brønsted acid sites, which alumina did not show, via an ion exchange aided transport.

\subsection{Conclusions}

In this study we investigated the catalytic performance of hydrated niobium pentoxide and niobium phosphate as solid acids combined with a copper-based methanol synthesis catalyst for the direct synthesis of DME from synthesis gas. Gamma-alumina, a commonly used solid acid for this reaction, was investigated as a reference material. The solid acids were physically mixed with the copper-based methanol synthesis catalyst and their catalytic performance was evaluated at $40 \mathrm{bar}, \mathrm{H}_{2} / \mathrm{CO}=2 \mathrm{v} / \mathrm{v}$ and two different reaction temperatures $\left(260\right.$ or $280{ }^{\circ} \mathrm{C}$ ) for $120 \mathrm{~h}$ on stream. The mixing of the methanol synthesis catalyst and the solid acid led to increased CO conversions, compared to the methanol synthesis catalyst without solid acid or arranged in stacked-bed configuration with the solid acid downstream of the methanol synthesis catalyst. All physical mixtures showed excellent activity and DME selectivity. Particularly, niobium phosphate performed as good as gamma-alumina, with improved DME productivity per unit volume due to its high density and acid site concentration. However, the close contact between both functionalities in all mixtures also led to a 
slight increase in $\mathrm{C}_{1}-\mathrm{C}_{4}$ hydrocarbon selectivities. Furthermore, the stabilities of all mixtures differed depending on the nature of the solid acid, indicative of different deactivation mechanisms. The used catalysts were characterized in order to understand the main cause of deactivation. XRD results showed that the solid acids maintained their initial crystal structures after the reaction, therefore a major structural rearrangement in the solid acids was not the cause of deactivation under the reaction conditions used here. $\mathrm{Cu}$ crystallite size of the methanol synthesis catalyst grew during reaction conditions, but their growth was similar within the different mixtures so deactivation could not be solely explained by the loss of copper surface area. However, other structural changes in the Cu-based catalyst could not be completely excluded, one of the Cu-based catalysts in a mixture with $\gamma-\mathrm{Al}_{2} \mathrm{O}_{3}$ after reaction showed an extra diffraction peak corresponding to $\mathrm{ZnO}$ nanostructure, an indication that the methanol catalyst could be susceptible to structural changes during DME synthesis. Thermogravimetric analysis of the used solid acids showed that $\gamma-\mathrm{Al}_{2} \mathrm{O}_{3}$ accumulated more coke compared to the niobium-based materials, which might partially explain the loss in DME production particularly for $\gamma-\mathrm{Al}_{2} \mathrm{O}_{3}$. EDX analysis of STEM images of the used catalysts revealed that the niobium-based solid acids and not the alumina one ended up with some copper on their surface after reaction. This might be an indication of ion migration from the copper-based methanol synthesis catalyst to the surface of the solid acids, and most likely compromising the performance of both the methanol synthesis catalyst and the acid sites. $\mathrm{Nb}_{2} \mathrm{O}_{5} \cdot n \mathrm{H}_{2} \mathrm{O}$ and $\mathrm{NbOPO}_{4}$ showed Lewis and Brønsted acid sites, while $\gamma-\mathrm{Al}_{2} \mathrm{O}_{3}$ showed only Lewis acid sites, this might explain the susceptibility of Cu migration in the case of the niobium-based materials. To summarize, the catalytic performance and characterization results point out that deactivation of the physical mixtures originated mainly from structural changes in the methanol synthesis catalysts. In the case of $\mathrm{Nb}_{2} \mathrm{O}_{5} \cdot n-$ $\mathrm{H}_{2} \mathrm{O}$ and $\mathrm{NbOPO}_{4}$, the deactivation might relate mainly to the migration of copper from the methanol synthesis catalyst to the Brønsted acid sites of these materials, while in the case of $\gamma-\mathrm{Al}_{2} \mathrm{O}_{3}$ deactivation might have generated from crystallite reconstruction of the $\mathrm{ZnO}$ in the methanol synthesis catalyst and coke deposition on the acid sites.

\section{Acknowledgements}

Companhia Brasileira de Metalurgia e Mineração (CBMM) is thanked for financial support of this research. Dr. Robson Monteiro and Mr. Rogério Ribas (CBMM) are acknowledged for useful discussions and supplying the niobium-based materials. Mrs. Savannah Turner and Mr. Dennie Wezendonk (Utrecht University) are acknowledged for performing STEM-EDX and TGA-MS measurements respectively. Mr. Miguel Rivera-Torrente (Utrecht University) is acknowledged for his help during the FTIR measurements. Dr. Kang Cheng (Utrecht University) is thanked for useful thermodynamic discussions. Mr. Lennart Weber, Mr. Rolf Beerthuis and Mr. Remco Dalebout are thanked for their support during the catalytic performance and maintenance of the Flowrence unit. Krijn P. de Jong acknowledges the European Research Council, EU FP7 ERC Advanced Grant no. 338846. 


\section{References}

1. Zhou, W. et al. New horizon in C1 chemistry: Breaking the selectivity limitation in transformation of syngas and hydrogenation of $\mathrm{CO}_{2}$ into hydrocarbon chemicals and fuels. Chem. Soc. Rev. 48, 3193-3228 (2019).

2. Bao, J., Yang, G., Yoneyama, Y. \& Tsubaki, N. Significant advances in C1 catalysis: highly efficient catalysts and catalytic reactions. ACS Catal. 9, 3026-3053 (2019).

3. Zečević, J., Vanbutsele, G., de Jong, K.P. \& Martens, J.A. Nanoscale intimacy in bifunctional catalysts for selective conversion of hydrocarbons. Nature 528, 245-248 (2015).

4. Weber, J. L. et al. Effect of proximity and support material on deactivation of bifunctional catalysts for the conversion of synthesis gas to olefins and aromatics. Catal. Today 342, 161-166 (2020).

5. Ham, H. et al. Enhanced stability of spatially confined copper nanoparticles in an ordered mesoporous alumina for dimethyl ether synthesis from syngas. ACS Catal. 6, 5629-5640 (2016).

6. Jeong, C. et al. Facile structure tuning of a methanol-Synthesis catalyst towards the direct synthesis of dimethyl ether from syngas. ChemCatChem 9, 4484-4489 (2017).

7. Müller, M. \& Hübsch, U. Dimethyl Ether. Ullmann’s Encyclopedia of Industrial Chemistry (2012).

8. Budiman, A. W. et al. Review of acetic acid synthesis from various feedstocks through different catalytic processes. Catal. Surv. from Asia 20, 173-193 (2016).

9. Song, W., Marcus, D. M., Fu, H., Ehresmann, J. O. \& Haw, J. F. An oft-studied reaction that may never have been: Direct catalytic conversion of methanol or dimethyl ether to hydrocarbons on the solid acids HZSM-5 or HSAPO-34. J.Am. Chem. Soc. 124, 3844-3845 (2002).

10. Joensen, F., Voss, B. \& Dybkjaer, I. Process for the preparation of acetic acid. Patent No. 5728871, 1-5 (1989).

11. Verbeek, R. P., Doorn, A. van \& Walwijk, M. van. Global assessment of dimethyl-ether as an automotive fuel. second ed., 96.OR.VM.029.1/RV, TNO Road-Vehicles Research Institute, (1996).

12. Semelsberger, T. A., Borup, R. L. \& Greene, H. L. Dimethyl ether (DME) as an alternative fuel. J. Power Sources 156, 497-511 (2006).

13. Fleisch, T. H., Basu, A. \& Sills, R. A. Introduction and advancement of a new clean global fuel: The status of DME developments in China and beyond. J. Nat. Gas Sci. Eng. 9, 94-107 (2012).

14. Dybkjær, I. \& Hansen, J. B. Large-scale production of alternative synthetic fuels from natural gas. Stud. Surf. Sci. Catal. 107, 99-116 (1997).

15. Ogawa, T., Inoue, N., Shikada, T. \& Ohno, Y. Direct dimethyl ether synthesis. J. Nat. Gas Chem. 12, 219-227 (2003).

16. Topp-Iørgensen, J. Topsøe Integrated gasoline synthesis - the tigas process. Stud. Surf. Sci. Catal. 36, 293-305 (1988).

17. Behrens, M. Promoting the synthesis of methanol: understanding the requirements for an industrial catalyst for the conversion of $\mathrm{CO}_{2}$. Angew. Chemie Int. Ed. 55, 14906-14908 (2016).

18. Dadgar, F., Myrstad, R., Pfeifer, P., Holmen, A. \& Venvik, H. J. Direct dimethyl ether synthesis from synthesis gas: The influence of methanol dehydration on methanol synthesis reaction. Catal. Today 270, 76-84 (2016).

19. Bartholomew, C. H. Mechanisms of catalyst deactivation. Appl. Catal. A Gen. 212, 17-60 (2001).

20. Sun, J., Yang, G., Yoneyama, Y. \& Tsubaki, N. Catalysis chemistry of dimethyl ether synthesis. ACS Catal. 4, 3346-3356 (2014).

21. Azizi, Z., Rezaeimanesh, M., Tohidian, T. \& Rahimpour, M. R. Dimethyl ether: A review of technologies and production challenges. Chem. Eng. Process. Process Intensif. 82, 150-172 (2014).

22. Sehested, J. Industrial and scientific directions of methanol catalyst development. J. Catal. 371, 368-375 (2019).

23. Waugh, K. C. Methanol synthesis. Catal. Today 15, 51-75 (1992).

24. Sheldon, D. Methanol production - A technical history. Johnson Matthey Technol. Rev. 61, 172-182 (2017).

25. Olah, G. A., Goeppert, A. \& Prakash, G. K. S. Chemical recycling of carbon dioxide to methanol and dimethyl ether: From greenhouse gas to renewable, environmentally carbon neutral fuels and synthetic hydrocarbons. J. Org. Chem. 74, 487-498 (2009).

26. Álvarez, A. et al. Challenges in the greener production of formates/formic acid, methanol, and DME by Heter- 
ogeneously catalyzed $\mathrm{CO}_{2}$ hydrogenation processes. Chem. Rev. 117, 9804-9838 (2017).

27. Blaszkowski, S. R. \& Van Santen, R. A. The mechanism of dimethyl ether formation from methanol catalyzed by zeolitic protons. J.Am. Chem. Soc. 118, 5152-5153 (1996).

28. Knözinger, H. \& Köhne, R. The dehydration of alcohols over alumina. I. The reaction scheme. J. Catal. 5, 264-270 (1966).

29. Spivey, J. J. Review: Dehydration catalysts for the methanol/dimethyl ether reaction. Chem. Eng. Commun. 110, 123-142 (1991).

30. Tamm, S. Coking During DME synthesis: A calorimeter study. Top. Catal. 58, 833-842 (2015).

31. Wei, Y. et al. Enhanced catalytic performance of zeolite ZSM-5 for conversion of methanol to dimethyl ether by combining alkaline treatment and partial activation. Appl. Catal.A Gen. 504, 211-219 (2015).

32. Vishwanathan, V., Jun, K. W., Kim, J. W. \& Roh, H. S. Vapour phase dehydration of crude methanol to dimethyl ether over Na-modified H-ZSM-5 catalysts. Appl. Catal. A Gen. 276, 251-255 (2004).

33. Štich, I., Gale, J. D., Terakura, K. \& Payne, M. C. Role of the zeolitic environment in catalytic activation of methanol. J.Am. Chem. Soc. 121, 3292-3302 (1999).

34. Xu, M., Lunsford, J. H., Goodman, D. W. \& Bhattacharyya, A. Synthesis of dimethyl ether (DME) from methanol over solid-acid catalysts. Appl. Catal. A Gen. 149, 289-301 (1997).

35. Topsøe, H. DME-99 ECOTM. (2019). Available at: https://www.topsoe.com/products/catalysts/dme-99-ecotm.

36. Boon, J. et al. Reversible deactivation of $\gamma$-alumina by steam in the gas-phase dehydration of methanol to dimethyl ether. Catal. Commun. 119, 22-27 (2019).

37. Akarmazyan, S. S., Panagiotopoulou, P., Kambolis, A., Papadopoulou, C. \& Kondarides, D. I. Methanol dehydration to dimethylether over $\mathrm{Al}_{2} \mathrm{O}_{3}$ catalysts. Appl. Catal. B Environ. 145, 136-148 (2014).

38. Nowak, I. \& Ziolek, M. Niobium compounds: Preparation, characterization, and application in heterogeneous catalysis. Chem. Rev. 99, 3603-3624 (1999).

39. Tanabe, K. Catalytic application of niobium compounds. Catal. Today 78, 65-77 (2003).

40. Okazaki, S. \& Wada, N. Surface properties and catalytic activities of amorphous niobium phosphate and a comparison with those of $\mathrm{H}_{3} \mathrm{PO}_{4}$-treated niobium oxide. Catal. Today 16, 349-359 (1993).

41. Hayashi, S. et al. $\mathrm{Nb}_{2} \mathrm{O}_{5} \cdot n \mathrm{H}_{2} \mathrm{O}$ as a heterogeneous catalyst with water-tolerant lewis acid sites. J.Am. Chem. Soc. 133, 4224-4227 (2011).

42. Ushikubo, T. et al. Study of the structure of niobium oxide by X-ray absorption fine structure and surface science techniques. Catal. Today 28, 59-69 (1996).

43. Carniti, P., Gervasini, A., Bossola, F. \& Dal Santo, V. Cooperative action of Brønsted and Lewis acid sites of niobium phosphate catalysts for cellobiose conversion in water. Appl. Catal. B Environ. 193, 93-102 (2016).

44. Sun, Q., Fu, Y., Yang, H., Auroux, A. \& Shen, J. Dehydration of methanol to dimethyl ether over $\mathrm{Nb}_{2} \mathrm{O}_{5}$ and $\mathrm{NbOPO}_{4}$ catalysts: Microcalorimetric and FT-IR studies. J. Mol. Catal. A Chem. 275, 183-193 (2007).

45. Liu, D., Yao, C., Zhang, J., Fang, D. \& Chen, D. Catalytic dehydration of methanol to dimethyl ether over modified $\gamma-\mathrm{Al}_{2} \mathrm{O}_{3}$ catalyst. Fuel 90, 1738-1742 (2011).

46. Ladera, R., Finocchio, E., Rojas, S., Fierro, J. L. G. \& Ojeda, M. Supported niobium catalysts for methanol dehydration to dimethyl ether: FTIR studies of acid properties. Catal. Today 192, 136-143 (2012).

47. Rocha, A. S., Aline, A. M., Lachter, E. R., Sousa-Aguiar, E. F. \& Faro, A. C. Niobia-modified aluminas prepared by impregnation with niobium peroxo complexes for dimethyl ether production. Catal. Today 192, 104-111 (2012).

48. Lima, S. H., Forrester, A. M. S., Palacio, L. A. \& Faro, A. C. Niobia-alumina as methanol dehydration component in mixed catalyst systems for dimethyl ether production from syngas. Appl. Catal.A Gen. 488, 19-27 (2014).

49. Wojdyr, M. Fityk: A general-purpose peak fitting program. J. Appl. Crystallogr. 43, 1126-1128 (2010).

50. Emeis, C. A. Determination of integrated molar extinction coefficients for infrared absorption bands of pyridine adsorbed on solid acid catalysts. J. Catal. 141, 347-354 (1993).

51. Schäfer, H., Gruehn, R. \& Schulte, F. The modifications of niobium pentoxide. Angew. Chemie Int. Ed. 5, 40-52 (1966)

52. Griffith, K. J., Forse, A. C., Griffin, J. M. \& Grey, C. P. High-rate intercalation without nanostructuring in meta- 
stable $\mathrm{Nb}_{2} \mathrm{O}_{5}$ bronze phases. J.Am. Chem. Soc. 138, 8888-8899 (2016).

53. Iizuka, T., Ogasawara, K. \& Tanabe, K. Acidic and catalytic properties of niobium pentaoxide. Bull. Chem. Soc. Jpn. 56, 2927-2931 (1983).

54. Hernández Mejía, C., den Otter, J. H., Weber, J. L. \& de Jong, K. P. Crystalline niobia with tailored porosity as support for cobalt catalysts for the Fischer-Tropsch synthesis. Appl. Catal.A Gen. 548, 143-149 (2017).

55. Lebarbier, V., Houalla, M. \& Onfroy, T. New insights into the development of Bronsted acidity of niobic acid. Catal. Today 192, 123-129 (2012).

56. Florentino, A., Cartraud, P., Magnoux, P. \& Guisnet, M. Textural, acidic and catalytic properties of niobium phosphate and of niobium oxide. Influence of the pretreatment temperature. Appl.Catal.A, Gen. 89, 143-153 (1992).

57. Kline, C. H. \& Turkevich, J. The vibrational spectrum of pyridine and the thermodynamic properties of pyridine vapors. J. Chem. Phys. 12, 300-309 (1944).

58. Morterra, C. \& Magnacca, G. A case study: Surface chemistry and surface structure of catalytic aluminas, as studied by vibrational spectroscopy of adsorbed species. Catal. Today 27, 497-532 (1996).

59. Parry, E. P. An infrared study of pyridine adsorbed on acidic solids. Characterization of surface acidity. J. Catal. 2,371-379 (1963).

60. Liu, X. \& Truitt, R. E. DRFT-IR studies of the surface of $\gamma$-Alumina. J.Am. Chem. Soc. 119, 9856-9860 (1997).

61. Datka, J., Turek, A. M., Jehng, J. M. \& Wachs, I. E. Acidic properties of supported niobium oxide catalysts: An infrared spectroscopy investigation. J. Catal. 135, 186-199 (1992).

62. Carr, R. T., Neurock, M. \& Iglesia, E. Catalytic consequences of acid strength in the conversion of methanol to dimethyl ether. J. Catal. 278, 78-93 (2011).

63. Blaszkowski, S. R. \& Van Santen, R. A. The mechanism of dimethyl ether formation from methanol catalyzed by zeolitic protons. J.Am. Chem. Soc. 118, 5152-5153 (1996).

64. Foo, G. S., Wei, D., Sholl, D. S. \& Sievers, C. Role of Lewis and brønsted acid sites in the dehydration of glycerol over niobia. ACS Catal. 4, 3180-3192 (2014).

65. Peláez, R., Bryce, E., Marín, P. \& Ordóñez, S. Catalyst deactivation in the direct synthesis of dimethyl ether from syngas over $\mathrm{CuO} / \mathrm{ZnO} / \mathrm{Al}_{2} \mathrm{O}_{3}$ and $\gamma-\mathrm{Al}_{2} \mathrm{O}_{3}$ mechanical mixtures. Fuel Process. Technol. 179, 378-386 (2018).

66. Lunkenbein, T. et al. Bridging the time gap: a copper/zinc oxide/aluminum oxide catalyst for methanol synthesis studied under industrially relevant conditions and time scales. Angew. Chemie - Int. Ed. 55, 12708-12712 (2016).

67. Liang, B. et al. Investigation on deactivation of $\mathrm{Cu} / \mathrm{ZnO} / \mathrm{Al}_{2} \mathrm{O}_{3}$ catalyst for $\mathrm{CO}_{2}$ hydrogenation to methanol. Ind. Eng. Chem. Res. 58, 9030-9037 (2019).

68. Laurenti, M. et al. Wettability control on $\mathrm{ZnO}$ nanowires driven by seed layer properties. Eur. J. Inorg. Chem. 2013, 2520-2527 (2013).

69. Tak, Y. \& Yong, K. Controlled growth of well-aligned $\mathrm{ZnO}$ nanorod array using a novel solution method. J. Phys. Chem. B 109, 19263-19269 (2005).

70. Yamazaki, H. et al. Direct production of propene from methoxy species and dimethyl ether over H-ZSM-5. J. Phys. Chem. C 116, 23851-24392 (2012).

71. Ereña, J., Sierra, I., Olazar, M., Gayubo, A. G. \& Aguayo, A. T. Deactivation of a CuO-ZnO- $\mathrm{Al}_{2} \mathrm{O}_{3} / \gamma-\mathrm{Al}_{2} \mathrm{O}_{3}$ catalyst in the synthesis of dimethyl ether. Ind. Eng. Chem. Res. 47, 2238-2247 (2008).

72. Sierra, I., Ereña, J., Aguayo, A. T., Olazar, M. \& Bilbao, J. Deactivation kinetics for direct dimethyl ether synthesis on a CuO-ZnO- $-\mathrm{Al}_{2} \mathrm{O}_{3} / \gamma-\mathrm{Al}_{2} \mathrm{O}_{3}$ catalyst. Ind. Eng. Chem. Res. 49, 481-489 (2010).

73. Sen, B., Falconer, J. L., Mao, T. F., Yu, M. \& Flesner, R. L. Spillover of $\mathrm{CO}$ and $\mathrm{H}_{2}$ onto $\mathrm{Al}_{2} \mathrm{O}_{3}$ surfaces. J. Catal. 126, 465-476 (1990).

74. Chen, B. \& Falconer, J. L. Hydrogenation of organic oxygenates on $\mathrm{Ni} / \mathrm{Al}_{2} \mathrm{O}_{3}$ and $\mathrm{Ni} / \mathrm{SiO}_{2}$ catalysts. J. Catal. 147, 72-81 (1994). 
Summary, Conclusions and Outlook 


\section{Summary and conclusions}

Liquid fuels play a crucial role in the fulfilment of the current global energy demand, especially for the transportation sector. This large demand has promoted the efficient production of fuels and feedstock diversification. In this regard, synthesis gas has become an attractive alternative source for the production of chemicals and fuels. Within the key catalytic processes for this transformation are the Fischer-Tropsch synthesis (FT) and methanol synthesis reactions. The catalysts that enable these processes need to be active, selective and stable and therefore are subjects of research and continuous innovation.

Cobalt-catalyzed FT produces mainly long-chain hydrocarbons $\left(\mathrm{C}_{5+}\right)$, which can be further upgraded to liquid fuels such as gasoline and diesel. The selectivity to $\mathrm{C}_{5_{+}}$hydrocarbons of cobalt FT catalysts is enhanced when reducible metal oxides (e.g. $\mathrm{Nb}_{2} \mathrm{O}_{5}, \mathrm{TiO}_{2}$ ) are used as promotors and/or support material. These oxides display strong metal-support interaction (SMSI) with transition metals, which occurs during partial reduction of the support and consequent suboxides formation. These suboxides can migrate over the surface of the supported metal. Partial surface coverage with these suboxides is known to promote the intrinsic catalytic activity and selectivity towards $\mathrm{C}_{5+}$ products of the metal. Methanol synthesis in industry is currently performed by copper-based catalysts, co-promoted with $\mathrm{ZnO}$. The catalysts are highly selective for methanol, although the conversion levels are thermodynamically restricted. Combination however with a solid acid can enhance the synthesis gas conversion levels to other chemical such as DME and olefins, the formation of which is thermodynamically more favored than that of methanol.

Transition metal oxides can promote the activity and/or selectivity as components of catalysts for synthesis gas conversion. Although less known, niobium oxide, or niobia, can effectively promote the activity and $\mathrm{C}_{5+}$ selectivity of cobalt-based FT catalysts. Throughout most of the research in this thesis, niobia was used as support material, for cobalt in chapters 3 and 4, for cobalt-nickel in chapter 5 and for nickel in chapter 6 . Different synthetic strategies were explored in order to understand and expand the performance of niobium-supported metal catalysts. Furthermore, In chapter 7, Hydrated niobium pentoxide and niobium phosphate were studied in combination with a methanol synthesis catalyst for the direct synthesis of DME, particularly focusing on the stability of such systems. These solid acids are capable of maintaining high catalytic activity and stability when water is involved which is an attractive feature for dehydration reactions. Hereafter, highlights of the results of each chapter are summarized.

The literature analysis on metal-support interactions and tuning strategies presented in chapter 2 demonstrated that supports are more than an inert structural matrix and that their chemical properties can be applied to enhance catalytic performance. The various strategies recently reported in literature were systematically arranged and discussed. Moreover, we provided a quantitative analysis of the scale of performance enhancement achieved in $\mathrm{C} 1$ chemistry, showing that effective tuning of the metal-support interactions can improve catalytic activity by one order of magnitude. It was also observed that metal nanoparticles smaller than four nanometers are more susceptible to metal-support interaction 
effects. We provided a perspective of recent available synthetic tools to effectively control metal-support interactions and the design of catalysts for enhanced performance.

The first experimental chapter, chapter 3, introduced some of the necessary properties of niobia to serve as support material for cobalt-based FT catalysts. A comprehensive study was reported based on crystal phase, porosity and cobalt loading for an effective catalytic performance. Niobia crystallization above $400{ }^{\circ} \mathrm{C}$ prior to cobalt deposition proved necessary to obtain an active catalyst. The precursor, niobium oxide hydrate, was too reactive and led to non-reducible cobalt-niobium oxide species. The high temperature crystallization treatment, however, caused a collapse of the porous structure of the precursor and loss of specific surface area, limiting the cobalt loading. To circumvent this, a carbon templating method was used to restrict the structural collapse during crystallization. The resulting crystalline niobia maintained an important fraction of the $2-5 \mathrm{~nm}$ mesopores from the niobium oxide hydrate. The porous structure allowed higher cobalt loadings leading to an increased catalyst-weight-normalized catalytic activity.

A reduction-oxidation-reduction (ROR) pre-treatment in chapter $\mathbf{4}$ was applied to cobalt supported on reducible supports (niobia and titania) to tune the coverage of cobalt nanoparticles by SMSI-species. This resulted in a twofold increase in accessible cobalt metal surface area and a proportional enhancement of the cobalt-based FT catalytic activity. In contrast, a decrease in cobalt surface area and activity was observed when ROR was applied to a cobalt supported on alpha-alumina (a non-reducible oxide) catalyst. The increased activity for niobia and titania was attributed to more accessible cobalt metal surface sites as revealed by the constant turnover frequency in FT, while maintaining the full promotional effect of the SMSI-species. Coincidentally, hollow cobalt oxide nanoparticles were observed after oxidation as part of ROR for the samples that subsequently showed the highest activities. Formation of these hollow oxide nanoparticles was proposed to be instrumental in tuning the coverage by SMSI-species.

In chapter 5, we showed that the combination of cobalt-nickel bimetallic nanoparticles and reducible metal oxides as support (e.g. niobia and titania) allowed for increased FT performance. Addition of nickel to cobalt increased the dispersion of the metal nanoparticles and aided the reduction of the mixed metal oxides. Low-pressure FT performance results showed substantially higher activities, $\mathrm{C}_{5+}$ selectivities and stabilities for the bimetallic nanoparticles supported on reducible oxides. On the other hand, alumina-supported catalysts showed low activities and $\mathrm{C}_{5+}$ selectivities than Co independent of the Co-Ni composition and, moreover, a continuous loss of activity. The marked contrast in catalytic performance was tentatively coined to a shift of the rate determining step, as derived from the trend between TOF and CO-FTIR. A weaker CO adsorption was inferred for Co-Ni supported on reducible oxides, which in turn was proposed to improve hydrogen adsorption and the catalytic activity.

Nickel supported on niobia for CO hydrogenation was studied in chapter $\mathbf{6}$ with focus on different reduction temperatures. We showed that niobia used as support material offers the possibility to obtain stable nickel-based catalysts for CO hydrogenation with tunable product spectrum. Low reduction temperatures provided high initial activities but 
fast deactivation due to nickel particle growth, whereas a high reduction temperature led to lower but stable activity and no significant particle growth. FTIR measurements of CO adsorbed on $\mathrm{Ni} / \mathrm{Nb}_{2} \mathrm{O}_{5}$ showed that nickel subcarbonyls readily formed after low but not after high reduction temperature. We inferred that the particle growth involved the formation and diffusion of nickel carbonyls that bring about Ostwald Ripening. Moreover, the reduction treatment had a strong influence in the product distribution. The highest selectivity towards $\mathrm{C}_{5_{+}}\left(55 \mathrm{wt} . \%\right.$ ) was obtained after reduction at $350{ }^{\circ} \mathrm{C}$, while a further increase of the reduction temperature shifted the product distribution towards lighter products.

In chapter 7 , hydrated niobium pentoxide and niobium phosphate were used in combination with a methanol synthesis catalyst for production of DME from synthesis gas. All physical mixtures showed excellent activity and DME selectivity. Particularly, niobium phosphate performed as good as gamma-alumina (used as reference material), with improved DME productivity per unit volume due to its high density and acid site concentration. Furthermore, the stabilities of all mixtures differed depending on the nature of the solid acid, indicative of different deactivation mechanisms. STEM-EDX analysis of the used catalysts revealed that the niobium-based solid acids and not the alumina one ended up with some copper on their surface after reaction. This might be an indication of ion migration from the copper-based methanol synthesis catalyst to the surface of the solid acids, and most likely compromising the performance of both the methanol synthesis catalyst and the acid sites.

\section{Outlook}

As usual in scientific research, solving some of the research questions in this thesis led to new ones. From chapter 3 we learned that mesopores from the precursor for crystalline niobia can be partially maintained. These mesopores appear as small cavities (2-5 nm) over the niobia and seem to be characteristic of niobium oxides. The formation mechanism of these mesopores remains however unclear. The cavities might be used to restrain small nanoparticles, for example to avoid particle mobility and metal sintering. The size of such cavities is not optimal for FT or methanol synthesis catalysts, however other reactions particularly involving nanoparticles of precious metals might benefit.

The SMSI effect is a phenomenon that was extensively discussed throughout the thesis, although we could only present indirect evidence of its structure and impact. It is indeed still a scientific challenge to directly detect the suboxide coverage of metal nanoparticles during SMSI, particularly for base metals. Nowadays, coverage by suboxides has been possible to observed by high-resolution TEM for noble metals and at extreme conditions (e.g. pure hydrogen and reduction temperatures higher than $500{ }^{\circ} \mathrm{C}$ ). More sensitive detectors, 'transparent' cells capable to withstand higher gas pressures and a better understanding of the effects of the electron beam on gas systems at high pressure are needed in order to study SMSI of a working catalyst. Similarly, Near-Ambient Pressure XPS (NAP-XPS) is another attractive characterization technique that might be able to help us to study the SMSI effect. The phenomenon has been observed by XPS but mainly for model systems. Moreover, NAP- 
XPS has the same challenges as with microscopy techniques. We explored the use of NAPXPS at the synchrotron facility BESSY II, however the results showed that the relatively low gas pressures of the cell did not lead to reduction of the supported cobalt oxide. The mobility of the suboxides, their crystallinity and their Lewis acidity are some of the unknown characteristics that remain to be solved. Knowing this could help us to understand why for instance titania used as support for cobalt or cobalt-nickel nanoparticles presents a higher TOF than niobia as support. As well it can increase our understanding of the promotional effect of reducible supports on chain-growth and $\mathrm{C}_{5+}$ selectivity.

In chapter 4 , one of the important observations was the formation of hollow cobalt oxide nanoparticles by the Kirkendall effect for the most active samples. This was proposed to be instrumental in tuning the surface composition of the metallic cobalt nanoparticles and hence the increased activity. An in-depth study of this mechanism can be of great interest to further understand the possible re-distribution of the suboxides. This will require extremely sensible characterization techniques, capable of operating at the various reductive and oxidative conditions. Moreover, from previous research it is known that cobalt supported on niobia shows high surface specific activity when promoted with a noble metal $(\mathrm{Pt})$, and now the question arises whether or not this CoPt system also would benefit from the ROR pre-treatment.

For the bimetallic cobalt-nickel system from chapter 5 the very high activities and particularly high $\mathrm{C}_{5+}$ selectivities at already 1 bar were remarkable. A future research challenge would be to maintain those active sites at higher pressures. First, a kinetic study of these catalysts can improve our understanding of the nanoparticle's composition and support interaction. Second, we could explore synthetic strategies to maximize the promotional effect of the reducible supports and bimetallic nanoparticles. The ROR pre-treatment might improve the distribution of suboxides and perhaps their effectiveness. However, Co$\mathrm{Ni}$ dealloying might take place upon oxidation, most likely resulting in a core-shell arrangement since cobalt will undergo oxidation before nickel. This might be beneficial for the active sites, since it was observed a similar phenomenon of surface enrichment with cobalt upon $\mathrm{CO}$ adsorption for the most active samples. Beside this, we also observed an increase in dispersion of the metal nanoparticles over the support when nickel was added to cobalt, this however makes it difficult to disentangle the effects from particle size and nanoparticle composition. Colloidal synthesis of bimetallic nanoparticles is a tool that can help us understand these systems better. Although difficult to execute, the nanoparticles' properties can be better controlled by use of a colloidal synthesis than with standard synthesis methods. In this way we could explore different particle sizes and the distribution of the metals within a nanoparticle.

An additional challenge would be to avoid the formation of nickel tetracarbonyl at higher $\mathrm{CO}$ pressures for $\mathrm{CoNi}$ catalysts using for example a higher reduction temperature, as learned from chapter 6 . The metal-support interaction was not fully optimized for these systems and the ROR pre-treatment might improve the performance after a high initial reduction temperature. The ample techniques to tune the metal-support interaction in the literature, as shown in chapter 2, might serve as inspiration to tackle these challenges. 
The use of hydrated niobium oxide and niobium phosphate in chapter 7 showed promising results in the application of these materials for DME synthesis. Ion migration from the copper-based methanol synthesis catalyst to these materials was observed, leading most likely to a loss in activity and increased hydrocarbon selectivity. This might be avoided by quenching the Brønsted acid sites, which are typically linked to the ion migration phenomenon. There are several niobium-base acidic materials, with various structures, types of acid sites and strengths, which can allow an optimal design as stable DME synthesis catalysts. However, the mechanism of ion migration during reaction conditions, and similar deactivation mechanisms, remains poorly understood. The recent interest in use of bifunctional systems for synthesis gas conversion has attracted attention into studying the stability of such systems. Characterization techniques that can be used at elevated pressure will be important to increase our knowledge of these catalysts.

Overall, the aim of this thesis was to reflect the potential and versatility of niobium-based catalysts in synthesis gas conversion, to understand the underlying mechanisms for improved catalytic performance and expand the available synthetic tools for catalyst design. 


\section{Nederlandse samenvatting}

Vloeibare brandstoffen spelen een cruciale rol in de huidige globale vraag naar energie, met name in de transportsector. Deze enorme vraag naar energie heeft efficiënte productie van brandstoffen en diversificatie van grondstoffen gestimuleerd. Wat betreft diversificatie van grondstoffen is synthesegas, verkregen uit grondstoffen zoals aardgas en biomassa, een interessant alternatief voor de productie van chemicaliën en brandstoffen. De belangrijke katalytische processen voor deze transformatie zijn de Fischer-Tropschsynthese (FT) en methanolsynthese. De katalysatoren die deze processen mogelijk maken dienen actief, selectief en stabiel te zijn en zijn daarom het onderwerp van onderzoek en innovatie.

Door kobalt gekatalyseerde FT produceert hoofdzakelijk koolwaterstoffen met lange ketens van koolstofatomen $\left(\mathrm{C}_{5^{+}}\right)$, die verder verwerkt kunnen worden tot vloeibare brandstoffen zoals benzine en diesel. De selectiviteit voor $\mathrm{C}_{5+}$ koolwaterstoffen van FT katalysatoren gebaseerd op kobalt wordt verhoogd wanneer reduceerbare metaaloxiden (e.g. $\mathrm{Nb}_{2} \mathrm{O}_{5}$, $\mathrm{TiO}_{2}$ ) gebruikt worden als promotor en/of dragermateriaal. Deze oxiden vertonen sterke metaal-dragerinteracties (SMSI) met transitiemetalen, welke plaatsvinden gedurende gedeeltelijke reductie van de drager en de daaropvolgende formatie van suboxiden. Deze suboxiden kunnen zich over de oppervlakte van het metaaldeeltjes verplaatsen. Het is bekend dat gedeeltelijke bedekking van het metaaloppervlak met deze suboxiden de intrinsieke katalytische activiteit en selectiviteit naar $\mathrm{C}_{5+}$ producten van het metaal bevorderen. Methanolsynthese wordt momenteel uitgevoerd in de industrie door koper-gebaseerde katalysatoren, gepromoteerd door $\mathrm{ZnO}$. De katalysatoren zijn zeer selectief voor methanol, ondanks dat de conversieniveaus beperkt zijn door het thermodynamisch evenwicht van synthesegas en methanol. Combinatie met een vast zuur daarentegen kan de conversieniveaus van het synthesegas via methanol tot andere chemicaliën, zoals DME en olefinen, verhogen. De formatie van deze deze andere chemicaliën is thermodynamisch gunstiger dan die van methanol.

Wanneer transitiemetaaloxiden als component aan de katalysator voor synthesegasconversie worden toegevoegd, kunnen deze de katalytische activiteit en/of selectiviteit verhogen. Hoewel minder bekend, kan niobiumoxide, ook wel niobia genoemd, de activiteit en $\mathrm{C}_{5+}$-selectiviteit van kobalt-gebaseerde FT katalysatoren efficiënt verhogen. Gedurende het overgrote deel van het onderzoek in dit proefschrift werd niobia gebruikt als dragermateriaal. Niobia werd als dragermateriaal gebruikt voor kobalt in hoofdstuk 3 en 4, voor kobalt-nikkel in hoofdstuk 5 en voor nikkel in hoofdstuk 6 . Verschillende synthesestrategieën zijn onderzocht om de prestatie van niobium-gedragen metaalkatalysatoren te begrijpen en te verbeteren. Verder zijn in hoofdstuk 7 gehydrateerde niobiumpentoxide en niobiumfosfaat bestudeerd in combinatie met een methanolsynthesekatalysator voor de directe synthese van DME, met als focus de stabiliteit van zulke systemen. Wanneer er water bij betrokken is, zijn deze vaste zuren in staat om hoge katalytische activiteit en stabiliteit te behouden, wat een interessante eigenschap is voor dehydratiereacties. Hierna worden de hoogtepunten van de resultaten van ieder hoofdstuk omschreven.

De literatuurstudie van metaal-dragerinteracties en strategieën om die te beïnvloeden die in hoofdstuk 2 gepresenteerd wordt, toont aan dat dragers meer dan een structu- 
rele matrix zijn en dat de chemische eigenschappen gebruikt kunnen worden om de katalytische prestaties te verbeteren. De verschillende strategieën die recentelijk gerapporteerd zijn in de literatuur zijn systematisch geordend en bediscussieerd. Bovendien presenteren wij een kwantitatieve analyse van de schaal van prestatie-verbetering behaald in C1-chemie, waarbij wordt aangetoond dat efficiënte regulering van de metaal-dragerinteracties de katalytische activiteit met een orde van grootte kan verbeteren. Ook werd geobserveerd, dat metalen nanodeeltjes kleiner dan 4 nanometer gevoeliger zijn dan grotere deeltjes voor de effecten van metaal-dragerinteracties. Wij bieden een perspectief op de huidige beschikbare synthetische gereedschappen om metaal-dragerinteracties efficiënt te controleren en katalysatoren te ontwerpen met verbeterde prestaties.

In hoofdstuk 3, het eerste experimentele hoofdstuk, worden enkele van de eigenschappen van niobia gepresenteerd die noodzakelijk zijn om als dragermateriaal voor kobalt-gebaseerde FT katalysatoren te kunnen fungeren. Een uitgebreide studie wordt beschreven die gebaseerd was op kristalfase, porositeit en de gebruikte hoeveelheid kobalt (kobaltbelading) voor efficiënte katalytische prestaties. Kristallisatie van niobia boven $400{ }^{\circ} \mathrm{C}$, voor afzetting van kobalt, bleek nodig te zijn om een actieve katalysator te verkrijgen. De uitgangsstof, niobiumoxidehydraat, was te reactief en leidde tot niet-reduceerbare varianten van kobaltniobiumoxide. De kristallisatiebehandeling bij hoge temperatuur, daarentegen, leidde tot een afname van de porositeit van de uitgangsstof en een verlies van het specifiek oppervlak, waardoor de kobaltbelading gelimiteerd werd. Om dit te omzeilen werd een 'templating' methode met koolstof gebruikt om de structurele degradatie gedurende kristallisatie te beperken. Het resulterende kristallijne niobia behield een belangrijke fractie van de 2-5 nm mesoporiën van het niobiumoxidehydraat. De poreuze structuur liet een hogere kobaltbelading toe, wat leidde tot een toename van de op katalysatorgewicht genormaliseerde katalytische activiteit.

Een reductie-oxidatie-reductie (ROR) voorbehandeling werd toegepast in hoofdstuk 4 op kobalt op reduceerbare dragers (niobia en titania) om de bedekking van kobaltnanodeeltjes door SMSI-verbindingen te reguleren. Dit resulteerde in een toename van het beschikbare kobalt metaaloppervlak en een proportionele verbetering van de kobalt-gebaseerde katalytische FT activiteit met een factor twee. In tegenstelling, een afname in kobaltoppervlak en activiteit werd waargenomen toen ROR toegepast werd op een kobaltkatalysator gedragen op een alfa-alumina (een niet-reduceerbaar oxide). De toegenomen activiteit voor niobia en titania werd toegeschreven aan de toename van beschikbare kobalt metaaloppervlakteplekken met identieke structuur, met een de constante oppervlak-gebaseerde omzettingsfrequentie in FT die erop wijzen dat de effecten van de SMSI-verbindingen werden behouden. Tegelijkertijd werden holle kobaltoxidenanodeeltjes waargenomen na oxidatie als onderdeel van de ROR behandeling in de monsters die de hoogste activiteit vertoonden. Formatie van deze holle oxidenanodeeltjes werd als belangrijk verondersteld in de regulering van de bedekking door SMSI-verbinding.

In hoofdstuk 5 wordt getoond dat de combinatie van kobalt-nikkel nanodeeltjes en reduceerbare metaaloxiden als drager (e.g. niobia en titania) verbeterde FT prestaties leveren. De toevoeging van nikkel aan kobalt verhoogde de verdeling van de metalen nano- 
deeltjes over de drager en bevorderde de reductie van de metaaloxiden. De resultaten van FT reactie onder lage druk toonden substantieel hogere activiteit, $\mathrm{C}_{5+}$ selectiviteit en stabiliteit voor de CoNi-nanodeeltjes op reduceerbare oxiden. Anderzijds toonden alumina-gedragen bimetallische katalysatoren lagere activiteit en $\mathrm{C}_{5+}$ selectiviteit dan Co, onafhankelijk van de kobalt-nikkel samenstelling. De nikkel-houdende katalysatoren op alumina vertoonden bovendien een voortdurende afname in activiteit. Het contrast in katalytische prestaties wordt voorlopig toegeschreven aan een verandering in de snelheidsbepalende stap, zoals afgeleid uit de trend tussen TOF en CO-FTIR. Een lagere CO-adsorptie werd gevonden voor Co-Ni gedragen op reduceerbare oxiden, wat vervolgens werd voorgesteld als reden voor de verbetering van waterstofadsorptie en de katalytische activiteit.

Nikkel op niobia voor CO-hydrogenatie wordt beschreven in hoofdstuk 6 met focus op verschillende reductietemperaturen. We tonen aan dat niobia, wanneer gebruikt als dragermateriaal, de mogelijkheid biedt om stabiele nikkel-gebaseerde katalysatoren te verkrijgen voor CO-hydrogenatie met een variabel productenspectrum. Lage reductietemperaturen zorgden voor hoge initiële activiteiten maar snelle deactivering door de groei van nikkeldeeltjes, terwijl een hoge reductietemperatuur leidde tot lagere maar stabielere activiteit en geen significante groei van deeltjes. FTIR metingen van CO geadsorbeerd op $\mathrm{Ni} / \mathrm{Nb}_{2} \mathrm{O}_{5}$ toonden dat nikkel-subcarbonylen vormden na lage reductietemperaturen, maar niet na hoge reductietemperaturen. Wij leidden hieruit af dat bij de groei van deeltjes de formatie en diffusie van nikkelcarbonylen via zogenaamde Ostwald Ripening betrokken waren. Bovendien had de reductiebehandeling een sterke invloed op de productdistributie. De hoogste selectiviteit naar $\mathrm{C}_{5+}\left(55 \mathrm{wt}\right.$. \%) werd behaald na reductie op $350{ }^{\circ} \mathrm{C}$, terwijl een verdere toename van de reductietemperatuur de productdistributie verschoof naar lichtere producten.

In hoofdstuk 7 werden gehydrateerde niobiumpentoxide en niobiumfosfaat gebruikt in combinatie met een methanolsynthesekatalysator voor de productie van DME uit synthesegas. Alle fysische mengsels vertoonden excellente activiteit en DME-selectiviteit. Met name niobiumfosfaat presteerde even goed als gamma-alumina (gebruikt als referentiemateriaal), met verhoogde DME-productiviteit per eenheid volume door de hoge dichtheid en concentratie van zure plaatsen. Verder verschilde de stabiliteit van alle fysische mengsels, afhankelijk van het type vast zuur, wat wijst op verschillende deactivatiemechanismen. STEM-EDX analyse van de gebruikte katalysatoren toonde aan dat de niobium-gebaseerde vaste zuren, en niet degenen gebaseerd op alumina, eindigden met wat koper op het oppervlak na de reactie. Dit kan een indicatie zijn van migratie van koperionen van de methanolsynthesekatalysatoren naar het oppervlak van de vaste zuren, wat hoogstwaarschijnlijk leidt tot een vermindering van de prestaties van zowel de methanolsynthesekatalysator als ook van de zure katalysator. 



\section{Appendix A}

\section{Supporting Information Chapter 2}

Control of Metal-Support Interactions in Heterogeneous Catalysts to Enhance Activity and Selectivity

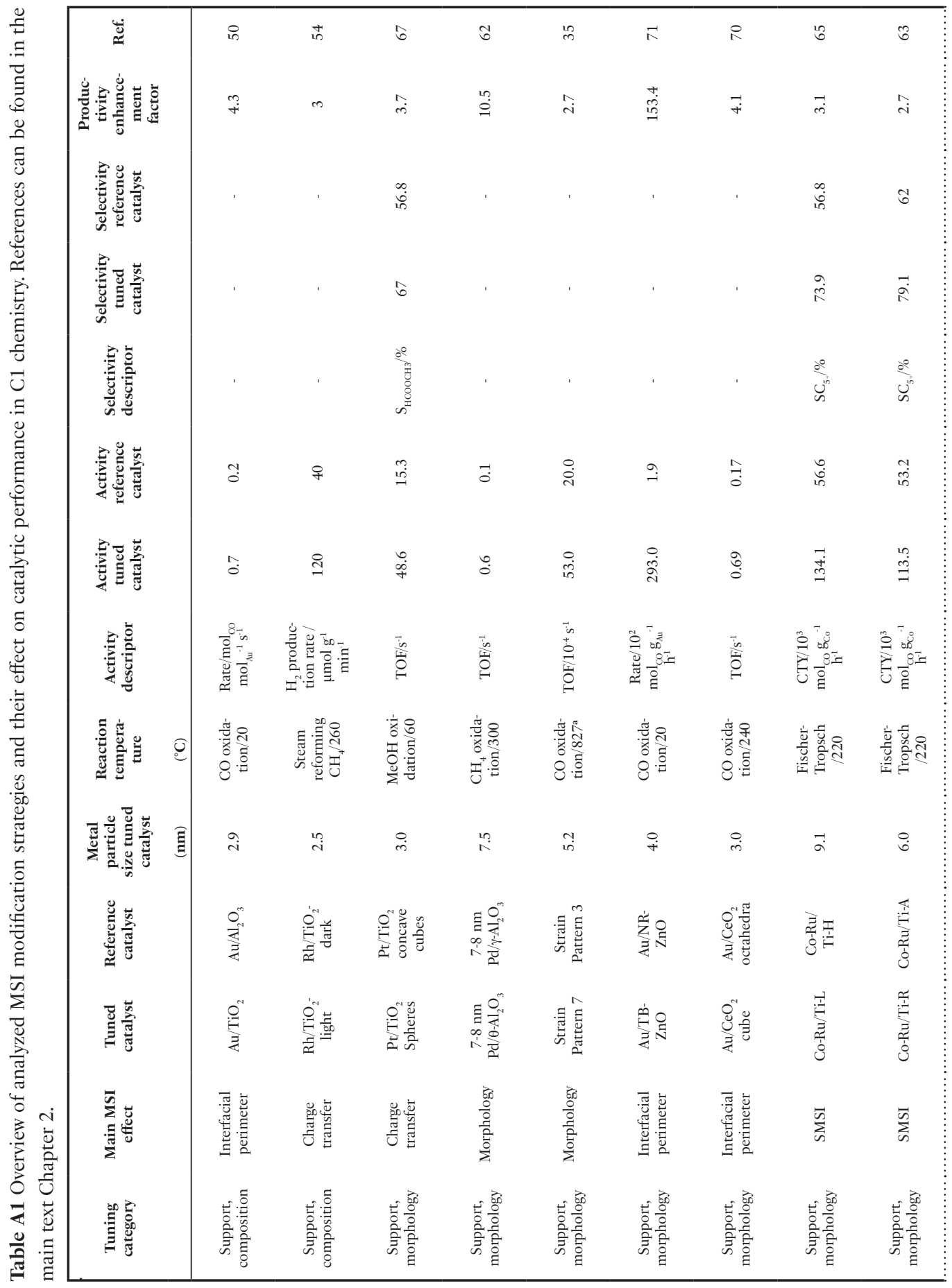




\begin{tabular}{|c|c|c|c|c|c|c|c|c|c|c|}
\hline 8 & $N$ & $\approx$ & in & ส & $\infty$ & 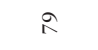 & $\infty$ & के & 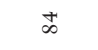 & \& \\
\hline$\stackrel{\overbrace{}}{\stackrel{\leftrightarrow}{\ominus}}$ & $\overbrace{i}$ & $\stackrel{Y}{-}$ & $\exists$ & $\exists$ & $\stackrel{\circ}{\circ}$ & $\stackrel{\infty}{i}$ & $\stackrel{+}{i}$ & $\ddot{m}$ & $\stackrel{\overbrace{}}{-}$ & $\stackrel{\Im}{-}$ \\
\hline$\stackrel{\infty}{i n}$ & & $\begin{array}{l}+ \\
\stackrel{\infty}{n}\end{array}$ & ' & . & & $\stackrel{3}{\mathrm{i}}$ & ' & & & . \\
\hline$\infty$ & ' & $\stackrel{\infty}{\infty}$ & ' & & . & $\begin{array}{l}0 \\
\stackrel{2}{0}\end{array}$ & . & & . & . \\
\hline$\frac{0^{0}}{i^{8}}$ & . & $\frac{\partial^{\circ}}{n^{\frac{1}{6}}}$ & & & & $\overbrace{}^{\circ}$ & & & & \\
\hline$\hat{o}$ & $\stackrel{0}{\dot{\rho}}$ & $\begin{array}{l}0 \\
\dot{0} \\
\dot{0}\end{array}$ & $\stackrel{+}{-}$ & $\stackrel{0}{\circ}$ & $\stackrel{\circ}{\circ}$ & $\hat{b}$ & 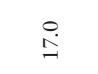 & $\begin{array}{l}\stackrel{0}{+} \\
\underset{\infty}{\infty}\end{array}$ & in. & $\stackrel{\infty}{\infty}$ \\
\hline$\stackrel{+r}{+}$ & $\stackrel{\dot{R}}{\mathrm{i}}$ & m. & $\stackrel{0}{-}$ & $\stackrel{\infty}{\stackrel{\infty}{0}}$ & ir & $\hat{\sigma}$ & 迁 & 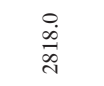 & $\begin{array}{l}0 \\
0\end{array}$ & 官 \\
\hline $\begin{array}{l}\text { in } \\
0 \\
0 \\
0 \\
0 \\
0\end{array}$ & $\frac{20}{x^{8}}$ & 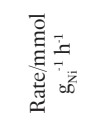 & 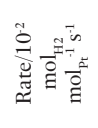 & 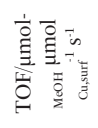 & $\stackrel{i}{i}$ & 둥 & $\frac{\partial^{\circ}}{\stackrel{7}{t}^{\frac{7}{x}}}$ & 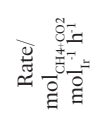 & 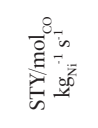 & $\frac{\partial^{0}}{x^{8}}$ \\
\hline ○莺 & 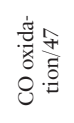 & 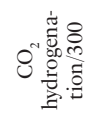 & $\begin{array}{l}8 \\
\frac{0}{2} \\
3 \\
13\end{array}$ & 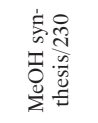 & 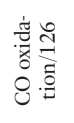 & 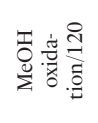 & 总递总 & 昜总递 & 总总员 & 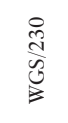 \\
\hline$\stackrel{\circ}{\circ}$ & ir & $\stackrel{m}{\Theta}$ & $\underset{\mathrm{i}}{\mathrm{i}}$ & $\stackrel{\odot}{\stackrel{\Theta}{0}}$ & $\stackrel{+}{i}$ & in & $\stackrel{10}{n}$ & 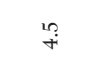 & $\stackrel{\circ}{\circ}$ & $\stackrel{+}{i}$ \\
\hline 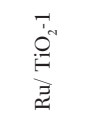 & 总 & 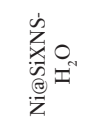 & 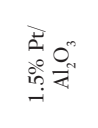 & \begin{tabular}{l}
0 \\
\multirow{N}{*}{} \\
$\Xi$
\end{tabular} & $\begin{array}{l}\text { O } \\
\text { N } \\
\text { D }\end{array}$ & 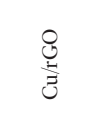 & $\frac{\bar{z}}{\bar{z}}$ & $\stackrel{0}{0}_{\Xi}^{0}$ & $\begin{array}{l}\text { 菩 } \\
\text { z }\end{array}$ & $\begin{array}{l}8_{0}^{\prime \prime} \\
\frac{8}{4}\end{array}$ \\
\hline$\stackrel{\infty}{6}^{2}$ & 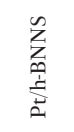 & 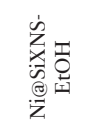 & 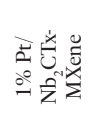 & 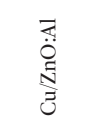 & 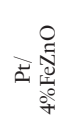 & $\begin{array}{l}\frac{0}{b} \\
\frac{1}{3} \\
3\end{array}$ & $\stackrel{ }{\stackrel{7}{3}}$ & $\begin{aligned} 0^{N} \\
\Xi \\
\dot{J}^{\circ}\end{aligned}$ & 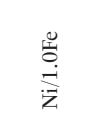 & 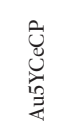 \\
\hline$\sum_{\bar{n}}^{\vec{n}}$ & 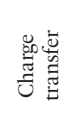 & 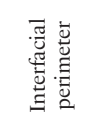 & 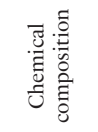 & 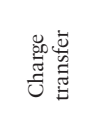 & 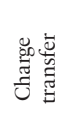 & 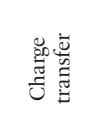 & 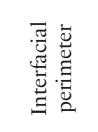 & 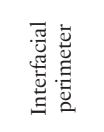 & 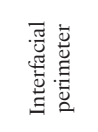 & 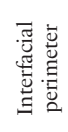 \\
\hline 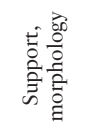 & 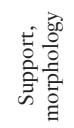 & 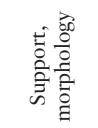 & 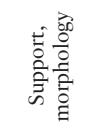 & 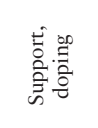 & 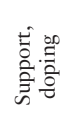 & 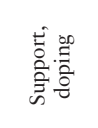 & 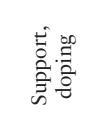 & 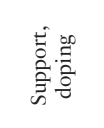 & 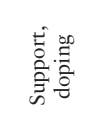 & 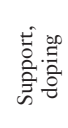 \\
\hline
\end{tabular}




\begin{tabular}{|c|c|c|c|c|c|c|c|c|c|c|}
\hline${ }_{\infty}^{10}$ & $\widetilde{\widetilde{\sigma}}$ & $\dddot{2}$ & 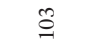 & $\stackrel{t}{\stackrel{\Delta}{\sigma}}$ & & $\stackrel{\infty}{\stackrel{\circ}{\circ}}$ & 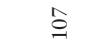 & $\stackrel{10}{=}$ & $\stackrel{3}{=}$ & $\hat{\exists}$ \\
\hline$\stackrel{\circ}{ \pm}$ & $\stackrel{?}{\rightarrow}$ & $\underset{\mathrm{i}}{\stackrel{\circ}{ }}$ & $\stackrel{\overbrace{}}{+}$ & $\stackrel{\circ}{\circ}$ & $\tilde{i}$ & $\stackrel{\Im}{\sim}$ & $\stackrel{\circ}{ \pm}$ & $\stackrel{\infty}{\circ}$ & $\hat{\infty}_{\infty}$ & $\stackrel{\leftrightarrow}{-}$ \\
\hline & . & $\infty$ & $\hat{\dot{\infty}}$ & 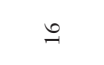 & $\hat{त}$ & 3 & 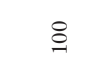 & $\stackrel{\stackrel{+}{+}}{+}$ & & ' \\
\hline & . & $\AA$ & $\frac{\partial}{\infty}$ & $F$ & ల & 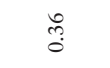 & 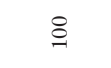 & $\begin{array}{l}\stackrel{2}{2} \\
\stackrel{\alpha}{\alpha}\end{array}$ & & . \\
\hline & & $\frac{\partial^{\circ}}{n^{b^{3}}}$ & $\frac{0^{\circ}}{n^{8}}$ & $\frac{2^{\circ}}{n^{\frac{1}{0}}}$ & $\frac{\partial^{0}}{n^{6}}$ & $\frac{0^{0}}{n^{8}}$ & $\frac{\partial^{\circ}}{n^{\frac{1}{0}}}$ & $\frac{0^{\circ}}{n^{8}}$ & . & \\
\hline$\because$ & $\hat{o}$ & $\stackrel{\circ}{\dot{m}}$ & $\begin{array}{l}\infty \\
\stackrel{\infty}{\infty}\end{array}$ & $\overrightarrow{0}$ & $\underset{-}{\stackrel{\leftrightarrow}{-}}$ & $\stackrel{3}{0}$ & $\stackrel{10}{0}$ & $\begin{array}{l}10 \\
\infty \\
\infty \\
0\end{array}$ & $\stackrel{\circ}{=}$ & 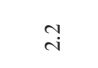 \\
\hline$\stackrel{+}{\circ}$ & $\hat{\circ}$ & $\stackrel{\ddot{r}}{\circ}$ & $\begin{array}{l}\text { 足 } \\
\text { 苞 }\end{array}$ & ช̊ & $\stackrel{+}{-}$ & $\stackrel{3}{0}$ & $\stackrel{+}{\wedge}$ & ir & 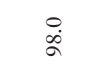 & $\stackrel{\infty}{i}$ \\
\hline 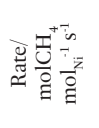 & $\begin{array}{l}\text { in } \\
\text { o } \\
0 \\
0 \\
0\end{array}$ & $\begin{array}{l}\text { in } \\
\hat{0} \\
0 \\
0 \\
0\end{array}$ & 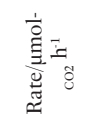 & 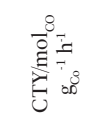 & $\begin{array}{l}\text { in } \\
\text { o } \\
0 \\
0 \\
0\end{array}$ & 离 & is & 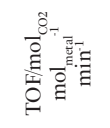 & $x^{\circ}$ & 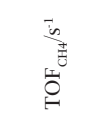 \\
\hline 总号 & 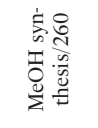 & 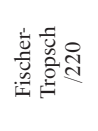 & 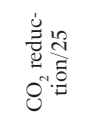 & 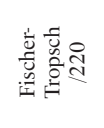 & 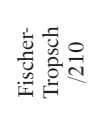 & 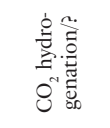 & 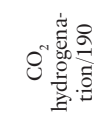 & 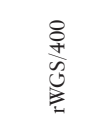 & 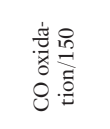 & 量高总 \\
\hline$\stackrel{m}{\longrightarrow}$ & $\underset{\mathrm{i}}{\mathrm{i}}$ & $\stackrel{i}{i}$ & $\dot{r}$ & $\stackrel{\oplus}{\oplus}$ & $\hat{i}$ & $\stackrel{\leftrightarrow}{-}$ & $\stackrel{\overbrace{}}{-}$ & $\stackrel{\circ}{-}$ & $\stackrel{\circ}{\dot{I}}$ & $\stackrel{0}{+}$ \\
\hline 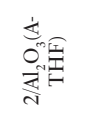 & $\begin{array}{l}\approx \\
\tilde{3}\end{array}$ & 道空 & 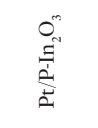 & 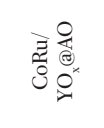 & 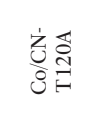 & $\stackrel{8}{2}$ & $\sum_{\bar{\Xi}}^{\bar{Z}} O^{\prime}$ & $\begin{array}{l}\frac{10}{4} \\
\frac{0}{0} \\
\frac{0}{z} \\
\stackrel{z}{z}\end{array}$ & $\begin{array}{l}3 \\
\tilde{H}^{\circ}\end{array}$ & $\begin{array}{l}\frac{y}{0} \\
: \frac{1}{5} \\
\dot{2}\end{array}$ \\
\hline 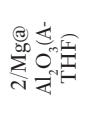 & $\begin{array}{l}\vec{z} \\
z \\
\tilde{u}\end{array}$ & 岁要 & $\begin{array}{l}0^{n} \\
\underbrace{n} \\
\dot{0} \\
2\end{array}$ & 产 & 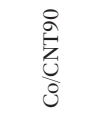 & 产 & 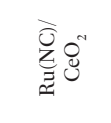 & 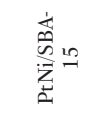 & $\tilde{E}_{0}^{\circ}$ & 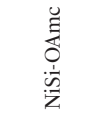 \\
\hline 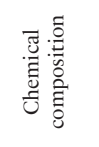 & $\begin{array}{l}\text { हों } \\
\frac{0}{0} \\
\frac{0}{2} \\
\frac{0}{2}\end{array}$ & 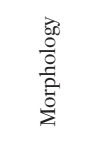 & 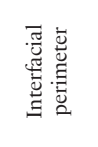 & $\sum_{\bar{n}}^{\bar{n}}$ & 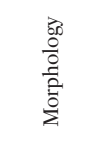 & 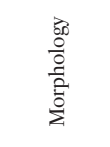 & 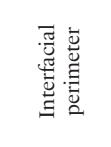 & 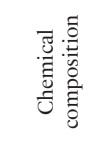 & 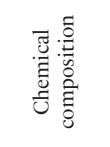 & 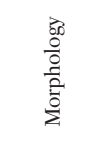 \\
\hline 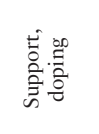 & 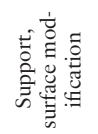 & 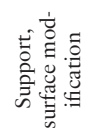 & 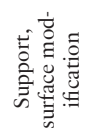 & 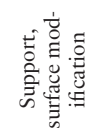 & 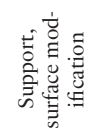 & 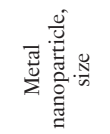 & 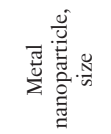 & 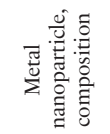 & 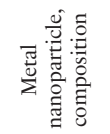 & 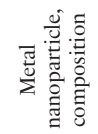 \\
\hline
\end{tabular}




\begin{tabular}{|c|c|c|c|c|c|c|c|c|c|c|}
\hline in & $\stackrel{2}{\beth}$ & $\stackrel{\mathbb{I}}{ }$ & $\widetilde{I}$ & $\stackrel{ \pm}{\beth}$ & $\mathbb{I}$ & $\vec{\Omega}$ & $\overrightarrow{\mathrm{n}}$ & $\stackrel{\infty}{\rightarrow}$ & $\stackrel{10}{\Omega}$ & $\stackrel{\vec{d}}{\rightarrow}$ \\
\hline \multirow[t]{4}{*}{$\stackrel{9}{-}$} & $\overrightarrow{\mathrm{i}}$ & $\stackrel{\circ}{\stackrel{\infty}{\sim}}$ & $\stackrel{3}{-}$ & $\stackrel{\infty}{\circ}$ & $\hat{o}$ & $\stackrel{\partial}{r}$ & $\stackrel{\stackrel{\mathcal{I}}{]}}{ }$ & $\stackrel{\text { In }}{\mathrm{i}}$ & $\stackrel{3}{-}$ & $\stackrel{\infty}{\infty}$ \\
\hline & $\begin{array}{l}\text { ¿ } \\
\text { L్ }\end{array}$ & & & $\stackrel{\circ}{\dot{q}}$ & . & & & $\underset{+}{\stackrel{+}{+}}$ & $\stackrel{?}{\stackrel{2}{1}}$ & \\
\hline & $\vec{a}$ & & & $\ddot{\ddot{d}}$ & . & & & $\underset{\infty}{\infty} \underset{\infty}{\infty}$ & $\begin{array}{l}\stackrel{0}{\infty} \\
\stackrel{\infty}{\infty}\end{array}$ & \\
\hline & $\frac{\partial^{\circ}}{n^{8}}$ & & & $\frac{\partial^{0}}{c^{3}}$ & . & & & $\frac{2^{\circ}}{n^{60}}$ & $\frac{\partial^{\circ}}{c^{b}}$ & \\
\hline$\stackrel{\infty}{-}$ & $\stackrel{9}{-}$ & ir & : & $\tilde{i}$ & $\begin{array}{l}\stackrel{0}{0} \\
\dot{B}\end{array}$ & $\stackrel{\dot{\infty}}{\infty}$ & $\stackrel{3}{0}$ & $\hat{b}$ & $\stackrel{\circ}{\rightarrow}$ & $\stackrel{3}{0}$ \\
\hline$\stackrel{+}{\dot{m}}$ & $\stackrel{\infty}{\infty}$ & $\stackrel{\circ}{\circ}$ & $\underset{\infty}{\stackrel{\leftrightarrow}{\infty}}$ & $\hat{i}$ & $\underset{\text { in }}{\stackrel{0}{i}}$ & $\ddot{\dot{b}}$ & $\hat{i}$ & 盷 & $\stackrel{\Im}{-}$ & $\stackrel{\circ}{\rightarrow}$ \\
\hline 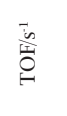 & 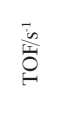 & $\frac{0^{\circ}}{x^{8}}$ & $\frac{0^{\circ}}{x^{8}}$ & 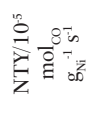 & 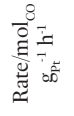 & $\frac{0^{\circ}}{x^{\circ}}$ & 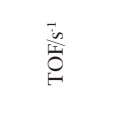 & 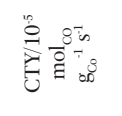 & 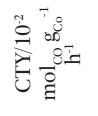 & 萿 \\
\hline 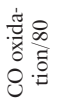 & 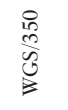 & 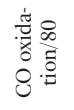 & 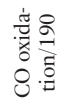 & 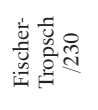 & 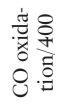 & 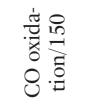 & 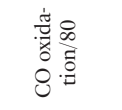 & 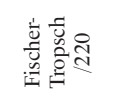 & 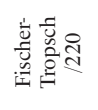 & 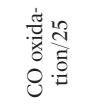 \\
\hline$\stackrel{\circ}{i}$ & $\begin{array}{l}\text { In } \\
\stackrel{I}{]}\end{array}$ & ir & $\stackrel{+}{i}$ & $\stackrel{\text { ¿ }}{\text { ते }}$ & $\stackrel{i}{i}$ & $\stackrel{\circ}{-}$ & $\stackrel{10}{\mathrm{i}}$ & $\stackrel{\circ}{\stackrel{\leftrightarrow}{\leftrightarrows}}$ & $\stackrel{\infty}{=}$ & $\stackrel{\infty}{\stackrel{\infty}{\rho}}$ \\
\hline 尊京 & 䨔 & 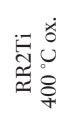 & 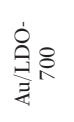 & 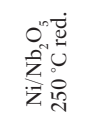 & 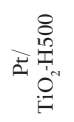 & 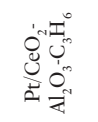 & 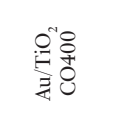 & $\stackrel{0}{\pi}^{\sim}$ & 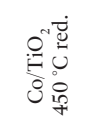 & 然" \\
\hline 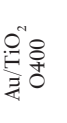 & 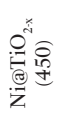 & 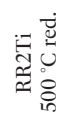 & 实 & 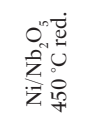 & 站 & 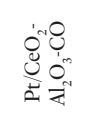 & 疍条 & 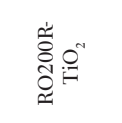 & 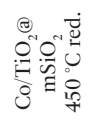 & $\stackrel{5}{3}^{\prime \prime}$ \\
\hline 总离 & $\sum_{\dot{n}}^{\bar{n}}$ & $\overrightarrow{\sum_{n}}$ & $\sum_{\infty}^{\bar{n}}$ & $\sum_{\dot{n}}^{\vec{n}}$ & $\sum_{n=}^{\bar{n}}$ & 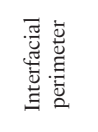 & 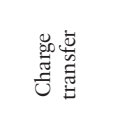 & $\sum_{\bar{n}}^{\bar{n}}$ & 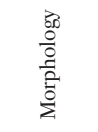 & 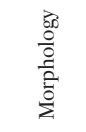 \\
\hline 氮吾 & 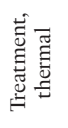 & 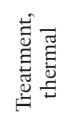 & 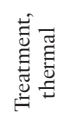 & 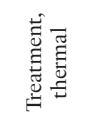 & 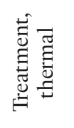 & 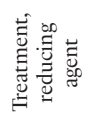 & 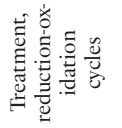 & 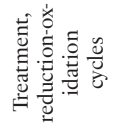 & 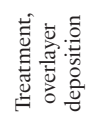 & 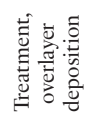 \\
\hline
\end{tabular}




\begin{tabular}{|c|c|c|c|c|c|c|c|}
\hline$\stackrel{\infty}{\stackrel{\sim}{\hookrightarrow}}$ & $\stackrel{g}{I}$ & 导 & $\stackrel{\overbrace{}}{\oplus}$ & ले & $\stackrel{I}{I}$ & $\stackrel{?}{q}$ & $\stackrel{\text { i }}{9}$ \\
\hline in & $\stackrel{\infty}{\mathrm{I}}$ & $\hat{n}$ & $\stackrel{+}{\dot{m}}$ & $\stackrel{m}{\stackrel{3}{\rho}}$ & $\underset{i}{\stackrel{0}{i}}$ & $\stackrel{\infty}{-}$ & ભี \\
\hline . & İ & $\stackrel{\infty}{a}$ & . & & & & $\stackrel{\circ}{ \pm}$ \\
\hline & $\underset{\infty}{\stackrel{\infty}{\infty}}$ & $\underset{\stackrel{+}{\infty}}{+}$ & & . & . & . & 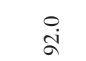 \\
\hline & $\frac{\partial^{\circ}}{\omega^{\prime \prime}}$ & 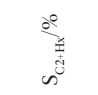 & & . & & ' & $\frac{\partial^{\circ}}{n^{\circ}}$ \\
\hline$\hat{o}$ & t) & $\stackrel{+}{\dot{m}}$ & กั & ir. & $\stackrel{m}{\circ}$ & $\begin{array}{l}\stackrel{0}{+} \\
\stackrel{+}{2}\end{array}$ & 암 \\
\hline$\dot{\sigma}$ & $\stackrel{\text { I }}{\rightarrow}$ & $\stackrel{\circ}{ \pm}$ & $\stackrel{\infty}{\circ}$ & $\stackrel{\dot{q}}{\dot{q}}$ & $\hat{0}$ & $\stackrel{0}{\dot{\infty}}$ & 엄 \\
\hline 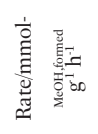 & 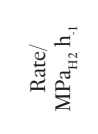 & $\begin{array}{l}i \\
i \\
0 \\
0 \\
0 \\
0\end{array}$ & 离 & $\frac{e^{\circ}}{x^{8}}$ & 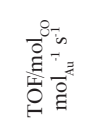 & $\frac{0^{\circ}}{x^{8}}$ & 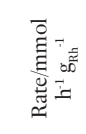 \\
\hline 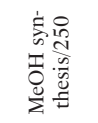 & 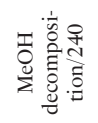 & 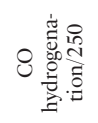 & 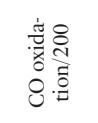 & 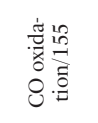 & 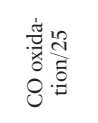 & 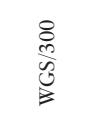 & 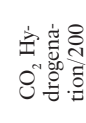 \\
\hline$\dot{\sim}$ & $\stackrel{\infty}{0}$ & $\hat{i}$ & & $\stackrel{\leftrightarrow}{i}$ & $\stackrel{\circ}{i}$ & $\begin{array}{l}\text { in } \\
\stackrel{\lambda}{2}\end{array}$ & $\stackrel{\circ}{i}$ \\
\hline $\begin{array}{l}0^{n} \\
\vdots \\
\tilde{J}\end{array}$ & 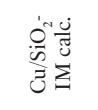 & $\frac{0^{N}}{\sum_{\infty}^{N}}$ & 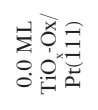 & $\begin{array}{l}0^{n} \\
2 \\
2\end{array}$ & 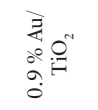 & 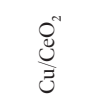 & $\overbrace{\overparen{a}}^{N}$ \\
\hline$\dot{J}^{\circ} \tilde{\sigma}^{\prime}$ & 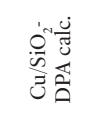 & 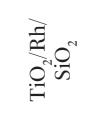 & 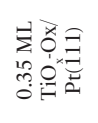 & 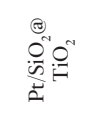 & 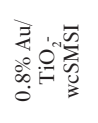 & 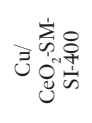 & 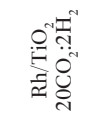 \\
\hline 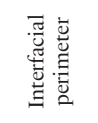 & 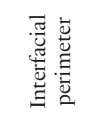 & $\sum_{\bar{n}}^{\bar{n}}$ & $\sum_{\bar{n}}^{\bar{n}}$ & $\sum_{\infty}^{\frac{5}{n}}$ & $\sum_{n}^{5}$ & $\sum_{n}^{5}$ & $\sum_{\bar{n}}^{\bar{n}}$ \\
\hline 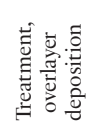 & 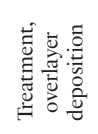 & 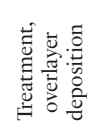 & 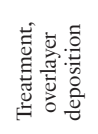 & 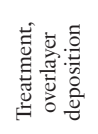 & 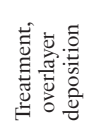 & 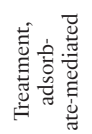 & 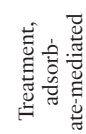 \\
\hline
\end{tabular}





\section{Appendix B}

\section{Supporting Information Chapter 3}

Crystalline Niobia with Tailored Porosity as Support for Cobalt Catalysts for the Fischer-Tropsch Synthesis
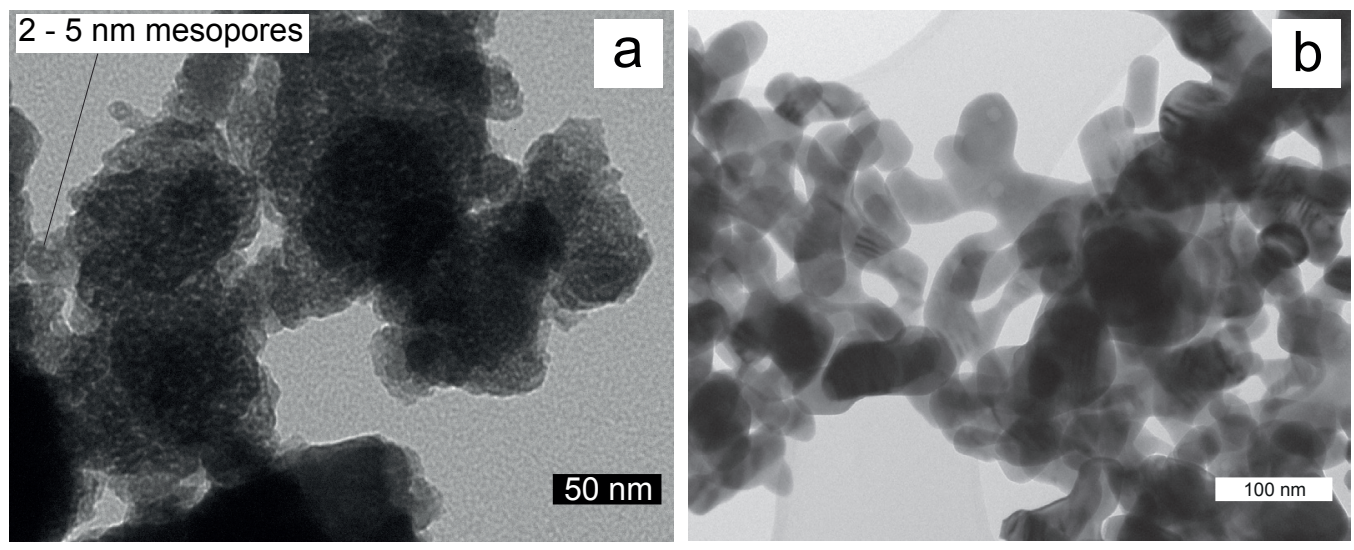

Figure B1 Bright field TEM images for niobium oxide hydrate calcined at $120{ }^{\circ} \mathrm{C}(\mathbf{a})$ and calcined at $600{ }^{\circ} \mathrm{C}(\mathbf{b})$. Reproduced from den Otter, J. H. Niobia-supported Cobalt Catalysts for Fischer-Tropsch Synthesis. (Utrecht University, 2016).

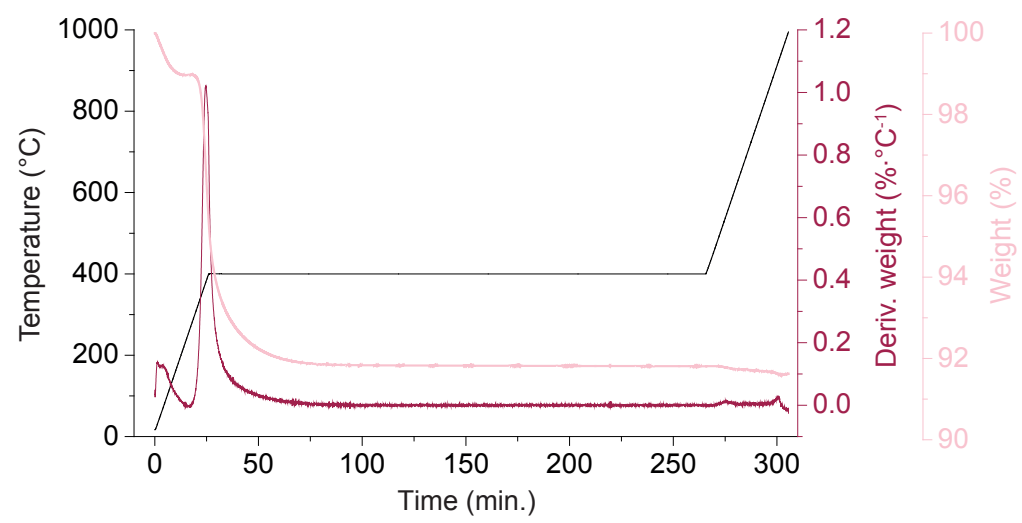

Figure B2 Thermogravimetric analysis (TGA) for the carbon deposited on niobia in air flow. 
Table B1 Catalytic results for the Fischer-Tropsch reaction at $20 \mathrm{bar}, 220{ }^{\circ} \mathrm{C}$ and $\mathrm{H}_{2} / \mathrm{CO}=2, \mathrm{GHSV}=4500 \mathrm{~h}^{-1}$, TOS $=100 \mathrm{~h}$.

\begin{tabular}{|c|c|c|c|c|c|c|c|c|c|}
\hline \multirow[b]{2}{*}{ Support } & \multirow[b]{2}{*}{$\begin{array}{c}\text { Cobalt } \\
\text { loading } \\
\text { (wt.\%) }\end{array}$} & \multicolumn{3}{|c|}{ Catalytic Activity } & \multicolumn{3}{|c|}{ Selectivity (wt.\%) } & \multicolumn{2}{|c|}{ Olefin/Parffin } \\
\hline & & $\begin{array}{c}\mathrm{CO} \\
\text { conversion } \\
(\%) \\
\end{array}$ & $\begin{array}{c}\text { Weight- } \\
\text { Time-Yield } \\
\left(10^{-6} \mathrm{~mol}_{\mathrm{CO}} \mathrm{g}_{\text {Cat. }}{ }^{-1} \mathrm{~s}^{-1}\right.\end{array}$ & $\begin{array}{c}\text { Cobalt- } \\
\text { Time-Yield } \\
\left(10^{-5} \mathbf{m o l}_{\left.\mathrm{Co}_{\mathrm{Co}} \mathrm{g}_{\mathrm{Co}}^{-1} \mathbf{s}^{-1}\right)}\right.\end{array}$ & $\mathrm{C}_{1}$ & $\mathrm{C}_{2-4}$ & $\mathbf{C}_{5^{+}}$ & $\begin{array}{c}\mathrm{C}_{3} \mathbf{H}_{6} / \\
\mathrm{C}_{3} \mathbf{H}_{8}\end{array}$ & $\begin{array}{l}\mathrm{C}_{4} \mathbf{H}_{8} / \\
\mathrm{C}_{4} \mathbf{H}_{10}\end{array}$ \\
\hline \multicolumn{10}{|l|}{ Crystalline } \\
\hline \multirow[t]{2}{*}{$\begin{array}{c}\mathrm{Nb}_{2} \mathrm{O}_{5} \\
\left(\text { calc. } 600^{\circ} \mathrm{C} \text { ) }\right.\end{array}$} & 6 & 19 & 2.7 & 4.5 & 12 & 8 & 80 & 1.5 & 0.91 \\
\hline & 6 & 18 & 2.8 & 4.2 & 12 & 8 & 80 & 1.4 & 0.94 \\
\hline \multicolumn{10}{|l|}{$\mathrm{Nb}_{2} \mathrm{O}_{5}-\mathrm{MC}$} \\
\hline & 10 & 25 & 4.0 & 3.7 & 11 & 8 & 81 & 1.8 & 1.0 \\
\hline
\end{tabular}




\section{Appendix C}

\section{Supporting Information Chapter 4}

Activity Enhancement of Cobalt Catalysts by Tuning Metal-Support Interactions

Table C1 Cobalt loading of $\mathrm{Co} / \mathrm{TiO}_{2}, \mathrm{Co} / \mathrm{Nb}_{2} \mathrm{O}_{5}$ and $\mathrm{Co} / \alpha-\mathrm{Al}_{2} \mathrm{O}_{3}$, as determined by inductively coupled plasma-optical emission spectroscopy (ICP-OES).

\begin{tabular}{cc}
\hline Sample & $\begin{array}{c}\text { Cobalt loading } \\
\text { (wt.\%) }\end{array}$ \\
\hline $\mathrm{Co} / \mathrm{TiO}_{2}$ & 6.8 \\
$\mathrm{Co} / \mathrm{Nb}_{2} \mathrm{O}_{5}$ & 5.7 \\
$\mathrm{Co} / \mathrm{Al}_{2} \mathrm{O}_{3}$ & 6.0 \\
\hline
\end{tabular}
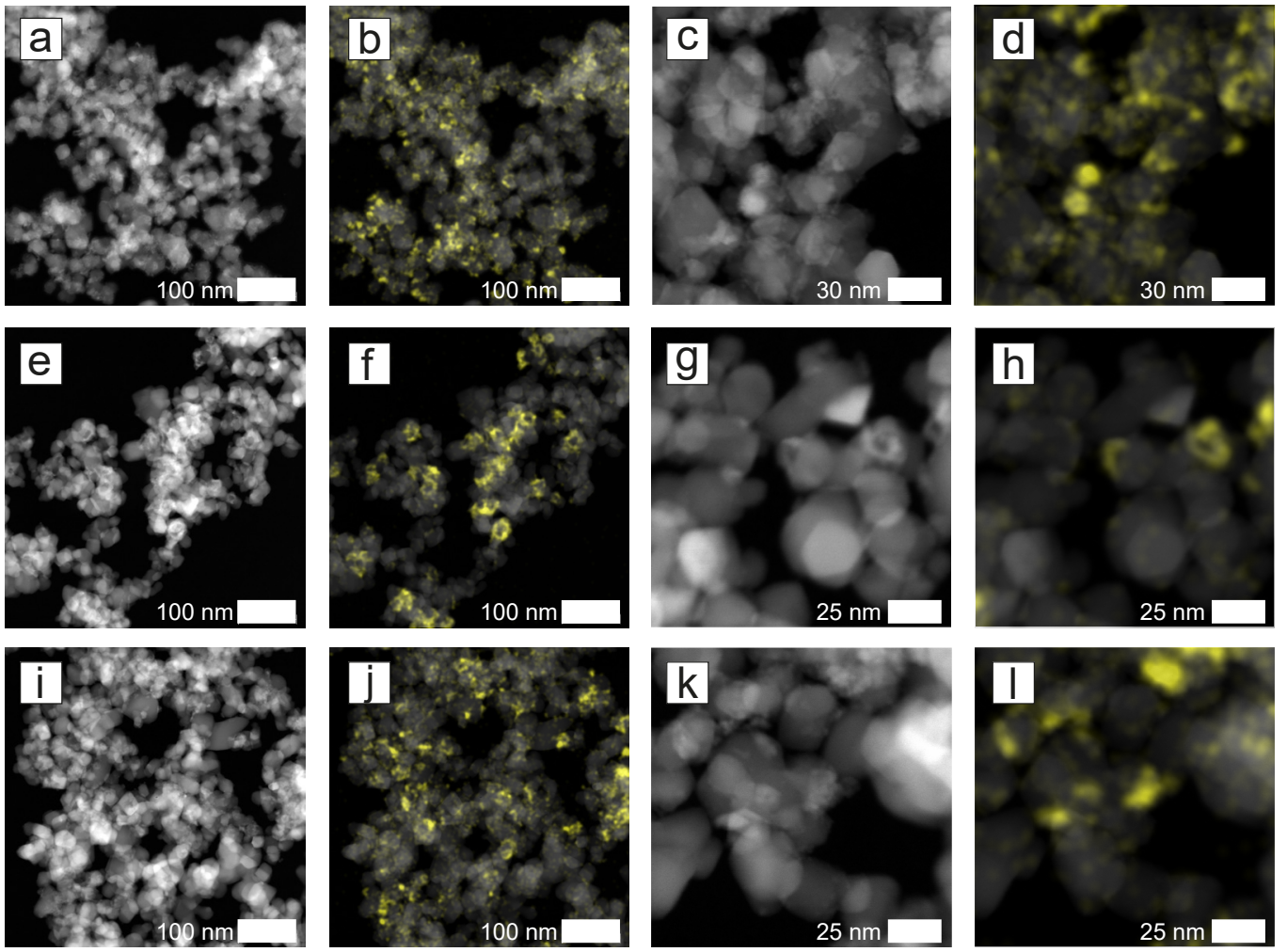

Figure $\mathbf{C 1}$ Additional electron microscopy images of the $\mathrm{TiO}_{2}$-supported samples upon reduction-oxidation-reduction treatments. STEM-HAADF combined with EDX mapping of $\mathrm{Co} / \mathrm{TiO}_{2}$ at various stages of the ROR treatment. Co is depicted in yellow. $\mathbf{a}, \mathbf{b}, \mathbf{c}, \mathbf{d}$, Samples after reduction at $350{ }^{\circ} \mathrm{C}$ and passivation $\left(\mathrm{R}^{-T i O}{ }_{2}\right) ; \mathbf{e}, \mathbf{f}, \mathbf{g}, \mathbf{h}$, samples after reduction at $350{ }^{\circ} \mathrm{C}$ and oxidation at $200{ }^{\circ} \mathrm{C}\left(\mathrm{RO} 200-\mathrm{TiO}_{2}\right) ; \mathbf{i}, \mathbf{j}, \mathbf{k}, \mathbf{1}$, samples after reduction at $350{ }^{\circ} \mathrm{C}$, oxidation at $200{ }^{\circ} \mathrm{C}$ and reduction at $220{ }^{\circ} \mathrm{C}\left(\mathrm{RO} 200 \mathrm{R}-\mathrm{TiO}_{2}\right)$ and passivation. 

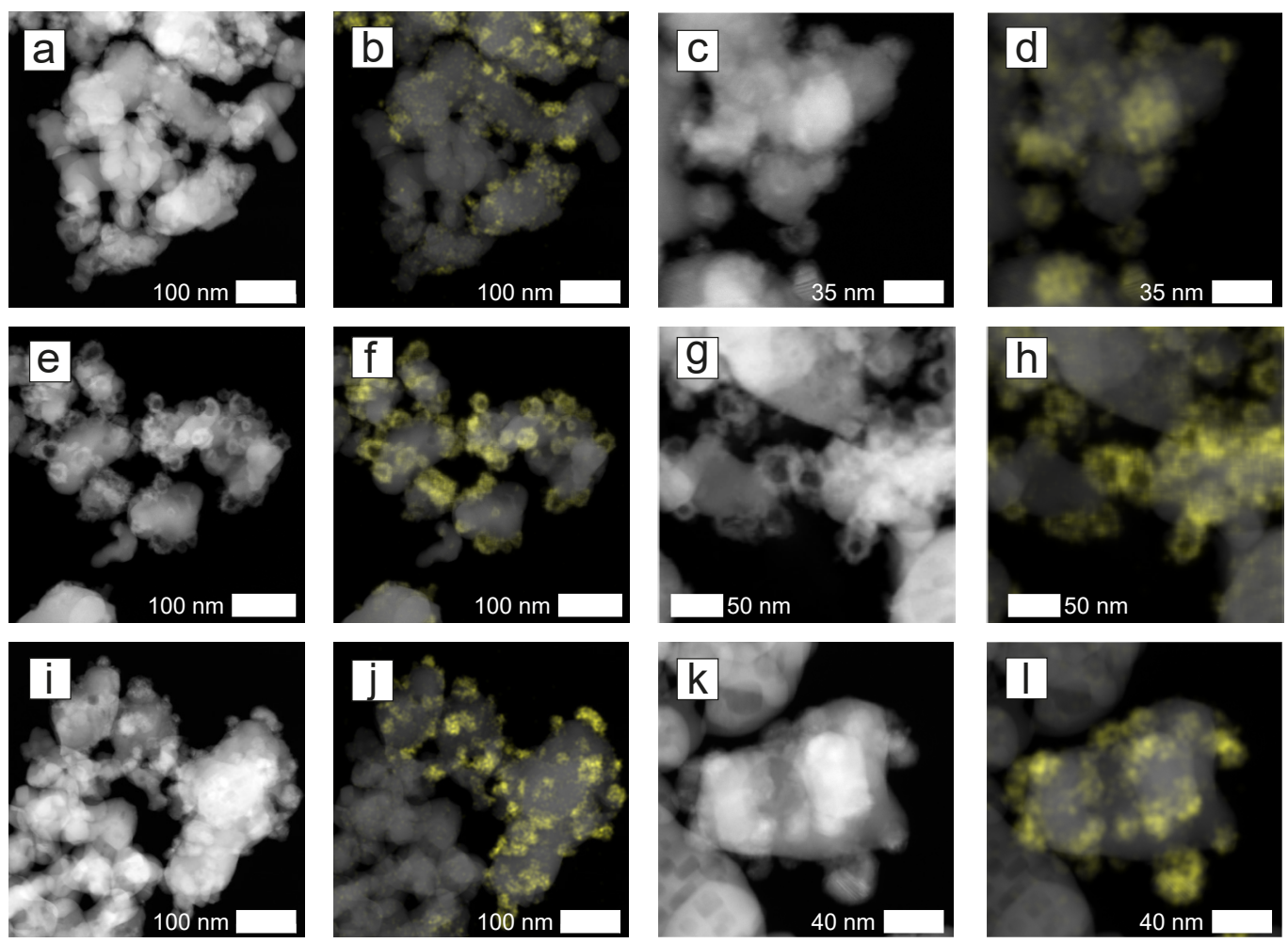

Figure C2 Additional electron microscopy images of the $\mathrm{Nb}_{2} \mathrm{O}_{5}$-supported samples upon reduction-oxidation-reduction treatments. STEM-HAADF combined with EDX mapping of $\mathrm{Co} / \mathrm{Nb}_{2} \mathrm{O}_{5}$ at various stages of the ROR treatment. Co is depicted in yellow. $\mathbf{a}, \mathbf{b}, \mathbf{c}, \mathbf{d}$, Samples after reduction at $350{ }^{\circ} \mathrm{C}$ and passivation $\left(\mathrm{R}-\mathrm{Nb}_{2} \mathrm{O}_{5}\right) ; \mathbf{e}, \mathbf{f}, \mathbf{g}$, $\mathbf{h}$, samples after reduction at $350{ }^{\circ} \mathrm{C}$ and oxidation at $200{ }^{\circ} \mathrm{C}\left(\mathrm{RO} 200-\mathrm{Nb}_{2} \mathrm{O}_{5}\right) ; \mathbf{i}, \mathbf{j}, \mathbf{k}, \mathbf{1}$, samples after reduction at $350{ }^{\circ} \mathrm{C}$, oxidation at $200{ }^{\circ} \mathrm{C}$ and reduction at $220{ }^{\circ} \mathrm{C}\left(\mathrm{RO} 200 \mathrm{R}-\mathrm{Nb}_{2} \mathrm{O}_{5}\right)$ and passivation. 

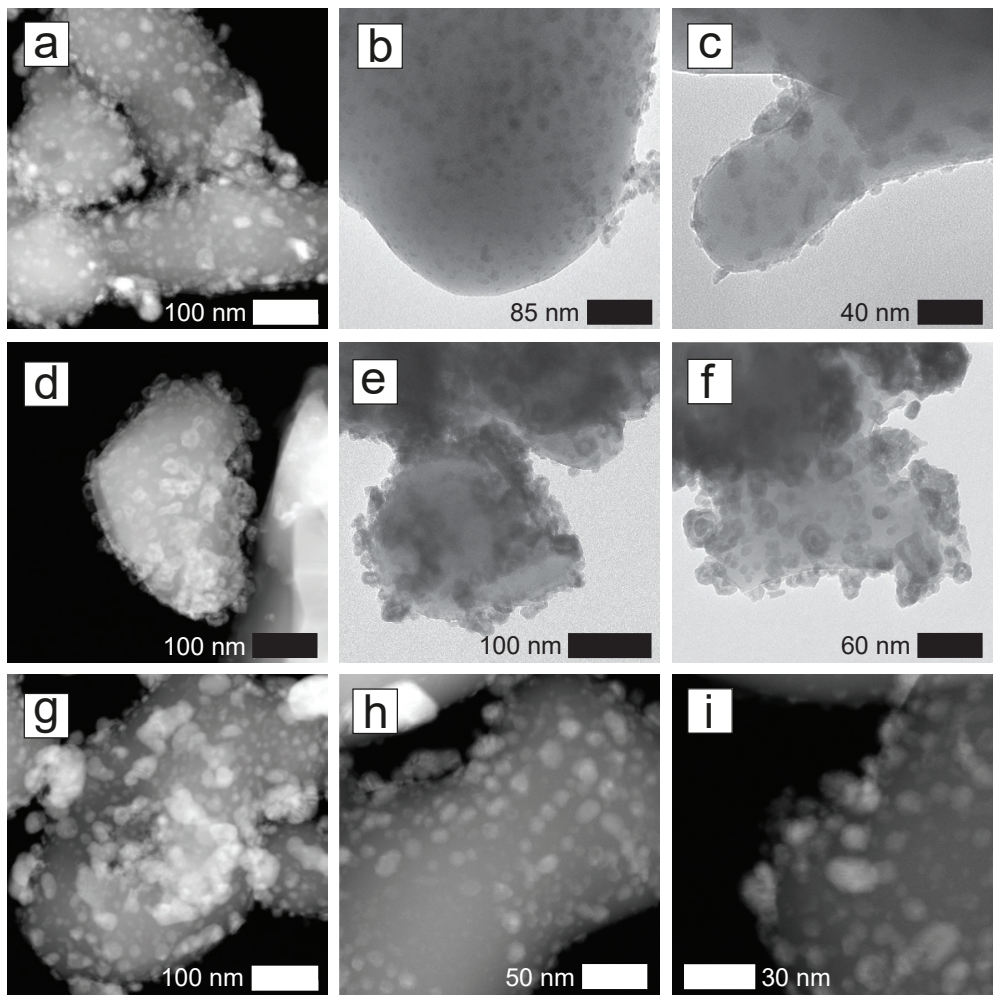

Figure C3 Additional electron microscopy images of the $\mathrm{Al}_{2} \mathrm{O}_{3}$-supported samples upon reduction-oxidation-reduction treatments. a, d, $\mathbf{g}, \mathbf{h}, \mathbf{i}$, STEM-HAADF and $\mathbf{b}, \mathbf{c}, \mathbf{e}, \mathbf{f}$, bright-field TEM of $\mathrm{Co} / \mathrm{Al}_{2} \mathrm{O}_{3}$ at various stages of the ROR treatment. $\mathbf{a}, \mathbf{b}, \mathbf{c}$, Samples after reduction at $350{ }^{\circ} \mathrm{C}$ and passivation $\left(\mathrm{R}-\mathrm{Al}_{2} \mathrm{O}_{3}\right) ; \mathbf{d}, \mathbf{e}, \mathbf{f}$, samples after reduction at $350{ }^{\circ} \mathrm{C}$ and oxidation at $200{ }^{\circ} \mathrm{C}\left(\mathrm{RO}_{200}-\mathrm{Al}_{2} \mathrm{O}_{3}\right) ; \mathbf{g}, \mathbf{h}, \mathbf{i}$, samples after reduction at $350{ }^{\circ} \mathrm{C}$, oxidation at $200{ }^{\circ} \mathrm{C}$ and reduction at $220{ }^{\circ} \mathrm{C}\left(\mathrm{RO} 200 \mathrm{R}-\mathrm{Al}_{2} \mathrm{O}_{3}\right)$ and passivation. 


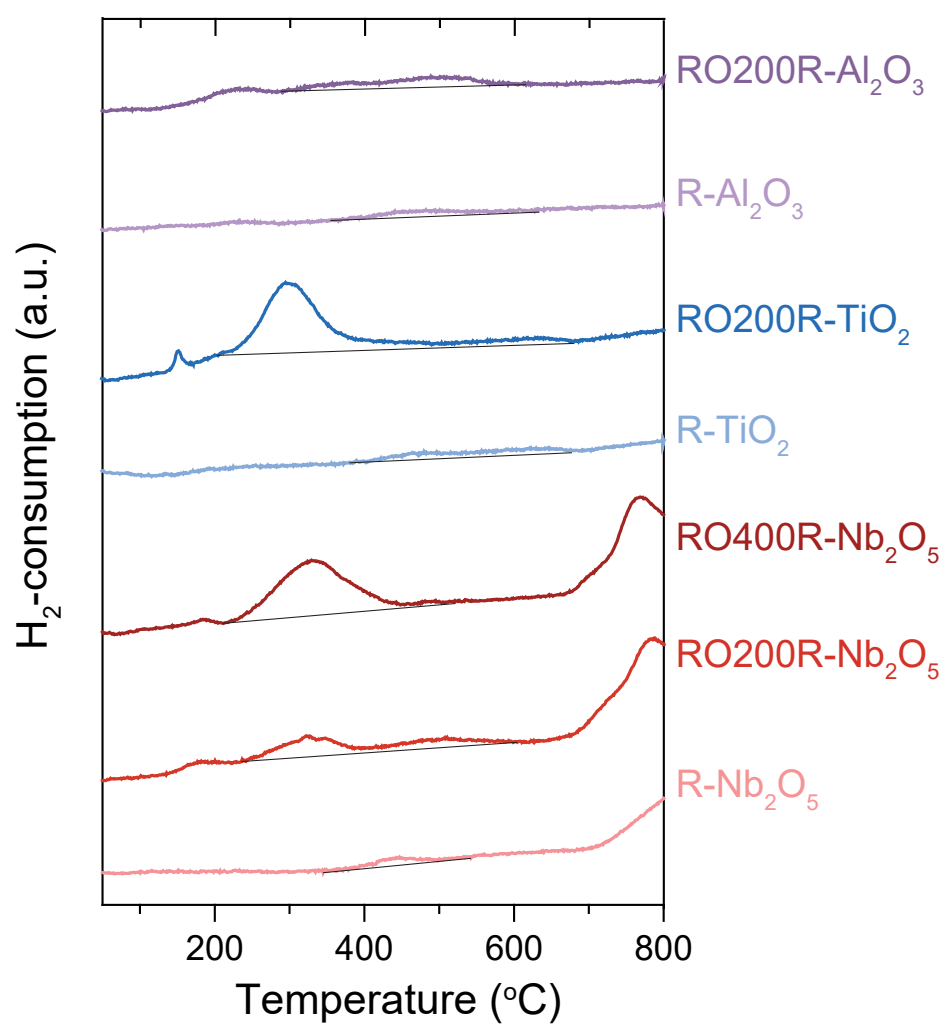

Figure C4 TPR profiles used to determine the degree of reduction of cobalt. The baseline is shown for the peaks that were integrated as cobalt that had not been reduced and thus lowered the degree of reduction. The degree of reduction was determined after reduction at $350^{\circ} \mathrm{C}$ (R-samples), after reduction at $350{ }^{\circ} \mathrm{C}$, oxidation at $200{ }^{\circ} \mathrm{C}$ and reduction at $220^{\circ} \mathrm{C}\left(\right.$ RO200R-samples) and after reduction at $350{ }^{\circ} \mathrm{C}$, oxidation at $400{ }^{\circ} \mathrm{C}$ and reduction at $220^{\circ} \mathrm{C}$ (RO400R- $-\mathrm{Nb}_{2} \mathrm{O}_{5}$ ). 
Table C2 The degree of cobalt reduction (DOR) at various stages of the ROR treatment, as measured by TPR. The degree of reduction was determined after reduction at $350{ }^{\circ} \mathrm{C}$ (R-samples), after reduction at $350{ }^{\circ} \mathrm{C}$, oxidation at $200{ }^{\circ} \mathrm{C}$ and reduction at $220^{\circ} \mathrm{C}$ (RO200R-samples) and after reduction at $350{ }^{\circ} \mathrm{C}$, oxidation at $400{ }^{\circ} \mathrm{C}$ and reduction at $220^{\circ} \mathrm{C}\left(\mathrm{RO} 400 \mathrm{R}-\mathrm{Nb}_{2} \mathrm{O}_{5}\right)$.

\begin{tabular}{cccc}
\hline Sample & \multicolumn{3}{c}{ DOR $(\%)$} \\
\cline { 2 - 4 } & $\mathbf{R}$ & RO200R & RO400R \\
\hline $\mathrm{Co} / \mathrm{TiO}_{2}$ & 97 & 86 & n.d. \\
$\mathrm{Co} / \mathrm{Nb}_{2} \mathrm{O}_{5}$ & 98 & 93 & 84 \\
$\mathrm{Co} / \mathrm{Al}_{2} \mathrm{O}_{3}$ & 98 & 95 & n.d. \\
\hline
\end{tabular}

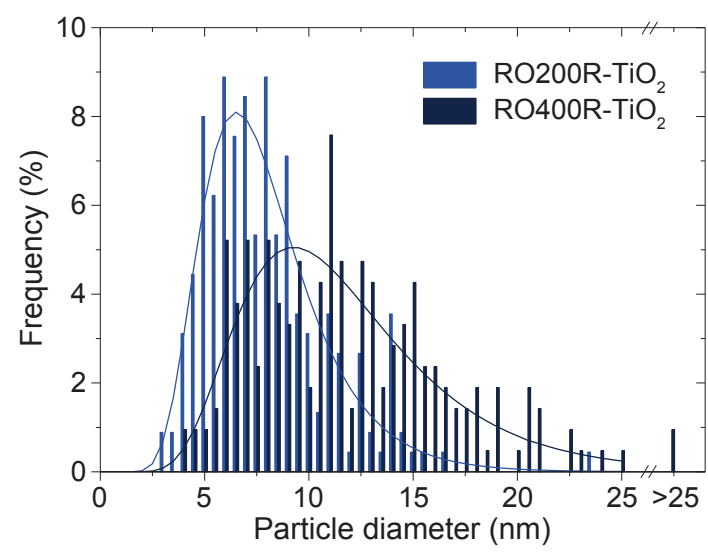

Figure C5 Particle growth at higher oxidation temperature. Histogram of particle sizes of $\mathrm{RO}^{200 \mathrm{R}-\mathrm{TiO}} \mathrm{O}_{2}$ and RO400R-TiO ${ }_{2}$. The samples were reduced under hydrogen flow at $220{ }^{\circ} \mathrm{C}$ and then exposed to air at room temperature. Afterwards, the samples were analyzed by STEM-EDX mapping. 
a

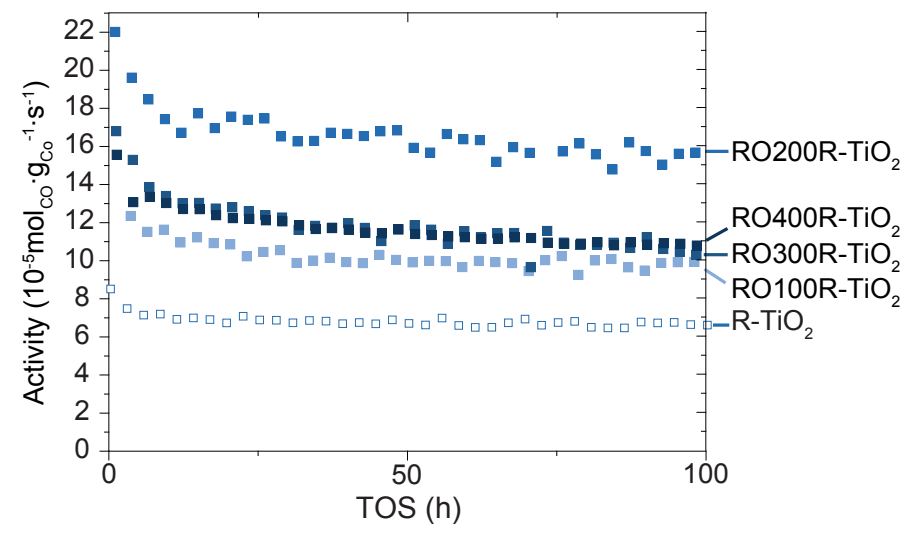

b

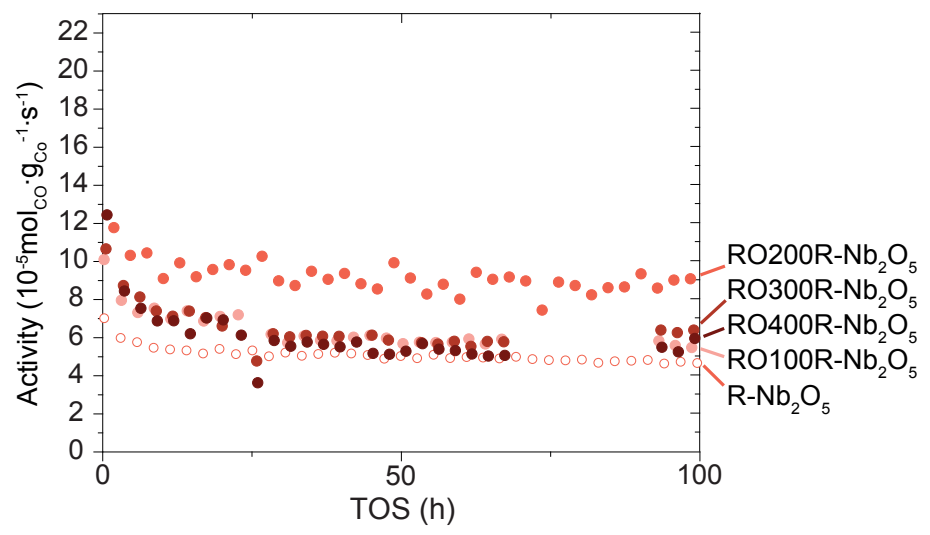

C

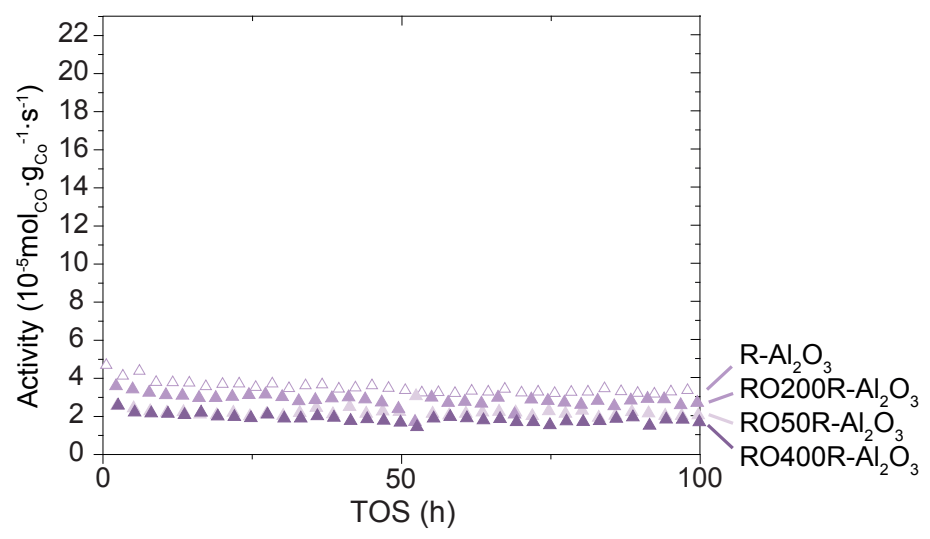

Figure C6 Cobalt-weight-based activity over time-on-stream. Cobalt-weight-based catalytic activity of $\mathrm{Co} / \mathrm{TiO}{ }_{2}(\mathbf{a})$, $\mathrm{Co} / \mathrm{Nb}_{2} \mathrm{O}_{5}$ (b) and $\mathrm{Co} / \mathrm{Al}_{2} \mathrm{O}_{3}$ (c) after various reduction-oxidation-reduction treatments plotted against time-onstream. Reaction conditions: 20 bar, $220{ }^{\circ} \mathrm{C}, \mathrm{H}_{2} / \mathrm{CO}=2 \mathrm{~V} / \mathrm{V}, \mathrm{GHSV}=1000-13000 \mathrm{~h}^{-1}$ and $\mathrm{CO}$ conversion $=15-34 \%$ $\left(\mathrm{TiO}_{2}\right), 17-25 \%\left(\mathrm{Nb}_{2} \mathrm{O}_{5}\right), 8-12 \%\left(\mathrm{Al}_{2} \mathrm{O}_{3}\right)$. 
Table C3 Summary of the catalytic performance. Reaction conditions: 20 bar, $220{ }^{\circ} \mathrm{C}$ and $\mathrm{H}_{2} / \mathrm{CO}=2 \mathrm{~V} / \mathrm{V}$. The reported data was averaged over three data points between 90-100 $\mathrm{h}$ on stream.

\begin{tabular}{|c|c|c|c|c|c|c|c|}
\hline \multirow[t]{2}{*}{ Sample } & \multirow{2}{*}{$\begin{array}{c}\text { GHSV } \\
\left(\mathbf{h}^{-1}\right) \\
\end{array}$} & \multirow{2}{*}{$\begin{array}{c}\text { CO conv. } \\
(\%)\end{array}$} & \multirow{2}{*}{$\begin{array}{l}\text { Cobalt-Time- } \\
\text { Yield } \\
\left(10^{-5} \mathrm{~mol}_{\mathrm{Co}} \cdot \mathrm{g}_{\mathrm{Co}}^{-1} \cdot \mathbf{s}^{-1}\right)\end{array}$} & \multirow{2}{*}{$\begin{array}{l}\text { TOF } \\
(s-1) \\
\end{array}$} & \multicolumn{3}{|c|}{ Selectivity (\%) } \\
\hline & & & & & $\mathrm{C}_{1}$ & $\mathrm{C}_{2-4}$ & $\mathrm{C}_{5_{+}}$ \\
\hline \multicolumn{8}{|c|}{$\mathrm{TiO}_{2}$} \\
\hline $\mathrm{R}^{-\mathrm{TiO}_{2}}$ & 5560 & 20.6 & 6.7 & 0.10 & 8.5 & 7.5 & 84.0 \\
\hline RO100R-TiO & 8290 & 18.2 & 9.8 & 0.11 & 7.0 & 5.0 & 88.0 \\
\hline $\mathrm{RO}_{200 \mathrm{R}-\mathrm{TiO}_{2}}$ & 13540 & 19.3 & 15.7 & 0.10 & 7.5 & 4.5 & 88.0 \\
\hline $\mathrm{RO}_{300 \mathrm{R}-\mathrm{TiO}_{2}}$ & 13540 & 15.1 & 10.5 & 0.074 & 8.8 & 5.4 & 85.8 \\
\hline RO400R-TiO & 5640 & 34.0 & 10.8 & 0.11 & 6.8 & 4.7 & 88.5 \\
\hline \multicolumn{8}{|c|}{$\mathrm{Nb}_{2} \mathrm{O}_{5}$} \\
\hline $\mathrm{R}-\mathrm{Nb}_{2} \mathrm{O}_{5}$ & 3266 & 17.0 & 4.7 & 0.087 & 8.6 & 6.1 & 85.3 \\
\hline RO100R- $\mathrm{Nb}_{2} \mathrm{O}_{5}$ & 3024 & 19.6 & 5.6 & 0.051 & 7.8 & 3.9 & 88.3 \\
\hline $\mathrm{RO} 200 \mathrm{R}-\mathrm{Nb}_{2} \mathrm{O}_{5}$ & 3874 & 24.6 & 8.9 & 0.068 & 6.7 & 4.2 & 89.1 \\
\hline $\mathrm{RO} 300 \mathrm{R}-\mathrm{Nb}_{2} \mathrm{O}_{5}$ & 3070 & 25.5 & 6.2 & 0.058 & 8.5 & 3.6 & 87.9 \\
\hline $\mathrm{RO} 400 \mathrm{R}-\mathrm{Nb}_{2} \mathrm{O}_{5}$ & 2954 & 19.3 & 5.5 & 0.077 & 11.4 & 4.6 & 85.0 \\
\hline \multicolumn{8}{|c|}{$\mathrm{Al}_{2} \mathrm{O}_{3}$} \\
\hline $\mathrm{R}^{-\mathrm{Al}_{2} \mathrm{O}_{3}}$ & 1249 & 12.5 & 3.3 & 0.025 & 10.9 & 14.2 & 85.8 \\
\hline RO50R-Al ${ }_{2} \mathrm{O}_{3}$ & 940 & 9.62 & 2.0 & 0.031 & 5.8 & 4.4 & 89.8 \\
\hline $\mathrm{RO} 200 \mathrm{R}-\mathrm{Al}_{2} \mathrm{O}_{3}$ & 952 & 8.98 & 2.8 & 0.035 & 6.2 & 4.1 & 89.7 \\
\hline $\mathrm{RO} 400 \mathrm{R}-\mathrm{Al}_{2} \mathrm{O}_{3}$ & 956 & 8.17 & 1.7 & 0.029 & 7.6 & 6.0 & 86.4 \\
\hline
\end{tabular}


a

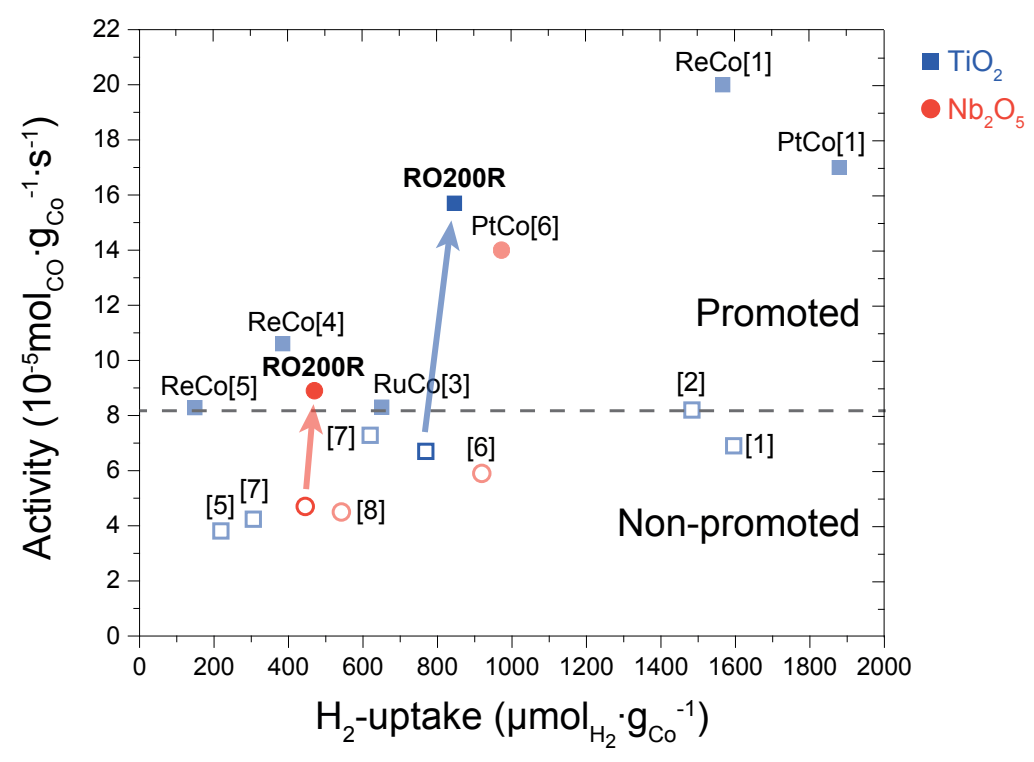

b

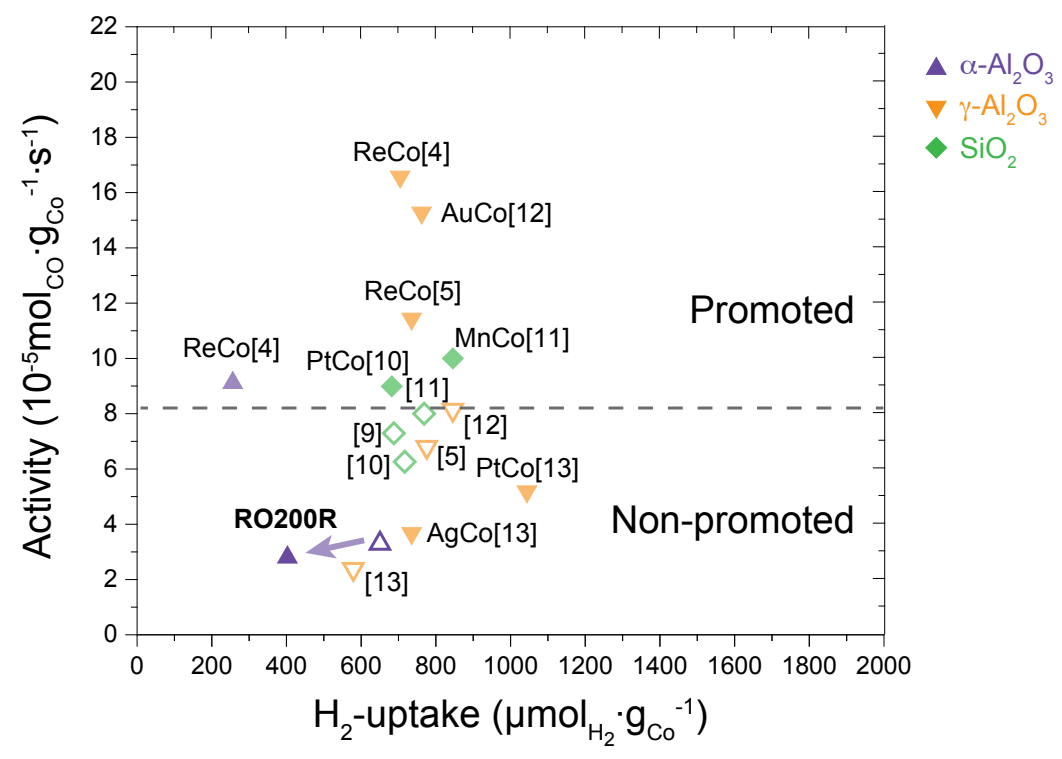

Figure C7 Literature overview of cobalt-weight-based activities as a function of $\mathrm{H}_{2}$-uptake. Values obtained from literature were divided into two plots: a shows cobalt-based catalysts supported on reducible oxides $\left(\mathrm{TiO}_{2}\right.$ and $\left.\mathrm{Nb}_{2} \mathrm{O}_{5}\right)$ and $\mathbf{b}$ shows cobalt-based catalysts supported on irreducible oxides $\left(\alpha-\mathrm{Al}_{2} \mathrm{O}_{3}, \gamma-\mathrm{Al}_{2} \mathrm{O}_{3}\right.$ and $\left.\mathrm{SiO}_{2}\right)$. Open symbols refer to non-promoted, pristine cobalt catalysts and solid symbols to cobalt catalysts with enhanced activity either via noble metal/Mn promotion or via an ROR treatment (this work). $\mathrm{H}_{2}$-uptake values were calculated based on the reported particle sizes from either $\mathrm{H}_{2}$-chemisorption (refs. 7,13), TEM or XRD. Activity values were recalculated to match the units reported here. FT was performed at 20 bar and $\mathrm{H}_{2} / \mathrm{CO}=2 \mathrm{~V} / \mathrm{V}$ in all cases, except ref. 9 where $\mathrm{H}_{2} / \mathrm{CO}=1 \mathrm{~V} / \mathrm{V}$. When the catalytic performance was reported at a temperature different than $220{ }^{\circ} \mathrm{C}$, the activity was recalculated to that at $220^{\circ} \mathrm{C}$ using the Arrhenius equation with an apparent activation energy of $100 \mathrm{~kJ} \cdot \mathrm{mol}^{-1}$. 
Table C4 Lewis acidity of various metal oxides. Data obtained from ref 14.

\begin{tabular}{ccc}
\hline $\begin{array}{c}\text { Formal oxidation state } \\
\text { of the cation } \\
(\mathbf{N m})\end{array}$ & $\begin{array}{c}\text { Formula of the corre- } \\
\text { sponding metal oxide }\end{array}$ & $\begin{array}{c}\text { Lewis acid character } \\
\left(\mathbf{N}_{\mathbf{M}}-\mathbf{2} \delta_{\mathbf{M}}\right)^{\mathbf{a}}\end{array}$ \\
\hline $5+$ & $\mathrm{Nb}_{2} \mathrm{O}_{5}$ & 3.895 \\
$4+$ & $\mathrm{TiO}_{2}$ & 3.046 \\
$\mathrm{NbO}_{2}$ & 2.877 \\
\multirow{2}{*}{$3+$} & $\mathrm{Ti}_{2} \mathrm{O}_{3}$ & 1.930 \\
& $\mathrm{Nb}_{2} \mathrm{O}_{3}$ & 1.883 \\
& $\mathrm{Al}_{2} \mathrm{O}_{3}$ & 2.274 \\
\hline
\end{tabular}

a. $\delta \mathrm{M}$ corresponds to the Sanderson's partial charge of the cation.

\section{References}

1. Eschemann, T. O., Oenema, J. \& de Jong, K. P. Effects of noble metal promotion for $\mathrm{Co} / \mathrm{TiO}_{2}$ Fischer-Tropsch catalysts. Catal. Today 261, 60-66 (2016).

2. Eschemann, T. O. \& de Jong, K. P. Deactivation Behavior of $\mathrm{Co} / \mathrm{TiO}_{2}$ Catalysts during Fischer-Tropsch Synthesis. ACS Catal. 5, 3181-3188 (2015).

3. Prieto, G. et al. Cobalt-catalyzed Fischer-Tropsch synthesis: Chemical nature of the oxide support as a performance descriptor. ACS Catal. 5, 3323-3335 (2015).

4. Lögdberg, S. et al. Effect of water on the space-time yield of different supported cobalt catalysts during Fischer-Tropsch synthesis. Appl. Catal. A Gen.393, 109-121 (2011).

5. Storsæter, S., Borg, Ø., Blekkan, E. A. \& Holmen, A. Study of the effect of water on Fischer-Tropsch synthesis over supported cobalt catalysts. J. Catal. 231, 405-419 (2005).

6. den Otter, J. H., Yoshida, H., Ledesma, C., Chen, D. \& De Jong, K. P. On the superior activity and selectivity of $\mathrm{PtCo} / \mathrm{Nb}_{2} \mathrm{O}_{5}$ Fischer Tropsch catalysts. J. Catal. 340, 270-275 (2016).

7. Iglesia, E. Design, synthesis, and use of cobalt-based Fischer-Tropsch synthesis catalysts. Appl. Catal. A Gen. 161, 59-78 (1997).

8. Hernández Mejía, C., den Otter, J. H., Weber, J. L. \& de Jong, K. P. Crystalline niobia with tailored porosity as support for cobalt catalysts for the Fischer-Tropsch synthesis. Appl. Catal.A Gen. 548, 143-149 (2017).

9. Sun, X. et al. Manufacture of highly loaded silica-supported cobalt Fischer-Tropsch catalysts from a metal organic framework. Nat. Commun. 8, 1680 (2017).

10. Cheng, K. et al. The role of carbon pre-coating for the synthesis of highly efficient cobalt catalysts for FischerTropsch synthesis. J. Catal. 337, 260-271 (2016).

11. Johnson, G. R., Werner, S. \& Bell, A. T. An Investigation into the Effects of Mn Promotion on the Activity and Selectivity of $\mathrm{Co} / \mathrm{SiO}_{2}$ for Fischer-Tropsch Synthesis: Evidence for Enhanced CO Adsorption and Dissociation. ACS Catal. 5, 5888-5903 (2015).

12. Nabaho, D., Niemantsverdriet, J. W., Claeys, M. \& Steen, E. van. Hydrogen spillover in the Fischer-Tropsch synthesis: An analysis of gold as a promoter for cobalt-alumina catalysts. Catal. Today 275, 27-34 (2016).

13. Jermwongratanachai, T. et al. Fischer-Tropsch synthesis: Comparisons between $\mathrm{Pt}$ and $\mathrm{Ag}$ promoted $\mathrm{Co} / \mathrm{Al}_{2} \mathrm{O}_{3}$ catalysts for reducibility, local atomic structure, catalytic activity, and oxidation-reduction (OR) cycles. Appl. Catal. A Gen. 464-465, 165-180 (2013).

14. Jeong, N. C., Lee, J. S., Tae, E. L., Lee, Y. J. \& Yoon, K. B. Acidity Scale for Metal Oxides and Sanderson's Electronegativities of Lanthanide Elements. Angew. Chemie Int. Ed. 47, 10128-10132 (2008). 



\section{Appendix D}

\section{Supporting Information Chapter 5}

Cobalt-Nickel Nanoparticles Supported on Reducible Oxides as Fischer-Tropsch Catalysts

Table D1 Co and Ni weight loadings for the different samples supported on niobia, titania and alpha-alumina and the corresponding $\mathrm{H}_{2}$-uptake derived from the temperature programmed reduction (TPR) analyses. The last column shows the molar ratio of hydrogen consumend by the total metal content.

\begin{tabular}{|c|c|c|c|c|c|}
\hline \multirow[t]{2}{*}{ Support } & \multirow{2}{*}{$\begin{array}{c}\mathbf{N i} /(\mathbf{N i}+\mathbf{C o}) \\
(\mathbf{a t} / \mathbf{a t}) \\
\end{array}$} & \multicolumn{2}{|c|}{$\begin{array}{l}\text { Metal loading } \\
\text { (wt.) }\end{array}$} & \multirow{2}{*}{$\begin{array}{c}\mathbf{H}_{2} \text {-uptake } \\
\left(\mu \mathrm{mol}_{\mathrm{H} 2} \cdot \mathrm{g}_{\text {Metal }}^{-1}\right)\end{array}$} & \multirow{2}{*}{$\begin{array}{c}\mathbf{H}_{2} \text {-uptake/Metal loadig } \\
(\mathbf{m o l} / \mathbf{m o l}) \\
\end{array}$} \\
\hline & & Co & $\mathrm{Ni}$ & & \\
\hline \multirow{5}{*}{$\mathrm{Nb}_{2} \mathrm{O}_{5}$} & 0.0 & 6.1 & 0.0 & 1423 & 1.4 \\
\hline & 0.25 & 4.5 & 1.6 & 1231 & 1.2 \\
\hline & 0.50 & 3.0 & 2.9 & 1236 & 1.2 \\
\hline & 0.75 & 1.5 & 4.4 & 997 & 1.0 \\
\hline & 1.0 & 0.0 & 6.5 & 1101 & 1.0 \\
\hline \multirow{5}{*}{$\mathrm{TiO}_{2}$} & 0.0 & 7.8 & 0.0 & 1821 & 1.4 \\
\hline & 0.25 & 5.4 & 1.9 & 1477 & 1.2 \\
\hline & 0.50 & 4.0 & 4.0 & 1798 & 1.3 \\
\hline & 0.75 & 2.0 & 5.8 & 1430 & 1.1 \\
\hline & 1.0 & 0.0 & 7.8 & 1291 & 1.0 \\
\hline \multirow{5}{*}{$\alpha-\mathrm{Al}_{2} \mathrm{O}_{3}$} & 0.0 & 8.0 & 0.0 & 1867 & 1.4 \\
\hline & 0.25 & 4.7 & 1.6 & 1420 & 1.3 \\
\hline & 0.50 & 3.3 & 3.2 & 1420 & 1.3 \\
\hline & 0.75 & 1.6 & 4.7 & 1376 & 1.3 \\
\hline & 1.0 & 0.0 & 6.0 & 979 & 1.0 \\
\hline
\end{tabular}
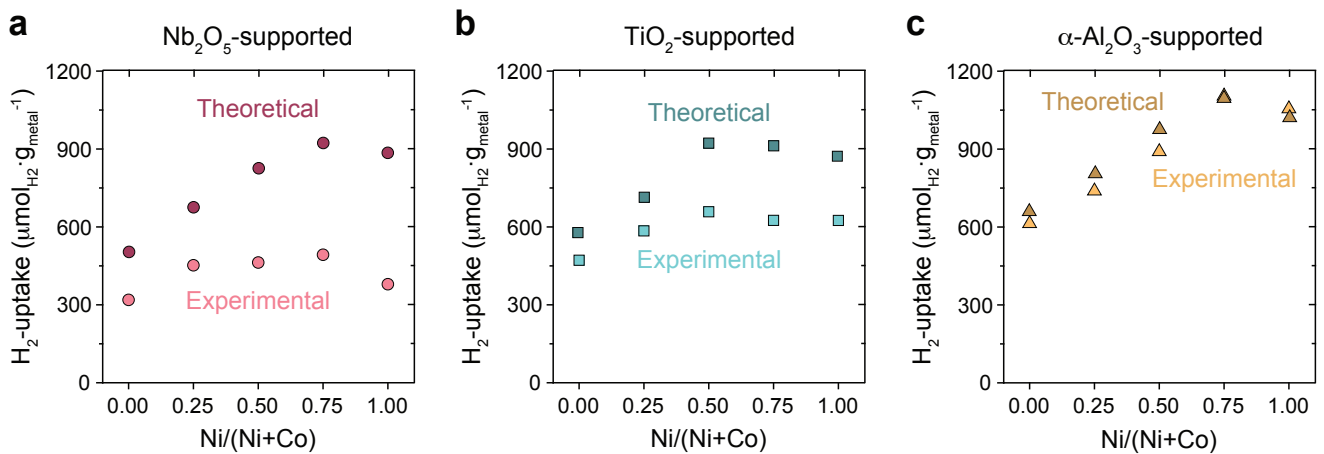

Figure D1 Theoretical and experimental $\mathrm{H}_{2}$-uptake for all the different metal compositions supported on niobia (a), titania (b) and alpha-alumina (c). Experimental hydrogen uptake was measured by hydrogen-chemisorption. After the chemisorption measurments, samples were analysed by TEM to obtain the average particle size and these values were used to derive the corresponding theoretical hydrogen uptake. Values can be found in Table 5.1 in the main text. 


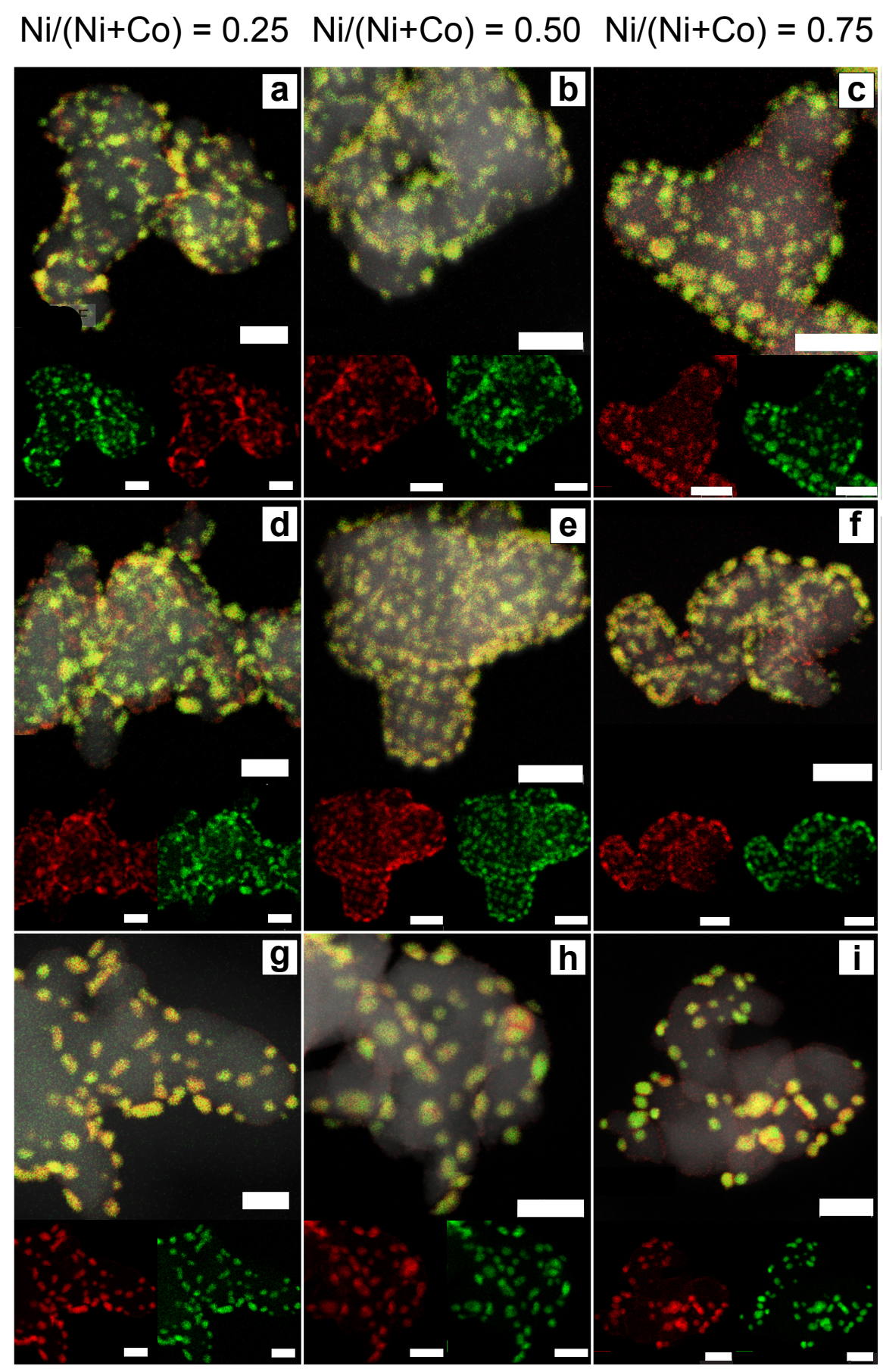

Figure D2 STEM-EDX of niobia-supported samples after reduction at $350{ }^{\circ} \mathrm{C}$ and passivation at room temperature $(\mathbf{a}, \mathbf{b}$ and $\mathbf{c})$, after $40 \mathrm{~h}$ on stream at 1 bar total pressure $\left(\mathrm{H}_{2} / \mathrm{CO}=2 \mathrm{v} / \mathrm{v}\right), 220{ }^{\circ} \mathrm{C}(\mathbf{d}, \mathrm{e}$ and $\mathbf{f})$ and after $100 \mathrm{~h}$ on stream at 20 bar total pressure $\left(\mathrm{H}_{2} / \mathrm{CO}=2 \mathrm{v} / \mathrm{v}\right), 220^{\circ} \mathrm{C}(\mathbf{g}, \mathbf{h}$ and $\mathbf{i})$. Nominal Ni/(Ni+Co) $=0.25 \mathrm{at} / \mathrm{at}(\mathbf{a}, \mathbf{d}$ and g), 0.50 at/at (b,e and $\mathbf{h})$ and 0.75 at/at (c, f and $\mathbf{i})$. The main images correspond to an overlap of Dark-field STEM with the EDX mapping for cobalt (shown in red) and nickel (shown in green), the scale bars correspond to $40 \mathrm{~nm}$. 


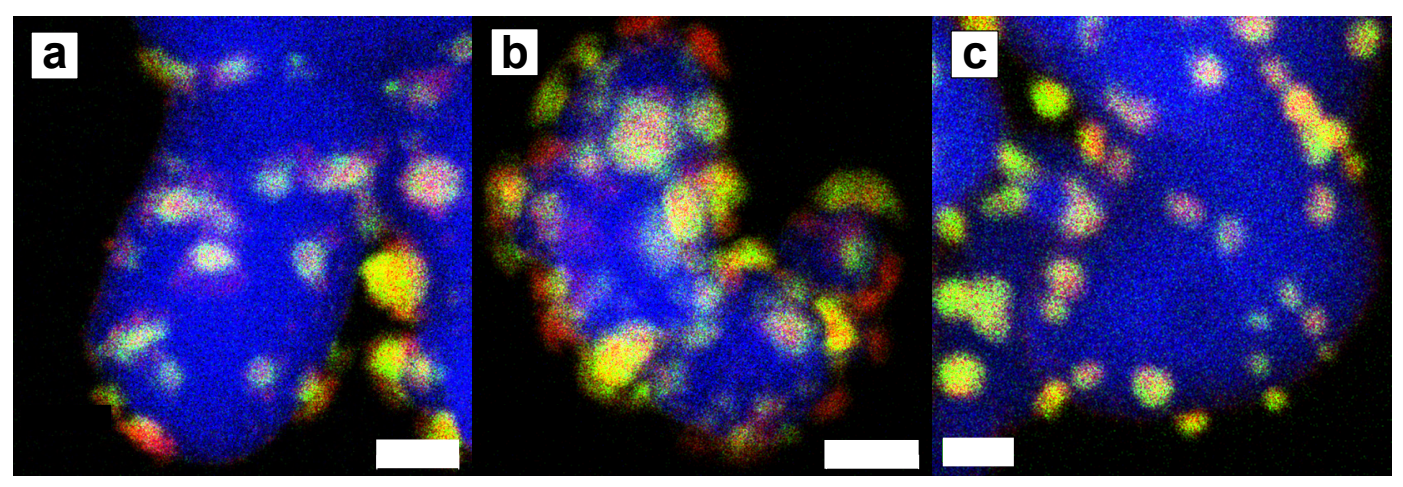

Figure D3 STEM-EDX of the niobia supported sample $(\mathrm{Ni} /(\mathrm{Ni}+\mathrm{Co})=0.25 \mathrm{at} / \mathrm{at}): \mathbf{a}$, after reduction at $350^{\circ} \mathrm{C}$ and passivation at room temperature. $\mathbf{b}$, after FT catalytic performance at 1 bar, $220^{\circ} \mathrm{C}$ and 40 h-on-stream. $\mathbf{c}$, after FT catalytic performance at $20 \mathrm{bar}, 220^{\circ} \mathrm{C}$ and $100 \mathrm{~h}$-on-stream. Signal corresponding to cobalt is shown in red, to nickel in green and to niobium in blue. Scale bars are equivalent to $20 \mathrm{~nm}$. 


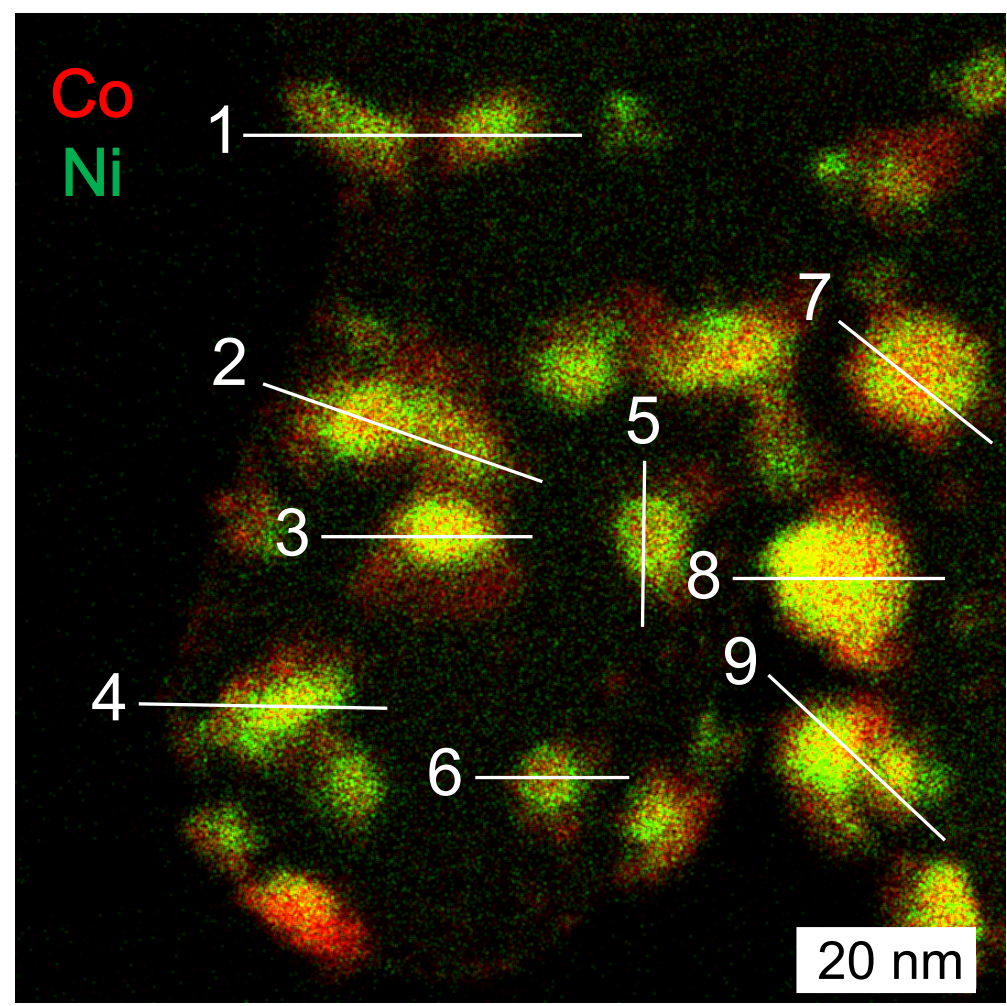

1

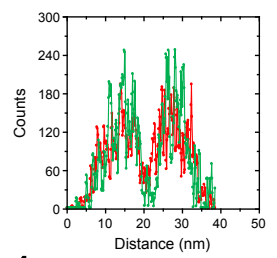

4

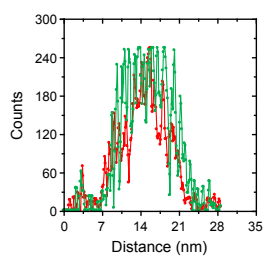

7

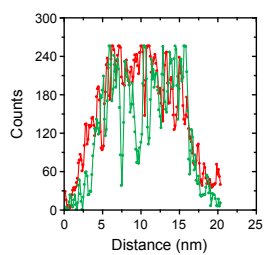

2

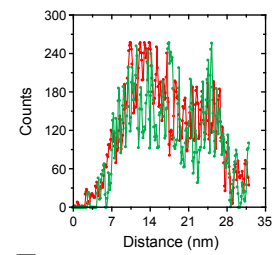

5

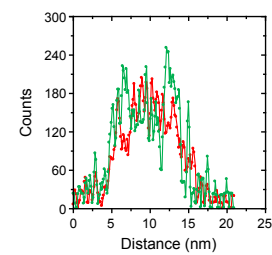

8

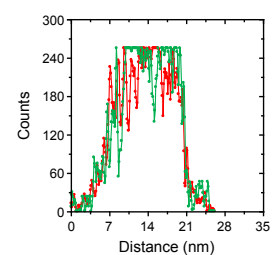

3
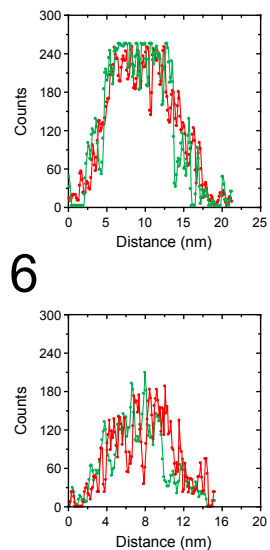

9

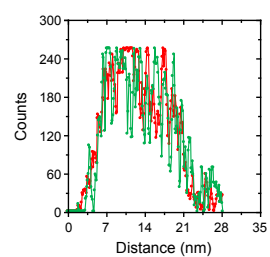

Figure D4 STEM-EDX and atomic Co-Ni distribution of the niobia-supported sample with composition $\mathrm{Ni} /(\mathrm{Ni}+\mathrm{Co})=0.25 \mathrm{at} / \mathrm{at}$, after reduction at $350^{\circ} \mathrm{C}$ and passivation at room temperature. Cobalt is shown in red and nickel in green. Co-Ni distribution cross-section analysis of the indicated nanoparticles is shown on the right side. 

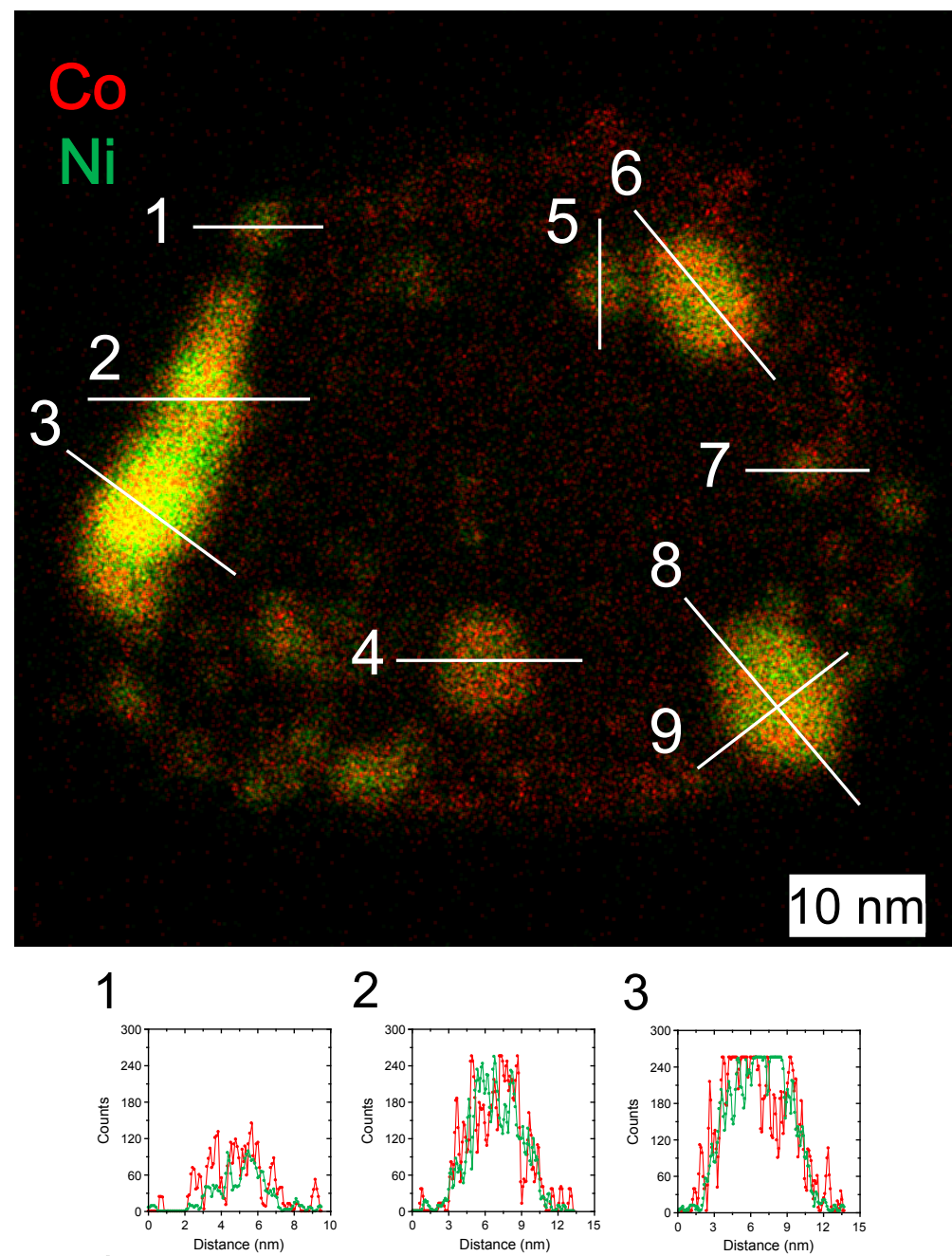

4

2

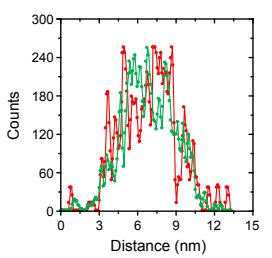

5

3
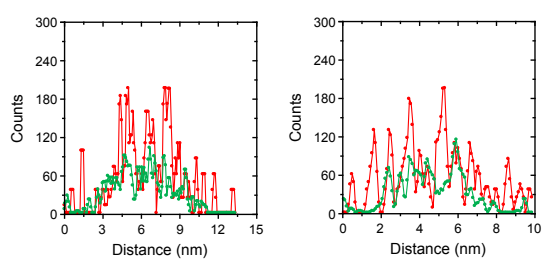

8
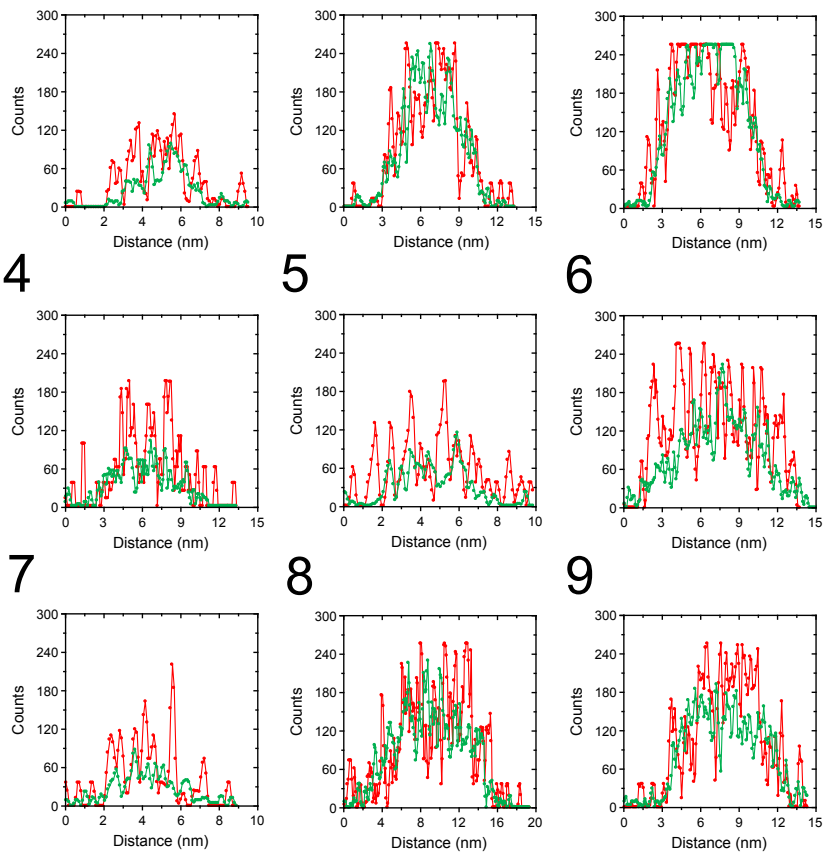

6

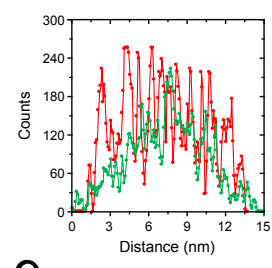

9

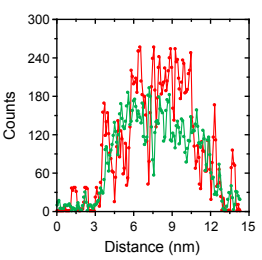

Figure D5 STEM-EDX and atomic Co-Ni distribution of the niobia-supported sample with composition $\mathrm{Ni} /(\mathrm{Ni}+\mathrm{Co})=0.75 \mathrm{at} / \mathrm{at}$, after reduction at $350^{\circ} \mathrm{C}$ and passivation at room temperature. Cobalt is shown in red and nickel in green. Co-Ni distribution cross-section analysis of the indicated nanoparticles is shown on the right side. 


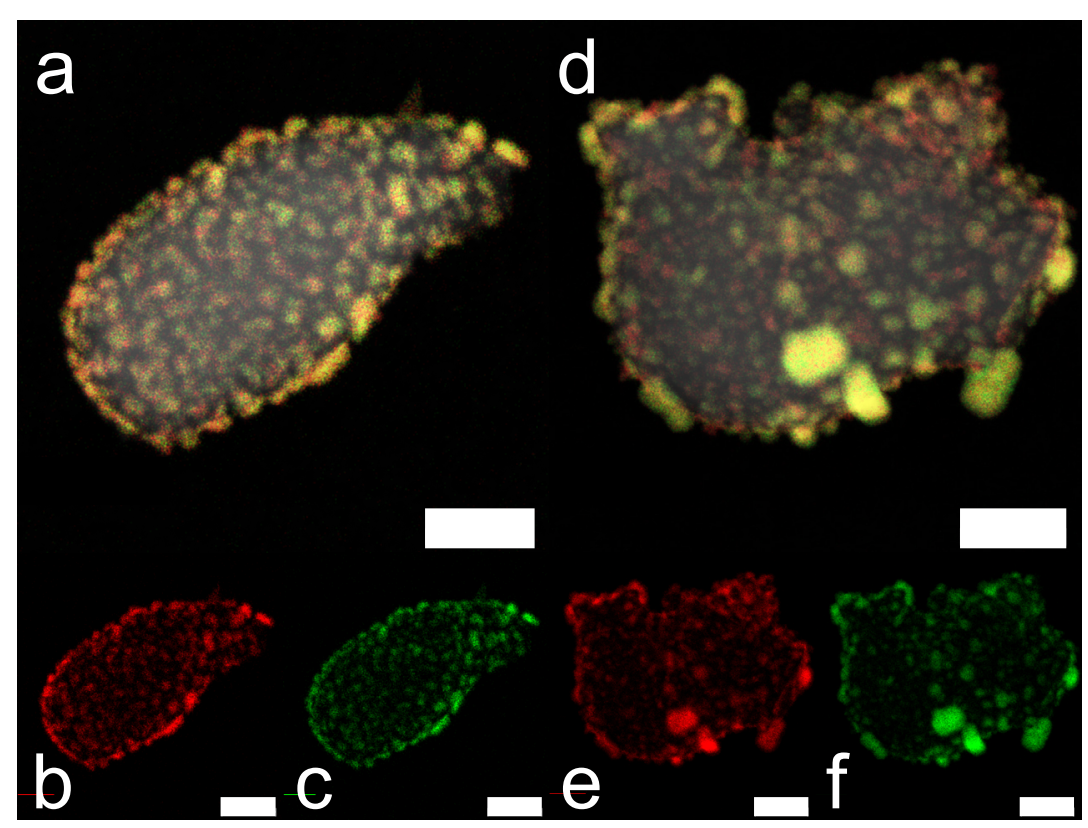

Figure D6 STEM-EDX of the $\alpha$-alumina-supported sample $\left(\mathrm{Ni} /(\mathrm{Ni}+\mathrm{Co})=0.50\right.$ at/at) after reduction at $350{ }^{\circ} \mathrm{C}$ and passivation at room temperature (a,b and $\mathbf{c})$ and after FT catalytic performance at 1 bar, $220{ }^{\circ} \mathrm{C}$ and 40 h-onstream (d, e and f). EDX signal for cobalt is shown in red and for nickel in green. $\mathbf{a}$ and $\mathbf{d}$ show an overlap of the dark-field image and EDX mapping of cobalt and nickel. b and e show the corresponding cobalt EDX map and c and $\mathbf{f}$ show the corresponding nickel EDX map. Scale bars correspond to $50 \mathrm{~nm}$.

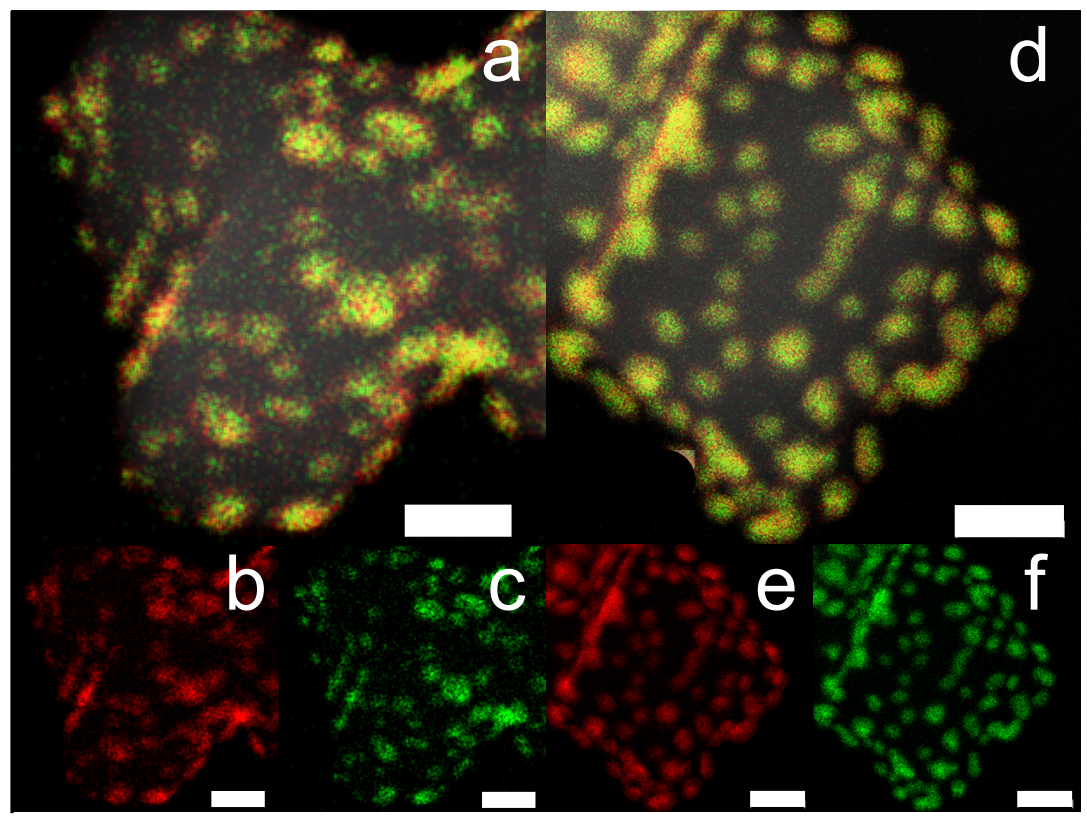

Figure D7 STEM-EDX of the titania-supported sample $(\mathrm{Ni} /(\mathrm{Ni}+\mathrm{Co})=0.50 \mathrm{at} / \mathrm{at})$ after reduction at $350{ }^{\circ} \mathrm{C}$ and passivation at room temperature (a, b and c) and after FT catalytic performance at 20 bar, $220{ }^{\circ} \mathrm{C}$ and 100 h-onstream (d, e and f). EDX signal for cobalt is shown in red and for nickel in green. $\mathbf{a}$ and $\mathbf{d}$ show an overlap of the dark-field image and EDX mapping of cobalt and nickel. b and e show the corresponding cobalt EDX map and c and $\mathbf{f}$ show the corresponding nickel EDX map. Scale bars correspond to $30 \mathrm{~nm}$. 

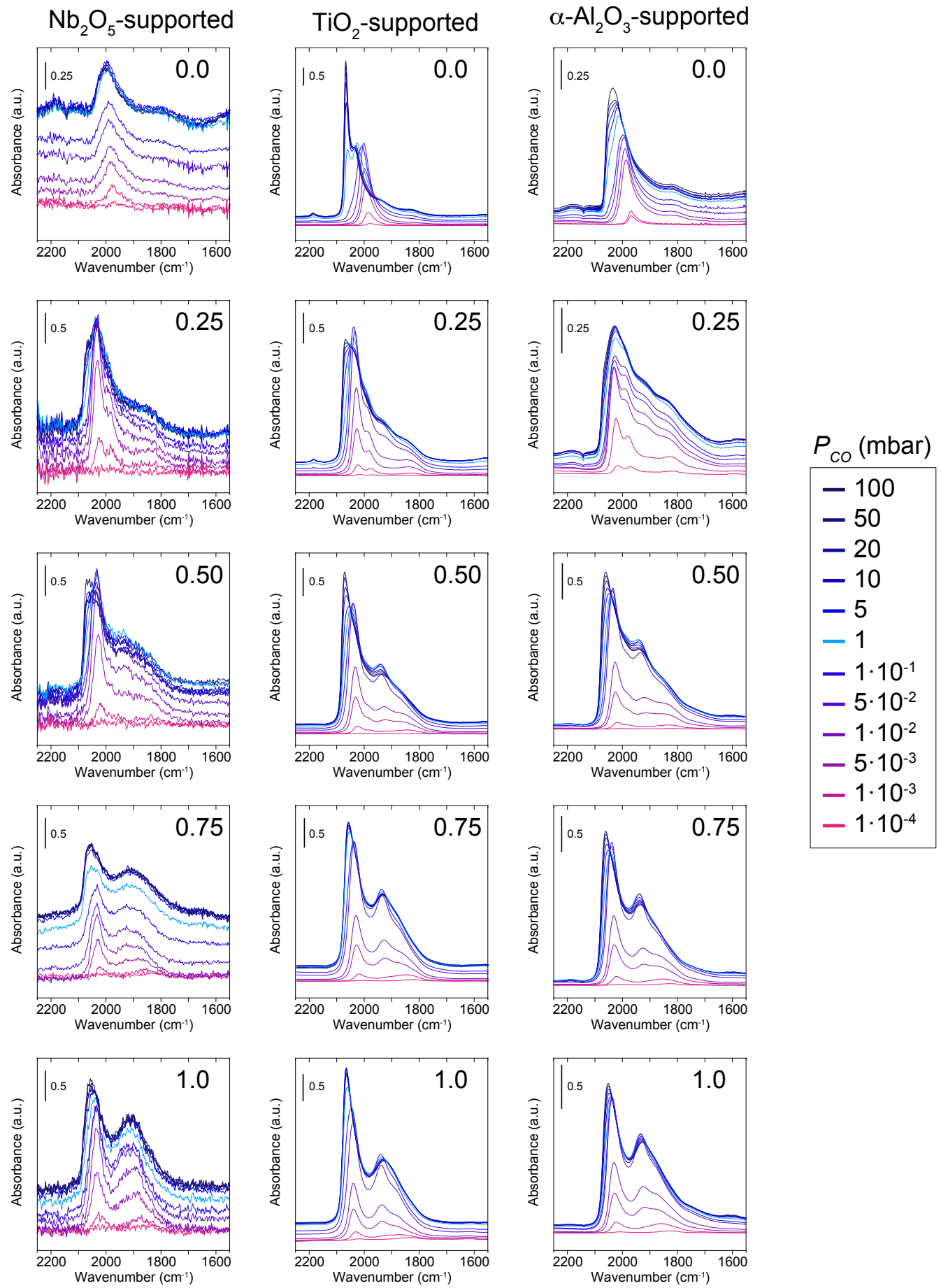

Figure D8 Fourier transform infrared spectra of $\mathrm{CO}$ as probe molecule (CO-FTIR) of the in-situ reduced samples supported on niobia, titania and alpha-alumina at different $\mathrm{CO}$ pressures and at $220{ }^{\circ} \mathrm{C}$. For each sample's set of spectra, the $\mathrm{Ni} /(\mathrm{Ni}+\mathrm{Co})$ composition is indicated on the top right. 


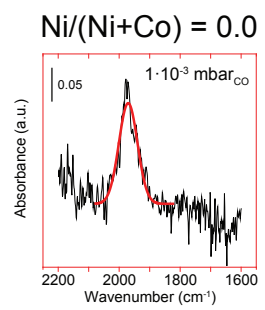

$\mathrm{Ni} /(\mathrm{Ni}+\mathrm{Co})=0.25 \mathrm{Ni} /(\mathrm{Ni}+\mathrm{Co})=0.50$

$\mathrm{Ni} /(\mathrm{Ni}+\mathrm{Co})=0.75$

$\mathrm{Ni} /(\mathrm{Ni}+\mathrm{Co})=1.0$
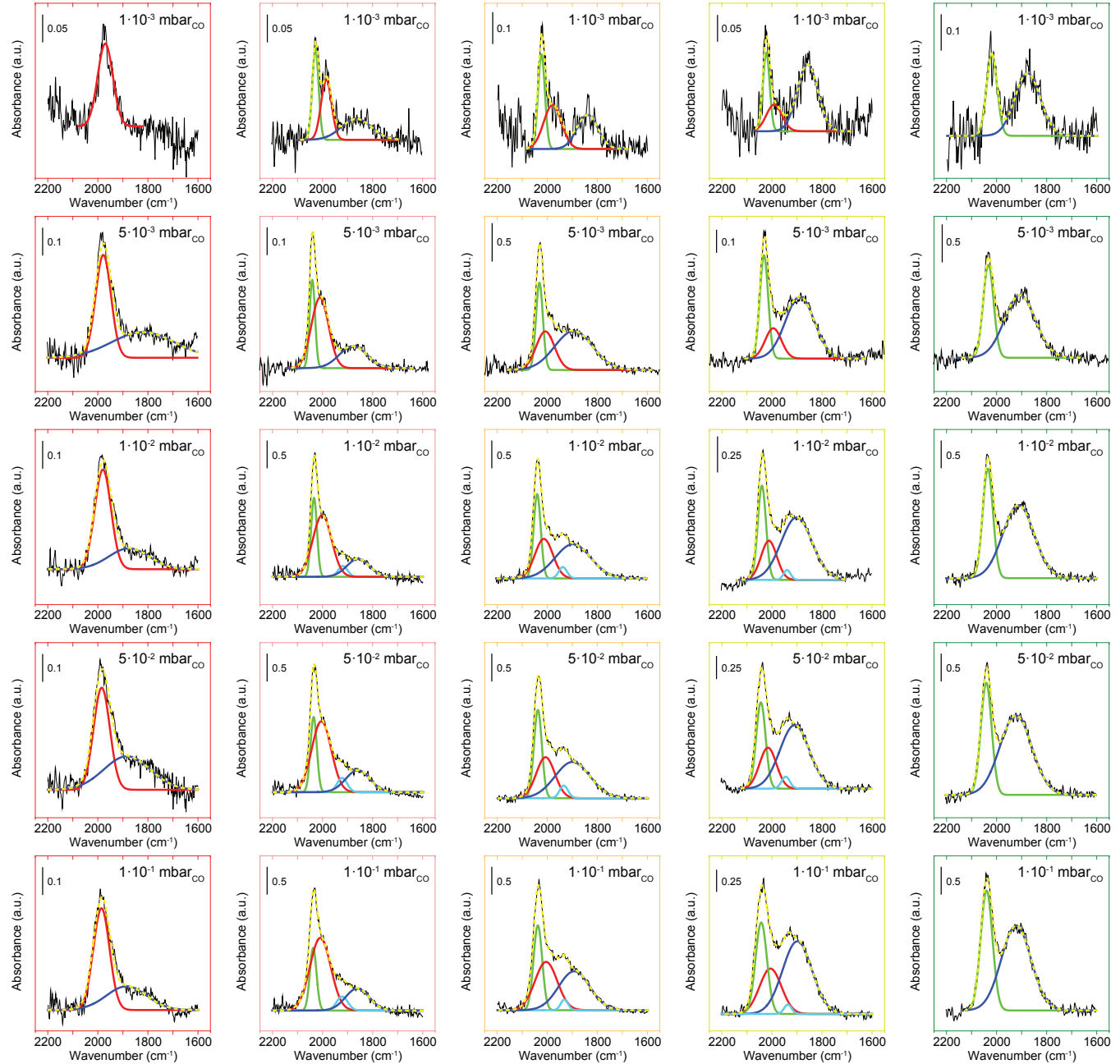

Figure D9 Deconvoluted CO-FTIR spectra of the niobia-supported samples at CO pressures from $1 \cdot 10^{-3}$ to $1 \cdot 10^{-1}$ mbar and at $220^{\circ} \mathrm{C} . \mathrm{Ni} /(\mathrm{Ni}+\mathrm{Co})$ composition is indicated above the spectra. Spectra are plotted with a black line. Deconvoluted curves correspond to linearly CO adsorbed on cobalt (red), linearly CO adsorbed on nickel (green), $\mathrm{CO}$ adsorbed on bridged mode (light and dark blue) and the resulting curve (dashed yellow). Areas of linearly adsorbed $\mathrm{CO}$ on cobalt and nickel for the bimetallic samples were normalized by the areas of the linearly adsorbed $\mathrm{CO}$ of the corresponding monometallic sample. 

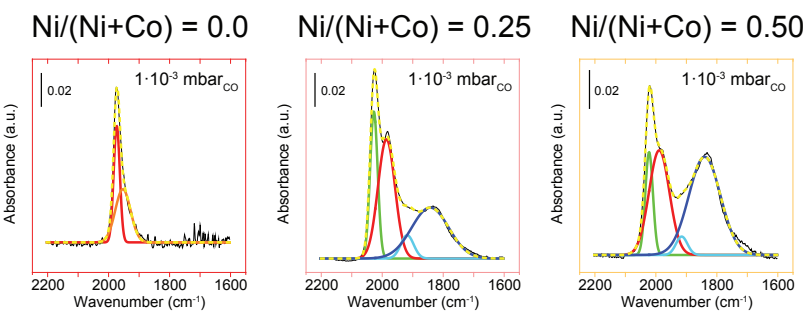

$\mathrm{Ni} /(\mathrm{Ni}+\mathrm{Co})=0.75$

$\mathrm{Ni} /(\mathrm{Ni}+\mathrm{Co})=1.0$
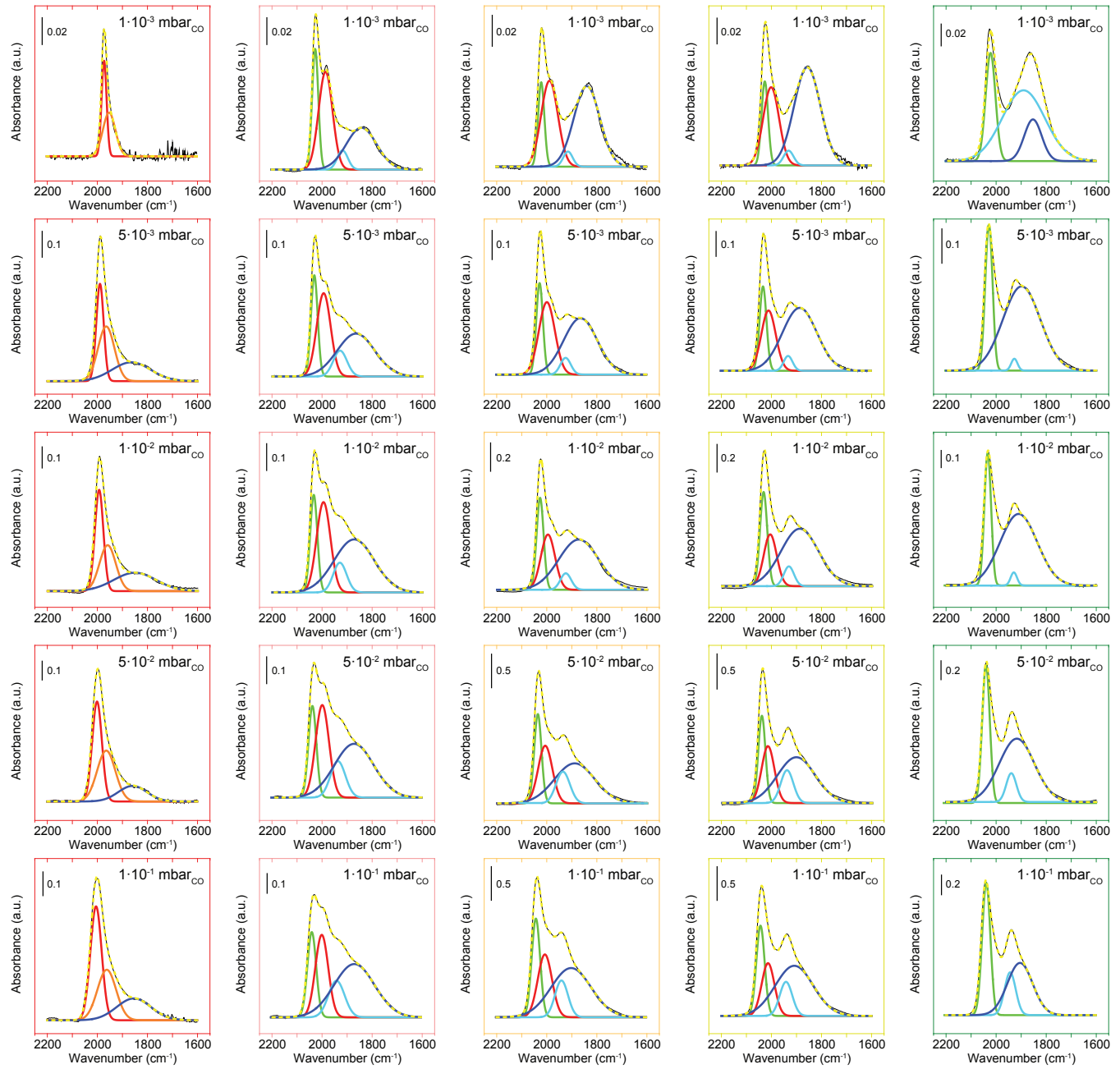

Figure D10 Deconvoluted CO-FTIR spectra of the $\alpha$-alumina-supported samples at CO pressures from $1 \cdot 10^{-3}$ to $1 \cdot 10^{-1} \mathrm{mbar}$ and at $220^{\circ} \mathrm{C}$. $\mathrm{Ni} /(\mathrm{Ni}+\mathrm{Co})$ composition is indicated on top. Spectra are plotted with a black line. Deconvoluted curves correspond to linearly CO adsorbed on cobalt (red and orange), linearly CO adsorbed on nickel (green), $\mathrm{CO}$ adsorbed on bridged mode (light and dark blue) and the resulting curve (dashed yellow). Areas of linearly adsorbed $\mathrm{CO}$ on cobalt and nickel for the bimetallic samples were normalized by the areas of the linearly adsorbed $\mathrm{CO}$ of the corresponding monometallic sample. 


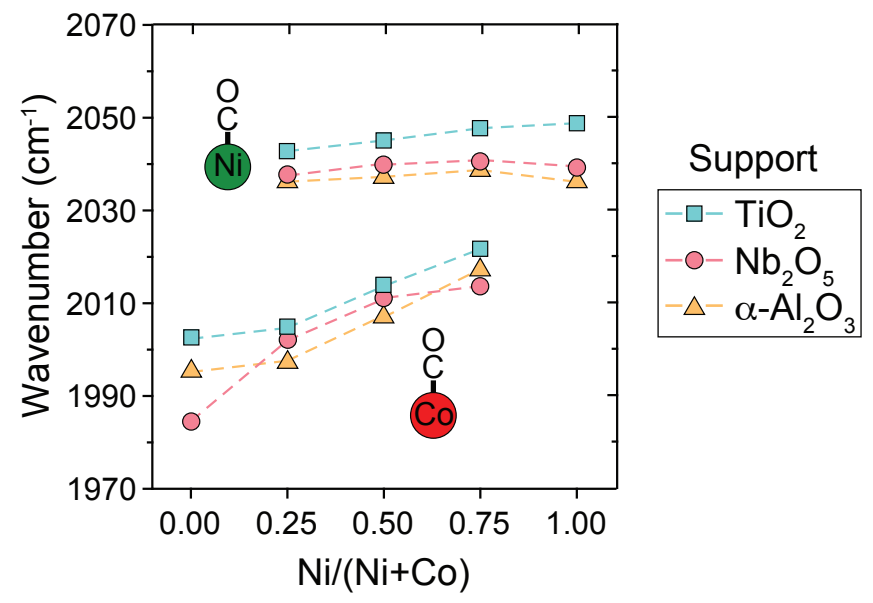

Figure D11 Wavenumber values of maximum absorbance of linear-CO on cobalt and on nickel for the different Co-Ni compositions on titania, niobia or alpha-alumina at $\mathrm{P}_{\mathrm{CO}}=0.1 \mathrm{mbar}$. 
Table D2 Comprehensive data of the catalytic performance for the samples with various cobalt to nickel ratios supported on reducible $\left(\mathrm{Nb}_{2} \mathrm{O}_{5}\right.$ and $\left.\mathrm{TiO}_{2}\right)$ and non-reducible $\left(\alpha-\mathrm{Al}_{2} \mathrm{O}_{3}\right)$ oxides. The values are reported at 40 h-onstream for the 1 bar experiments and at $100 \mathrm{~h}$-on-stream for the 20 bar experiments and in all cases the synthesis gas composition corresponded to $\mathrm{H}_{2} / \mathrm{CO}=2 \mathrm{v} / \mathrm{v}$. Prior reaction conditions, samples were in-situ reduced under hydrogen flow at $350{ }^{\circ} \mathrm{C}$.

\begin{tabular}{|c|c|c|c|c|c|c|c|c|c|c|}
\hline \multirow{2}{*}{$\begin{array}{c}\text { Pressure } \\
\text { (bar) }\end{array}$} & \multirow{2}{*}{$\begin{array}{l}\text { Temp. } \\
\left({ }^{\circ} \mathrm{C}\right)\end{array}$} & \multirow[t]{2}{*}{ Support } & \multirow{2}{*}{$\begin{array}{c}\mathrm{Ni} /(\mathrm{Ni}+\mathrm{Co}) \\
(\text { at/at })\end{array}$} & \multirow{2}{*}{$\begin{array}{c}\text { Activity } \\
\left(10^{-5} \mathrm{~mol}_{\mathrm{Co}} \cdot \mathrm{g}_{\text {Metal }}^{-1} \cdot \mathrm{s}^{-1}\right)\end{array}$} & \multirow{2}{*}{$\begin{array}{c}\text { CO conversion } \\
(\%)\end{array}$} & \multicolumn{2}{|c|}{$\operatorname{TOF}\left(10^{-2} s^{-1}\right)$} & \multicolumn{3}{|c|}{ Selectivity (wt.\%) } \\
\hline & & & & & & $\mathbf{A}$ & $\mathbf{B}$ & $\mathrm{C}_{1}$ & $\mathrm{C}_{2-4}$ & $\mathrm{C}_{5^{+}}$ \\
\hline \multirow{15}{*}{1} & \multirow{15}{*}{220} & \multirow{5}{*}{$\mathrm{Nb}_{2} \mathrm{O}_{5}$} & 0.0 & 2.4 & 1.4 & 3.7 & 2.4 & 51 & 28 & 21 \\
\hline & & & 0.25 & 4.7 & 2.6 & 5.3 & 3.6 & 69 & 16 & 15 \\
\hline & & & 0.50 & 6.0 & 2.9 & 6.7 & 3.7 & 77 & 13 & 10 \\
\hline & & & 0.75 & 6.7 & 3.7 & 7.0 & 3.7 & 76 & 15 & 9 \\
\hline & & & 1.0 & 3.4 & 2.4 & 4.7 & 2.0 & 61 & 26 & 13 \\
\hline & & \multirow{5}{*}{$\mathrm{TiO}_{2}$} & 0.0 & 3.6 & 1.2 & 4.0 & 3.2 & 55 & 32 & 28 \\
\hline & & & 0.25 & 4.9 & 2.9 & 4.3 & 3.5 & 71 & 14 & 15 \\
\hline & & & 0.50 & 5.8 & 3.4 & 5.1 & 3.6 & 76 & 13 & 12 \\
\hline & & & 0.75 & 7.4 & 4.4 & 6.0 & 4.2 & 76 & 15 & 9 \\
\hline & & & 1.0 & 2.1 & 1.4 & 1.7 & 1.2 & 54 & 31 & 15 \\
\hline & & \multirow{5}{*}{$\alpha-\mathrm{Al}_{2} \mathrm{O}_{3}$} & 0.0 & 1.0 & 0.8 & 0.8 & 0.8 & 26 & 33 & 41 \\
\hline & & & 0.25 & 1.1 & 0.7 & 0.8 & 0.7 & 31 & 30 & 39 \\
\hline & & & 0.50 & 1.3 & 1.0 & 0.7 & 0.7 & 26 & 31 & 43 \\
\hline & & & 0.75 & 1.0 & 0.6 & 0.5 & 0.4 & 31 & 31 & 39 \\
\hline & & & 1.0 & 0.5 & 0.5 & 0.2 & 0.3 & 23 & 36 & 40 \\
\hline \multirow{24}{*}{20} & \multirow{8}{*}{220} & \multirow{4}{*}{$\mathrm{Nb}_{2} \mathrm{O}_{5}$} & 0.0 & 6.2 & 17 & 9.8 & 6.4 & 86 & 6 & 8 \\
\hline & & & 0.25 & 10.0 & 20 & 11.4 & 7.7 & 83 & 7 & 11 \\
\hline & & & 0.50 & 7.5 & 16 & 8.4 & 4.7 & 74 & 11 & 15 \\
\hline & & & 0.75 & 5.3 & 12 & 6.5 & 3.4 & 71 & 15 & 13 \\
\hline & & \multirow{4}{*}{$\mathrm{TiO}_{2}$} & 0.0 & 10.5 & 28 & 18.3 & 14.9 & 82 & 6 & 12 \\
\hline & & & 0.25 & 12.3 & 27 & 13.6 & 11.1 & 83 & 7 & 10 \\
\hline & & & 0.50 & 9.0 & 21 & 8.7 & 6.2 & 75 & 13 & 12 \\
\hline & & & 0.75 & 4.3 & 15 & 5.9 & 4.1 & 68 & 18 & 13 \\
\hline & \multirow{8}{*}{240} & \multirow{4}{*}{$\mathrm{Nb}_{2} \mathrm{O}_{5}$} & 0.0 & 17.3 & 16 & 35.8 & 23.3 & 74 & 11 & 16 \\
\hline & & & 0.25 & 21.3 & 20 & 32.7 & 21.9 & 72 & 11 & 17 \\
\hline & & & 0.50 & 19.4 & 18 & 29.3 & 16.3 & 72 & 12 & 16 \\
\hline & & & 0.75 & 14.3 & 12 & 18.2 & 9.6 & 74 & 13 & 13 \\
\hline & & \multirow{4}{*}{$\mathrm{TiO}_{2}$} & 0.0 & 18.8 & 20 & 25.3 & 20.6 & 69 & 11 & 20 \\
\hline & & & 0.25 & 25.5 & 26 & 27.9 & 22.8 & 76 & 10 & 14 \\
\hline & & & 0.50 & 19.5 & 23 & 19.3 & 13.8 & 74 & 12 & 14 \\
\hline & & & 0.75 & 12.8 & 17 & 15.5 & 10.7 & 72 & 15 & 14 \\
\hline & \multirow{8}{*}{260} & \multirow{4}{*}{$\mathrm{Nb}_{2} \mathrm{O}_{5}$} & 0.0 & 42.8 & 19 & 87.4 & 56.9 & 67 & 14 & 19 \\
\hline & & & 0.25 & 58.2 & 26 & 84.3 & 56.6 & 68 & 14 & 19 \\
\hline & & & 0.50 & 53.4 & 22 & 76.4 & 42.5 & 69 & 15 & 17 \\
\hline & & & 0.75 & 40.6 & 22 & 48.5 & 25.6 & 70 & 15 & 15 \\
\hline & & \multirow{4}{*}{$\mathrm{TiO}_{2}$} & 0.0 & 51.7 & 22 & 71.3 & 58.0 & 68 & 13 & 19 \\
\hline & & & 0.25 & 56.5 & 32 & 75.9 & 62.1 & 68 & 13 & 18 \\
\hline & & & 0.50 & 48.3 & 21 & 48.6 & 34.6 & 70 & 14 & 16 \\
\hline & & & 0.75 & 28.1 & 13 & 29.7 & 20.5 & 73 & 12 & 15 \\
\hline
\end{tabular}

A.Derived from $\mathrm{H}_{2}$-chemisorption

B.Derived from TEM 
Table D3 Values for figure 5.6 in the main text comprasing the wavenumber of maximum absorbance of linear-CO on cobalt $\left(\mathrm{P}_{\mathrm{CO}}=0.1 \mathrm{mbar}\right)$ and turn-over-frequency (TOF, based on the experimental $\mathrm{H}_{2}$-uptake) for the different Co-Ni compositions on niobia, titania and alpha-alumina.

\begin{tabular}{cccc}
\hline Support & $\begin{array}{c}\mathbf{N i} /(\mathbf{N i}+\mathbf{C o}) \\
(\mathbf{a t} / \mathbf{a t})\end{array}$ & $\begin{array}{c}\text { Wavenumber } \\
\left(\mathbf{c m}^{-\mathbf{1}}\right)\end{array}$ & $\begin{array}{c}\text { TOF } \\
\left(\mathbf{1 0}^{-2} \mathbf{s}^{\mathbf{1}}\right)\end{array}$ \\
\hline & 0.0 & 1984 & 3.7 \\
$\mathrm{Nb}_{2} \mathrm{O}_{5}$ & 0.25 & 2002 & 5.3 \\
& 0.50 & 2009 & 6.7 \\
& 0.75 & 2012 & 7.0 \\
\hline & 0.0 & 2002 & 4.0 \\
$\mathrm{TiO}_{2}$ & 0.25 & 2004 & 4.3 \\
& 0.50 & 2014 & 5.1 \\
& 0.75 & 2021 & 6.0 \\
\hline & 0.0 & 1995 & 0.8 \\
& 0.25 & 1997 & 0.8 \\
& 0.50 & 2007 & 0.7 \\
& 0.75 & 2017 & 0.5 \\
\hline
\end{tabular}

Table D4 Metal composition expressed as $\mathrm{Ni} /(\mathrm{Ni}+\mathrm{Co})$ at/at quantified by ICP and/or EDX. The $\mathrm{Ni} /(\mathrm{Ni}+\mathrm{Co})$ was derived from the $\mathrm{Co} / \mathrm{Ni}$ ratio for samples after reduction at $350{ }^{\circ} \mathrm{C}$, FT catalytic performance at $220{ }^{\circ} \mathrm{C}$ and 1 bar (40 h-on stream) or 20 bar (100 h-on-stream).

\begin{tabular}{|c|c|c|c|c|c|c|c|}
\hline \multirow[t]{3}{*}{ Support } & \multicolumn{7}{|c|}{$\mathbf{N i} /(\mathbf{N i}+\mathrm{Co})(\mathrm{at} / \mathrm{at})$} \\
\hline & \multirow[t]{2}{*}{ Nominal } & \multicolumn{3}{|c|}{ ICP } & \multicolumn{3}{|c|}{ EDX } \\
\hline & & $\begin{array}{l}\text { After re- } \\
\text { duction }\end{array}$ & $\begin{array}{c}\text { After } 1 \text { bar } \\
\text { FT }\end{array}$ & $\begin{array}{c}\text { After } 20 \\
\text { bar FT }\end{array}$ & $\begin{array}{l}\text { After re- } \\
\text { duction }\end{array}$ & $\begin{array}{c}\text { After } 1 \text { bar } \\
\text { FT }\end{array}$ & $\begin{array}{c}\text { After } 20 \\
\text { bar FT }\end{array}$ \\
\hline \multirow{3}{*}{$\mathrm{Nb}_{2} \mathrm{O}_{5}$} & 0.25 & 0.26 & 0.25 & 0.20 & 0.24 & 0.26 & 0.21 \\
\hline & 0.50 & 0.50 & 0.50 & 0.37 & 0.50 & 0.49 & 0.41 \\
\hline & 0.75 & - & - & - & 0.74 & 0.78 & 0.58 \\
\hline \multirow{2}{*}{$\mathrm{TiO}_{2}$} & 0.25 & - & - & - & 0.31 & - & 0.21 \\
\hline & 0.50 & 0.51 & 0.51 & 0.35 & - & - & - \\
\hline \multirow{2}{*}{$\alpha-\mathrm{Al}_{2} \mathrm{O}_{3}$} & 0.50 & 0.50 & 0.48 & - & 0.52 & 0.50 & - \\
\hline & 0.75 & 0.75 & 0.76 & - & - & - & - \\
\hline
\end{tabular}




\section{Support / Reference}

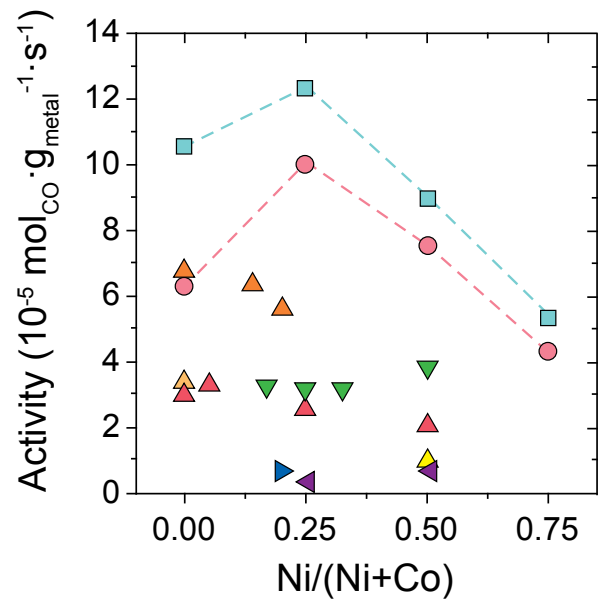

$\square \mathrm{TiO}_{2} /$ This work

- $\mathrm{Nb}_{2} \mathrm{O}_{5} /$ This work

$\triangle \alpha-\mathrm{Al}_{2} \mathrm{O}_{3} / 1$

$\triangle \alpha-\mathrm{Al}_{2} \mathrm{O}_{3} / 2$

$\triangle \theta-\mathrm{Al}_{2} \mathrm{O}_{3} / 3$

$\triangle \mathrm{Al}_{2} \mathrm{O}_{3} / 4$

$\nabla \mathrm{SiO}_{2}-\mathrm{Al}_{2} \mathrm{O}_{3} / 5$

$\triangleleft \mathrm{SiO}_{2} / 6$

$\checkmark \mathrm{La}_{2} \mathrm{O}_{3} / 7$

Figure D12 Literature overview of metal-weight-based activities at $220{ }^{\circ} \mathrm{C}$ as a function of cobalt-nickel composition for different supports. FT was performed at high pressure $(10-20 \mathrm{bar})$ and $\mathrm{H}_{2} / \mathrm{CO}=2 \mathrm{v} / \mathrm{v}$ in all cases. Values from Table D5. 
Table D5 Literature overview comparing the FT catalytic performance of cobalt-nickel supported on different supports. FT was performed in fix-bed configuration, at high pressures and $\mathrm{H}_{2} / \mathrm{CO}=2 \mathrm{v} / \mathrm{v}$ in all cases. Activity values were recalculated to match the units reported here; when the catalytic performance was reported at a temperature different than $220{ }^{\circ} \mathrm{C}$, the activity was recalculated to that at $220{ }^{\circ} \mathrm{C}$ using an apparent activation energy of $100 \mathrm{~kJ} \cdot \mathrm{mol}^{-1}$.

\begin{tabular}{|c|c|c|c|c|c|c|c|c|}
\hline Support & $\begin{array}{c}\text { Temper- } \\
\text { ature } \\
\left({ }^{\circ} \mathbf{C}\right)\end{array}$ & $\begin{array}{c}\text { Pressure } \\
\text { (bar) }\end{array}$ & $\begin{array}{l}\text { TOS } \\
\text { (h) }\end{array}$ & $\begin{array}{c}\mathbf{N i} /(\mathbf{N i}+\mathbf{C o}) \\
(\mathbf{a t} / \mathbf{a t}) \\
\end{array}$ & $\begin{array}{c}\text { Activity } \\
\left(10^{-5} \mathrm{~mol}_{\mathrm{Co}} \cdot \mathrm{g}_{\text {Metal }}^{-1} \cdot \mathrm{s}^{-1}\right)\end{array}$ & $\begin{array}{c}\mathrm{C}_{5+} \\
\text { selectivity } \\
\text { (wt.\%) }\end{array}$ & $\begin{array}{l}\text { Activity at } 220^{\circ} \mathrm{C} \\
\left(10^{-5} \mathrm{~mol}_{\mathrm{Co}} \cdot \mathrm{g}_{\text {Metal }}^{-1} \cdot \mathrm{s}^{-1}\right)\end{array}$ & Ref. \\
\hline \multirow{4}{*}{$\mathrm{Nb}_{2} \mathrm{O}_{5}$} & \multirow{4}{*}{220} & \multirow{4}{*}{20} & \multirow{4}{*}{100} & 0.0 & 6.2 & 86 & 6.2 & \multirow{4}{*}{$\begin{array}{l}\text { This } \\
\text { work }\end{array}$} \\
\hline & & & & 0.25 & 10.0 & 83 & 10.0 & \\
\hline & & & & 0.50 & 7.5 & 74 & 7.5 & \\
\hline & & & & 0.75 & 5.3 & 71 & 5.3 & \\
\hline \multirow{4}{*}{$\mathrm{TiO}_{2}$} & \multirow{4}{*}{220} & \multirow{4}{*}{20} & \multirow{4}{*}{100} & 0.0 & 10.5 & 82 & 10.5 & \multirow{4}{*}{$\begin{array}{l}\text { This } \\
\text { work }\end{array}$} \\
\hline & & & & 0.25 & 12.3 & 83 & 12.3 & \\
\hline & & & & 0.50 & 9.0 & 75 & 9.0 & \\
\hline & & & & 0.75 & 4.3 & 68 & 4.3 & \\
\hline$\alpha-\mathrm{Al}_{2} \mathrm{O}_{3}$ & 220 & 20 & 100 & 0.0 & 3.3 & 86 & 3.3 & 1 \\
\hline \multirow{3}{*}{$\alpha-\mathrm{Al}_{2} \mathrm{O}_{3}$} & \multirow{3}{*}{210} & \multirow{3}{*}{20} & \multirow{3}{*}{100} & 0.0 & 4.1 & 85 & 6.8 & \multirow{3}{*}{2} \\
\hline & & & & 0.14 & 3.8 & 85 & 6.3 & \\
\hline & & & & 0.20 & 3.4 & 85 & 5.6 & \\
\hline \multirow{4}{*}{$\theta-\mathrm{Al}_{2} \mathrm{O}_{3}$} & \multirow{4}{*}{230} & \multirow{4}{*}{10} & \multirow{4}{*}{8} & 0 & 5.1 & 76 & 3.1 & \multirow{4}{*}{3} \\
\hline & & & & 0.05 & 5.4 & 77 & 3.3 & \\
\hline & & & & 0.25 & 4.3 & 67 & 2.6 & \\
\hline & & & & 0.50 & 3.5 & 59 & 2.1 & \\
\hline $\mathrm{Al}_{2} \mathrm{O}_{3}$ & 240 & 10 & 12 & 0.50 & 2.5 & 83 & 0.96 & 4 \\
\hline \multirow{4}{*}{$\mathrm{SiO}_{2}-\mathrm{Al}_{2} \mathrm{O}_{3}$} & \multirow{4}{*}{230} & \multirow{4}{*}{20} & \multirow{4}{*}{-} & 0.50 & 6.1 & 81 & 3.76 & \multirow{4}{*}{5} \\
\hline & & & & 0.33 & 5 & 87 & 3.08 & \\
\hline & & & & 0.25 & 5.1 & 89 & 3.14 & \\
\hline & & & & 0.17 & 5.1 & 88 & 3.14 & \\
\hline \multirow{2}{*}{$\mathrm{SiO}_{2}$} & \multirow{2}{*}{250} & \multirow{2}{*}{10} & \multirow[b]{2}{*}{ - } & 0.25 & 1.1 & 45 & 0.27 & \multirow{2}{*}{6} \\
\hline & & & & 0.50 & 3.1 & 35 & 0.76 & \\
\hline $\mathrm{La}_{2} \mathrm{O}_{3}$ & 220 & 10 & 15 & 0.20 & 0.57 & - & 0.57 & 7 \\
\hline
\end{tabular}

\section{EDX analysis}

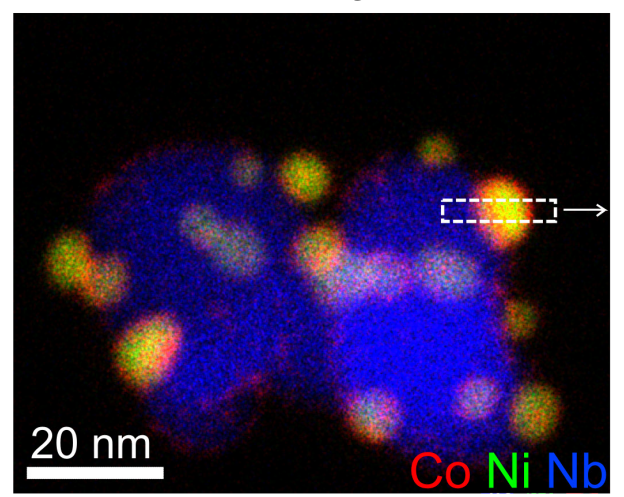

Atomic Co-Ni distribution

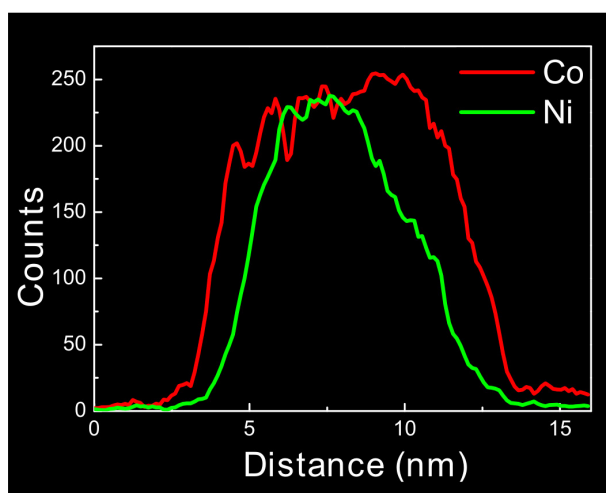

Figure D13 STEM-EDX and atomic Co-Ni distribution of the used niobia-supported catalyst with composition $\mathrm{Ni} /(\mathrm{Ni}+\mathrm{Co})=0.75 \mathrm{at} / \mathrm{at}$, after high-pressure FT $\left(220{ }^{\circ} \mathrm{C}, 20 \mathrm{bar}, \mathrm{TOS}=100 \mathrm{~h}\right.$ and $\mathrm{H}_{2} / \mathrm{CO}=2 \mathrm{v} / \mathrm{v}$. $)$. Cobalt is shown in red, nickel in green and niobium in blue. 
A

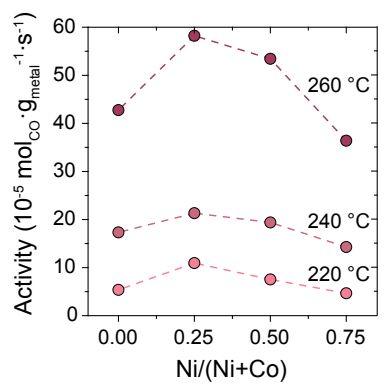

C

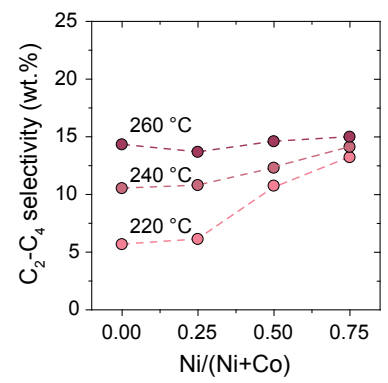

B

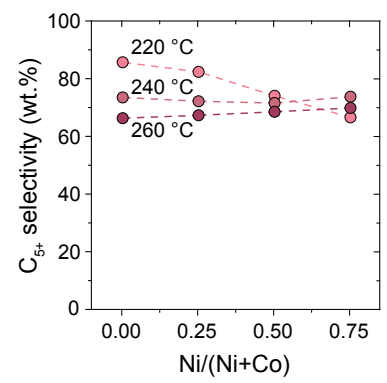

D

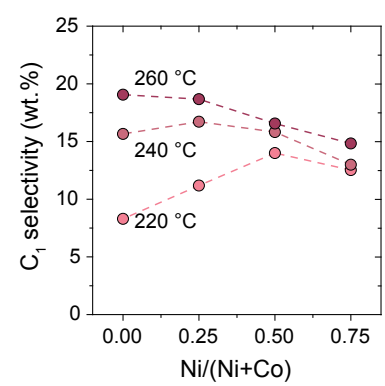

Figure D14 Catalytic activities (A), $\mathrm{C}_{5}, \mathrm{C}_{2}-\mathrm{C}_{4}$ and $\mathrm{C}_{1}$ selectivities (B, C and $\mathbf{D}$ respectively) for the niobia-supported catalysts at 220,240 and $260{ }^{\circ} \mathrm{C}, 20 \mathrm{bar}\left(\mathrm{H}_{2} / \mathrm{CO}=2 \mathrm{v} / \mathrm{v}\right)$ and after $100 \mathrm{~h}$-on stream. Prior to reaction conditions, samples were reduced in-situ at $350{ }^{\circ} \mathrm{C}$ in 25 vol. $\% \mathrm{H}_{2}$ in $\mathrm{He}$ at 1 bar.

A

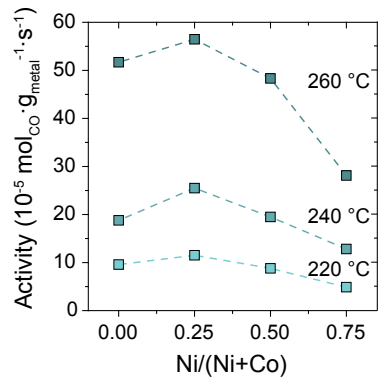

C

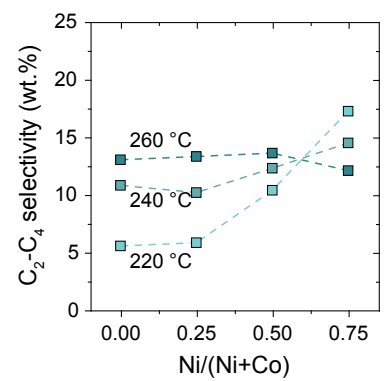

B

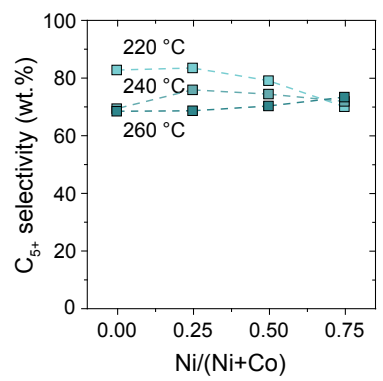

D

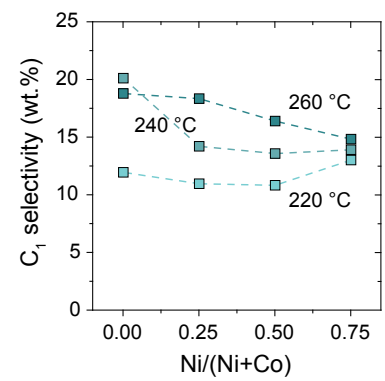

Figure D15 Catalytic activities (A), $\mathrm{C}_{5}, \mathrm{C}_{2}-\mathrm{C}_{4}$ and $\mathrm{C}_{1}$ selectivities (B,C and $\mathbf{D}$ respectively) for the titania-supported catalysts at 220,240 and $260{ }^{\circ} \mathrm{C}, 20 \mathrm{bar}\left(\mathrm{H}_{2} / \mathrm{CO}=2 \mathrm{v} / \mathrm{v}\right)$ and after $100 \mathrm{~h}$-on stream. Prior to reaction conditions, samples were reduced in-situ at $350{ }^{\circ} \mathrm{C}$ in 25 vol. $\% \mathrm{H}_{2}$ in $\mathrm{He}$ at 1 bar. 


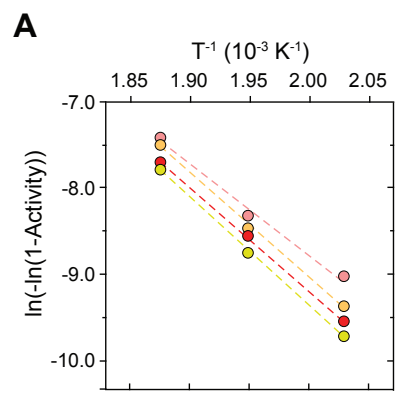

\begin{tabular}{|llll|}
\multicolumn{4}{c}{$\mathrm{Nb}_{2} \mathrm{O}_{5}$-supported } \\
\multicolumn{1}{c}{$\mathrm{Ni} /(\mathrm{Ni}+\mathrm{Co})$} & Slope & $\mathrm{E}_{\mathrm{a}}\left(\mathrm{kJ} \cdot \mathrm{mol}^{-1}\right)$ \\
\hline 0.0 & -12.7 & 106 \\
0 & 0.25 & -11.2 & 93 \\
$\circ$ & 0.50 & -12.9 & 107 \\
$\circ$ & 0.75 & -13.4 & 111 \\
\hline
\end{tabular}

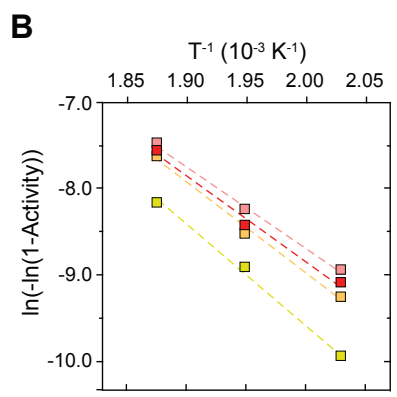

\begin{tabular}{|cccc|}
\multicolumn{4}{c}{$\mathrm{TiO}_{2}$-supported } \\
\begin{tabular}{|cccc}
$\mathrm{Ni} /(\mathrm{Ni}+\mathrm{Co})$ & Slope & $\mathrm{E}_{\mathrm{a}}\left(\mathrm{kJ} \cdot \mathrm{mol}^{-1}\right)$ \\
\hline $\begin{array}{c}0 \\
0.0\end{array}$ & -10.5 & 87 \\
$\square$ & 0.25 & -10.0 & 83 \\
$\square$ & 0.50 & -11.0 & 92 \\
$\square$ & 0.75 & -12.4 & 103 \\
\hline
\end{tabular}
\end{tabular}

Figure D16 Arrhenius plots for the niobia- and titania-supported catalysts ( $\mathbf{A}$ and $\mathbf{B}$ respectively). Apperrent activation energies $\left(\mathrm{E}_{\mathrm{a}}\right)$ were obtained from the slopes of the Arrhenius equation in the linear form: $\ln (-\ln (1-$ Activity $))=$ $\ln A-\mathrm{E}_{\mathrm{a}}(\mathrm{RT})^{-1}$, in which Activity corresponds to the metal-normalized catalytic activity (Table D1), A to the pre-exponential factor, $\mathrm{R}$ to the gas constant $\left(8.3145 \mathrm{~J} \cdot \mathrm{K}^{-1} \cdot \mathrm{mol}^{-1}\right)$ and $\mathrm{T}$ to the reaction temperature $(\mathrm{K})$. Reaction conditions: $20 \mathrm{bar}, \mathrm{H}_{2} / \mathrm{CO}=2 \mathrm{v} / \mathrm{v}$, after $100 \mathrm{~h}$ on stream and 220,240 and $260{ }^{\circ} \mathrm{C}$.

\section{References}

1. Hernández Mejía, C., van Deelen, T. W. \& de Jong, K. P. Activity enhancement of cobalt catalysts by tuning metal-support interactions. Nat. Commun. 9, 4459 (2018).

2. Rytter, E., Skagseth, T. H., Eri, S. \& Sjåstad, A. O. Cobalt fischer-tropsch catalysts using nickel promoter as a rhenium substitute to suppress deactivation. Ind. Eng. Chem. Res. 49, 4140-4148 (2010).

3. Shimura, K., Miyazawa, T., Hanaoka, T. \& Hirata, S. Fischer-Tropsch synthesis over alumina supported bimetallic Co-Ni catalyst: Effect of impregnation sequence and solution. J. Mol. Catal. A Chem. 407, 15-24 (2015).

4. Yu, H., Zhao, A., Zhang, H., Ying, W. \& Fang, D. Bimetallic catalyst of co and Ni for Fischer-Tropsch synthesis supported on alumina. Energ. Source. Part A 37, 47-54 (2015).

5. van Helden, P. et al. Cobalt-nickel bimetallic Fischer-Tropsch catalysts: A combined theoretical and experimental approach. Catal. Today 342, 88-98 (2020).

6. Ishihara, T. et al. Effect of alloying on $\mathrm{CO}$ hydrogenation activity over $\mathrm{SiO}_{2}$-supported $\mathrm{CoNi}$ alloy catalysts. J. Catal. 136, 232-241 (1992).

7. Mirzaei, A. A., Shirzadi, B., Atashi, H. \& Mansouri, M. Modeling and operating conditions optimization of Fischer-Tropsch synthesis in a fixed-bed reactor. J. Ind. Eng. Chem. 18, 1515-1521 (2012). 


\section{Appendix E}

\section{Supporting Information Chapter 6}

Stable Niobia-Supported Nickel Catalysts for the Hydrogenation of Carbon Monoxide to Hydrocarbons

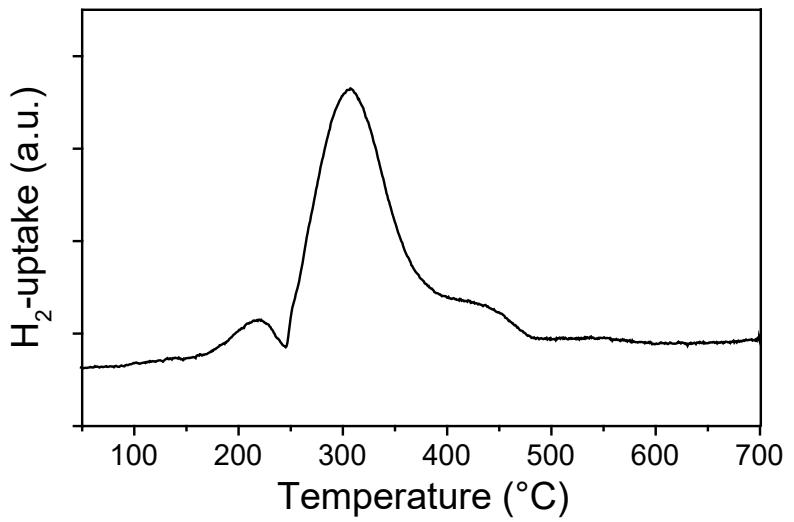

Figure $\mathbf{E} 1 \mathrm{H}_{2}$-TPR profile of the calcined $\mathrm{NiO} / \alpha-\mathrm{Al}_{2} \mathrm{O}_{3}$ sample. Heating ramp of $5{ }^{\circ} \mathrm{C} \cdot \mathrm{min}^{-1}$ with a $5 \mathrm{vol} \% \mathrm{H}_{2} / \mathrm{Ar}$ flow.
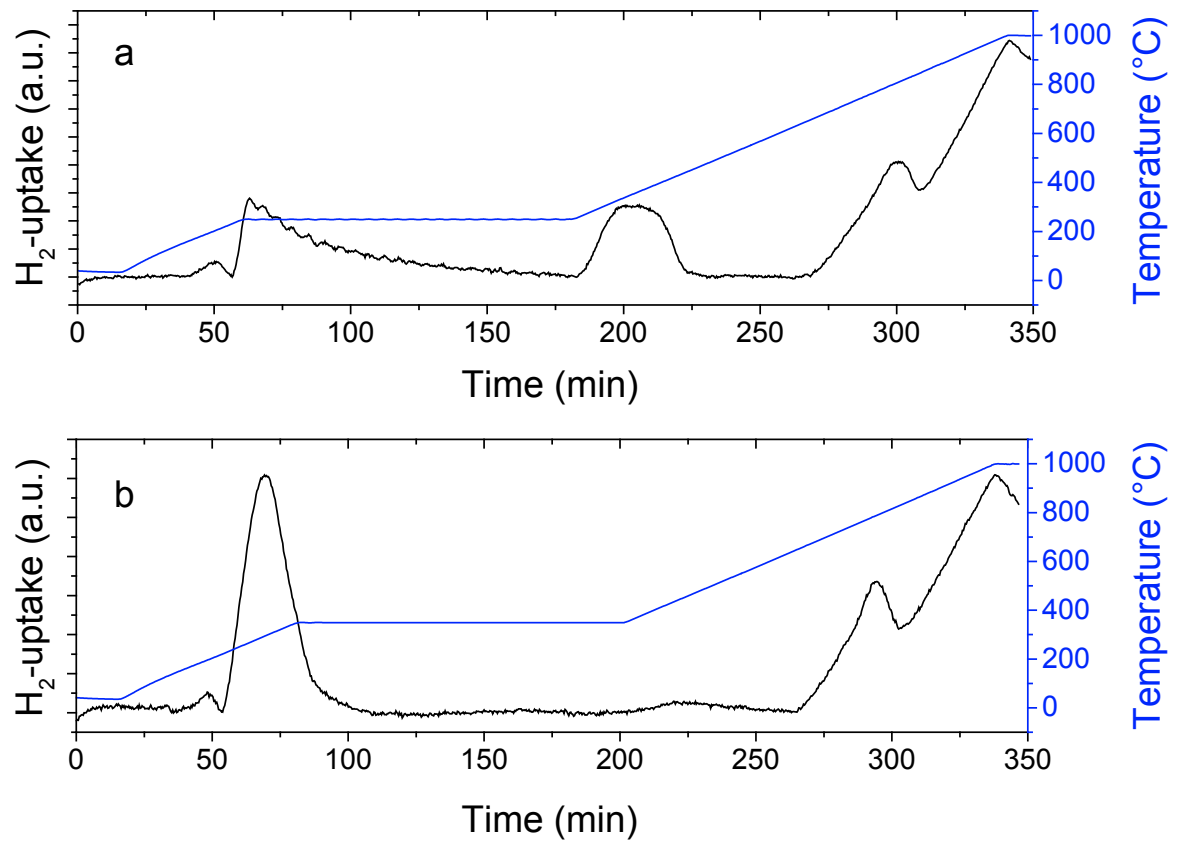

Figure E2 TPR experiments for the calcined nickel oxide supported on niobia with a $2 \mathrm{~h}$ dwell at $250{ }^{\circ} \mathrm{C}(\mathbf{a})$ or $350{ }^{\circ} \mathrm{C}(\mathbf{b})$. Heating ramp of $5{ }^{\circ} \mathrm{C} \cdot \mathrm{min}^{-1}$ with a $5 \mathrm{vol} \% \mathrm{H}_{2} / \mathrm{Ar}$ flow. 

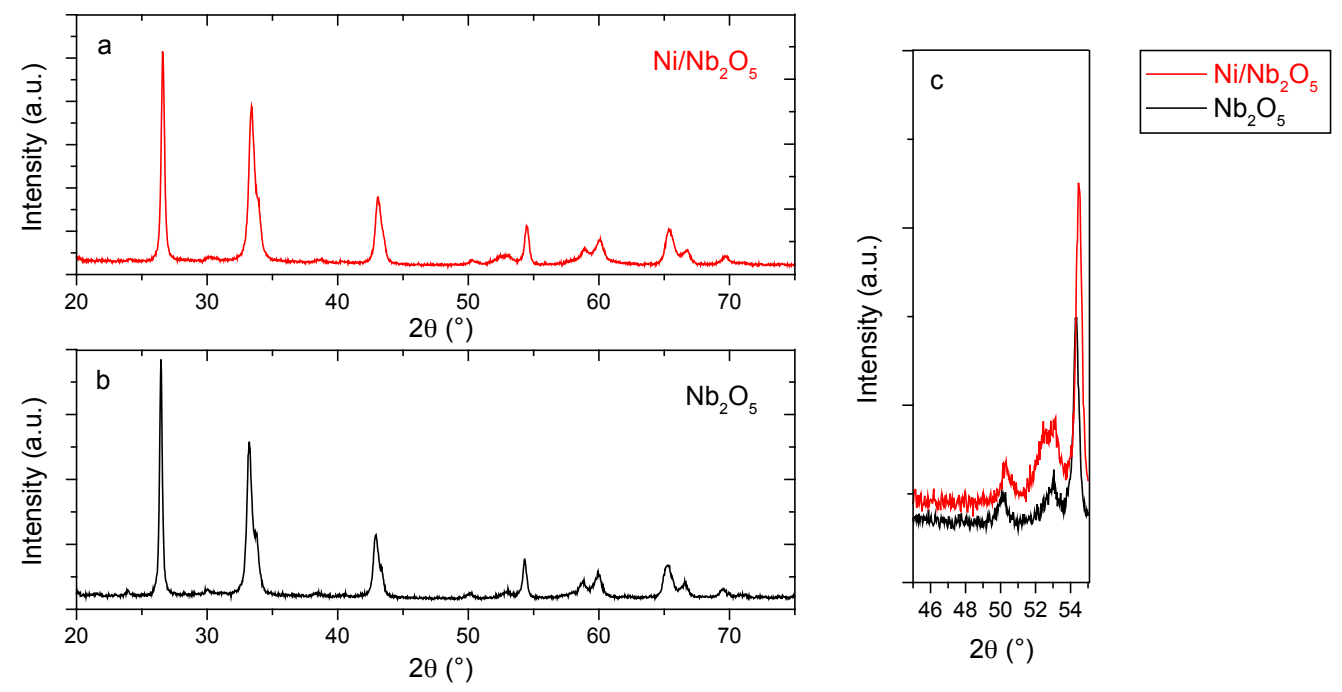

Figure E3 Powder X-ray diffractograms for nickel supported on niobia after reduction at $450{ }^{\circ} \mathrm{C}$ and passivation at room temperature (a), the pristine support (b) and a comparison in the $2 \theta$ range from $45^{\circ}$ to $55^{\circ}$ (c). The diffraction peak observed at $2 \theta=52.6^{\circ}$ for the $\mathrm{Ni} / \mathrm{Nb}_{2} \mathrm{O}_{5}$ sample was attributed to metallic nickel (hexagonal crystal phase, ID: PDF-04-002-8298 or cubic crystal phase, ID: PDF-04-010-6148). 


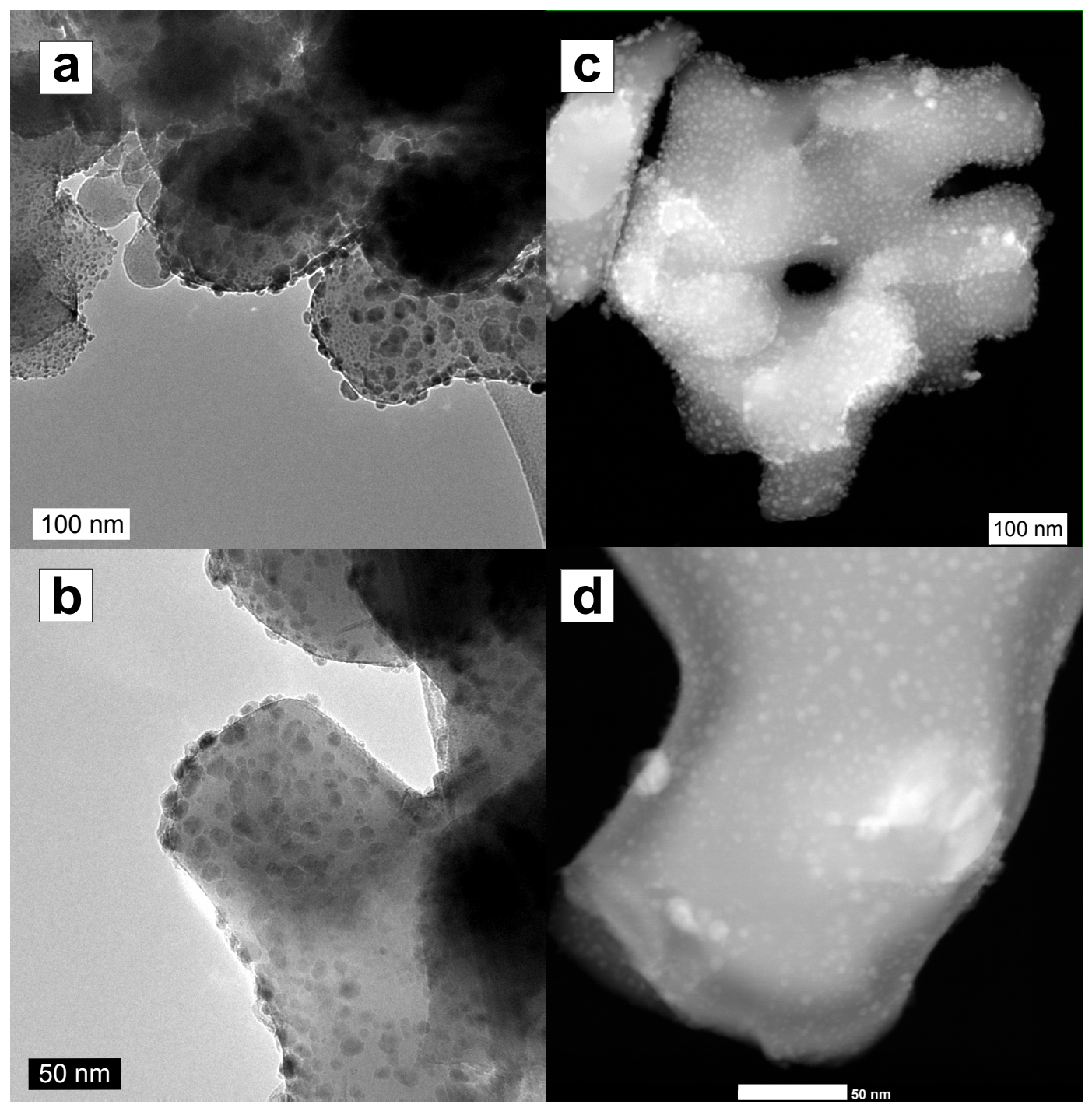

Figure E4 TEM images of nickel-supported on $\alpha$-alumina after reduction at $350{ }^{\circ} \mathrm{C}(\mathbf{a}$ and $\mathbf{b})$ or $450{ }^{\circ} \mathrm{C}(\mathbf{c}$ and $\mathbf{d})$ followed by hydrogen chemisorption measurements and exposure to air. In the case of the bright-field images (a and b) the dark colored supported particles correspond to nickel nanoparticles and for the dark-field images (c and d) the light colored supported particles correspond to nickel nanoparticles. 


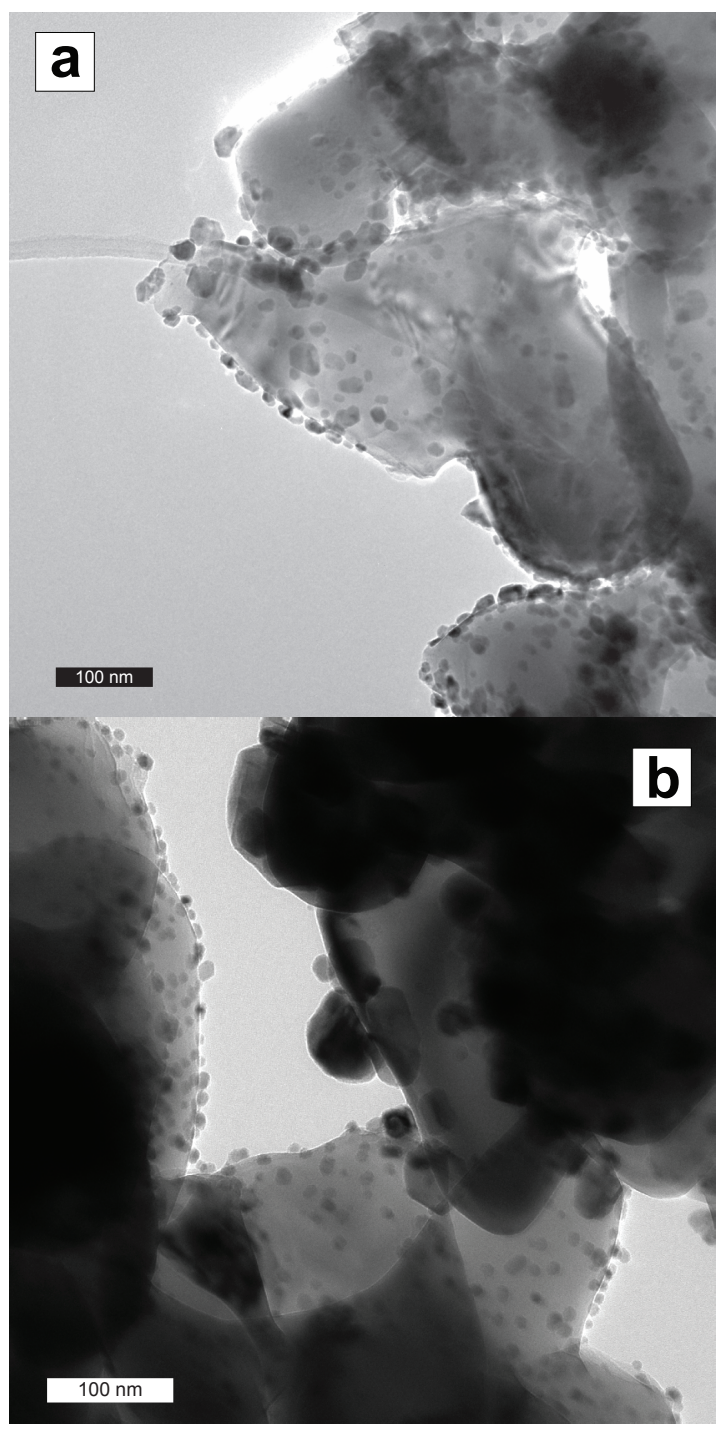

Figure E5 Bright-field TEM images of the spent nickel-supported on $\alpha$-alumina catalyst after reduction at $350{ }^{\circ} \mathrm{C}$ with a $\mathrm{D}[3,2]$ value of $28 \mathrm{~nm}(\mathbf{a})$ or $450{ }^{\circ} \mathrm{C}$ with a $\mathrm{D}[3,2]$ value of $36 \mathrm{~nm}(\mathbf{b})$. Reaction conditions: $230{ }^{\circ} \mathrm{C}, 1$ bar, $\mathrm{H}_{2} / \mathrm{CO}=2.0 \mathrm{v} / \mathrm{v}, \mathrm{GHSV}=28000 \mathrm{~h}^{-1}$ and $90 \mathrm{~h}$ TOS. The dark colored supported particles correspond to nickel nanoparticles. 


\section{Appendix F}

\section{Supporting Information Chapter 7}

Niobium-based Solid Acids in Combination with a Methanol Synthesis Catalyst for the Direct Production of Dimethyl Ether from Synthesis Gas
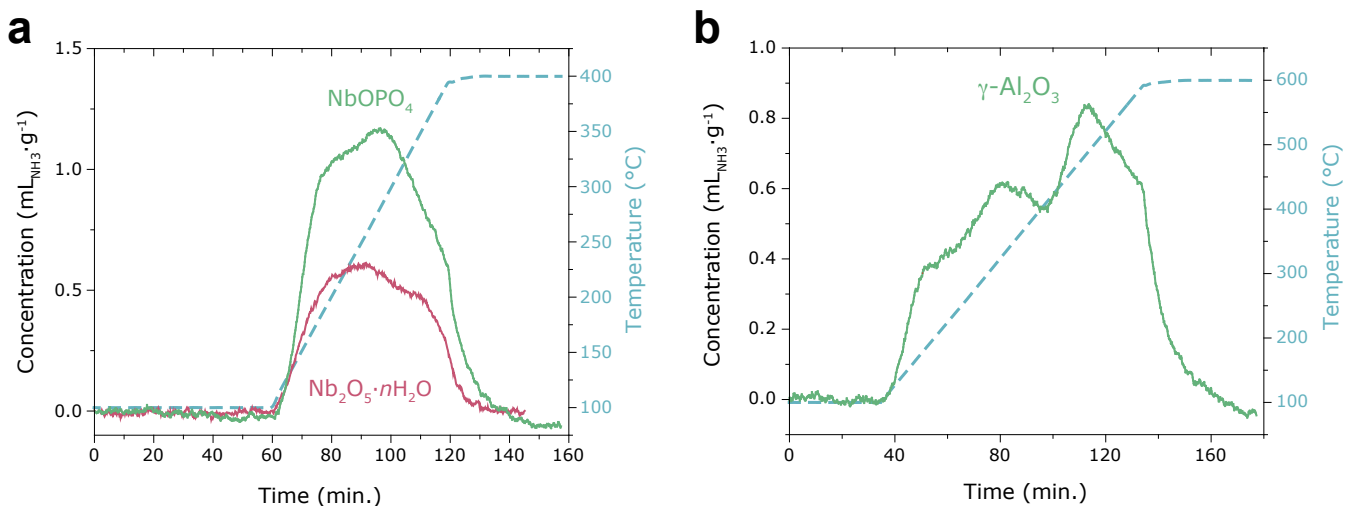

Figure F1 Ammonia Temperature Programmed Desorption ( $\left.\mathrm{NH}_{3} \mathrm{TPD}\right)$ results for $\mathrm{Nb}_{2} \mathrm{O}_{5} \cdot n \mathrm{H}_{2} \mathrm{O}$ and $\mathrm{NbOPO}_{4}(\mathbf{a})$ and $\gamma-\mathrm{Al}_{2} \mathrm{O}_{3}(\mathbf{b})$, reaching the temperature to which the materials were previously dried, $400{ }^{\circ} \mathrm{C}$ for the niobium based materials and $600{ }^{\circ} \mathrm{C}$ for $\gamma-\mathrm{Al}_{2} \mathrm{O}_{3}$.

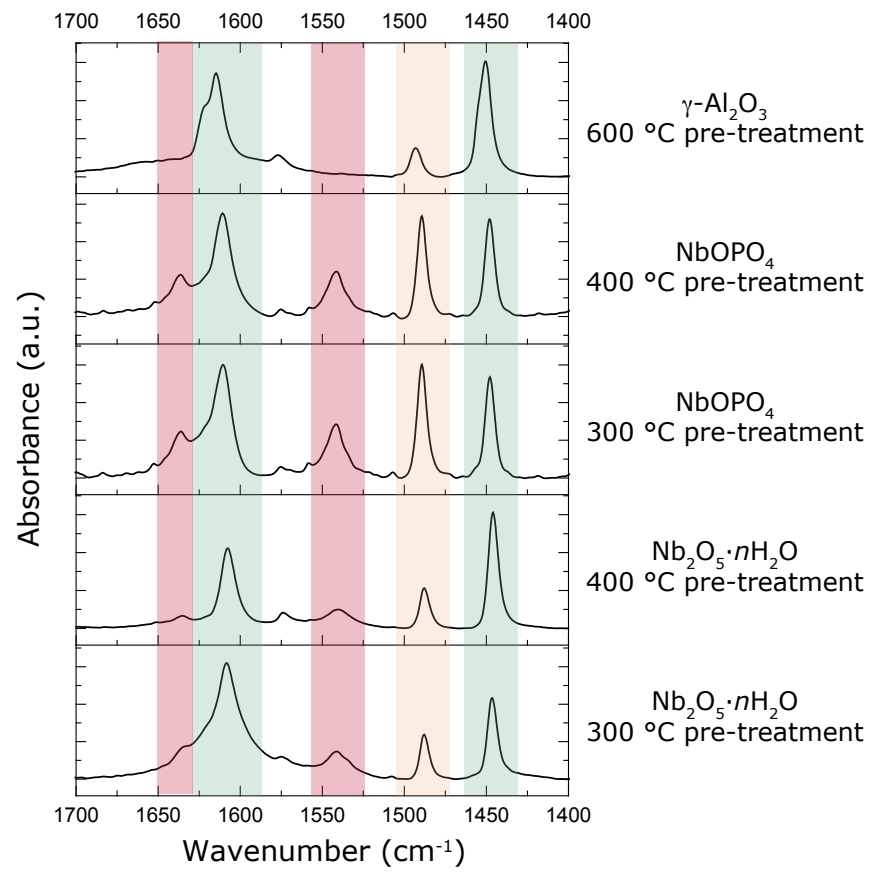

Figure F2 FTIR with pyridine as probe molecule of the solid acids (indicated on the right part of the plot) after different calcination temperatures. IR bands highlighted in red at 1639 and $1540 \mathrm{~cm}^{-1}$ correspond to pyridinium ion on Brønsted acid sites, IR bands highlighted in green at 1446 and $1606 \mathrm{~cm}^{-1}$ correspond to pyridine coordinated to Lewis acid sites and the IR band highlighted in yellow at $1489 \mathrm{~cm}^{-1}$ corresponds to a common band for both acid sites. 

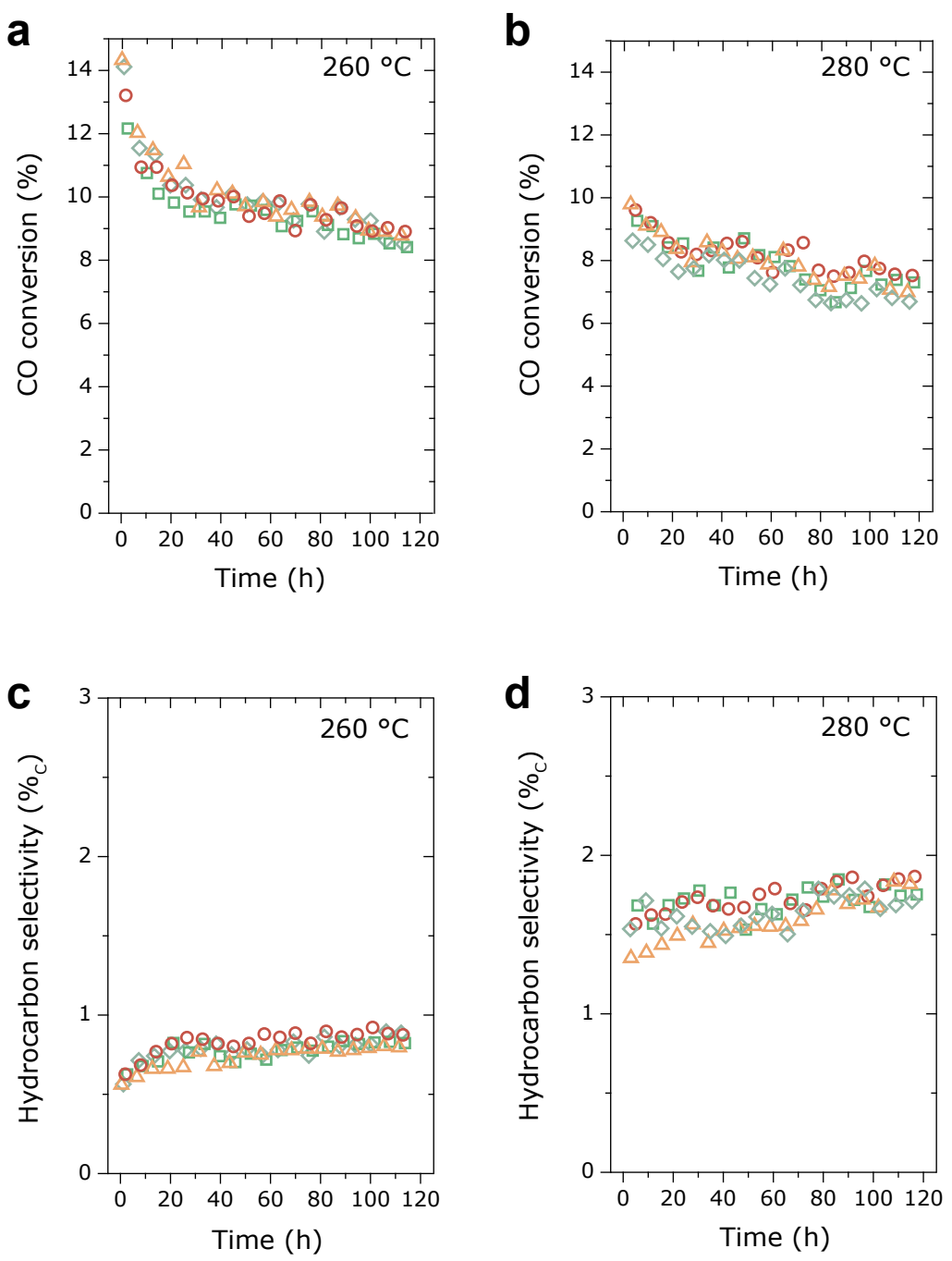

Solid Acid
$-\mathrm{Nb}_{2} \mathrm{O}_{5} \cdot n \mathrm{H}_{2} \mathrm{O}$
$\square \mathrm{NbOPO}_{4}$
$\triangle \gamma-\mathrm{Al}_{2} \mathrm{O}_{3}$

Methanol

$\diamond$ synthesis catalyst

Figure F3 A CO conversion as a function of time at $260{ }^{\circ} \mathrm{C}(\mathbf{a})$ or $280{ }^{\circ} \mathrm{C}(\mathbf{b})$ and the respective hydrocarbon selectivities (c and $\mathbf{d}$ ) for the catalysts in stacked-bed configuration, with the solid acid downstream of the methanol synthesis catalyst. Around $15 \mathrm{mg}$ of copper-based methanol synthesis catalyst were used for the experiments at $260{ }^{\circ} \mathrm{C}$ and around $10 \mathrm{mg}$ for the experiments at $280{ }^{\circ} \mathrm{C}$, the performance of only the methanol synthesis catalyst is also shown (grey diamonds). The amount of solid acid used was fixed to have the same amount of acid sites per reactor, $6 \cdot 10^{-3} \mathrm{mmol}_{\mathrm{NH} 3}$ at $260{ }^{\circ} \mathrm{C}$ and $3 \cdot 10^{-3} \mathrm{mmol}_{\mathrm{NH} 3}$ at $280{ }^{\circ} \mathrm{C}$. Reaction conditions: $40 \mathrm{bar}, \mathrm{H}_{2} / \mathrm{CO}=2 \mathrm{v} / \mathrm{v}$. 

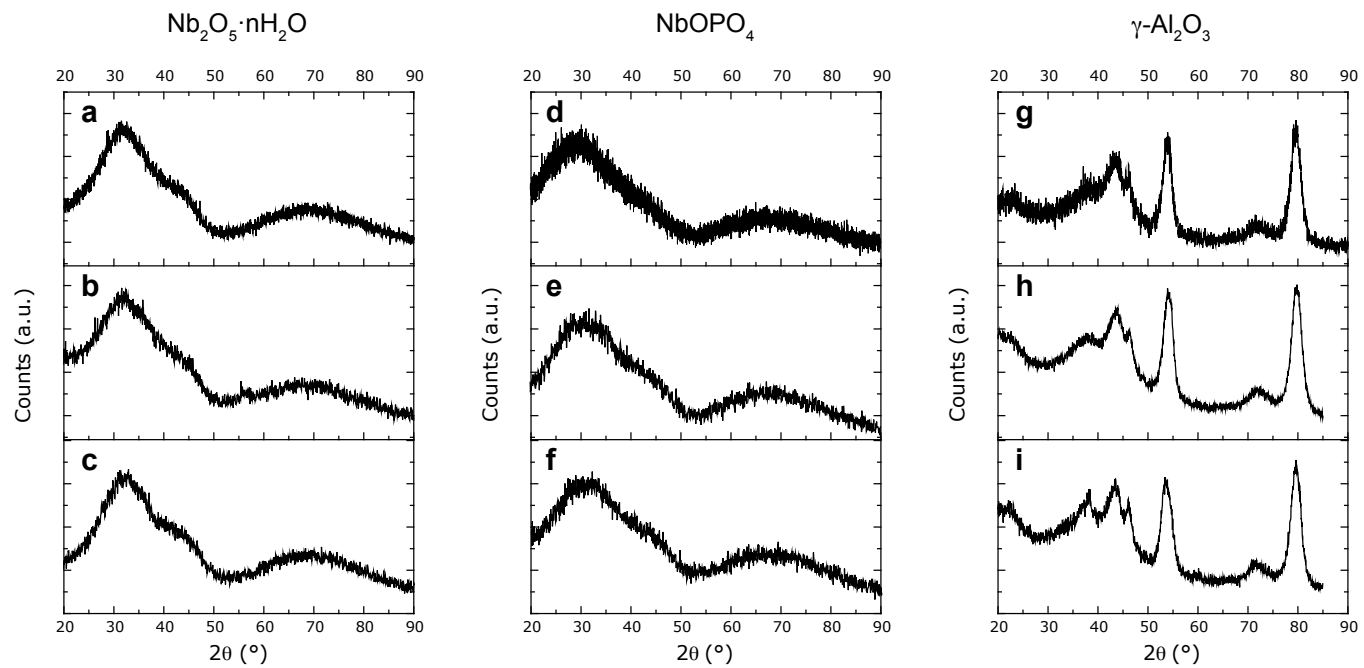

Figure F4 Powder XRD diffractograms of solid acids: hydrated niobium pentoxide on the left, niobium phosphate on the center and gamma-alumina on the right. $\mathbf{a}, \mathbf{d}$ and $\mathbf{g}$ solid acids before reaction. Used solid acids after reaction $\left(40\right.$ bar, $\mathrm{H}_{2} / \mathrm{CO}=2 \mathrm{v} / \mathrm{v}$, TOS $\left.=120 \mathrm{~h}\right)$ at $260{ }^{\circ} \mathrm{C}(\mathbf{b}, \mathbf{e}$ and $\mathbf{h})$ and at $280{ }^{\circ} \mathrm{C}(\mathbf{c}, \mathbf{f}$ and $\mathbf{i})$. In all cases, hydrated niobium pentoxide and niobium phosphate maintained an amorphous diffraction pattern and alumina a gamma phase (JPCS data 10-0425).
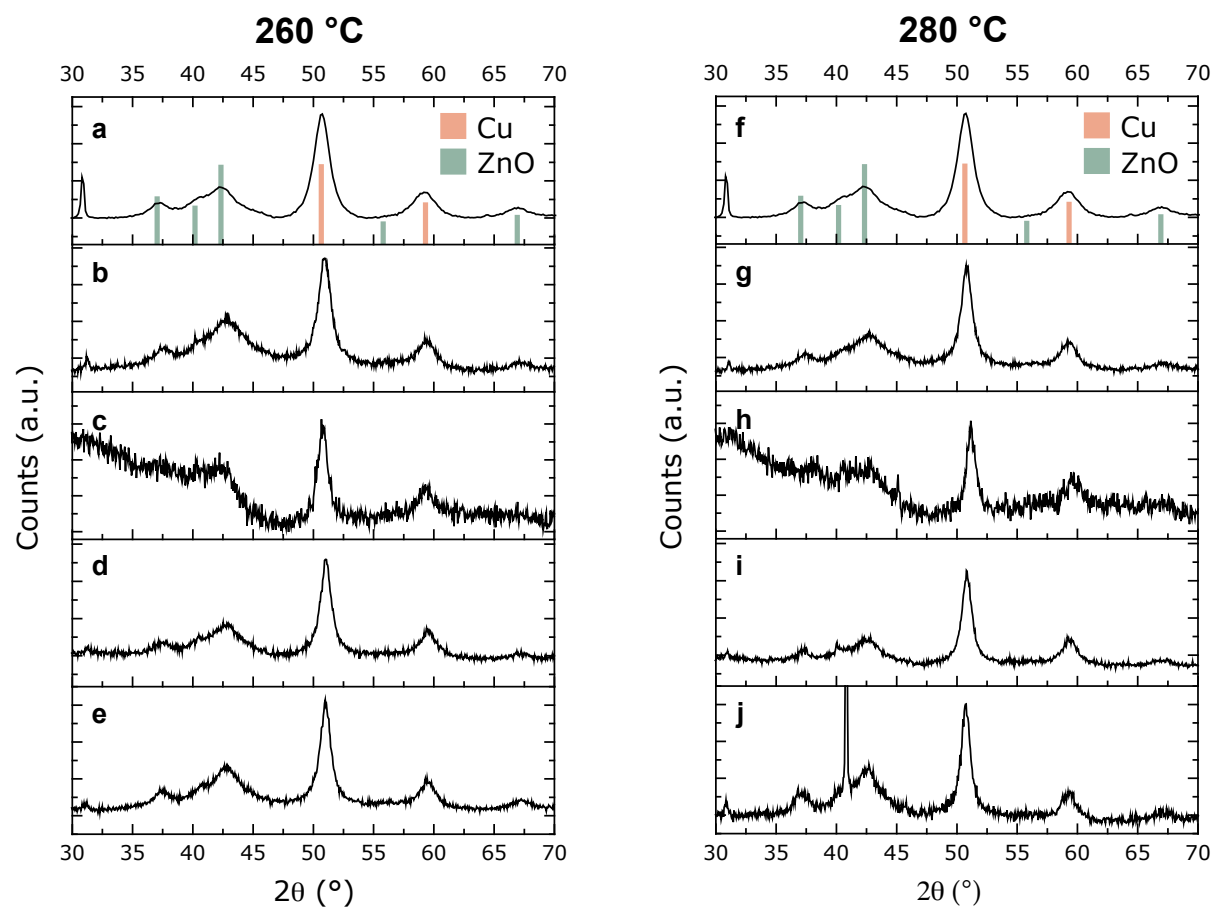

Figure F5 Powder XRD diffractograms of the copper-based methanol synthesis catalyst after reduction at $250{ }^{\circ} \mathrm{C}$ (a and b). Passivated catalyst after reaction $\left(40 \mathrm{bar}, \mathrm{H}_{2} / \mathrm{CO}=2 \mathrm{v} / \mathrm{v}, \mathrm{TOS}=120 \mathrm{~h}\right)$ at $260{ }^{\circ} \mathrm{C}(\mathbf{b}-\mathbf{e})$ or $280{ }^{\circ} \mathrm{C}(\mathbf{g}-\mathbf{j})$. Diffractograms 'b' and ' $\mathbf{g}$ ' correspond to the used copper-based catalyst without solid acid, diffractograms 'c' and ' $\mathbf{h}$ ' correspond to the used copper-based catalyst from the physical mixture with $\mathrm{Nb}_{2} \mathrm{O}_{5} \cdot n \mathrm{H}_{2} \mathrm{O}$, ' $\mathbf{d}$ ' and ' $\mathbf{i}$ ' from the physical mixture with $\mathrm{NbOPO}_{4}$ and 'e' and ' $\mathfrak{j}$ ' from the physical mixture with $\gamma-\mathrm{Al}_{2} \mathrm{O}_{3}$. 
Table F1 Summary of the copper crystallite size obtained from powder XRD (Figure F7) of the Cu-based catalyst after reduction $\left(25 \%\right.$ vo $\mathrm{H}_{2} / \mathrm{N}_{2}$ flow, $2 \mathrm{~h}$ at $\left.250{ }^{\circ} \mathrm{C}\right)$ and after reaction $\left(40\right.$ bar, 260 or $280{ }^{\circ} \mathrm{C}, \mathrm{H}_{2} / \mathrm{CO}=2$, TOS $=120 \mathrm{~h}$ ) used in the physical mixture or in itself.

\begin{tabular}{|c|c|c|c|c|c|}
\hline Sample & $\begin{array}{c}\text { Reaction Tem- } \\
\text { perature } \\
\left({ }^{\circ} \mathbf{C}\right)\end{array}$ & $\begin{array}{l}\text { Corresponding } \\
\text { Diffractogram } \\
\text { from Figure F7 }\end{array}$ & $\begin{array}{l}\text { Solid Acid in } \\
\text { the physical } \\
\text { mixture }\end{array}$ & $\begin{array}{c}\text { Cu crystallite } \\
\text { size }^{\mathbf{b}} \\
(\mathbf{n m})\end{array}$ & $\begin{array}{l}\text { Increase } \\
\text { relative to } \\
\text { the reduced } \\
\text { catalyst } \\
(\%)\end{array}$ \\
\hline $\begin{array}{l}\text { Reduced Cu-based } \\
\text { catalyst }^{\mathrm{a}}\end{array}$ & - & $a, f$ & - & 6.6 & - \\
\hline $\begin{array}{l}\text { Cu-based } \\
\text { catalyst after } \\
\text { reaction }\end{array}$ & & b & - & 7.1 & 7 \\
\hline \multirow{3}{*}{$\begin{array}{l}\mathrm{Cu} \text {-based cata- } \\
\text { lyst in physical } \\
\text { mixture after } \\
\text { reaction }\end{array}$} & 260 & c & $\mathrm{Nb}_{2} \mathrm{O}_{5} \cdot n \mathrm{H}_{2} \mathrm{O}$ & 7.6 & 13 \\
\hline & & d & $\mathrm{NbOPO}_{4}$ & 7.7 & 14 \\
\hline & & $\mathrm{e}$ & $\gamma-\mathrm{Al}_{2} \mathrm{O}_{3}$ & 7.9 & 16 \\
\hline $\begin{array}{l}\text { Cu-based } \\
\text { catalyst after } \\
\text { reaction }\end{array}$ & & g & - & 7.6 & 14 \\
\hline \multirow{3}{*}{$\begin{array}{l}\text { Cu-based cata- } \\
\text { lyst in physical } \\
\text { mixture after } \\
\text { reaction }\end{array}$} & 280 & $\mathrm{~h}$ & $\mathrm{Nb}_{2} \mathrm{O}_{5} \cdot n \mathrm{H}_{2} \mathrm{O}$ & 8.9 & 27 \\
\hline & & $\mathrm{i}$ & $\mathrm{NbOPO}_{4}$ & 8.3 & 20 \\
\hline & & $\mathrm{j}$ & $\gamma-\mathrm{Al}_{2} \mathrm{O}_{3}$ & 8.7 & 24 \\
\hline
\end{tabular}

a. 'Reduced Cu-based catalyst' was reduced and placed in an air-tight sample holder to record the diffraction pattern, the other samples were exposed to air after reaction, sieved and characterized.

b. Obtained from the copper (111) diffraction line. 
$\mathrm{Nb}_{2} \mathrm{O}_{5} \cdot \mathrm{nH}_{2} \mathrm{O}$
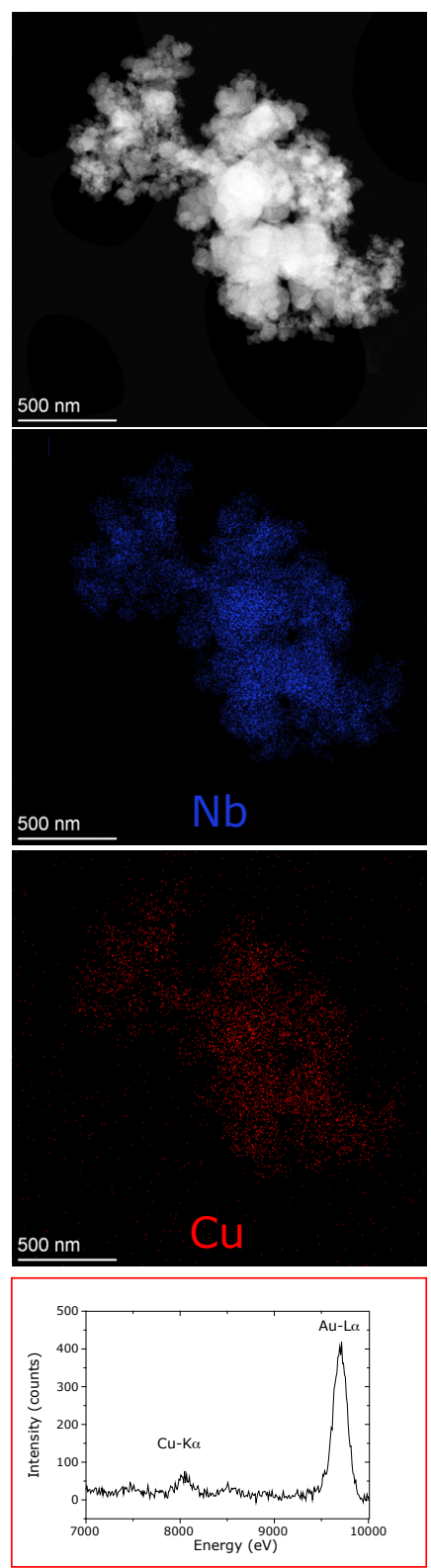

$\mathrm{NbOPO}_{4}$
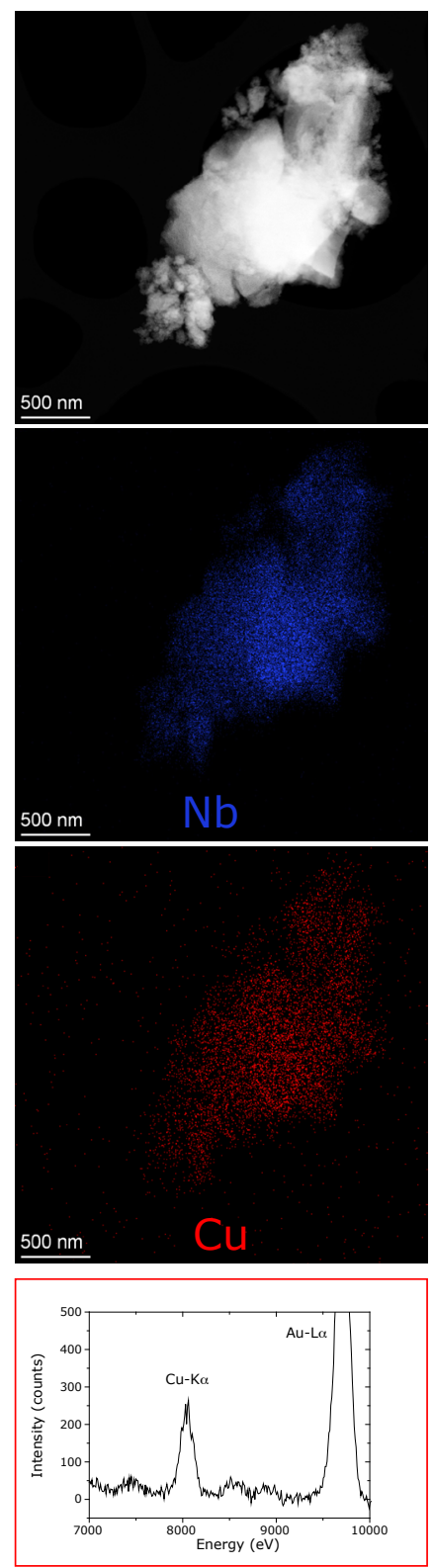

$\gamma-\mathrm{Al}_{2} \mathrm{O}_{3}$
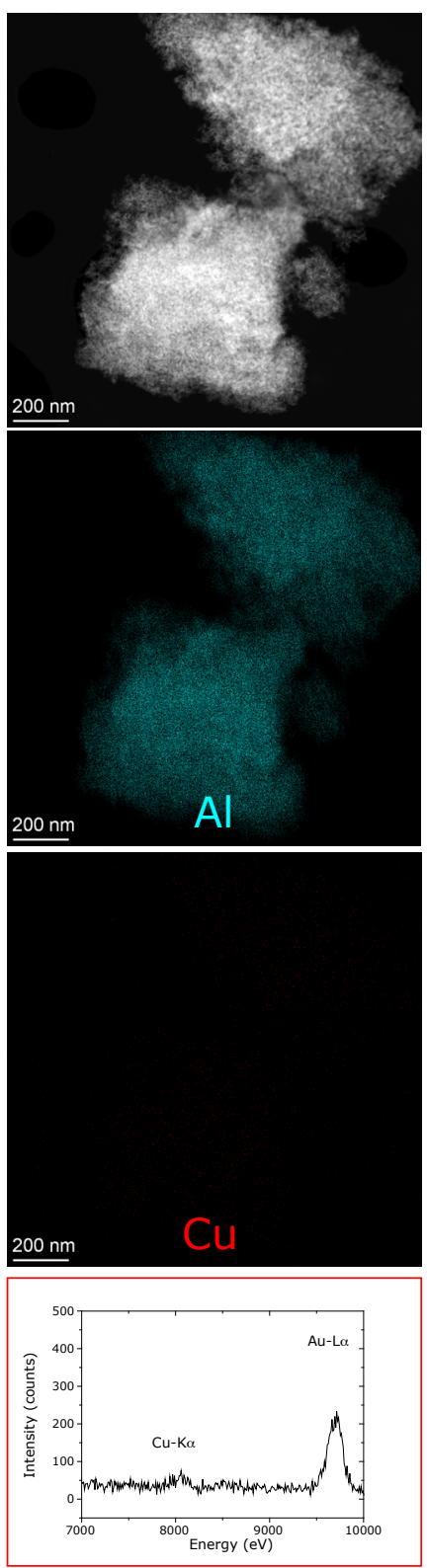

Figure F6 STEM-EDX mapping results of the used $\left(40 \mathrm{bar}, \mathrm{H}_{2} / \mathrm{CO}=2 \mathrm{v} / \mathrm{v}, \mathrm{GHSV}=1050 \mathrm{~h}^{-1}, 260^{\circ} \mathrm{C}\right.$ and $\left.\mathrm{TOS}=120 \mathrm{~h}\right)$ solid acids: $\mathrm{Nb}_{2} \mathrm{O}_{5} \cdot n \mathrm{H}_{2} \mathrm{O}$ (left column), $\mathrm{NbOPO}_{4}$ (center column) and $\gamma-\mathrm{Al}_{2} \mathrm{O}_{3}$ (right column). Dark-field images are shown for each material with the corresponding EDX-mapping of $\mathrm{Nb}$ (dark blue), $\mathrm{Al}$ (light blue), $\mathrm{Cu}$ (red) and the spectra in the energy region of $\mathrm{Cu}-\mathrm{K} \alpha$, the $\mathrm{Au}-\mathrm{L} \alpha$ signal originates from the grid supporting the sample. 



\section{List of publications and presentations}

\section{Publications in this thesis}

- Chapter 2: van Deelen, T. W., Hernández Mejía, C. \& de Jong, K. P. Control of metal-support interactions in heterogeneous catalysts to enhance activity and selectivity. Nat. Catal. 2, 955-970 (2019).

- Chapter 3: Hernández Mejía, C., den Otter, J. H., Weber, J. L. \& de Jong, K. P. Crystalline niobia with tailored porosity as support for cobalt catalysts for the Fischer-Tropsch synthesis. Appl. Catal. A Gen. 548, 143-149 (2017).

- Chapter 4: Hernández Mejía, C., van Deelen, T. W. \& de Jong, K. P. Activity enhancement of cobalt catalysts by tuning metal-support interactions. Nat. Commun. 9, 4459 (2018).

- Chapter 5: Hernández Mejía, C., van der Hoeven, J. E. S., de Jongh, P. E. \& de Jong, K. P. Cobalt-nickel nanoparticles supported on reducible oxides as Fischer-Tropsch catalysts. ACS Catal. 10, 7343-7354 (2020).

- Chapter 6: Hernández Mejía, C., Vogt, C., Weckhuysen, B. M. \& De Jong, K. P. Stable niobia-supported nickel catalysts for the hydrogenation of carbon monoxide to hydrocarbons. Catal. Today 343, 56-62 (2020).

- Chapter 7: Hernández Mejía, C., Verbart, D. M. A. \& de Jong, K. P. Niobium-based solid acids in combination with a methanol synthesis catalyst for the direct production of dimethyl ether from synthesis gas. Catal. Today, accepted.

\section{Other publications}

- Weber, J.L., Hernández Mejía, C., de Jong, K.P \& de Jongh, P.E. Fuels and Chemicals from Synthesis Gas via Bifunctional Catalysis - Chances and Challenges. Review article in preparation.

- Straß-Eifert, A., van der Wal, L. I., Hernández Mejía, C., Weber, J.L., Yoshida, H., Zečević, J., de Jong, K. P. \& Güttel, R. Bifunctional core-shell catalysts for Fischer-Tropsch synthesis: Descriptors affecting the product distribution. In preparation. 
- Rivera-Torrente, M., Hernández Mejía, C., Hartman, T., de Jong, K. P. \& Weckhuysen, B. M. Impact of Niobium in the Metal-Organic Framework-Mediated Synthesis of CoBased Catalysts for Synthesis Gas Conversion. Catal. Letters 149, 3279-3286 (2019).

- Oschatz, M., Krause, S., Krans, N. A., Hernández Mejía, C., Kaskel, S. \& de Jong, K. P. Influence of precursor porosity on sodium and sulfur promoted iron/carbon Fischer-Tropsch catalysts derived from metal-organic frameworks. Chem. Commun. 53, 1020410207 (2017).

- Dietrich, K., Hernández Mejía, C., Verschuren, P., Rothenberg, G. \& Raveendran, S. N. One-Pot Selective Conversion of Hemicellulose to Xylitol. Org. Process Res.Dev. 21, (2017).

- Hernández Mejía, C., Gnanakumar, E. S., Olivos-Suarez, A., Gascon, J., Greer, H. F., Zhou, W., Rothenberg, G. \& Raveendran, S. N. Ru/TiO ${ }_{2}$-catalysed hydrogenation of xylose: The role of the crystal structure of the support. Catal. Sci. Technol. 6, (2016).

- Gómez-Quero, S., Hernández Mejía, C., Hendrikx, R. \& Rothenberg, G. Understanding the redox behaviour of $\mathrm{PbCrO}_{4}$ and its application in selective hydrogen combustion. Dalt. Trans. 41, 12289-12295 (2012).

\section{Oral presentations}

\section{International Conferences}

"Co-Ni Supported on Reducible Oxides as Highly Active and Selective Fischer-Tropsch Catalysts"

$12^{\text {th }}$ Natural Gas Conversion Symposium

San Antonio, U.S.

June $2^{\text {nd }}-6^{\text {th }}, 2019$

"Impact of Reduction-Oxidation-Reduction Treatments on Supported Cobalt Catalysts" $18^{\text {th }}$ Nordic Symposium on Catalysis

Copenhagen, Denmark

August $26^{\text {th }}-28^{\text {th }}, 2018$

"Activity Enhancement by Reduction-Oxidation-Reduction Treatments of Supported Cobalt Catalysts for the Fischer-Tropsch Synthesis"

$13^{\text {th }}$ European Congress on Catalysis

Florence, Italy

August $27^{\text {th }}-31^{\text {st }}, 2017$ 
"Activity Enhancement in Cobalt Fischer-Tropsch Catalysts by Reduction-Oxidation-Reduction Treatments"

$25^{\text {th }}$ North American Catalysis Society Meeting

Denver, U.S.

June $4^{\text {th }}-9^{\text {th }}, 2017$

\section{National Conferences and Lectures}

"Support Effects on the Catalytic Behaviour of Cobalt-Nickel Alloy Catalysts for the Fischer-Tropsch Synthesis"

The Netherlands' Catalysis and Chemistry Conference XX

Noordwijkerhout, The Netherlands

March $4^{\text {th }}-6^{\text {th }}, 2019$

"Activity Enhancement of Cobalt Catalysts by Tuning Metal-Support Interactions"

Debye Lunch Lecture

Utrecht, The Netherlands

November $14^{\text {th }}, 2018$

"Activity Enhancement in Niobia-Supported Cobalt Fischer-Tropsch Catalysts by Reduction-Oxidation-Reduction treatments"

The Netherlands' Catalysis and Chemistry Conference XVIII

Noordwijkerhout, The Netherlands

March $6^{\text {th }}-8^{\text {th }}, 2017$

"Porosity Enhancement of Niobia-Supported Cobalt Catalysts for Fischer-Tropsch Synthesis

Chemistry as Innovating Science (CHAINS) conference”

Veldhoven, The Netherlands

December $6^{\text {th }}-8^{\text {th }}, 2016$

\section{Poster presentation}

"Reduction-Oxidation-Reduction Treatment for Niobia Supported Cobalt Catalysts" The Netherlands' Catalysis and Chemistry Conference XVII

Noordwijkerhout, The Netherlands

March $7^{\text {th }}-9^{\text {th }}, 2016$ 


\section{Acknowledgments}

Niobia refers to the oxide of the element niobium $(\mathrm{Nb})$. Niobium's name comes from Niobe, daughter of king Tantalus in the Greek mythology. The elements niobium and tantalum were originally thought to be identical due to their similar chemical properties, hence the names. The story of Niobe revolves around the killing of her daughters and sons at the hands of Apollo and Artemis in response to Niobe's arrogance. Because of her many daughters and sons, she believed she was better than Leto, mother of Apollo and Artemis. The story has little to do with the element niobium or its compounds, however it can be a good reminder of humility, particularly in science where no man is an island.

The journey to complete this research was accomplished without doubts thanks to the many extraordinary people I had the luck to be surrounded by. Krijn, doing my PhD research with you was a huge privilege. You are an excellent supervisor, dedicated teacher, extraordinary scientist and humane person. I learned so much from you over the years, both in the scientific and personal aspects. You not only allowed me to develop all my creative scientific ideas, but you even guided and supported them all the time. Putting me back on track I am sure was not easy. Dank je wel dat jij een belangrijk onderdeel wilde zijn van zowel mijn professionele en persoonlijke ontwikkeling. Ontzettend bedankt voor alles!

All the collaborations that flourished throughout this research project with exceptional scientists allowed me to learn a lot in very different knowledge areas. I thank all my coauthors that made it possible to publish the results of always exciting experiments. This thesis would not have been materialized without all your crucial contributions. Robson and Rogerio, I greatly appreciate our discussions and your input for this research. I was always glad to have you as contact with CBMM and all the niobium knowledge you always brought to the table.

Dymph en Ilonka, jullie waren er altijd voor mij, voor de kleine en grote vragen, voor de goede gesprekken, om me te helpen Nederlands te oefenen, om elk jaar sponsor meetings te organiseren, dank jullie wel! Ook moet ik al het technische personeel bedanken: Ad, Ad, Jan Willem, Dennie, Hans, Marjan, Fouad, Oscar, Pascal, Herrick and Ramon. De laboratoria en apparatuur altijd laten werken is geen gemakkelijke taak, maar jullie hebben het mogelijk gemaakt. Bedankt voor jullie hulp en expertise tijdens mijn onderzoek. AdvdE, speciale dank voor de altjid goede gesprekken met een sigaret, of twee. De goede oefening om altijd samen in het Nederlands te praten heeft me zeker geholpen.

The starting point and core of this research was in the FT-team. First, within the cobalt people: Arjan, thank you for your helpful introduction to the cobalt-supported-on-niobia world and taking time to teach and guide me in the first months of my project. Also, to let me expand on your research line. Tom (aka tom-tom, the fine gentleman), we shared so much during these years: papers, conferences, supervisor, travels, cobalt, Albemarle, conundrums, flowrence runs, FT BBQ's, etc... it was always very enjoyable and pleasant to have you so close during this adventure, have a good one sir! Then, there was the iron people: Lennart, JX and Nynke. Thank you for making the FT team, FT meetings and Flowrence I maintenance so entertaining and refreshing. Lennart (aka Jan-Lenard, Juan Leonardo Teje- 
dor), I had such a great time having you as close colleague and as a friend. The chats during smoky-smoke and the development of secret projects made it fantastic to work with you. Thank you for being always very willing to help me in all sort of things, from understanding how a GC works to repairing my bike (several times), also for all the fruitful discussions on my project, crazy ideas, die (das? der?...) Deutsche Sprache, the economist, life and what not. Mi querido Miguel (alias Mijuell), gracias por siempre estar allí para platicar, de ciencia, de química y de la vida. Tu entusiasmo científico y dedicación han sido siempre inspiración. Que gusto que, a pesar de todos los obstáculos, al final sí pudimos sacar el paper juntos. José, todo el tiempo la tertulia amena y el acento latino contigo, gracias por tu amistad, los chistes, y las discusiones de FT y Latinoamérica. Siempre he valorado tu sensatez y honestidad, sobre todo en los tiempos difíciles. Bea, eres una de las personas mas inteligentes, alegres y dedicadas que conocí durante el $\mathrm{PhD}$, me da mucho gusto haberte conocido.

The copper people: Rolf, Lisette and Marisol. Rolf, such a nice surprise that you followed me from Amsterdam to Utrecht :-P. It was even nicer to work with someone so dedicated, creative and open to try new experiments. Thank you for all the help with the Flowrence II, the scientific discussions, borrels and good chats during the afterhours. Lisette (aka mevrouw), jij hebt altijd het anwoord voor alles of weet wie wat weet, en je deelde altijd. Dank je voor de methanolsysnthese kennis, het Nederlands oefenen, het samen thee drinken en de office chatter. Marisol, que agradable tener a alguien con quien hablar español del bueno, ¡mucho ánimo con tu PhD! Then the gold people: Thomas, Baira and Jessi. Thomas (aka hombre corazón, illustrator sensei), having you as a front neighbor for so many years made everyday very enjoyable and fun. I am happy that you have pursued the business of illustrating science, all your works (including of course this cover!) augur much success. Baira, I was always fond of our chats, even better that our time in the group was almost a perfect overlap. Thank you for those chats, good advises and conferences. Jessi, you are one of the best scientists I had the pleasure to work with! Thank you for your effort, expert opinion and excellent work for the Co-Ni project. The good talks we had either behind the TEM or a beer were always delightful. The liquid people: Kang (aka professor), Justine and Jogchum. It was always pleasant having you around, for good chats in the office, but especially at borrels with a beer. Please take good care of the Flowrence I. Jovana, you were my first contact with the group and thanks to you I had the opportunity to do this PhD. Thank you for this and all the nice chats and advises (with a coffee/tea and cigarettes) throughout all my time in Utrecht.

Donglong, XinWei, Fang and Kang (again), thank you for always being there (including weekends!). You all have been a window for me to a different mindset, in work and in life. Thank you for explaining China to me and answering my many questions over and over. More importantly thank you for the fun at the lab, borrels, delicious hot pots, courses and conferences. Katarina and Stano, the other communist team :-P, it was great to have you guys for almost all the $\mathrm{PhD}$ nearby, you are both very kind and smart people, willing to listen and share. All the students I worked with: Arie, Claudia, David, Jochem and all the second-year bachelor students, supervising your projects taught me so much. Thank you for taking the risk of doing your thesis projects with me, I hope I could have spread to you a 
bit of enthusiasm for inorganic chemistry. David, thank you for entrusting me to supervise your master's research and helping me to learn more about DME, which resulted in chapter 7. There were plenty of ups and downs during the time I could work with you, but I am glad of your good attitude, character and perseverance, because that just made it very enjoyable and happy times, thank you. I am proud of you, all the best for your future career!

All the huge group of people from the ICC made my $\mathrm{PhD}$ a fascinating experience, thank you for all the great time!

The support of my family, both the one in México and the one made in NL was crucial to accomplish this work. Zea, I feel very thankful of having you in my life for all these years (ten and counting!). Your friendship has made this time in the Netherlands so joyful and fun. Talking of fun, Vlien, thanks for the great moments, the great chats, the great commute with coffees in the ICloveline, the parties and most importantly being always such a close friend. Annemarie, your enthusiasm and cheerfulness have been always uplifting to me, I am so happy of having you as a friend. Trieu, thank you for being such an inspirational friend, sharing your constant amusement with life and helping me understand the Dutch.

Families Bekkers/Hautmans en Dijkema (Marjolein, Paul, Chris, Tessa, Tim...) bedankt dat jullie me een familiegevoel hebben gegeven, en ik waardeer de leuke momenten en gezelligheid. Ruben, hartelijk bedankt dat je er altijd voor me bent geweest in het laatste en gekste jaar van dit avontuur, zeker geen gemakkelijke taak. I enormously treasure all the moments we spent together and can only look forward for many more years of them.

Familias Hernández y Mejía, ¡Gracias! desde siempre estuvieron todos allí para apoyarme, incluida esta aventura en Holanda. En especial Laly y mi tía Martha. Ha sido un sacrificio difícil perderme tantos momentos con ustedes, espero que ahora podamos crear nuevos recuerdos. Sebastián y Emiliano, aunque hemos estado lejos sepan que han sido gran parte de motivación e inspiración para hacer este doctorado. Mi mamá (alias mamíos, coquito) y mi papá (alias papíos, el gordito), muchísimas gracias por darme su apoyo, las herramientas necesarias y sobre todo su amor, cualquier triunfo se los debo a ustedes igracias por todo! 


\section{Curriculum vitae}

Carlos Hernández Mejía was born the $4^{\text {th }}$ of July 1989 in Tijuana, Mexico. He studied chemistry at Universidad Nacional Autónoma de México (UNAM) in Mexico City. There he developed his interest for inorganic chemistry (particularly for transition metals), vastly from the enthusiasm and teachings of Prof. Dr. Laura Gasque Silva. During his studies he had the opportunity of doing an exchange at the University of Amsterdam, where he initially discovered the field of heterogeneous catalysis while doing a research internship under the supervision of Dr.

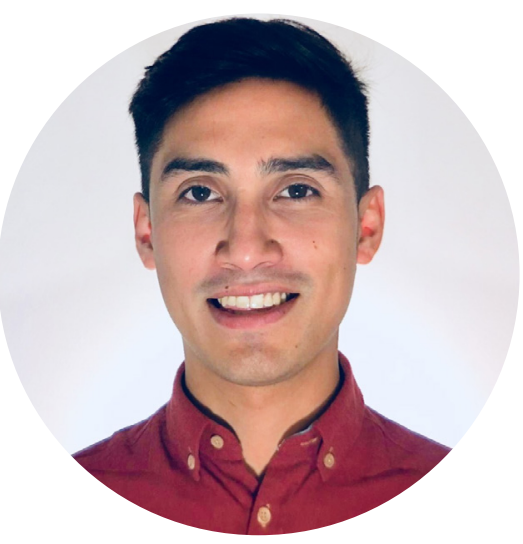
Santiago Gómez Quero and Prof. Dr. Gadi Rothenberg. After completing his bachelor's degree thesis on multiferroic ceramics supervised by Prof. Dr. Elizabeth Chavira Martinez and Dr. Ivonne Rosales Chavez at UNAM's Materials Institute, he moved back to the Netherlands in 2013 to follow a master's program at the University of Amsterdam. He carried out the master's research project at the group of Prof. Dr. Gadi Rothenberg supervised by Dr. Shiju Raveendran, the project focused on the upgrade of biomass-derived feedstocks to fine chemicals by use of heterogenous catalysts, in particular studying $\mathrm{Ru} / \mathrm{TiO}_{2}$ for hydrogenation reactions. Then he did an internship at Albemarle in Amsterdam under the supervision of Dr. Jaap Bergwerff, to study the synthesis of transition metal sulfide nanoparticles.

In 2015, Carlos started a PhD research project supervised by Prof. Dr. Krijn de Jong at the Inorganic Chemistry and Catalysis group from Utrecht University and with financial support from Companhia Brasileira de Metalurgia e Mineração (CBMM). The research focused on the synthesis and understanding of niobia-supported metal catalysts for their application in the conversion of synthesis gas to chemicals, mainly on the Fischer-Tropsch synthesis. The results of this research are described in this thesis, published in renowned scientific journals and presented at several national and international conferences. 